JAIRO DE LIMA SOUZA

\title{
INVESTIGAÇÃO DAS FALHAS DO SISTEMA DE ACIONAMENTO DE EMBREAGEM DO TIPO CILINDRO ESCRAVO CONCÊNTRICO EM VEICULOS COMERCIAIS PESADOS SOB AS CONDIÇÕES OPERACIONAIS DO MERCADO BRASILEIRO
}

\begin{abstract}
Dissertação apresentada à Escola Politécnica da Universidade de São Paulo para a obtenção do Título de Mestre Profissional em Engenharia Automotiva.
\end{abstract}

São Paulo 
JAIRO DE LIMA SOUZA

\title{
INVESTIGAÇÃO DAS FALHAS DO SISTEMA DE ACIONAMENTO DE EMBREAGEM DO TIPO CILINDRO ESCRAVO CONCÊNTRICO EM VEICULOS COMERCIAIS PESADOS SOB AS CONDIÇÕES OPERACIONAIS DO MERCADO BRASILEIRO
}

\author{
Dissertação apresentada à Escola Politécnica da \\ Universidade de São Paulo para a obtenção do \\ Título de Mestre Profissional em Engenharia \\ Automotiva. \\ Área de concentração: \\ Engenharia Automotiva \\ Orientador: \\ Prof. Dr. Marcos Mattos Pimenta
}

São Paulo 
"Dedico este trabalho aos meus amados filhos Amanda e Bruno e a minha amada esposa Adriana pelo carinho, compreensão e apoio”. 


\section{AGRADECIMENTOS}

Primeiramente agradeço a Deus pela amada provisão de energia e saúde, sem as quais este projeto de vida não teria sucesso.

Agradeço aos meus pais Eufrásio Nunes de Souza e Isabel de Lima Souza (in memorian), por terem me dado as oportunidades para a criação das condições que culminaram com mais este passo na minha vida.

Aos amigos Evandro Cirineu, Massaru Maeseki, Stefan Sylvander e Lars Matsson Marsell pelo incansável apoio e compreensão nos momentos difíceis por que passei para concluir esta empreitada.

Não posso deixar de mencionar e agradecer a grande contribuição dos amigos Fabio de Carvalho Jacoby e José Maria Reis que me receberam calorosamente na "cidade maravilhosa" do Rio de Janeiro onde iniciamos os trabalhos científicos de investigação.

À Joel Lopes de Carvalho, agradeço o apoio e grande contribuição científica através dos préstimos de seus vastos conhecimentos sobre o assunto em estudo.

Agradeço as empresas Lubrizol e Tirreno pelo comprometimento e contribuição de seus colaboradores para o sucesso deste trabalho.

A KTH - Kungl Tekniska Hogskolan (Escola de Engenharia da Universidade de Estocolmo) agradeço pela recepção e disponibilização de recursos físicos e de literatura técnica para a o estudo do tema apresentado neste trabalho.

Um especial agradecimento a Jan P. Johansson (in memorian) pelo apoio incondicional a este projeto e pelas incansáveis discussões e orientações dadas a mim naquelas tardes frias e escuras de inverno em Estocolmo na Suécia.

Agradeço a contribuição da equipe de testes (Natalino Miari, Vanderlei P. dos Santos Natal Gripa Neto, Marco A. Garcia e Itamar Peres Pedro) pela perseverança e comprometimento ao executar os testes com os veículos pelas tortuosas marginais Pinheiros / Tietê e rodovia Dutra em pleno horário de "rush".

Finalmente, agradeço ao Prof. Dr. Marcos Mattos Pimenta pela paciência e perseverança demonstrada ao longo deste trabalho. 


\section{RESUMO}

A evolução dos sistemas de transporte no modal rodoviário tem criado novas demandas operacionais devido à crescente concorrência e aumento da pressão para a redução de custos. Em face dessas novas demandas, muitas delas advindas da globalização, geraram uma mudança no perfil da frota de veículos comerciais pesados no mercado brasileiro. Frotas que anteriormente eram compostas por veículos comerciais pesados $4 \times 2$ (4 pontos de apoio no solo com tração em 2 pontos) operando com carretas de três eixos com capacidade de transporte de 45 toneladas, passaram a ser gradativamente substituídas por aquelas compostas por veículos comerciais pesados $6 \times 2$ (6 pontos de apoio no solo com tração em 2 pontos) com carretas do tipo bi-trem e rodo-trem com capacidade de transporte de 57 e 74 toneladas respectivamente. Esta mudança foi acompanhada pelo aumento da pressão do custo de aquisição dos veículos comerciais pesados, com isso, verificou-se que os principais frotistas brasileiros passaram a adaptar eixos de apoio nos veículos 4x2, aumentando assim as solicitações mecânicas impostas ao sistema de embreagem. Neste trabalho desenvolve-se, portanto, um estudo sobre as falhas ocorridas no sistema de acionamento de embreagem por cilindro escravo concêntrico no mercado brasileiro, avaliando-se a seleção de materiais empregados na construção do sistema através de ensaios químico-laboratoriais e testes de funcionalidade através de ensaios em condições reais de operação com veículos comerciais pesados devidamente instrumentados, mantendo o foco nos novos parâmetros operacionais impostos pelo novo perfil da composição tratora.

Como resultado, apontam-se duas alternativas para a solução das falhas encontradas no mercado brasileiro:

1. Proposição de nova solução técnica construtiva para o sistema de acionamento da embreagem a fim de aumentar a robustez do componente de maior suscetibilidade às falhas.

2. Proposição de um modelo matemático para a predição do intervalo mínimo de manutenção para o sistema de acionamento da embreagem por cilindro escravo concêntrico. 


\begin{abstract}
The evolution of highway transportation of goods in the brasilian market has created new operation requirements due to the increased competition allied to the cost reduction demands. This new demands, most of them coming from globalization, have generated a significant change on the profile of heavy commercial vehicles.

Fleets that were mainly composed of $4 \times 2$ tractors coupled to three wheeled semi-trailers with towing capacity of 45 tons, were in small steps exchanged by new compositions of tractors $6 \times 2$ coupled to bi-trains and road-trains with total towing capacity of 57 and 74 tons, respectively.

This change have been followed by the new purchasing demands from fleet owners by lowering acquisition costs of new heavy commercial vehicles, as a consequence, most of $4 \times 2$ trucks have been adapted with tag-axles in order to increase towing capacity, which means increasing the stresses over the clutch system.

On this research, a case study is developed about failures on clutch systems actuators by the concentric slave cylinder concept in the brasilian market.

The research is developed by the evaluation of types of materials selected to the system components through chemical test and functionality tests carried on actual operation conditions on instrumented vehicles, keeping always the focus on the new operational demands imposed by the new profile of vehicle compositions (bi-trains and road-trains). As a final result, two alternatives are appointed to solve the failures in the brasilian market:

1. By the determination of the most failure susceptible component, it is possible to propose a mathematical and theoretical model to determine the minimum maintenance interval to the clutch actuation system by concentric slave cylinder concept.

2. Proposition of a new technical construction to the system in order to increase the robustness of the component most susceptible to the failures.
\end{abstract}




\section{SUMÁRIO}

LISTA DE FIGURAS VIII

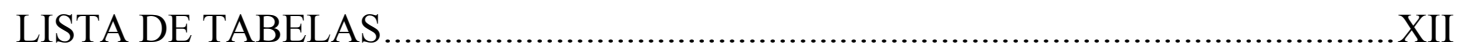

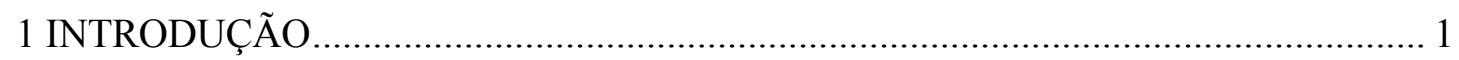

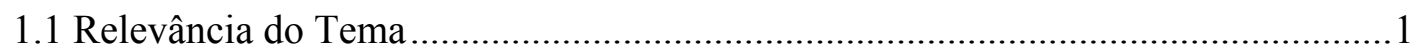

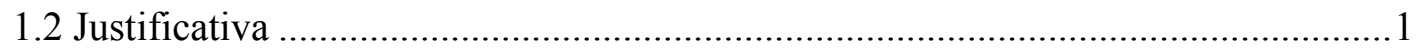

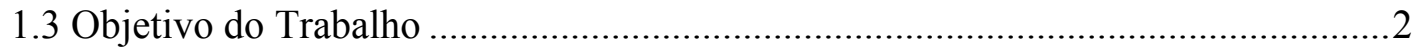

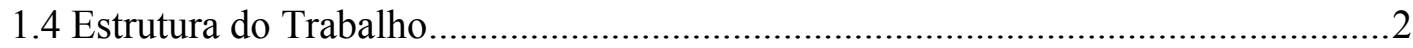

2. A COMPARAÇÃO DA SEVERIDADE DE OPERAÇÃO DOS VEÍCULOS COMERCIAIS PESADOS ENTRE EUROPA E MERCADO BRASILEIRO ........... 5

2.1 Comparação de Severidade Brasil x Europa ...........................................................

2.2 A Mudança do Perfil da Frota de Veículos Comerciais Pesados..............................

3. DESCRIÇÃO DOS SISTEMAS DE ACIONAMENTOS DE EMBREAGEM E

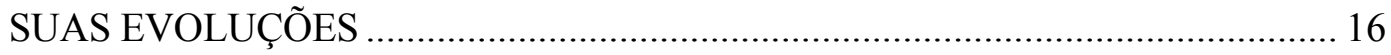

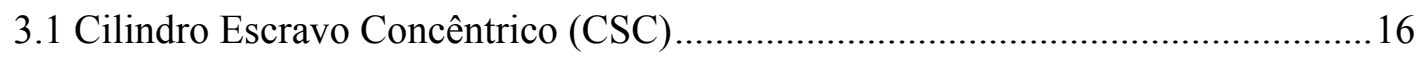

3.2 Sistemas de Acionamento de Embreagem por Cilindro Escravo Externo..............21

4. DESCRIÇÃO DAS FALHAS DE CAMPO DO SISTEMA DE ACIONAMENTO

DA EMBREAGEM POR CILINDRO ESCRAVO CONCÊNTRICO ...................... 24

4.1 Análise de Peças e Dados de Campo para Pré-Diagnóstico ..................................25

4.2 Análise de Contaminantes em Amostras Recolhidas no Campo ……....................22

4.3 Entrevistas Técnicas para Refinamento das Informações ....................................28

4.4. Formação de uma Matriz de Investigação Técnica...............................................29 
5. TESTES QUÍMICOS PARA AVALIAÇÃO DAS ESPECIFICAÇÕES DE FLUIDOS DE FREIO EMPREGADOS EM SISTEMAS DE EMBREAGEM ........35

5.1 Definição e Descrição das Propriedades e Características de um Fluido de Freio DOT4 e DOT 5.1

5.1.1 Estudo da Influência da Contaminação por Água no Ponto de Ebulição de Fluidos DOT 4 e DOT 5.1

5.1.2 Estudo da Influência da Contaminação por Água sobre as Propriedades de Fluidez

6. ESTUDO PARA A AVALIAÇÃO DA COMPATIBILIDADE QUÍMICA ENTRE O FLUIDO DE FREIO DOT 4 E OS ELASTÔMEROS EMPREGADOS NO SISTEMA DE EMBREAGEM

6.1 Estudo da Compatibilidade Química entre Fluido DOT 4 e Mangueira do Reservatório .42

6.2 Estudo da Compatibilidade Química entre Fluido DOT 4 com a Mangueira do Chassi

6.3 Estudo da Compatibilidade Química entre Fluido DOT 4 com os Anéis de Vedação do Servo-Mestre

6.4 Estudo da Compatibilidade Química entre Fluido DOT 4 com os Anéis de Vedação do Cilindro Escravo Concêntrico.

7. ESTUDO PARA A AVALIAÇÃO DA COMPATIBILIDADE QUÍMICA ENTRE

O FLUIDO DE FREIO DOT 4 E AS GRAXAS EMPREGADAS NO PROCESSO DE MONTAGEM DOS CONJUNTOS DO CILINDRO ESCRAVO CONCÊNTRICO E SERVO MESTRE.

7.1 Estudo dos Impactos Funcionais da Graxa Empregada na Montagem do Êmbolo do Cilindro Escravo Concêntrico

7.2 Estudo dos Impactos Funcionais da Graxa Empregada na Montagem do Êmbolo do Servo Mestre 
8. TESTES PARA AVALIAÇÃO DAS FUNCIONALIDADES MECÂNICAS DO SISTEMA DE ACIONAMENTO DE EMBREAGEM POR CILINDRO ESCRAVO CONCÊNTRICO

8.1 Descrição da Metodologia dos Testes para Avaliação das Funcionalidades

Mecânicas do Cilindro Escravo Concêntrico ..........................................................56

8.2 Descrição do Aparato para Aquisição de Dados Experimentais.............................57

8.2.1 Descrição dos Equipamentos de Medição de Temperatura e Pressão .............58

8.2.2 Descrição dos Pontos de Coleta de Dados de Temperatura e Pressão ..............58

8.3 Testes de Funcionalidade do Sistema em Condições Severas de Operação

Utilizando Fluido Contaminado (14\% em Volume de Água)................................65

8.4 Testes de Funcionalidade do Sistema em Condições Severas de Operação

Utilizando Fluido Contaminado (14\% de água) com Instalação de um Sistema de

Recirculação de ar no Ambiente da Embreagem (Carcaça da Embreagem Aberta).

8.5 Testes de Funcionalidade em Condições Severas de Operação Utilizando Fluido

Contaminado (14\% de água) com Instalação de um Sistema de Ventilação Forçada no Ambiente da Embreagem.

8.6 Testes de Funcionalidade em Condições Severas de Operação Utilizando Fluido

Contaminado (14\% de água) com Motorista Padrão Treinado pela Montadora....73

8.7 Estudos para Determinação da Fonte de Contaminação do Fluido por Umidade.. 75

9. DISCUSSÃO DOS RESULTADOS DE COMPATIBILIDADE QUÍMICA E TESTES DE FUNCIONALIDADES MECÂNICAS

9. DISCUSSÃO DOS RESULTADOS DE COMPATIBILIDADE QUÍMICA E TESTES DE FUNCIONALIDADES MECÂNICAS

10. PROPOSTA DE NOVA SOLUÇÃO CONSTRUTIVA PARA SISTEMA DE ACIONAMENTO DE EMBREAGEM 
11. PROPOSTA DE MODELO MATEMÁtico PARA PREDIÇÃO DE INTERVALO DE TROCA PARA FLUIDOS DE FREIO

11.1 Proposição de modelo Teórico para Determinação do Volume de Fluido Exposto a Contaminação por Água no Ambiente de Operação do Cilindro escravo Concêntrico.

11.2 Estudo da Taxa de Contaminação de um Fluido DOT4 Exposto a Ambiente com Umidade Relativa de $81 \%$.

12. CONCLUSÕES 91

12.1 Considerações Finais... .92

13. REFERÊNCIAS BIBLIOGRÁFICAS...... 94

14. ANEXOS 98

14.1 Tirreno - Procedimento para Análise de Absorção de Água pelo Fluido para Freio / Embreagem .98

14.2 Autorização Especial de Trânsito (AET) Distribuído pela Secretaria dos Transportes do Departamento Autônomo de Estradas de Rodagem. 100

14.3 U.S. Department of Transportation - Laboratory Test Procedure for FMVSS 116 - Motor Vehicle Brake Fluids. 108 


\section{LISTA DE FIGURAS}

Página

Figura 1.... Mapa de rotação do motor x débito de combustível em condições de estradas e operações européias.

Figura 2.... Mapa de rotação do motor x débito de combustível em condições de estradas e operações brasileiras.

Figura 3.... Variação de rotação aplicada no motor em condições de estradas e operações européias.

Figura 4.... Variação de rotação aplicada no motor em condições de estradas e operações brasileiras

Figura 5.... Evolução da frota bi-trem circulante no Brasil de 1998 a 2004

Figura 6.... Evolução da participação porcentual relativa entre bi-trem e demais Semi-reboques (SR) Brasil de 2001 a 2004.

Figura 7.... Dimensões típicas $(\mathrm{mm})$ de uma composição com carreta de três eixos - Peso Bruto Total Combinado (PBTC) 45 toneladas......

Figura 8.... Dimensões $(\mathrm{mm})$ de uma composição típica com carreta bi-trem de $7100 \mathrm{~mm}$ - Peso Bruto Total Combinado (PBTC) 57 toneladas...

Figura 9.... Dimensões (mm) de uma composição típica com carreta bi-trem de $7500 \mathrm{~mm}$ - Peso Bruto Total Combinado (PBTC) 57 toneladas..

Figura 10... Sistema de acionamento da embreagem por cilindro escravo concêntrico

Figura 11... Corte transversal do sistema de embreagem de acionamento por CSC

Figura $12 \ldots$ Corte longitudinal de um cilindro escravo concêntrico 
Figura 13... Corte transversal do sistema de embreagem de acionamento por cilindro escravo externo.

Figura 14.... Cilindro escravo concêntrico (em corte) avaliado em garantia

Figura $15 \ldots$ Árvore de falhas de um sistema de embreagem.

Figura 16... Matriz de dados colhidos na fase de pré-investigação das falhas do Cilindro Escravo Concêntrico (CSC).

Figura 17... Taxa de contaminação por água em fluidos DOT4 e DOT5.1 e seus impactos no ponto de ebulição.

Figura 18.... Efeitos da contaminação por água sobre a viscosidade cinemática

Figura 19.... Componentes do sistema de embreagem para análise de compatibilidade química

Figura 20.... Mangueira do reservatório de fluido de embreagem.

Figura 21... Fluido escurecido após teste de compatibilidade química com mangueira do reservatório de fluido de embreagem.

Figura 22.... Aspecto do fluido após teste de compatibilidade química com camada de borracha interna da mangueira do reservatório

Figura 23... Mangueira do chassi.....

Figura 24.... Aspecto do fluido após teste de compatibilidade química com camada de borracha interna da mangueira do reservatório

Figura 25.... Anéis de vedação do servo-mestre.

Figura 26.... Aspecto do fluido após teste de compatibilidade química com os anéis de vedação do servo-mestre.

Figura 27.... Anéis de compressão frontal e traseiro.

Figura 28.... Curva gerada no ensaio de infra-vermelho para a determinação da composição química do elastômero. 
Figura 29... Curva padrão para elastômeros com misturas de EPDM e Polipropileno (Santoprene)............................................................ 47

Figura 30... Anéis raspadores.............................................................................. 48

Figura 31... Curva gerada no ensaio de infra-vermelho para a determinação da composição química do elastômero................................................... 49

Figura 32.... Curva padrão para borracha nitrílicas.............................................. 49

Figura 33.... Graxa colhida do êmbolo do Cilindro Escravo Concêntrico para análise laboratorial........................................................................ 51

Figura 34.... Bolhas de graxa não diluídas no fluido DOT 4............................... 53

Figura 35... Graxa colhida do êmbolo do servo mestre para análise laboratorial.................................................................................... 54

Figura 36.... Instalação de equipamentos de medição de temperatura e pressão no ambiente da embreagem.............................................................. 60

Figura 37.... Instalação de equipamentos de medição de temperatura e pressão no ambiente da embreagem

Figura 38.... Pontos para instalação de termopares e transdutores de pressão no cilindro escravo concêntrico.

Figura 39.... Ponto para instalação de termopar para medição de temperatura no interior do cilindro escravo concêntrico.

Figura 40.... Ponto para instalação de termopar para medição de temperatura na carcaça da embreagem.

Figura 41.... Ponto para instalação de termopar para medição de temperatura ambiente.

Figura 42.... Instalação de termopar para medição de temperatura com sistema de recirculação de ar..

Figura 43.... Instalação de termopar para medição de temperatura na região da carcaça da embreagem com sistema de recirculação de ar.

Figura 44.... Instalação de ventilação forçada no ambiente da embreagem.......... 64

Figura 45.... Ponto de medição de temperatura no ventilador 
Figura 46.... Ponto de medição de temperatura no ventilador...

Figura $47 \ldots$. Teste em tráfego urbano intenso com parada em rampa e saída com utilização da embreagem

Figura 48... Repetição do teste 1 com carcaça da embreagem aberta (recirculação do ar no ambiente da embreagem)............................. $\quad 70$

Figura 49.... Teste com ventilação forçada no ambiente da embreagem.............. 72

Figura 50.... Teste com motorista padrão da montadora simulando as condições ideais de operação...........................................................

Figura 51.... Fluido de embreagem em processo de ebulição dentro do CSC....... $\quad 77$

Figura 52.... Cilindro escravo externo ao ambiente da embreagem - vista lateral.

Figura 53... Cilindro escravo externo ao ambiente da embreagem - vista

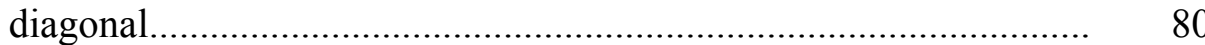

Figura 54 Representação esquemática da rugosidade superficial Ra................ 82

Figura 55 Representação esquemática da rugosidade superficial Rt................. 82

Figura 56 Procedimento experimental para medição de rugosidade em êmbolos.

Figura 57 Curva de absorção de água de um fluido DOT 4 exposto a ambiente com $81 \%$ de umidade relativa....

Figura 58 Curva de taxa de absorção de água por taxa de tempo de um fluido DOT 4 exposto a ambiente com umidade relativa de $81 \%$... 


\section{LISTA DE TABELAS}

Página

Tabela 1.... Comparativo entre especificações técnicas - veículos tratores

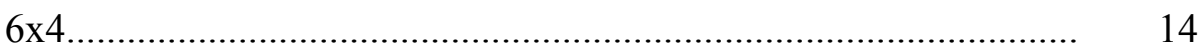

Tabela 2.... Comparativo entre especificações técnicas - veículos tratores $4 \times 2 . \quad 15$

$\begin{array}{lll}\text { Tabela 3.... Lista de componentes principais de um sistema de embreagem...... } & 17\end{array}$

Tabela 4.... Lista de componentes principais contidos no ambiente da embreagem.

Tabela 5... Lista de componentes principais de um cilindro escravo concêntrico

Tabela $6 \ldots$ Lista de componentes principais de um cilindro escravo externo....

Tabela 7.... Resultado de análise de amostras de campo de fluidos de embreagens

Tabela 8.... Requisitos versus Priorização das funções da embreagem

Tabela 9.... Testes de dispersância de água em fluidos DOT 4.

Tabela 10.. Resultados de ensaio com graxa de silicone em fluido DOT $4 .$.

Tabela 11.. $\quad$ Resultados de ensaio com graxa de poliglicol em fluido DOT 4.... 54

Tabela 12.. Pontos de medição de temperatura e suas localizações.................... 59

Tabela 13.. Resultado de amostras coletadas em diferentes pontos do sistema.. $\quad 75$

Tabela 14.. Valores experimentais de rugosidade Ra e Rt de duas amostras de êmbolos. 


\section{INTRODUÇÃO}

\subsection{Relevância do Tema}

As falhas do sistema de embreagem, seja no seu sistema de acionamento ou no próprio conjunto platô e disco não raramente causam paradas indesejadas dos veículos.

No caso dos veículos comerciais pesados, as paradas não programadas, normalmente causam transtornos logísticos aos clientes da cadeia de transporte de cargas.

Muitos usuários de veículos comerciais pesados no Brasil demonstraram uma grande insatisfação quanto à eficiência do conceito de acionamento de embreagem por cilindro escravo concêntrico, pois quando exposto a condições severas de operação, houve relatos de que o sistema apresentava instabilidade, a qual era sentida através de vibrações no pedal da embreagem, ou mesmo ocorrendo até a falta total de funcionalidade no momento em que o sistema não apresentava nenhum tipo de resposta aos acionamentos do pedal da embreagem.

\subsection{Justificativa}

O sistema de acionamento de embreagem por cilindro escravo concêntrico, embora considerado de alta tecnologia, tem apresentado altas taxas de falha no mercado brasileiro, chegando a $15 \%$ em ônibus interestaduais vendidos por uma determinada marca no ano de 2003.

Este valor se torna ainda mais vultuoso, ao considerar-se o volume de falhas no mercado brasileiro de veículos comerciais pesados no período de 1998 a 2003, chegando a taxas de falhas da ordem de $59 \%$ em ônibus rodoviários de longa distância e $29 \%$ para caminhões.

Fatores encontrados no mercado brasileiro tais como: variação de temperatura ambiente; umidade relativa do ar; grau de exposição dos componentes à poeira; altitude; regime de 
operação; geralmente não são levados em consideração na fase de projeto, que normalmente é desenvolvido no exterior.

Este trabalho desenvolve as suas atividades de análise das falhas do sistema de embreagem sob a ótica destes fatores que podem constituir as possíveis causas raízes para as falhas de campo no mercado brasileiro.

\subsection{Objetivo do Trabalho}

Este trabalho tem por objetivo avaliar as causas das falhas do sistema de acionamento de embreagem através de cilindro escravo concêntrico dentro das condições operacionais do mercado brasileiro, assim como, determinar quais são os componentes mais suscetíveis à falhas quando submetidos a aplicações severas em veículos comerciais pesados.

A partir da matriz de resultados colhidos ao longo da investigação e tomando-se como base o componente do sistema que apresenta menor resistência às condições impostas pela operação, pode-se construir um modelo matemático representativo, através do qual pode-se prognosticar o valor do intervalo de manutenção do cilindro escravo concêntrico.

\subsection{Estrutura do Trabalho}

O trabalho de pesquisa foi desenvolvido com base em estudo de dados colhidos através de relatos de usuários, bem como de dados gerados na pesquisa da comparação entre a agressividade do ambiente da embreagem e as características operacionais dos componentes do sistema de acionamento da embreagem por cilindro escravo concêntrico. 
O modelo de pesquisa adotado compreendeu numa primeira fase da comparação das características operacional entre o mercado brasileiro e o europeu, onde se originou este conceito para os veículos comerciais pesados em estudo.

Em sua segunda fase, atividades para compreensão dos componentes do sistema e suas funções são desenvolvidas a fim de permitir a avaliação da composição química destes e suas respectivas compatibilidades.

Com a finalização das análises químicas, onde se obtêm as informações sobre os tipos de materiais empregados para a construção do sistema e suas respectivas limitações, possibilita-se a submissão do sistema à avaliação funcional através de testes de campo em veículos comerciais pesados.

Estas três fases estão divididas da seguinte forma ao longo deste trabalho:

- Capítulo 2 - A comparação da severidade de operação dos veículos comerciais pesados entre Europa e mercado brasileiro;

- Capítulo 3 - Descrição dos sistemas de acionamentos de embreagem e suas evoluções;

- Capítulo 4 - Descrição das falhas de campo do sistema de acionamento da embreagem por cilindro escravo concêntrico;

- Capítulo 5 - Testes químicos para avaliação das especificações de fluidos de freio empregados em sistemas de embreagem;

- Capítulo 6 - Estudo para a avaliação da compatibilidade química entre o fluido de freio DOT 4 e os elastômeros empregados no sistema de embreagem;

- Capítulo 7 - Estudo para a avaliação da compatibilidade química entre o fluido de freio DOT 4 e as graxas empregadas no processo de montagem dos conjuntos do Cilindro Escravo Concêntrico e Servo Mestre;

- Capítulo 8 - Testes para avaliação das funcionalidades mecânicas do sistema de acionamento de embreagem por cilindro escravo concêntrico;

- Capítulo 9 - Discussão dos resultados de compatibilidade química e testes de funcionalidades mecânicas; 
Os resultados obtidos ao final desta fase da pesquisa permitiram a detecção da causa raiz para o problema em estudo, assim como a determinação do componente de maior suscetibilidade às falhas, a partir do qual desenvolvem-se duas soluções alternativas descritas nos capítulos seguintes:

- Capítulo 10 - Proposta de nova solução construtiva para o sistema de acionamento da embreagem;

- Capítulo 11 - Proposta de modelo matemático para a predição de intervalo de troca para fluidos de freio. 


\section{A COMPARAÇÃO DA SEVERIDADE DE OPERAÇÃO DOS VEÍCULOS COMERCIAIS PESADOS ENTRE EUROPA E MERCADO BRASILEIRO}

SCHIPPER et al. $(1992,145 p)$ pesquisando sobre o perfil das frotas de caminhões em países em desenvolvimento, constatam que países como Brasil, China e Coréia do Sul utilizam-se principalmente do modal rodoviário para a distribuição de seus produtos agrícolas.

Adicionalmente, verificaram que o perfil da frota de veículos comerciais em países em desenvolvimento, especialmente no Brasil, apresentam um aumento substancial da frota de veículos pesados.

O aumento da frota de veículos comerciais pesados também foi verificado por LANG, JAMES (1996, 119p) que cita suas experiências com veículos sobrecarregados na região Amazônica, a qual é amplamente dominada por rodovias não pavimentadas. Estas, rodovias não pavimentadas, reúnem segundo dados da Confederação Nacional do Transporte (CNT) uma extensão de 1.413 .982 quilômetros contra 196.094 quilômetros de rodovias pavimentadas em solo brasileiro.

Em 2005, a CNT realizou uma pesquisa para avaliação de 81.944 quilômetros (dos 196.094 quilômetros) de rodovias pavimentadas no Brasil, e destas 72 \% foram consideradas entre regular e péssimo quanto ao seu estado geral.

\subsection{Comparação de Severidade Brasil x Europa}

As condições de operação dos veículos comerciais pesados no mercado brasileiro sempre foram objeto de discussão em diferentes fóruns de debates. Há muito se fala no mercado brasileiro que as condições de operação para veículos comerciais pesados têm uma alta taxa de severidade se comparada às taxas encontradas no mercado europeu.

Embora haja escassez de literatura científica no Brasil quanto à correlação direta entre as condições e diferenças de operação entre Brasil e Europa, as montadoras européias de 
veículos comerciais pesados sempre realizaram estudos internos para o refinamento dos dados de entrada para novos projetos destinados ao continente latino americano.

Fatores como: alta taxa de umidade e poeira; combustível de baixa qualidade; falta de qualificação dos operadores; falta de manutenção preventiva; dentre outros, são apontados como os principais causadores das falhas de campo.

A análise do comportamento do sistema de embreagem requer o conhecimento do seu modo operacional, portanto a fim de criar-se as condições de contorno necessárias do ponto de vista de conhecimento para a avaliação do cilindro escravo concêntrico, buscaram-se dados operacionais reais em literatura técnica de uma montadora de veículos comerciais pesados. Nesta, faz-se comparação direta entre dois caminhões de configuração $4 \times 2$, ambos tracionando um peso bruto total combinado de 45 toneladas operando em condições semelhantes de estrada no Brasil e na Europa.

As figuras 1 e 2 demonstram o comportamento operacional do veículo em estradas européias e brasileiras, respectivamente.

Neste estudo verifica-se que no eixo das ordenadas são apresentados os valores de débito de combustível $(\mathrm{mg})$ x rotação do motor (rpm) que se encontram no eixo das abscissas. O resultado do tempo de operação (\%) é demonstrado pelas áreas de diferentes colorações, as quais dependem diretamente da maneira como o condutor utiliza a curva de potência do motor.

A somatória das áreas encontradas nestes mapas representam $100 \%$ do tempo de operação do motor. As diferentes colorações nestes mapas de áreas de operação são produtos de outras informações que são coletadas pela unidade de controle do motor como: temperatura do sistema de arrefecimento, pressão do turbo, posição do pedal do acelerador, etc.

Estes valores não são influenciados por fatores externos como poeira, umidade, etc, sendo, portanto, valores que representam as condições operacionais e que podem ser utilizados para comparação direta da severidade de aplicação. 


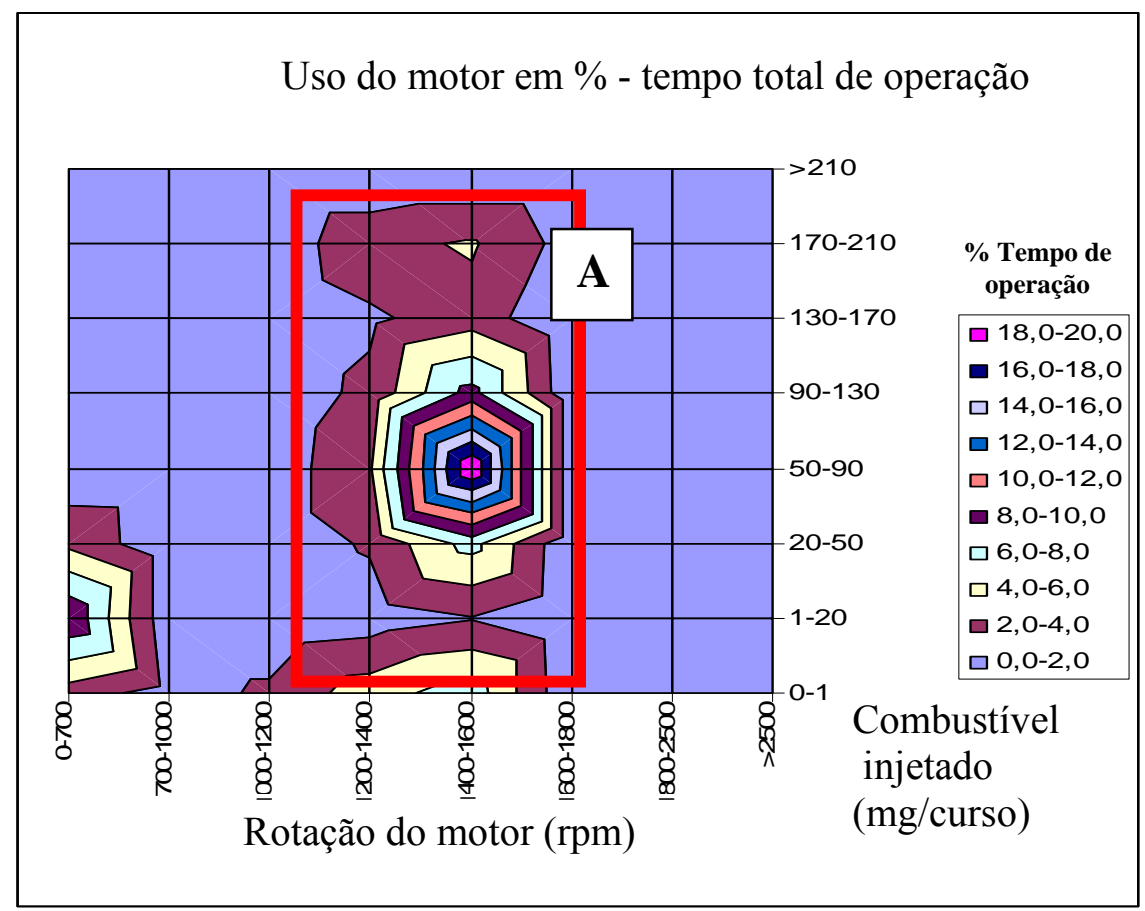

Figura 1. Mapa de rotação do motor $\mathrm{x}$ débito de combustível em condições de estradas e operações européias.

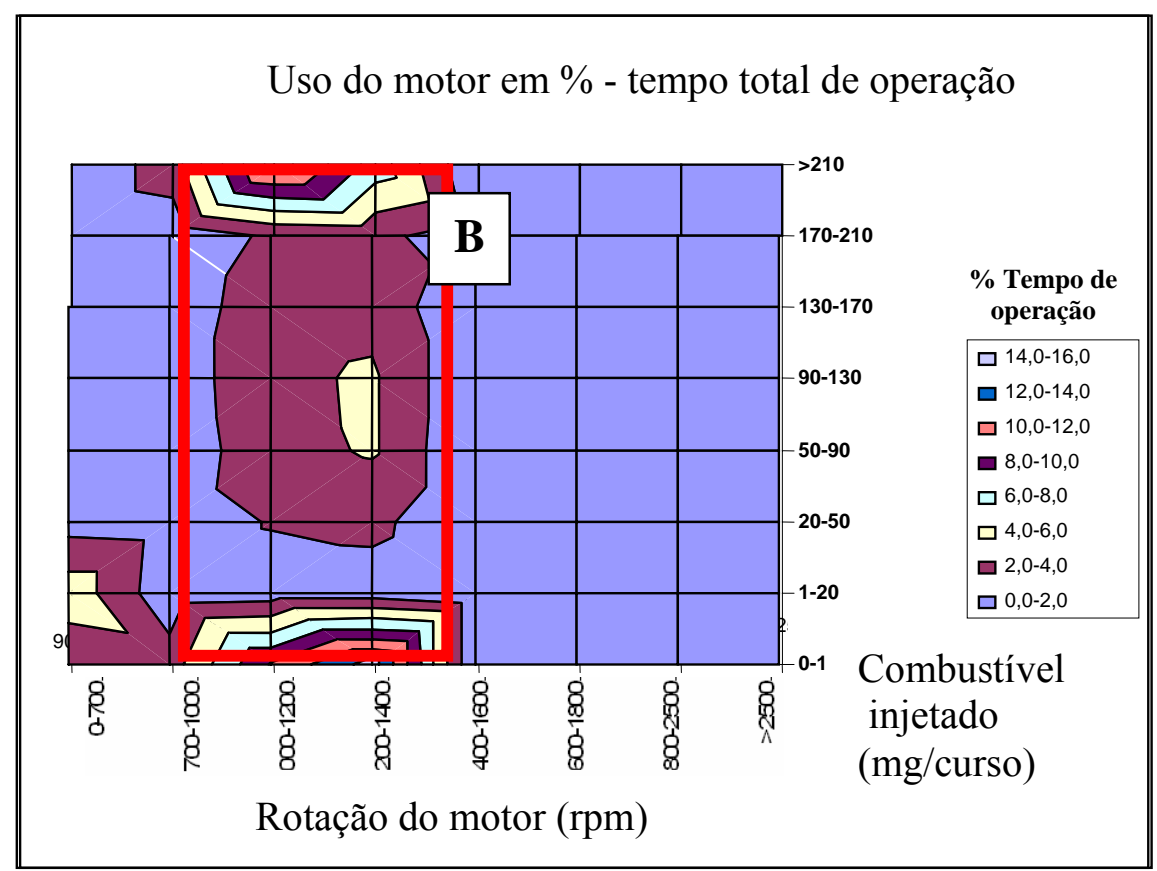

Figura 2 - Mapa de rotação do motor x débito de combustível em condições de estradas e operações brasileiras. 


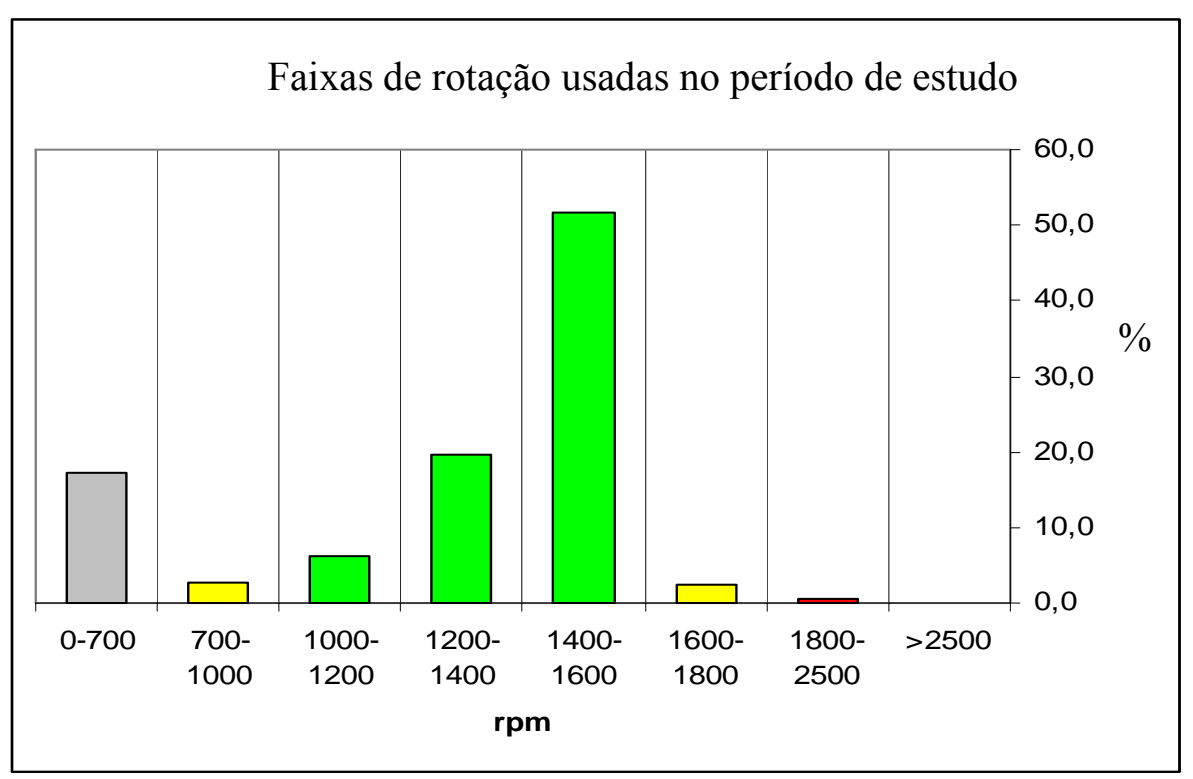

Figura 3 - Variação de rotação aplicada no motor em condições de estradas e operações européias.

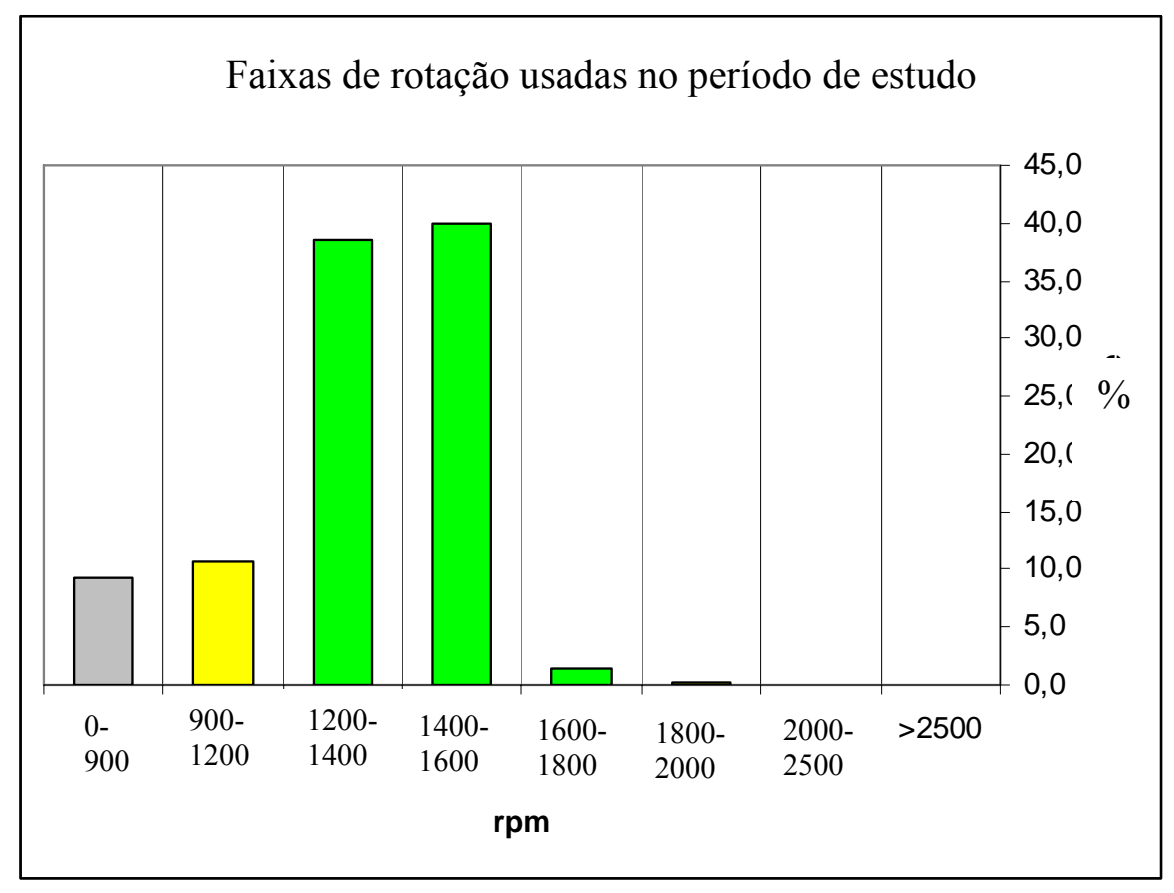

Figura 4 - Variação de rotação aplicada no motor em condições de estradas e operações brasileiras. 
Ao comparar as figuras 1 e 2, percebe-se que o motor europeu (representado pela fig. 1), apresenta uma área de operação em vermelho (A) concentrada na faixa entre $1200 \mathrm{e}$ $1800 \mathrm{rpm}$, além disso verifica-se que a quantidade de combustível injetada (centro geométrico da área A), concentra-se entre 50 e 90 mg/curso.

Conclui-se que o motor europeu trabalhou em regime de rotações mais alto, constante, (sempre entre 1400 e $1600 \mathrm{rpm}$ conforme figura 3), e com débito de combustível reduzido o que significa maior velocidade de cruzeiro com menor número de trocas de marchas.

Adicionalmente, pode-se perceber também que a área delimitada no canto inferior esquerdo da figura 1 é bastante reduzida, o que indica que este motor trabalhou durante muito pouco tempo no regime de marcha lenta.

O motor brasileiro, por sua vez, ao contrário do motor europeu, demonstra maior severidade na operação pois a área B representada na figura 2 está delimitada entre as rotações de 1000 e $1500 \mathrm{rpm}$ com o centro geométrico na faixa entre 90 e $130 \mathrm{mg} /$ curso. Esta informação é confirmada pela figura 4 que demonstra que a variação de rotação do motor se deu entre 1200 e $1600 \mathrm{rpm}$, indicando que o motor brasileiro trabalhou em regime de baixa rotação e alto débito de combustível, conseqüentemente com baixa velocidade de cruzeiro, caracterizando a maior severidade de operação do mesmo e a necessidade de maior número de trocas de marcha.

Portanto, conclui-se a partir dos dados acima que as condições de operações brasileiras são bastante severas, especialmente para aqueles sistemas nos quais há rejeição de energia tais como: sistemas de arrefecimento, transmissão, caixa de câmbio, lubrificação, embreagem, etc.

\subsection{A Mudança do Perfil da Frota de Veículos Comerciais Pesados}

HEINRICH $(2004,4 p)$ relata que "com a intenção de promover a ocupação territorial e a interiorização do Brasil, o investimento em rodovias foi um fator importante no desenvolvimento econômico e social do país a partir da década de 50. Isso favoreceu, e 
ainda favorece, o modal rodoviário que no Brasil é o maior responsável pelo transporte de cargas".

Com a concentração dos transportes de carga através do modal rodoviário (SCHIPPER; MEYERS, 1992), a manutenção, investimentos e ampliação da malha rodoviária é um desafio que o governo brasileiro deve enfrentar para manter um crescimento sustentado da economia.

SILVA (2004, 1p.) menciona em seus estudos que "a agricultura brasileira é hoje um dos setores econômicos mais estratégicos para a consolidação do programa de estabilização da economia, iniciado em 1994 com o Plano Real".

A estabilidade econômica e a globalização, segundo SILVA (2004, 2p.) tiveram um maior impacto no nível de exigência dos serviços, mudando a percepção empresarial quanto à logística.

Com esta mudança de percepção, a logística e seus custos passaram a ser vistos sob um novo espectro, ou seja, de atividade operacional simples para atividade estratégica capaz de gerar valor agregado ao produto.

Segundo SILVA $(2004,7 p$.) embora não existam levantamentos específicos, estima-se que no Brasil, os gastos com atividades logísticas correspondam a $17 \%$ do PIB. Os custos gerados com a guerra fiscal têm-se materializado nos custos de transporte (VARSANO, 1998), o que demonstra a criação de um novo cenário para o setor de transportes brasileiro.

A partir deste novo cenário, o mercado de transporte de cargas brasileiro passou a ser pressionado para reduzir os seus custos, como conseqüência houve uma forte pressão para redução do preço do frete, gerando por conseqüência, um impacto direto sobre toda a cadeia produtiva, incluindo os fabricantes de veículos comerciais.

Dentre as alternativas de redução de custos operacionais, a mais empregada foi a mudança do perfil dos semi-reboques de três eixos (que comportam 45 toneladas) para bi-trem e rodo-trem, que comportam 57 e 74 toneladas respectivamente. Desta maneira, os operadores logísticos passaram a transportar um maior volume de carga com custos relativamente semelhantes aos gerados pelos semi-reboques de 3 eixos. 
Esta mudança no perfil de operação dos veículos causou notoriamente um aumento da severidade de operação do conjunto do trem-de-força, pois aquele equipamento ora desenvolvido para o transporte de cargas em composições de até 45 toneladas de peso bruto total combinado passou a operar com semi-reboques bi-trem, transportando $21 \%$ a mais de carga.

Com a revogação em 2005 da necessidade de requerimento de autorização especial de trânsito (AET) para as composições bi-trem de 57 toneladas (Resolução 184/05 do Conselho Nacional de Trânsito - CONTRAN), houve um aumento significativo da frota circulante deste tipo de implemento rodoviário no mercado brasileiro. Reforçando a proposição de HADDAD $(2004,26$ p.) a qual ressalta que é possível especificar a tecnologia empregada no transporte ao considerar-se que uma fração da mercadoria transportada é usada no processo (custo) de transporte.

Tal proposição se mostra ainda mais evidente ao verificar-se a evolução do volume de vendas das composições bi-trem nas figuras 5 e 6 abaixo, conforme dados da Associação Nacional dos Fabricantes de Implementos Rodoviários (ANFIR).

\section{Combinações Bitrem em Circulação no Brasil}

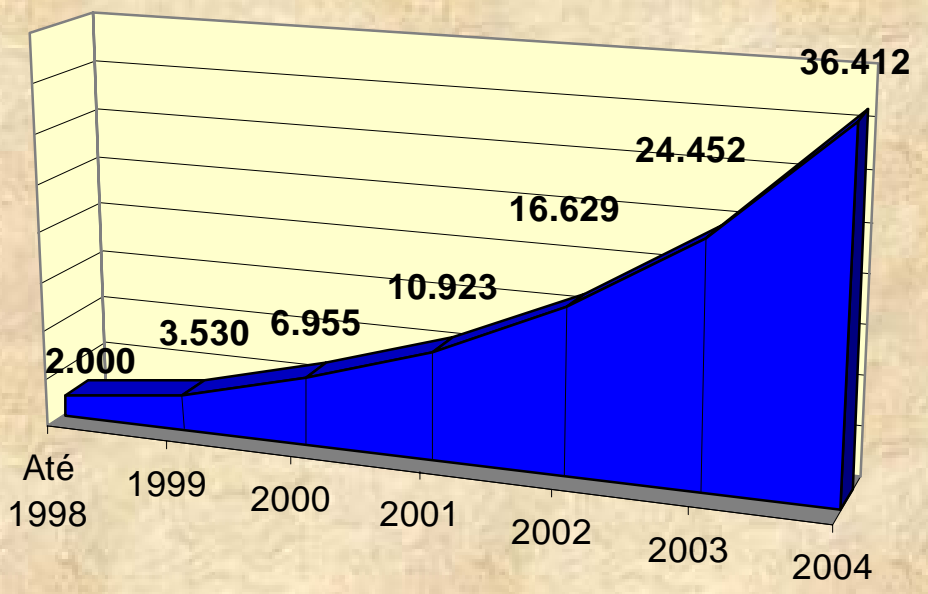

Figura 5 - Evolução da frota bi-trem circulante no Brasil de 1998 a 2004 segundo ANFIR 


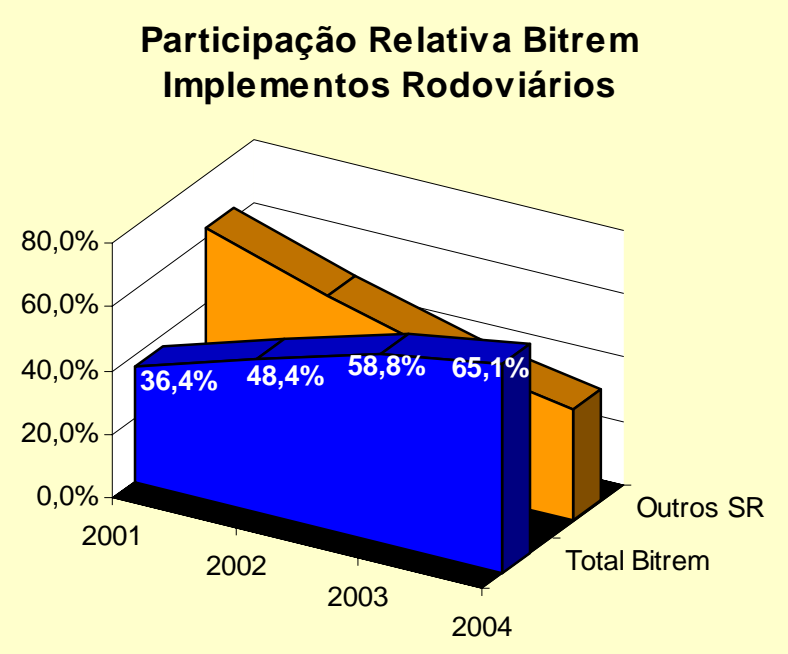

Figura 6 - Evolução da participação porcentual relativa entre bi-trem e demais Semireboques (SR) Brasil de 2001 a 2004 - segundo ANFIR.

Aliado à mudança do perfil dos semi-reboques, outro fenômeno que contribuiu para a redução do custo de transporte, foi o fato de os transportadores passarem a adquirir veículos tratores $4 \times 2$ com capacidade de carga de 45 toneladas e transformá-los para $6 \times 2$, com a adaptação de eixos de apoio, aumentando assim a sua capacidade de carga para 57 toneladas, conforme demonstrado nas figuras 7,8 e 9 .

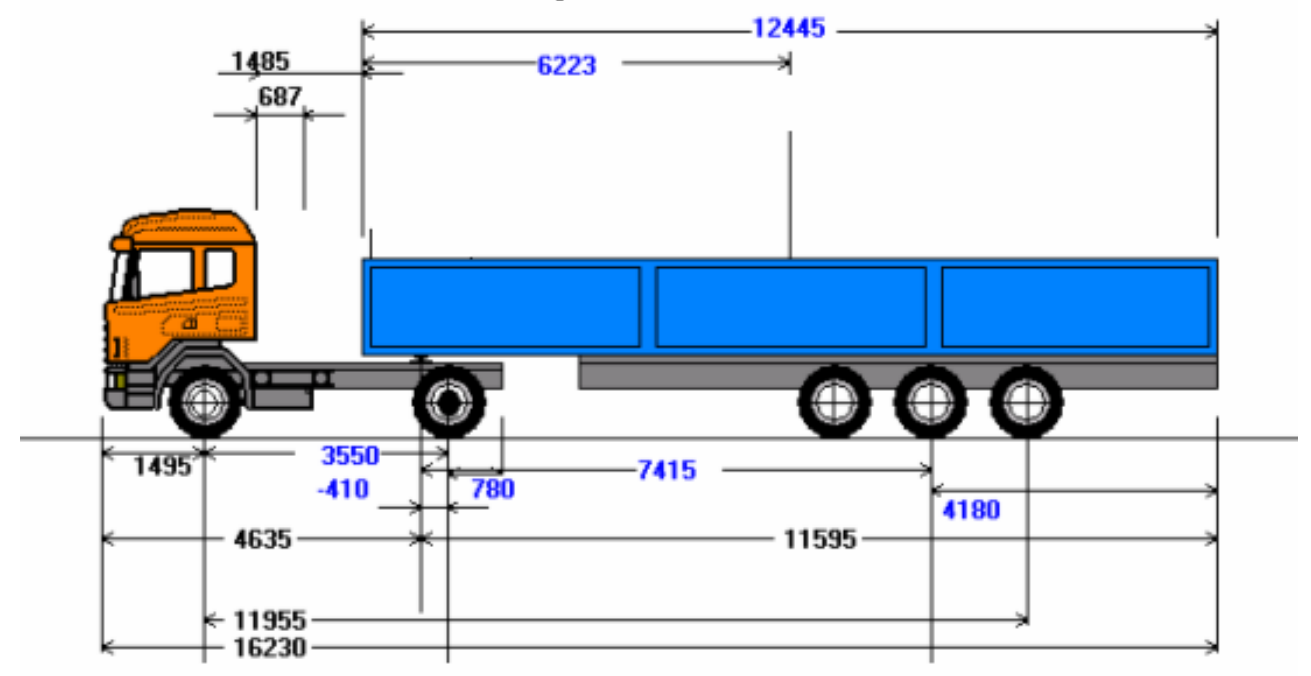

Figura 7 - Dimensões (mm) de uma composição típica com carreta de três eixos - Peso Bruto Total Combinado (PBTC) 45 toneladas. 


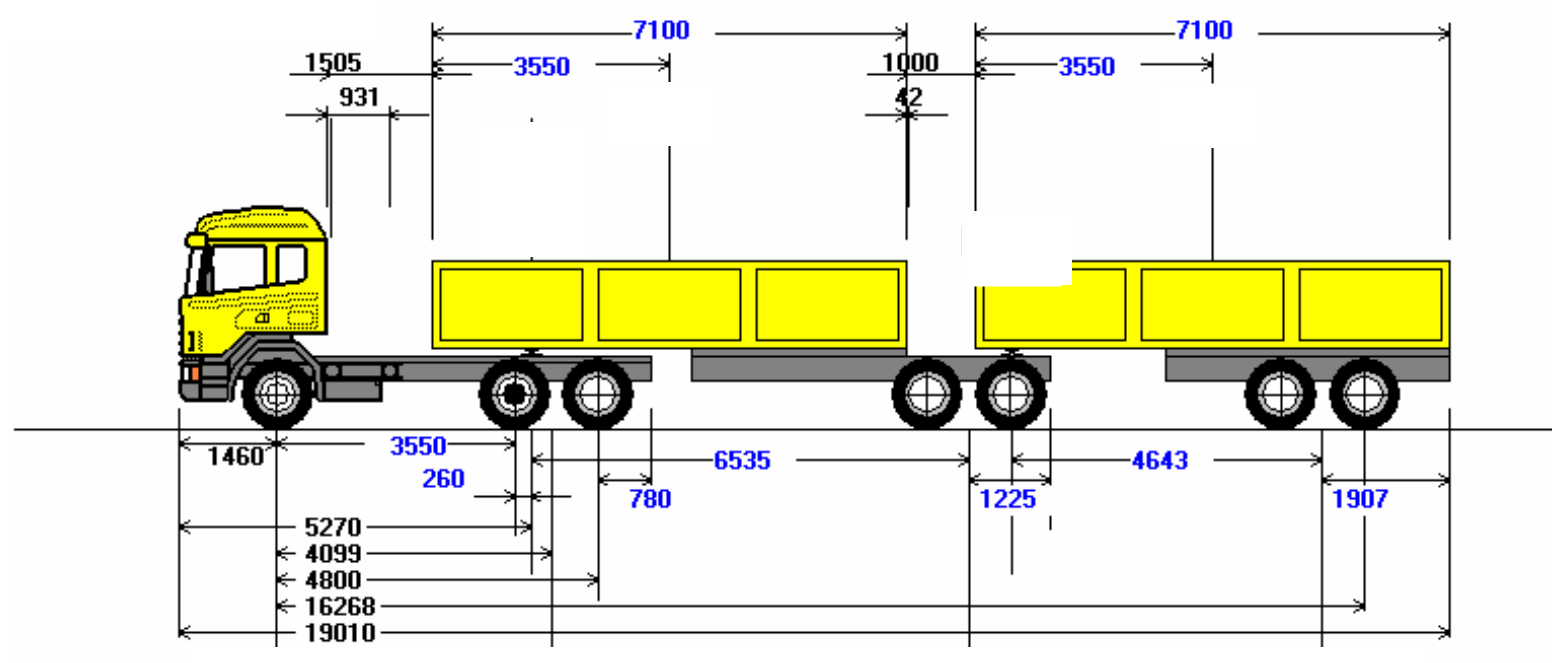

Figura 8 - Dimensões $(\mathrm{mm})$ de uma composição típica com carreta bi-trem de 7100mm Peso Bruto Total Combinado (PBTC) 57 toneladas

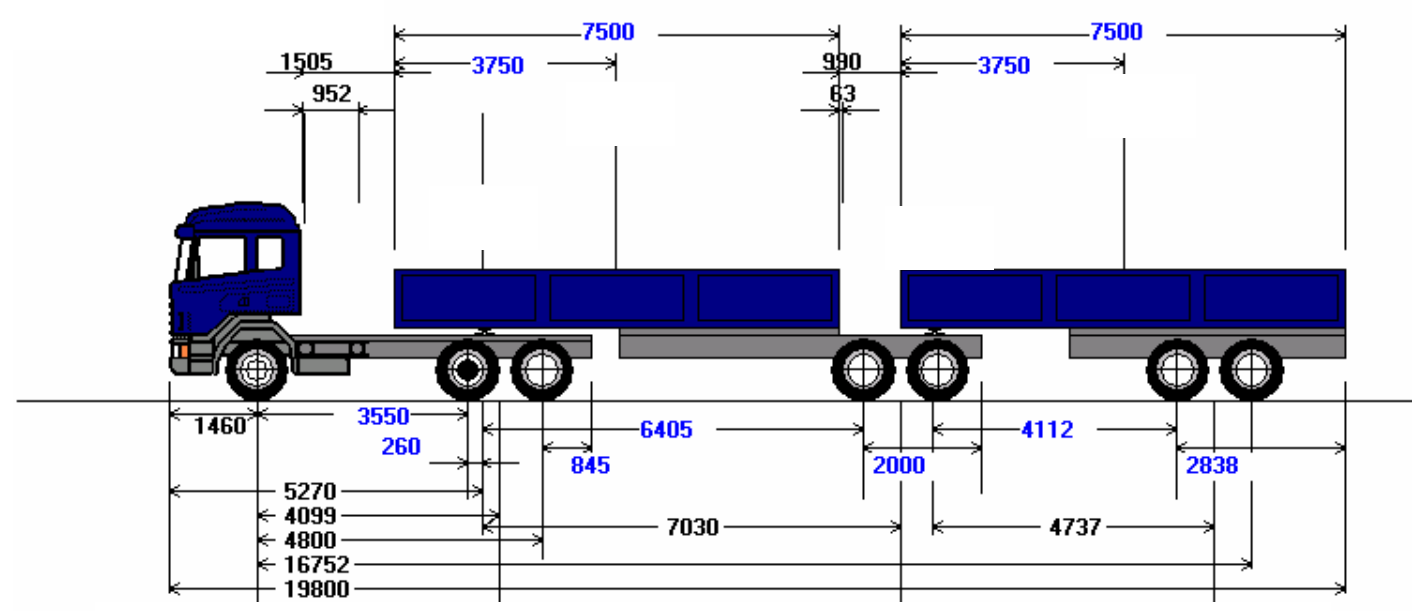

Figura 9 - Dimensões (mm) de uma composição típica com carreta bitrem de 7500mm - Peso Bruto Total Combinado (PBTC) 57 toneladas. 
As tabelas 1 e 2 refletem a comparação direta entre veículos de especificações semelhantes que são em geral destinados para o transporte de grãos, bi-trem na versão $4 \times 2$ adaptada com eixo de apoio (tabela 2) ou Rodo-trem na versão 6x4 articulada (tabela 1).

\begin{tabular}{|c|c|c|c|}
\hline \multirow{2}{*}{ Especificações } & \multicolumn{3}{|c|}{ Veículos tratores $6 \times 4$ Articulados } \\
\hline & Montadora A & Montadora B & Montadora $\mathrm{C}$ \\
\hline $\begin{array}{l}\text { Potência Máxima, } \\
\text { conforme } \\
\text { NBR ISO } 1585\end{array}$ & $\begin{array}{c}315 \mathrm{~kW}(428 \mathrm{cv}) \mathrm{a} \\
1900 \mathrm{rpm}\end{array}$ & $\begin{array}{c}309 \mathrm{~kW}(420 \mathrm{cv}) \\
\text { entre } 1500 \mathrm{e} \\
1800 \mathrm{rpm}\end{array}$ & $\begin{array}{c}313 \mathrm{~kW}(420 \mathrm{hp}) \mathrm{a} \\
1900 \mathrm{rpm}\end{array}$ \\
\hline $\begin{array}{l}\text { Torque Máximo, } \\
\text { conforme } \\
\text { NBR ISO } 1585\end{array}$ & $\begin{array}{c}2100 \mathrm{Nm}(214 \\
\text { mkgf) a } 1100 \mathrm{rpm}\end{array}$ & $\begin{array}{c}2000 \mathrm{Nm} \\
(204 \mathrm{mkgf}) \text { entre } \\
1050 \text { e } 1450 \mathrm{rpm}\end{array}$ & $\begin{array}{c}2000 \mathrm{Nm} \\
(204 \mathrm{mkgf}) \text { entre } \\
1100 \text { e } 1300 \mathrm{rpm}\end{array}$ \\
\hline Embreagem & $\begin{array}{l}\text { Diâmetro } 400 \mathrm{~mm} \text {, } \\
\text { disco duplo, servo- } \\
\text { assistido }\end{array}$ & $\begin{array}{l}\text { Diâmetro } 400 \mathrm{~mm} \text {, } \\
\text { disco duplo, servo } \\
\text { assistido }\end{array}$ & $\begin{array}{c}\text { Diâmetro } 430 \mathrm{~mm} \text {, } \\
\text { disco simples, servo } \\
\text { assistido }\end{array}$ \\
\hline $\begin{array}{c}\text { Capacidade } \\
\text { Máxima de Tração } \\
(\mathrm{CMT})(\mathrm{kg})\end{array}$ & 80.000 & 100.000 & 150.000 \\
\hline
\end{tabular}

Tabela 1 - Comparativo entre especificações técnicas - veículos tratores $6 \times 4$ 


\begin{tabular}{|c|c|c|c|}
\hline \multirow{2}{*}{ Especificações } & \multicolumn{3}{|c|}{ Veículos tratores $4 \times 2$ Articulados } \\
\hline & Montadora A & Montadora B & Montadora $\mathrm{C}$ \\
\hline $\begin{array}{l}\text { Potência Máxima, } \\
\text { conforme } \\
\text { NBR ISO } 1585\end{array}$ & $\begin{array}{c}315 \mathrm{~kW}(428 \mathrm{cv}) \mathrm{a} \\
1900 \mathrm{rpm}\end{array}$ & $\begin{array}{c}309 \mathrm{~kW}(420 \mathrm{cv}) \\
\text { entre } 1500 \mathrm{e} \\
1800 \mathrm{rpm}\end{array}$ & $\begin{array}{c}313 \mathrm{~kW}(420 \mathrm{hp}) \mathrm{a} \\
1900 \mathrm{rpm}\end{array}$ \\
\hline $\begin{array}{l}\text { Torque Máximo, } \\
\text { conforme } \\
\text { NBR ISO } 1585\end{array}$ & $\begin{array}{c}2100 \mathrm{Nm}(214 \\
\text { mkgf) a } 1100 \mathrm{rpm}\end{array}$ & $\begin{array}{c}2000 \mathrm{Nm} \\
(204 \mathrm{mkgf}) \text { entre } \\
1050 \text { e } 1450 \mathrm{rpm}\end{array}$ & $\begin{array}{c}2000 \mathrm{Nm} \\
(204 \mathrm{mkgf}) \text { entre } \\
1100 \text { e } 1300 \mathrm{rpm}\end{array}$ \\
\hline Embreagem & $\begin{array}{c}\text { Diâmetro } 430 \mathrm{~mm} \text {, } \\
\text { disco simples, } \\
\text { servo-assistido }\end{array}$ & $\begin{array}{c}\text { Diâmetro } 430 \mathrm{~mm} \text {, } \\
\text { disco simples, servo } \\
\text { assistido }\end{array}$ & $\begin{array}{c}\text { Diâmetro } 430 \mathrm{~mm} \text {, } \\
\text { disco simples, servo } \\
\text { assistido }\end{array}$ \\
\hline $\begin{array}{c}\text { Capacidade } \\
\text { Máxima de Tração } \\
(\mathrm{CMT})(\mathrm{kg})\end{array}$ & 80.000 & 57.000 & 66.000 \\
\hline
\end{tabular}

Tabela 2 - Comparativo entre especificações técnicas - veículos tratores 4x2

Ao comparar as tabelas 1 e 2 pode-se verificar que, ao contrário da montadora $\mathrm{C}$, as especificações técnicas para o sistema de embreagem das montadoras A e B são mais robustas em todos os modelos (disco de embreagem duplo), contudo, verifica-se que a capacidade máxima de tração $(\mathrm{CMT})$ da versão $4 \times 2$ da montadora $\mathrm{B}$ está sub dimensionada para a aplicação bi-trem rodoviária.

Isto pode indicar que os veículos $4 \times 2$ equipados com eixo traseiro da montadora $\mathrm{B}$ e $\mathrm{C}$, submeterão o sistema de embreagem a uma maior severidade.

Desta forma, como os conjuntos de trem de força (tabela 2) foram dimensionados originalmente para a versão $4 \times 2$ conforme demonstrado, estes passaram a sofrer maiores solicitações que àquelas previstas em projeto, as quais somadas às condições das estradas brasileiras demonstram que o conjunto do sistema de embreagem passou a estar mais suscetível às falhas. 


\section{DESCRIÇÃO DOS SISTEMAS DE ACIONAMENTOS DE EMBREAGEM E SUAS EVOLUÇÕES}

Os revestimentos utilizados nos discos de embreagem são submetidos a condições severas gerando uma grande rejeição de calor em períodos de tempo relativamente curtos (HEISLER, 2002).

Segundo a afirmação de JOHANSSON (2004) ${ }^{1}$ o material de fricção do disco de embreagem, trabalha em condições ideais com temperaturas entre $170^{\circ} \mathrm{C}$ e $260^{\circ} \mathrm{C}$. Segundo o mesmo, os componentes utilizados para o acionamento do conjunto de embreagem em veículos comerciais pesados podem ser submetidos a temperaturas de trabalho que podem variar de $130^{\circ} \mathrm{C}$ a $170^{\circ} \mathrm{C}$ na região periférica do ambiente da embreagem, o que requer boas propriedades mecânicas para o bom funcionamento do sistema.

Dentre os sistemas de acionamento de embreagem JOHANSSON (2004) ${ }^{1}$ informa que os mais conhecidos e utilizados pelas montadoras de veículos comerciais pesados são o sistema de acionamento por cilindro escravo concêntrico (CSC) e sistema de acionamento por cilindro escravo externo.

\subsection{Cilindro Escravo Concêntrico (CSC)}

Conforme demonstrado na figura 10 e tabela 3, o sistema de acionamento da embreagem por cilindro escravo concêntrico utiliza-se da pressão gerada a partir da compressão do fluido de freio dentro dos condutos do sistema.

Neste tipo de sistema de acionamento de embreagem utiliza-se fluido de freio, pois o mesmo apresenta baixa viscosidade cinemática que, aliada à propriedade de incompressibilidade do mesmo, apresenta respostas rápidas aos comandos do motorista.

O funcionamento deste sistema se dá através do acionamento do pedal da embreagem (1), que por sua vez promove a compressão do fluido dentro do servo-mestre (2). A mangueira de nível (3) está diretamente ligada ao reservatório de fluido de freio que se

Johansson (2004) - (informação verbal) ${ }^{1}$. 
encontra instalado embaixo do painel de instrumentos do veículo. Com a compressão, o fluido passa pela mangueira de alimentação (4) promovendo o enchimento da voluta do cilindro escravo concêntrico (5), gerando movimentações axiais do platô (7), este por sua vez libera o contato entre o disco de embreagem (6) e o volante do motor fazendo com que o mesmo gire livremente, permitindo assim a troca das marchas.

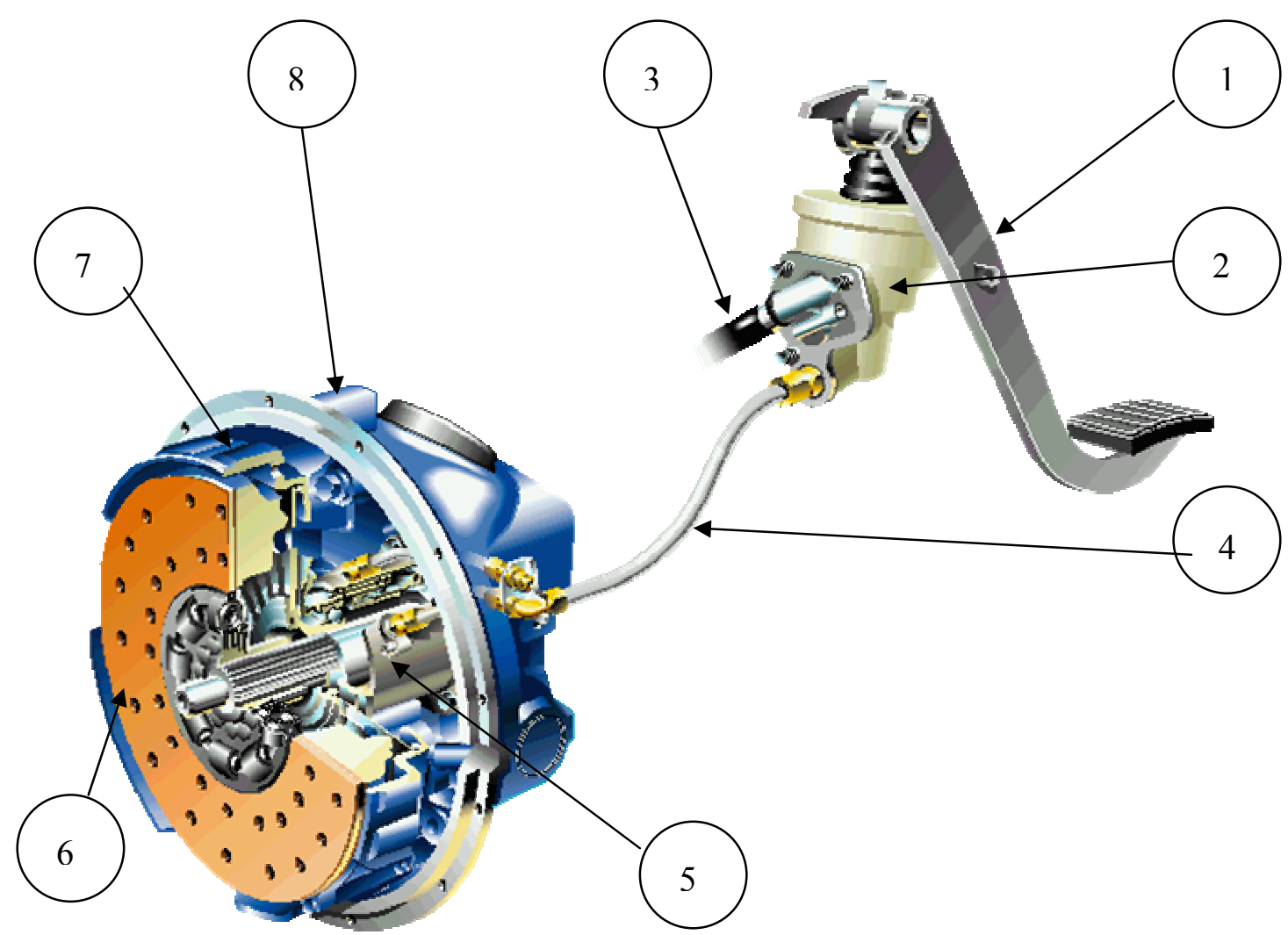

Figura 10 - Sistema de acionamento da embreagem por cilindro escravo concêntrico.

\begin{tabular}{|l|l|}
\hline 1 - Pedal da embreagem & 5 - Cilindro escravo concêntrico \\
\hline 2 - Servo-master da embreagem & 6 - Disco de embreagem/material de fricção \\
\hline 3 - Mangueira de nível & 7 - Platô \\
\hline 4 - Mangueira de alimentação & 8 - Carcaça da embreagem \\
\hline
\end{tabular}

Tabela 3 - Lista de componentes principais de um sistema de embreagem 
A figura 11 e tabela 4 ilustram um corte longitudinal do ambiente de um sistema de embreagem com acionamento pelo conceito CSC. Este fica delimitado entre a carcaça da embreagem (7) que é normalmente montada na caixa de câmbio e carcaça do volante (8), e esta por sua vez é montada na parte traseira do motor.

O volante do motor (1) tem a função de gerar massa inercial de rotação entre os ciclos de combustão do motor. O disco de embreagem (2) é o componente no qual é montado o material de fricção (3), o qual em atrito com o volante do motor transmitirá a rotação do motor para o eixo primário da caixa de câmbio (9).

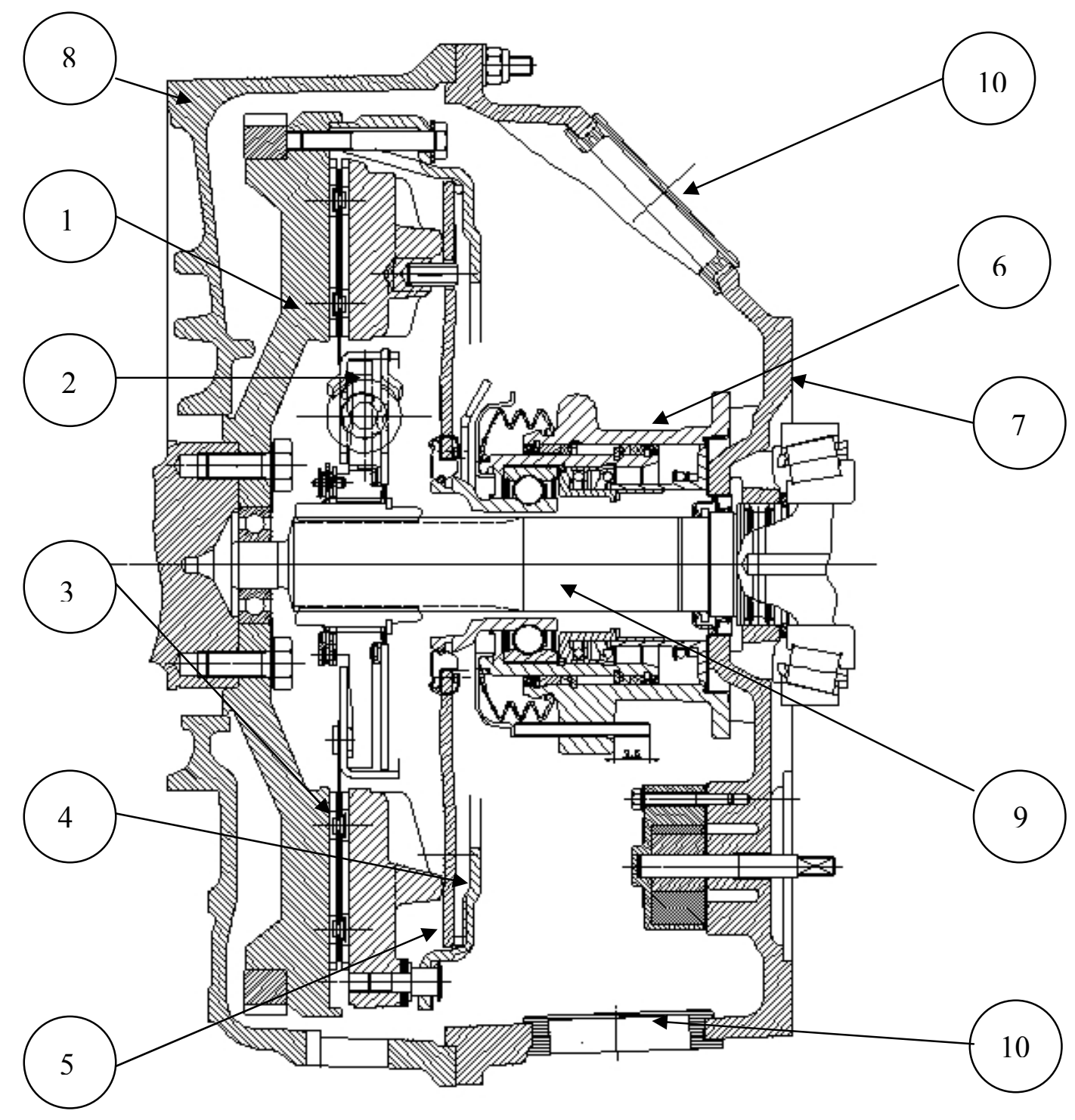

Figura 11 - Corte transversal do sistema de embreagem de acionamento por CSC. 


\begin{tabular}{|l|l|}
\hline 1 - Volante do motor & 6 - Cilindro escravo concêntrico \\
\hline 2 - Disco de embreagem & 7 - Carcaça da embreagem \\
\hline 3 - Material de fricção & 8 - Carcaça do volante \\
\hline 4 - Platô & 9 - Eixo primário da caixa de cambio \\
\hline 5 - Mola do platô & 10 - Tampões de borracha \\
\hline
\end{tabular}

Tabela 4 - Lista de componentes principais contidos no ambiente da embreagem

A figura 12 e tabela 5 ilustram em um corte longitudinal os componentes de um cilindro escravo concêntrico (CSC):

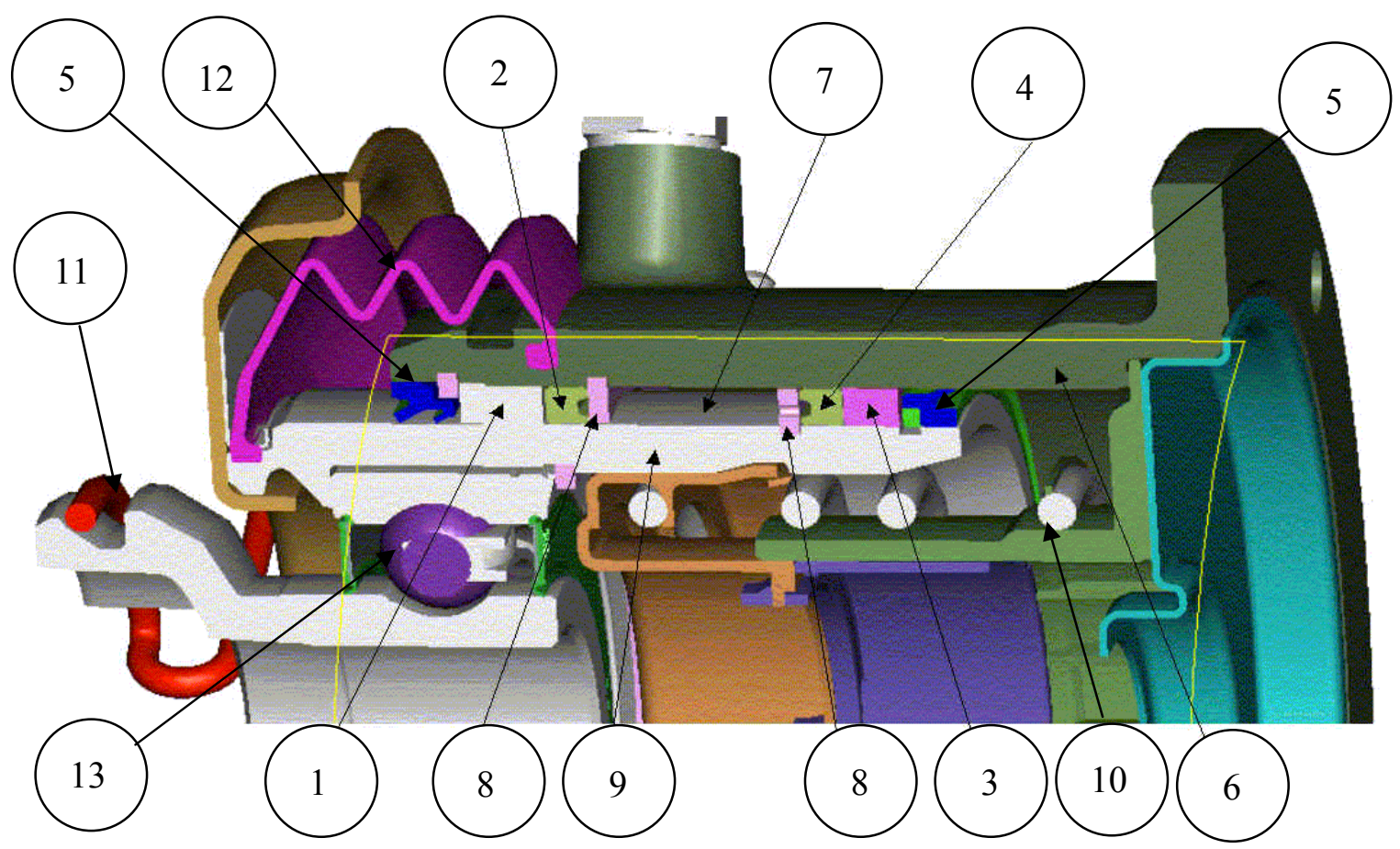

Figura 12 - Corte longitudinal de um cilindro escravo concêntrico 


\begin{tabular}{|l|l|}
\hline 1 - Anel de suporte anterior & 7 - Voluta de compressão do fluido de freio \\
\hline 2 - Anel de compressão frontal & 8 -Anel de ampliação de velocidade \\
\hline 3 - Anel de suporte posterior & 9 - Êmbolo \\
\hline $4-$ Anel de compressão traseiro & $10-$ Mola de retorno \\
\hline 5 - Anel raspador & $11-$ Cubo \\
\hline 6 - Carcaça externa & $12-$ Protetor de borracha \\
\hline
\end{tabular}

Tabela 5 - Lista de componentes principais de um cilindro escravo concêntrico

Quando o fluido é comprimido pelo pistão do cilindro através da rede de condutos para o interior da voluta (7), ocorre o enchimento da mesma, sendo que o fluido passará pelos furos localizados nos anéis de ampliação de velocidade (8) exercendo pressão contra os lábios dos anéis de compressão frontal (2) e traseiro (4), promovendo assim os movimentos axiais do êmbolo.

Os anéis de suporte anterior (1) e posterior (3) têm a função de promover a rigidez do conjunto de maneira a assegurar que toda a força transmitida para os anéis de compressão seja transformada em movimento axial do êmbolo (9) na direção da caixa de câmbio, comprimindo a mola (10). O retorno do êmbolo à sua posição inicial é feito através da mola (10).

O cilindro escravo concêntrico é fixado na carcaça da caixa de câmbio através do seu flange posterior e na sua parte frontal, o canal do cubo (11) é montado na mola do platô. O rolamento (13) absorverá a diferença de rotação entre o platô e o corpo do cilindro escravo.

Os anéis raspadores frontais e posteriores (5) devem assegurar que contaminantes externos (líquidos ou sólidos) não venham a entrar em contato com o fluido.

A rugosidade superficial do êmbolo é fator determinante para a boa vedação dos anéis raspadores.

As vantagens deste sistema são principalmente as facilidades de montagem quando em produção seriada e a racionalização de componentes. Este sistema é composto apenas do cilindro e dos condutos do fluido. 
Entretanto é importante mencionar que embora esta solução apresente uma boa otimização de componentes, a sua manutenção passou a ser a sua principal desvantagem, pois há sempre a necessidade de desmontagem do conjunto da carcaça da embreagem e até alguns componentes do motor, em caso de manutenção corretiva.

No caso de veículos comerciais, principalmente em ônibus rodoviários, qualquer falha deste tipo de sistema compromete seriamente a dirigibilidade do veiculo, causando a sua parada. O fato de que o sistema é de difícil acesso torna obrigatório o reparo em oficinas devidamente equipadas.

\subsection{Sistemas de Acionamento de Embreagem por Cilindro Escravo Externo}

O sistema de acionamento de embreagem por cilindro escravo externo utiliza um conjunto de alavancas para a transmissão do movimento de liberação do conjunto platô e disco de embreagem.

Conforme ilustração na figura 13 e descrição de componentes na tabela 6 , quando o pedal da embreagem é acionado, o fluido é pressionado dentro dos condutos e preenche a voluta do cilindro externo (1). Este por sua vez, através da movimentação de sua haste, aciona a alavanca (2) que está montada na articulação (4) transferindo o movimento axial para a bucha (5) liberando o conjunto platô-disco de embreagem.

$\mathrm{O}$ acionamento através de alavancas requer um numero maior de peças, o que comparado ao sistema de acionamento por cilindro escravo concêntrico, apresenta um maior custo para a montadora, sendo esta então, a principal desvantagem apontada deste sistema.

A vantagem do mesmo é que os componentes com maior suscetibilidade a falhas são instalados no ambiente externo da embreagem, facilitando, a manutenção preventiva e principalmente a corretiva.

As peças que são montadas dentro do ambiente da embreagem normalmente apresentam longos intervalos de manutenção, embora seja recomendada a troca do conjunto de 
acionamento axial (considerado como componente mais frágil deste sistema) a cada troca do disco de embreagem.

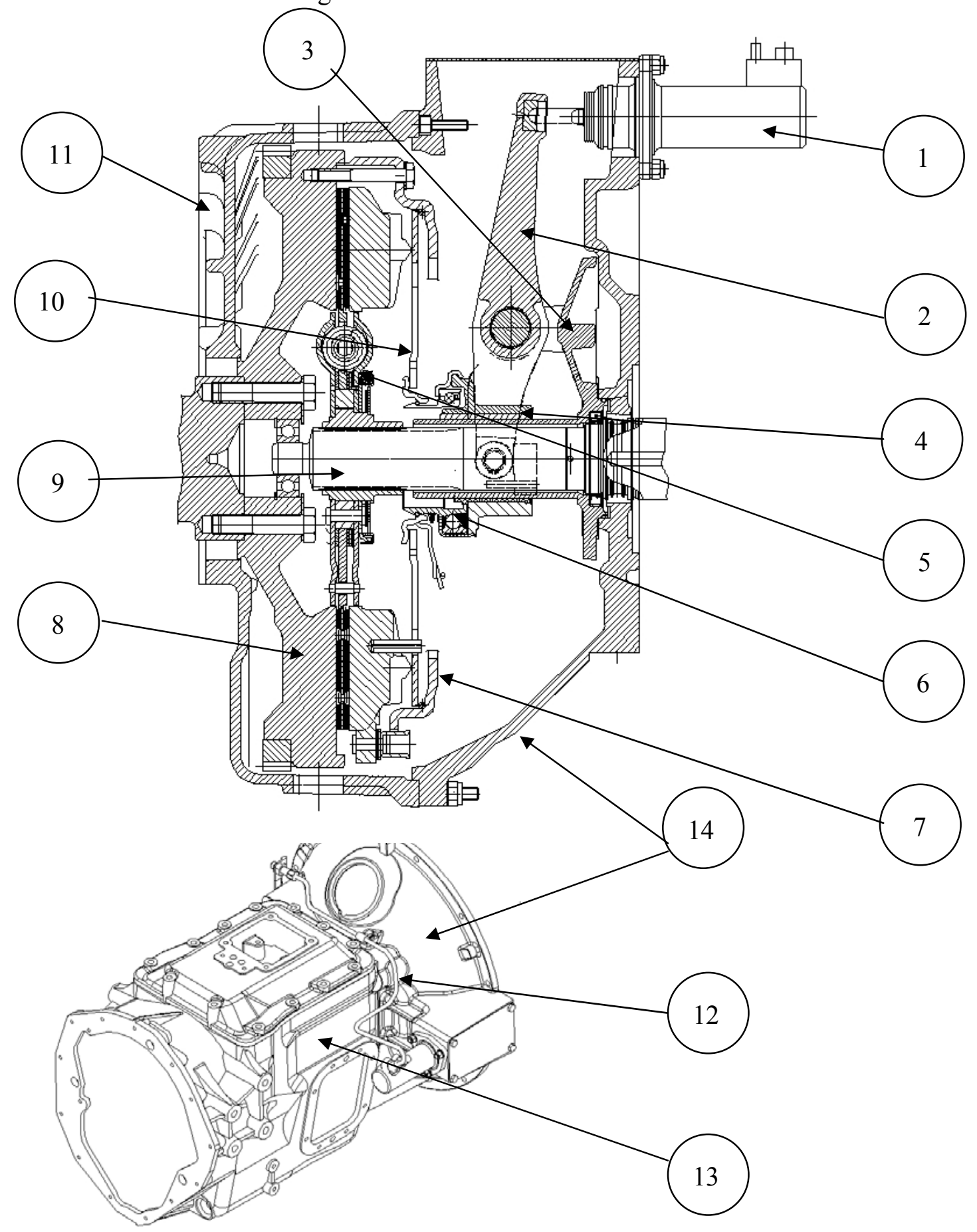

Figura 13 - Corte transversal do sistema de embreagem de acionamento por cilindro escravo externo 


\begin{tabular}{|l|l|}
\hline 1 - Cilindro escravo & 8 - Volante do motor \\
\hline $\begin{array}{l}2-\text { Alavanca de acionamento } \\
\text { na carcaça da embreagem }\end{array}$ & 9 - Eixo piloto da caixa de câmbio \\
\hline $\begin{array}{l}4-\text { Conjunto de acionamento axial } \\
\text { com rolamento }\end{array}$ & 11 - Carcaça do volante do motor \\
\hline 5 - Disco de embreagem & 12 - Condutos de alimentação de fluido \\
\hline 6 - Rolamento & 13 - Caixa de câmbio \\
\hline $7-$ Platô da embreagem & 14 - Carcaça da embreagem \\
\hline
\end{tabular}

Tabela 6 - Lista de componentes principais de um cilindro escravo externo

Portanto, ao analisar-se as duas concepções de projeto (cilindro escravo concêntrico e cilindro escravo externo), pode-se verificar que o conceito de cilindro escravo concêntrico apresenta uma construção bastante contemporânea que preserva a simplicidade externa da caixa de mudanças e da carcaça da embreagem, contudo, tornando a manutenção, seja preventiva ou corretiva o seu ponto fraco pelo difícil acesso.

O sistema de acionamento por cilindro escravo externo necessita de um numero maior de peças para exercer a mesma função aumentando o seu custo, contudo, o seu ponto forte é justamente a facilidade de manutenção pela ótima acessibilidade aos componentes do sistema.

Conclui-se, portanto, que para sistemas de baixa manutenção, a solução mais indicada para o sistema de acionamento da embreagem é o conceito de cilindro escravo concêntrico e para aqueles sistemas de alta taxa de manutenção a solução mais indicada é a de acionamento da embreagem por cilindro escravo externo. 


\section{DESCRIÇÃO DAS FALHAS DE CAMPO DO SISTEMA DE ACIONAMENTO DA EMBREAGEM POR CILINDRO ESCRAVO CONCÊNTRICO}

O sistema de acionamento de embreagem deve responder rapidamente aos comandos do motorista, permitindo trocas de marcha rápidas e precisas. O sistema deve ser totalmente isento de folgas, a fim de propiciar uma boa transmissão da força de acoplamento / desacoplamento do conjunto da embreagem.

Segundo TEIXEIRA (2004), "o torque do motor deve ser transmitido com segurança, mesmo em situações extremas, evitando portanto, a patinação da embreagem ou falha na sincronização dos movimentos entre motor e câmbio"; para isto, este mesmo autor menciona que "para a segurança da transmissão do torque, a embreagem deve ser dimensionada tomando-se como base o máximo torque a ser transmitido acrescido de um coeficiente de segurança de 40\%”.

Vibrações e variações de altura do pedal no momento de acionamento da embreagem são indícios de que o sistema apresenta falhas que podem ser diagnosticadas através de manutenções preventivas.

No caso em estudo, os motoristas que operavam com veículos dotados de sistema de acionamento de embreagem por cilindro escravo concêntrico, reclamavam que ao dirigirem por longas horas em regime de tráfego intenso (principalmente urbano) o pedal da embreagem começava a vibrar. Em alguns casos houve relatos de que havia um retardamento no tempo de resposta do sistema de acionamento da embreagem aos comandos do pedal.

Outros motoristas adicionaram aos relatos anteriores a informação de que, além da vibração do pedal, o mesmo tornava-se "elástico" ou seja, o início do acionamento da embreagem variava ao longo do curso do pedal em função do tempo e severidade da operação.

Estes relatos tornaram evidente que havia uma falha no acionamento da embreagem, notoriamente verificada quando o sistema era submetido a condições severas de operação.

Os técnicos de análise de componentes em garantia informaram que uma grande parte das peças analisadas apresentava vazamento do fluido de embreagem e que, em muitos casos, os 
relatórios de falha indicavam ambos os problemas (vibração e vazamento) como causas raízes para a falha.

Estranhamente havia relatos tanto dos técnicos de garantia quanto dos proprietários de que o número de falhas aumentava durante o verão (estação chuvosa) e diminuía nas outras estações do ano.

O sentimento dos técnicos de garantia era de que o índice de insatisfação de clientes era notoriamente maior em estados que apresentavam maior índice pluviométrico, especialmente nos estados da região norte do país, fornecendo assim indícios de que a falha poderia estar ligada ao índice pluviométrico da região de operação dos veículos.

\subsection{Análise de Peças e Dados de Campo para Pré-Diagnóstico}

Seguindo a proposição de MACEDO et. al (2006), no processo de investigação utilizou-se amplamente das experiências de campo para o refinamento da base de dados e definição de um cenário propício para simulações a fim de elucidar o mecanismo de falhas.

As informações provenientes de campo juntamente com a disponibilidade das peças para análise técnica em garantia, propiciaram um ambiente favorável para a formação de um cenário, a partir do qual foram estabelecidas às próximas etapas de investigação.

Para tanto, oito peças foram desmontadas na oficina de garantia, sendo que todas aparentemente apresentavam vazamento de fluido de embreagem entre o êmbolo e a carcaça externa na direção do protetor contra pó.

Ao verificar os anéis de compressão frontal e traseiro (figura 14) constatou-se um desgaste acentuado na região da vedação radial, onde os anéis (frontal e traseiro) mantêm contato com a carcaça do cilindro escravo concêntrico.

Os ressaltos internos dos anéis de vedação frontal e posterior (região onde o fluido é comprimido a partir da voluta) não apresentavam nenhum sinal de desgaste, o que pode indicar que de alguma forma pode haver uma movimentação de torção dos anéis no momento de sua compressão pelo fluido. 


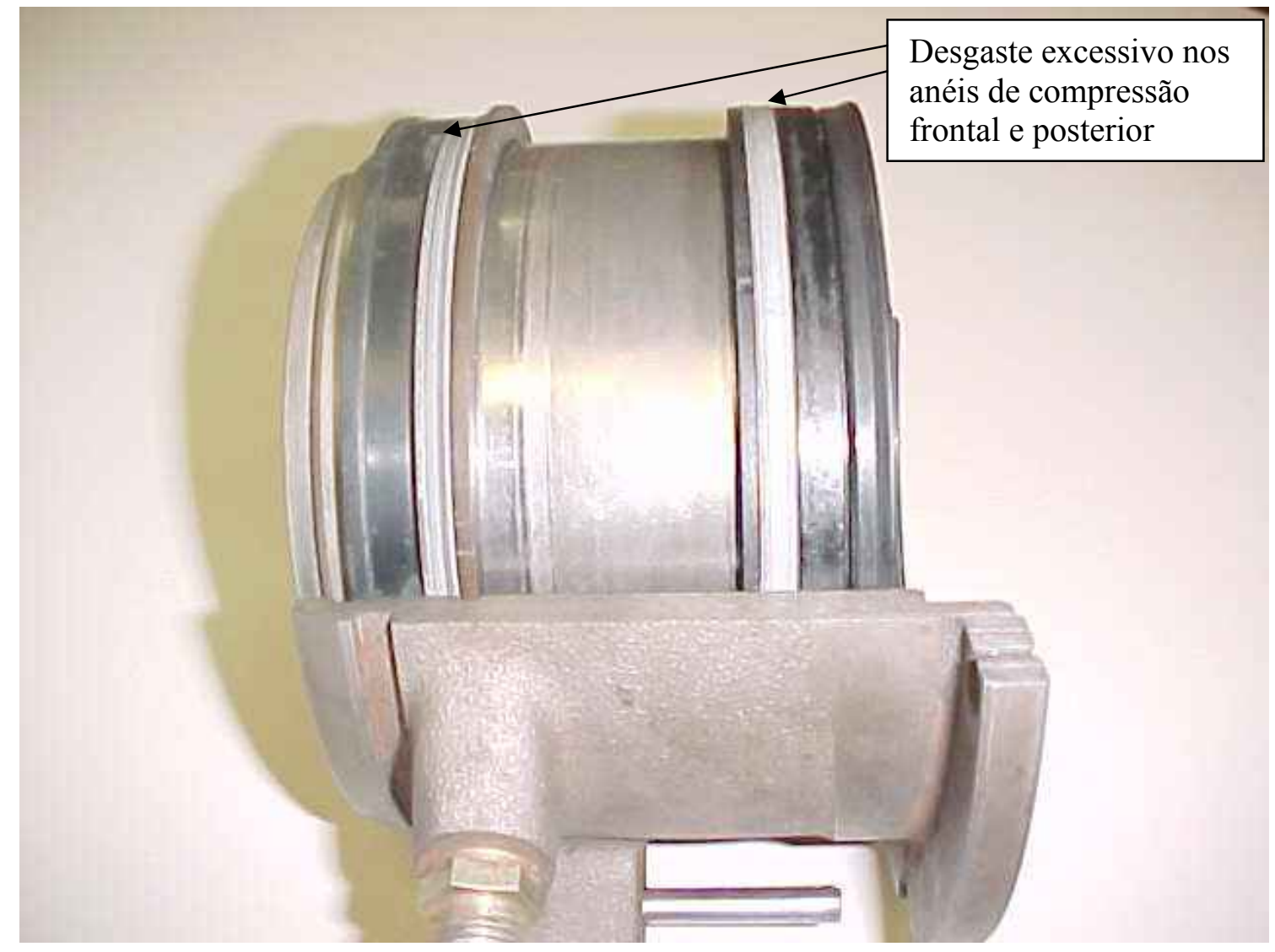

Figura 14 - Cilindro escravo concêntrico (em corte) avaliado em garantia

Os fluidos de embreagem recolhidos das peças apresentavam um demasiado escurecimento que também já fora causa de reclamações em garantia por falta de funcionamento da embreagem.

Os demais componentes do conjunto não apresentavam evidências de falhas, embora todos os êmbolos analisados apresentassem um grande acúmulo de pó de embreagem, aparentando vedação deficiente entre a carcaça do cilindro e o protetor contra pó. 


\subsection{Análise de Contaminantes em Amostras Recolhidas no Campo}

Os proprietários dos veículos que apresentaram as falhas no sistema de embreagem realizaram análises laboratoriais para avaliar a eventual influência de contaminantes externos ao fluido de embreagem.

Conforme requisitos do "Department of Transport" (DOT) do "National Highway Traffic Safety Administration” (NHTSA) dos Estados Unidos da América, a metodologia de teste adotada para verificação de contaminação por água foi realizada através de ensaios de laboratório de acordo com ASTM D4377 (metodologia de "Karl Fischer").

Conforme demonstrado na tabela 7 , concluiu-se que todos os fluidos analisados apresentavam um alto índice de contaminação por resíduos sólidos e água, sendo que não fora possível determinar a composição química dos contaminantes sólidos na ocasião dos testes.

\begin{tabular}{|c|c|c|c|}
\hline Contaminantes & $\begin{array}{r}\text { Amostra 1 } \\
(15.000 \mathrm{~km})\end{array}$ & $\begin{array}{r}\text { Amostra 2 } \\
(65.000 \mathrm{~km})\end{array}$ & $\begin{array}{r}\text { Amostra 3 } \\
(66.000 \mathrm{~km})\end{array}$ \\
\hline Água (\% vol) & 15,9 & 13,71 & 13,57 \\
\hline Viscosidade Cinemática $\left(-40^{\circ} \mathrm{C}\right)$ & $\begin{array}{c}\text { Não } \\
\text { (cSt) }\end{array}$ & 1540 & 1620 \\
\hline
\end{tabular}

Tabela 7 - Resultado de análise de amostras de campo de fluidos de embreagens

A amostra 1 apesar da baixa quilometragem, apresentou valores de contaminação por água extremamente elevada, o que pode indicar extremo mau uso do sistema de embreagem ou até mesmo ineficiência de manutenção, adicionalmente, os valores dos ensaios de viscosidade cinemática não foram disponibilizados para a pesquisa.

Por outro lado, as amostras 2 e 3 apresentaram pouca dispersão nos valores de contaminação o que indicou que estas eram mais confiáveis para o estudo das falhas do sistema de embreagem. 


\subsection{Entrevistas Técnicas para Refinamento das Informações}

Os métodos que se baseiam na modelação matemática, na experimentação laboratorial e nas especificações formais, classificam-se como métodos quantitativos (MACEDO et al, 2004), portanto ao reuni-los constituira-se uma base de dados robusta para a definição da linha de investigação científica.

A fim de propiciar um refinamento dos dados e suportar a investigação, foram realizadas três entrevistas técnicas com especialistas de diferentes segmentos ligados à engenharia automotiva.

A primeira foi realizada com o fabricante do fluido de embreagem, a segunda com dois químicos especializados em desenvolvimento de aditivos para combustíveis e lubrificantes e a terceira e última com um concessionário que reparava freqüentemente conjuntos de embreagem com características de falhas semelhantes às descritas na investigação. As duas últimas entrevistas foram realizadas no estado do Rio de Janeiro. $\mathrm{Na}$ primeira entrevista o químico relatou que as falhas mais comuns que ocorrem em sistemas que utilizam fluidos do tipo DOT 4 são decorrentes de falta de manutenção e, que dentre os diversos tipos de falhas, a mais recorrente é a alta taxa de contaminação do fluido por umidade, embora houvesse também casos de seu conhecimento em que os materiais não haviam sido selecionados de maneira correta na fase de projeto dos sistemas de freio / embreagem. Esta constatação sugeria que o estudo das falhas no sistema de embreagem deveria ser então subdividido entre testes de compatibilidade química e testes funcionais.

A segunda entrevista foi realizada com dois especialistas em química de uma empresa líder mundial na fabricação de aditivos para combustíveis e lubrificantes, sediada no estado do Rio de Janeiro.

Após a desmontagem completa de um conjunto do cilindro escravo concêntrico e explicação detalhada sobre seu funcionamento para os químicos da referida empresa, os mesmos não apontaram nenhum mecanismo como responsável direto pela falha.

Portanto, face à não indicação de possíveis mecanismos de falha nesta segunda entrevista, foi relatado aos químicos o conteúdo da primeira entrevista na qual 
apontavam-se como possíveis causas de falha, a incompatibilidade química entre materiais e a contaminação do fluido. $\mathrm{O}$ que foi prontamente endossado por este segundo grupo de químicos.

A terceira entrevista se deu em uma concessionária de uma montadora de veículos comerciais pesados, localizada na principal rodovia de acesso à cidade do Rio de Janeiro. Foram entrevistados nesta ocasião o gerente de manutenção da concessionária e um grupo de mecânicos. Estes relataram que a falha do sistema de embreagem ocorria notoriamente em alguns tipos de veículos comerciais pesados que operavam conhecidamente com excesso de carga no tráfego intenso da cidade do Rio de Janeiro.

Este último relato apontou que os sintomas das falhas eram exatamente os mesmos já mencionados anteriormente, ou seja: o pedal da embreagem apresentava em primeiro estágio um pouco de vibração seguida da perda parcial de função até a total perda de funcionalidade do sistema.

\subsection{Formação de uma Matriz de Investigação Técnica}

Diversos estudos sobre sistemas de acionamento de embreagem e seus respectivos modos de falhas foram desenvolvidos ao longo destes últimos anos, dentre estes podemos citar o trabalho realizado por TEIXEIRA (2004) que foca as falhas mecânicas dos sistemas de embreagem, propondo inclusive a árvore de falhas descrita na figura 15 . Este modelo foi desenvolvido através de pesquisas de funcionalidades mecânicas e portanto pode ser utilizado para suportar a construção de uma matriz de investigação técnica para o problema em estudo neste trabalho. 


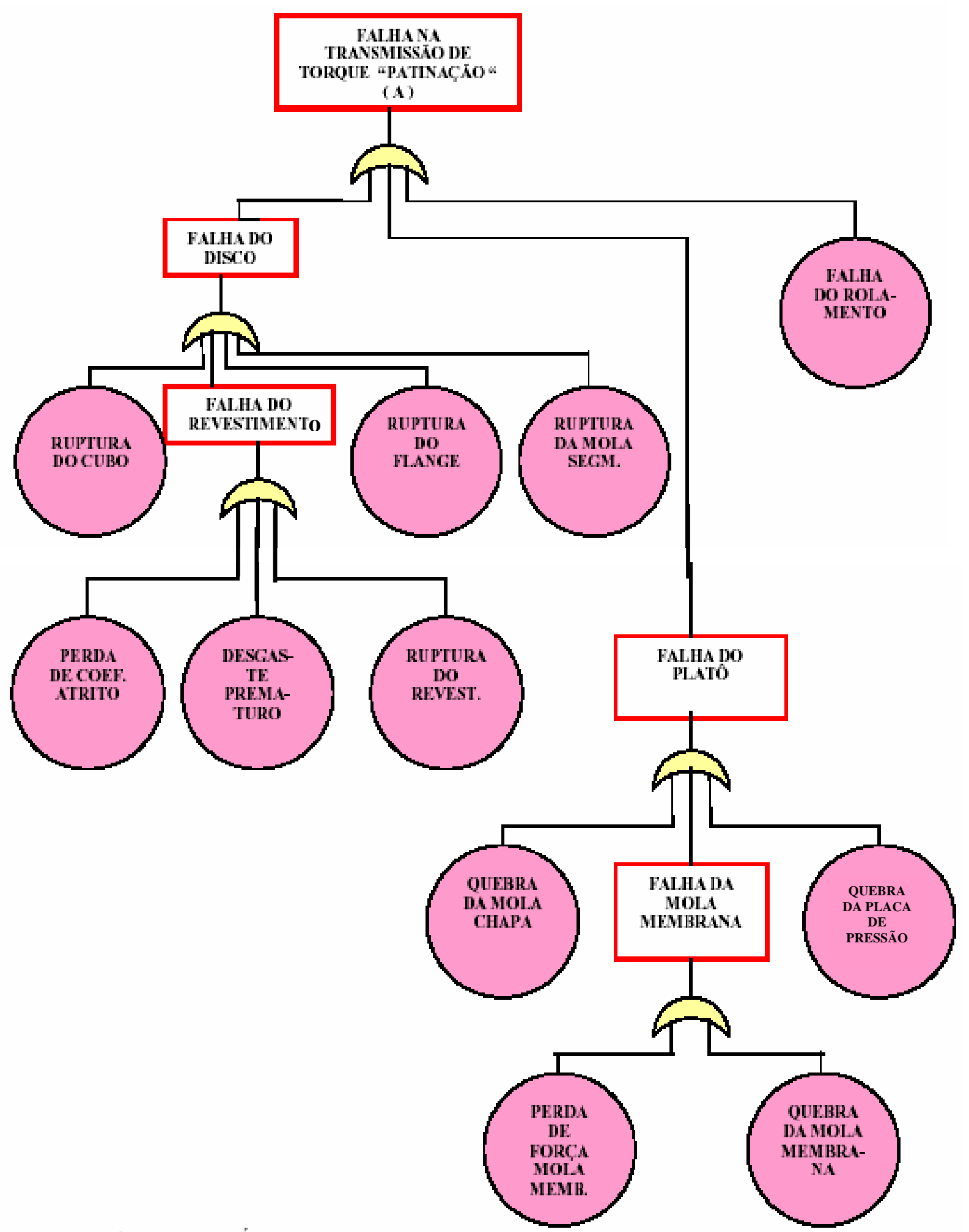

Figura 15 - Árvore de falhas de um sistema de embreagem segundo Teixeira, 2004 
Conforme já mencionado, TEIXEIRA (2004 78p) contempla os modos de falha do sistema de embreagem apenas do ponto de vista da funcionalidade mecânica.

Contudo, para o cumprimento dos principais requisitos de performance "acionamento leve do pedal" e "inexistência de trepidações", conforme proposto pelo mesmo autor na tabela 8 abaixo, há de se considerar os aspectos químicos e de compatibilidade de materiais do sistema de embreagem com o fluido utilizado no sistema.

\begin{tabular}{|c|c|c|}
\hline Função & $\begin{array}{c}\text { Importância Relativa } \\
\text { (escala de 0 a 3,5) }\end{array}$ & Requisito \\
\hline Acionamento leve do pedal & 3,01 & Desempenho \\
\hline Inexistência de trepidações & 2,96 & Desempenho \\
\hline Inexistência de patinação & 2,73 & Desempenho \\
\hline $\begin{array}{c}\text { Inexistência de ruído de } \\
\text { acionamento }\end{array}$ & 2,3 & Desempenho \\
\hline $\begin{array}{c}\text { Inexistência de ruído de } \\
\text { câmbio }\end{array}$ & 2,09 & Desempenho \\
\hline $\begin{array}{c}\text { Inexistência de raspagem } \\
\text { de marcha }\end{array}$ & 1,93 & da embreagem segundo
\end{tabular}
TEIXEIRA (2004)

Os dados levantados na investigação sobre as falhas do sistema de acionamento da embreagem por cilindro escravo concêntrico, sugerem que a linha de investigação técnica deve apresentar maior abrangência se comparado ao estudo de TEIXEIRA que se limitou apenas aos aspectos mecânicos. O foco do estudo deve ser mantido na informação colhida sobre a contaminação do fluido por água associada à linha de investigação das funcionalidades do sistema sob condições severas de operação, conforme demonstrado na figura 16. 
Desenvolveu-se então, um plano de investigação técnico dividido em duas abordagens distintas: a primeira sobre os aspectos químicos dos materiais e a segunda sobre aspectos funcionais dos componentes. 


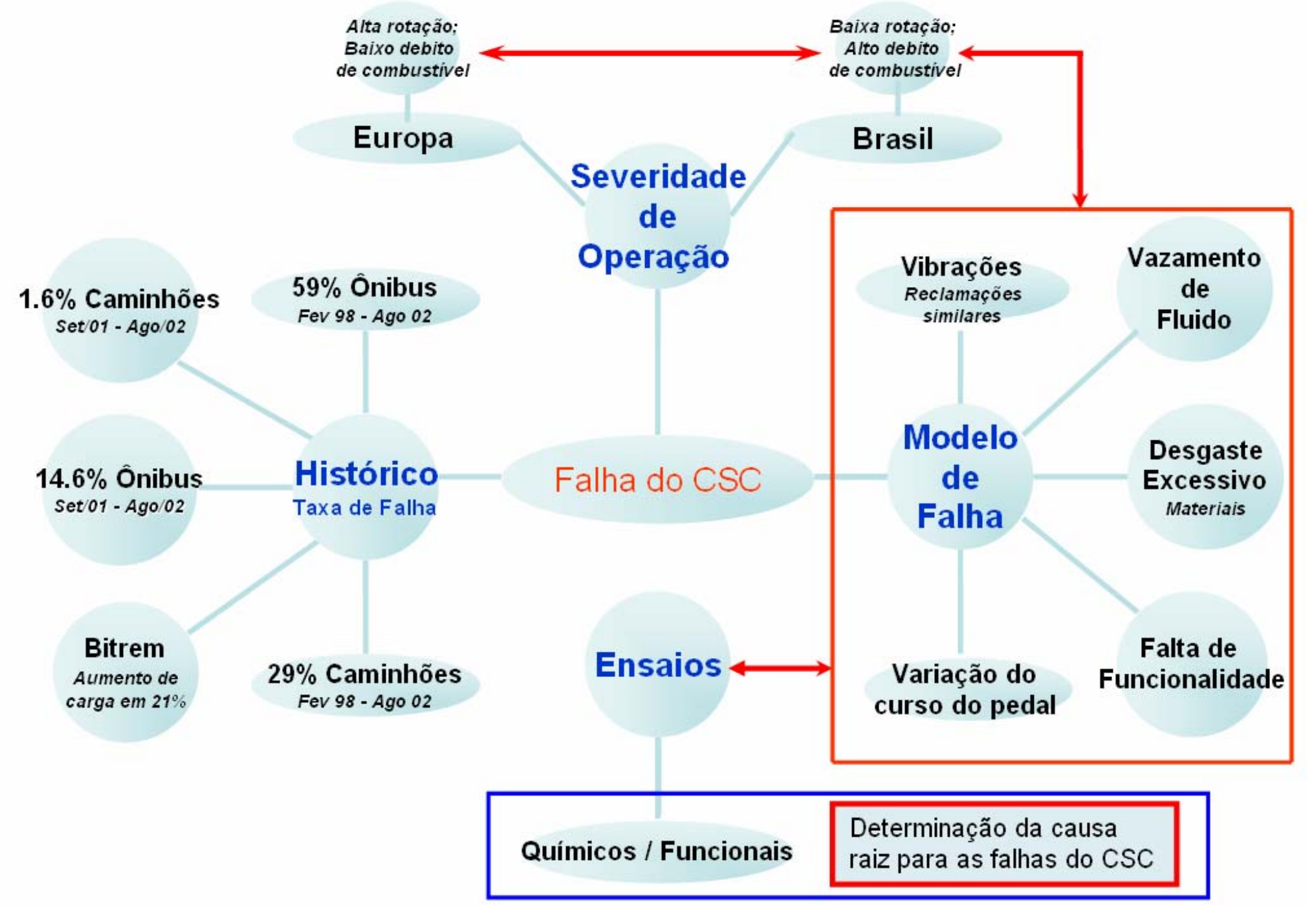

Figura 16 - Matriz de dados colhidos na fase de pré-investigação das falhas do Cilindro Escravo Concêntrico (CSC) 
A investigação técnico-química, conforme descrita nos capítulos 5 a 7 foi subdividida nas seguintes etapas :

- Investigação de compatibilidade química do fluido DOT 4 e 5.1 com os demais materiais do sistema;

- Revalidação dos testes de compatibilidade química para assegurar a reprodutibilidade dos resultados;

- Análise da composição química dos materiais de vedação e suas respectivas temperaturas máximas de trabalho;

- Análise química de contaminantes em amostras coletadas em campo;

- Investigação da influência da contaminação por água no ponto de ebulição do fluido de freio DOT 4 e DOT 5.1;

- Investigação da influência da contaminação por água no ponto de ebulição do fluido de freio DOT 4 de outros fabricantes no mercado;

- Investigação da taxa de concentração da contaminação por água ao longo do sistema.

A investigação dos aspectos funcionais conforme descrita no capítulo 8 foi subdividida nas seguintes etapas:

- Avaliação funcional das pressões e temperaturas no sistema;

- Teste de indução à falha utilizando-se fluido DOT 4 com $14 \%$ de taxa de contaminação por água;

- Investigação da influência da ventilação forçada sobre o ambiente da embreagem; 


\section{TESTES QUÍMICOS PARA AVALIAÇÃO DAS ESPECIFICAÇÕES DE FLUIDOS DE FREIO EMPREGADOS EM SISTEMAS DE EMBREAGEM}

Conforme descrito no capítulo anterior, os estudos de compatibilidade entre materiais complementam aqueles relacionados às funcionalidades mecânicas, propostos por TEIXEIRA (2004).

Para tanto, é preciso entender as propriedades requeridas para um fluido de embreagem (ou freio). Com isto houve a necessidade de avaliar os fluidos disponíveis no mercado brasileiro para assegurar a qualidade dos resultados da investigação química.

Foram colhidas amostras das três principais marcas de fluidos DOT 4 do mercado brasileiro para ensaios de laboratório. Estes ensaios se restringiram basicamente ao comparativo das propriedades higroscópicas e de dispersância de água em altas temperaturas com diferentes taxas de contaminação por água.

\begin{tabular}{|c|c|c|c|}
\hline \% Água (vol.) & $\begin{array}{c}\text { Fluido A - Ponto de } \\
\text { ebulição }\left({ }^{\circ} \mathrm{C}\right)\end{array}$ & $\begin{array}{c}\text { Fluido B - Ponto de } \\
\text { ebulição }\left({ }^{\circ} \mathrm{C}\right)\end{array}$ & $\begin{array}{c}\text { Fluido C - Ponto de } \\
\text { ebulição }\left({ }^{\circ} \mathrm{C}\right)\end{array}$ \\
\hline 20 & 110 & 113 & 113 \\
\hline 30 & 110 & 109 & Instável \\
\hline 40 & 108 & Instável & Instável \\
\hline
\end{tabular}

Tabela 9 - Testes de dispersância de água em fluidos DOT 4

Os resultados descritos na tabela 9, mostram uma boa capacidade de dispersão de água até a taxa de contaminação do fluido DOT 4 com $20 \%$ em volume de água, sendo que a instabilidade relatada para as taxas de contaminação de $30 \%$ e $40 \%$ é definida pelo início de formação de fases (fluido / água) durante a ebulição.

GUESSER, et. al (2003) em seus ensaios para desenvolvimento de novos materiais para discos de freio, demonstra que a temperatura na zona de contato com o disco pode chegar a valores acima de $240^{\circ} \mathrm{C}$, portanto, é de se considerar que fluidos de freio com 
taxas de contaminação por água de até $20 \%$ está de longe, muito acima dos limites de segurança para sistemas de freios.

Segundo SERBINO (2005), a taxa crítica para contaminação de um fluido por água é de $2 \%$ a $3 \%$, o que segundo o autor pode causar falhas no sistema de freios em condições severas de frenagem.

Entretanto, optou-se pela realização dos ensaios (tabela 9) face apenas aos resultados das análises das amostras de campo apresentadas no capítulo 4 (tabela 7).

\subsection{Definição e Descrição das Propriedades e Características de um Fluido de Freio DOT4 e DOT 5.1}

Segundo NHTSA (2005) o fluido de freio é caracterizado por um líquido desenhado para uso em sistemas de freio hidráulicos que deve ser compatível com componentes elastômeros feitos com borrachas de estireno e butadieno (SBR), etileno e propileno (EPR), policloropreno ou neoprene (CR), ou mesmo borracha natural.

O fluido DOT 4 e 5.1 podem ser caracterizados quimicamente pela composição de poliglicóis, ésteres de poliglicóis e aditivos anti-oxidantes (CARVALHO, 2005) ${ }^{1}$.

Um fluido de freio deve ter algumas características especiais para propiciar segurança e baixo tempo de resposta aos comandos do motorista. As principais características e propriedades são listadas abaixo:

- Baixa viscosidade cinemática: esta característica é essencial para a rápida fluidez dentro dos condutos, gerando portanto um baixo tempo de resposta aos comandos do motorista;

- Alta capacidade higroscópica e dispersância de água: no caso dos sistemas de freio, os êmbolos que acionam as pastilhas são expostos ao ar ambiente que, por sua vez, detêm uma certa umidade natural do ambiente em que opera o veículo. Ao absorver esta umidade o fluido deve distribuir as moléculas de água ao longo da sua cadeia molecular de maneira uniforme a fim de prevenir a criação de fases e, conseqüentemente diferentes pontos de ebulição dentro dos condutos; 
- Alto ponto de ebulição: o fluido é exposto a altas temperaturas quando submetido a frenagens bruscas. As temperaturas nos discos de embreagem não raramente chegam a $200^{\circ} \mathrm{C}$. Fluidos de freio DOT 4 e DOT 5.1 produzidos de acordo com as especificações norte americanas para contaminação por água têm o seu ponto de ebulição acima de $280^{\circ}$ C. Portanto, num sistema de freio, embora o fluido possa estar contaminado com água é imperativo que esta esteja distribuída ao longo das cadeias químicas do mesmo e que a taxa de contaminação não decresça o valor do ponto de ebulição causando a intersecção do mesmo;

- Proteção contra corrosão: embora o fluido tenha sua estrutura extremamente estável contra a oxidação faz-se necessário o uso de aditivos para a proteção dos componentes metálicos do sistema, pois como o fluido ao longo do tempo incorpora a umidade às suas cadeias, pode haver corrosão dos êmbolos nos cilindros mestres bem como dos condutos de freio.

\subsubsection{Estudo da Influência da Contaminação por Água no Ponto de Ebulição de Fluidos DOT 4 e DOT 5.1}

A contaminação do fluido de freio por água oriunda da umidade do ar é um dos principais fatores determinantes para a redução da resistência à ebulição do mesmo.

Os fabricantes de fluidos de freio, utilizam $0,2 \%$ como taxa máxima de contaminação por água ao final do processo de fabricação do mesmo conforme legislação norte americana (SERBINO, 2005 27p). Nestas condições, segundo experimentos laboratoriais demonstrados na figura 17, o ponto de ebulição para os fluidos DOT 4 e DOT 5.1 ultrapassa a temperatura de $280^{\circ} \mathrm{C}$.

Conforme já comentado anteriormente, o ponto de ebulição é fator determinante para a manutenção da segurança de um sistema de freio, pois a formação de bolhas durante a 
frenagem compromete a propriedade de incompressibilidade do fluido, podendo causar vibrações no pedal ou mesmo a total falta de funcionalidade do sistema.

Similarmente, o mesmo fenômeno pode ocorrer no sistema de acionamento da embreagem.

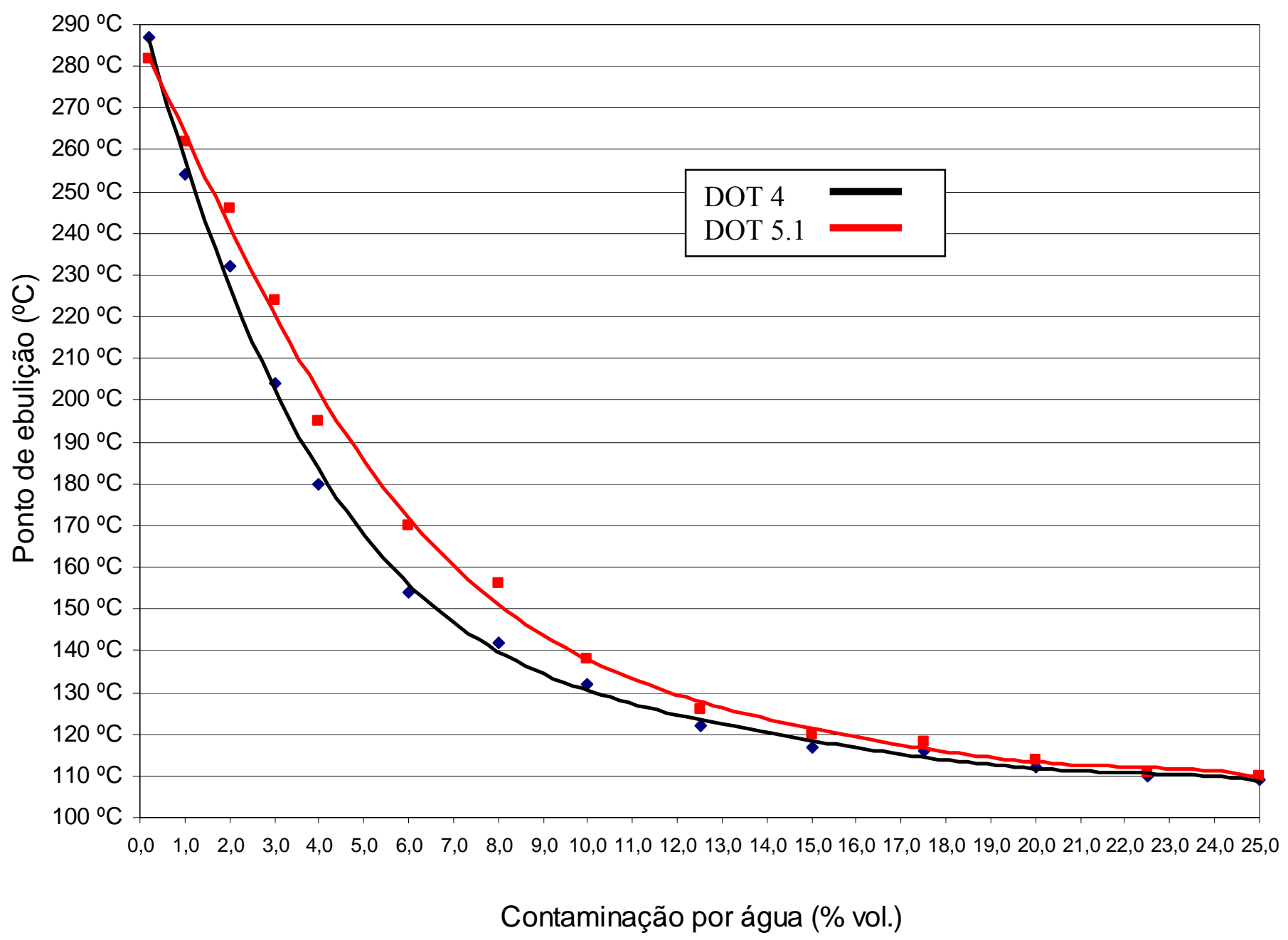

Figura 17 - Taxa de contaminação por água em fluidos DOT4 e DOT5.1 e seus impactos no ponto de ebulição 


\subsubsection{Estudo da Influência da Contaminação por Água sobre as Propriedades de Fluidez}

Conforme estudos de TEIXEIRA (2004), as duas principais funcionalidades de um sistema de embreagem são "acionamento leve do pedal e inexistência de trepidações". Dentre as propriedades físico-químicas de um fluido de freio, a viscosidade cinemática afeta diretamente estas duas funcionalidades, pois o tempo de resposta aos comandos do pedal é diretamente proporcional à viscosidade cinemática do fluido, esta por sua vez, é produto da taxa de contaminação por água.

Conforme relatado na entrevista técnica com os mecânicos no concessionário (capítulo 4 pág. 29), o pedal da embreagem apresentava vibração antes da perda total de função, o que sugeriu a investigação do comportamento de fluidez nos condutos do sistema.

Para tanto, experimentos em laboratório foram realizados para verificação do comportamento da viscosidade cinemática do fluido DOT 4 em função da taxa de contaminação por água, conforme demonstrado na figura 18 abaixo.

Fluído DOT4 - Contaminação por água x Visc. Cin. $\left(-40^{\circ} \mathrm{C}\right)$

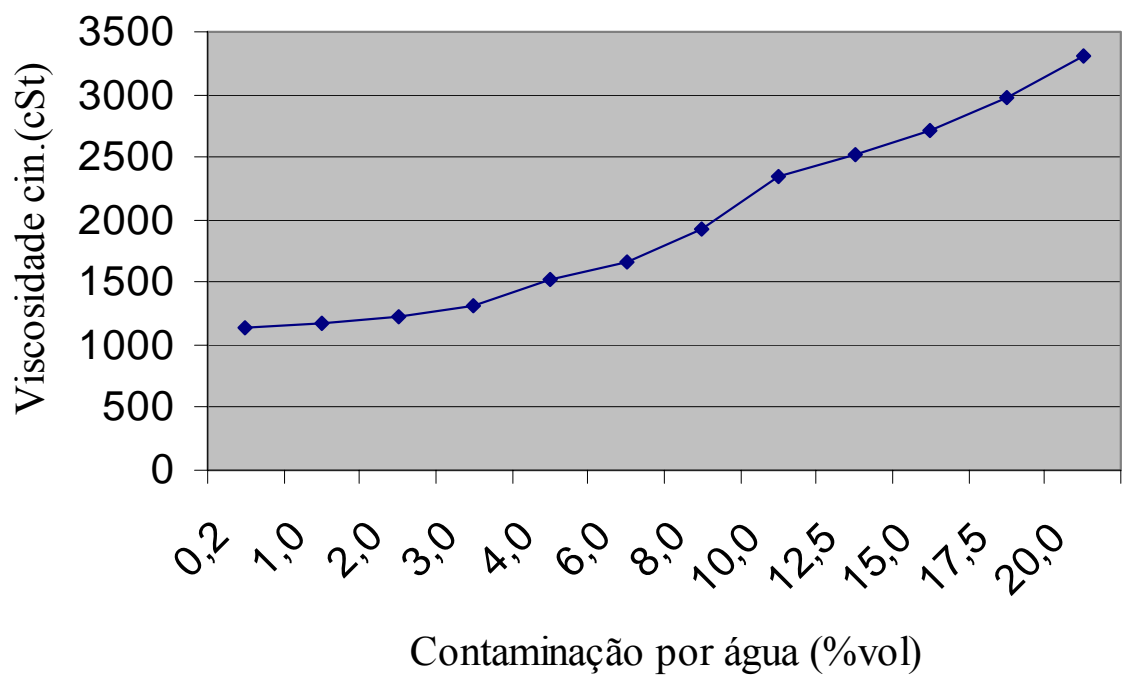

Figura 18 - Efeitos da contaminação por água sobre a viscosidade cinemática 
Os resultados deste experimento demonstram que a viscosidade cinemática para um fluido que apresenta taxas de contaminação em torno de 14\% como relatado no capítulo 4.2, tabela 7 , página 27 , é praticamente duas vezes e meia maior do que sua viscosidade cinemática inicial, o que pode ocasionar atrasos no tempo de resposta aos comandos dos pedais.

Outra conclusão que pode ser extraída da figura 18, é que as amostras de campo (número 2 e 3) analisadas por clientes (capítulo 4.2, tabela 7, página 27) apresentaram valores de viscosidade cinemática (1540 cSt e $1620 \mathrm{cSt}$, respectivamente) muito abaixo do valor esperado para as suas respectivas taxas de contaminação por água (15,9\% e 13,57\%). Neste caso sugere-se que por alguma razão, após os sistemáticos problemas apresentados pelo sistema de embreagem, os mesmos possam ter sido submetidos a limpeza (flushing) com alguma espécie de solvente.

Finalmente, pode-se concluir através desta investigação sobre a influência da contaminação do fluido por água que tanto as propriedades de fluidez quanto às de incompressibilidade e alto ponto de ebulição são totalmente comprometidas quando o mesmo encontra-se contaminado com altas taxas de água, podendo ocasionar então atrasos nos tempos de resposta ou mesmo a falta de funcionalidade quando o fluido se encontra em ebulição. 


\section{ESTUDO PARA A AVALIAÇÃO DA COMPATIBILIDADE QUÍMICA ENTRE O FLUIDO DE FREIO DOT 4 E OS ELASTÔMEROS EMPREGADOS NO SISTEMA DE EMBREAGEM}

Conforme definição da NHTSA (2005) um fluido de freio deve ser compatível com diversos tipos de elastômeros, que normalmente são empregados como matéria prima na fabricação dos componentes de um sistema de embreagem.

Portanto, para a continuação do processo de investigação técnica e determinar precisamente a causa raiz do mecanismo das falhas do sistema de embreagem é importante assegurar que todos os materiais, conforme demonstrado na figura 19, foram corretamente selecionados na fase de projeto.

Por questões de reprodutibilidade e disponibilidade laboratorial, a metodologia de teste foi definida como avaliação de compatibilidade química após imersão do componente em fluido DOT 4 isento de aditivo de coloração por um período de 120 horas a $120^{\circ} \mathrm{C}$.

Esta metodologia de análise é na atualidade amplamente empregada pelo maior fabricante brasileiro de fluidos de freio.

Segundo CARVALHO $(2006)^{1}$, tal metodologia é amplamente utilizada para relatar incompatibilidades químicas para as montadoras de automóveis brasileiras, fato que preserva a reprodutibilidade e confiabilidade dos ensaios.

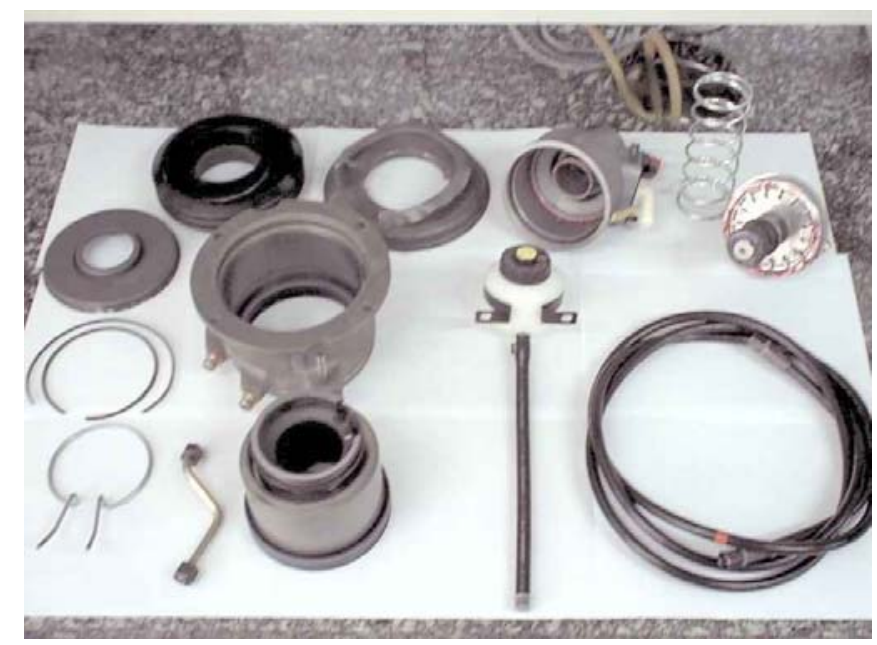

Figuras 19 - Componentes do sistema de embreagem para análise de compatibilidade química 


\subsection{Estudo da Compatibilidade Química entre Fluido DOT 4 e Mangueira do Reservatório}

Inicialmente a mangueira, demonstrada na figura 20 , foi completamente submersa em fluido de freio DOT 4, conforme metodologia já mencionada.

A avaliação da compatibilidade química concentra-se na verificação de possíveis inchamentos ou trincas causadas por ataques químicos.

Na figura 21, observa-se que o fluido adquire uma coloração escura após o teste o que poderia indicar um eventual ataque químico.

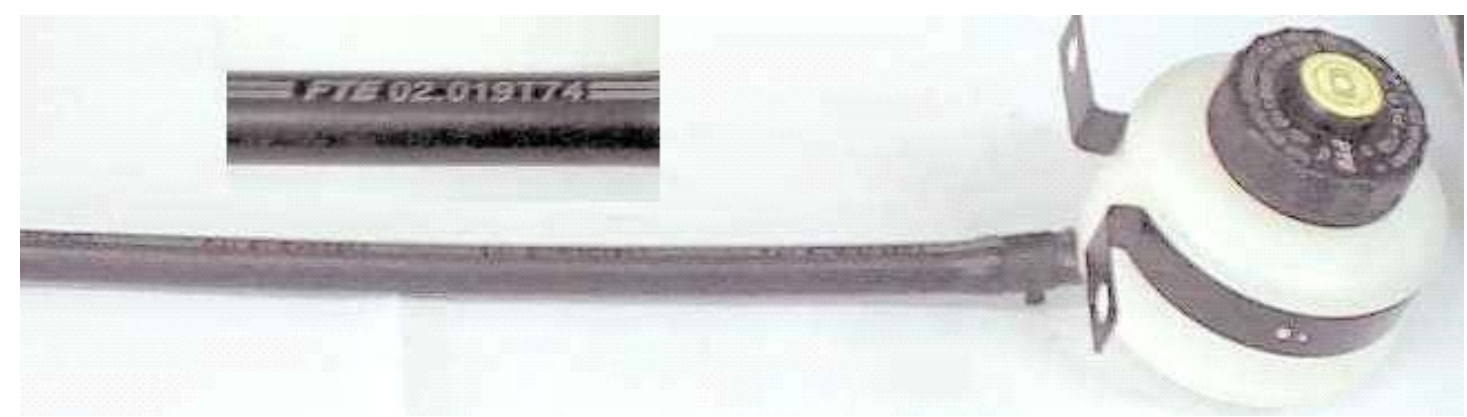

Figura 20 - Mangueira do reservatório de fluido de embreagem

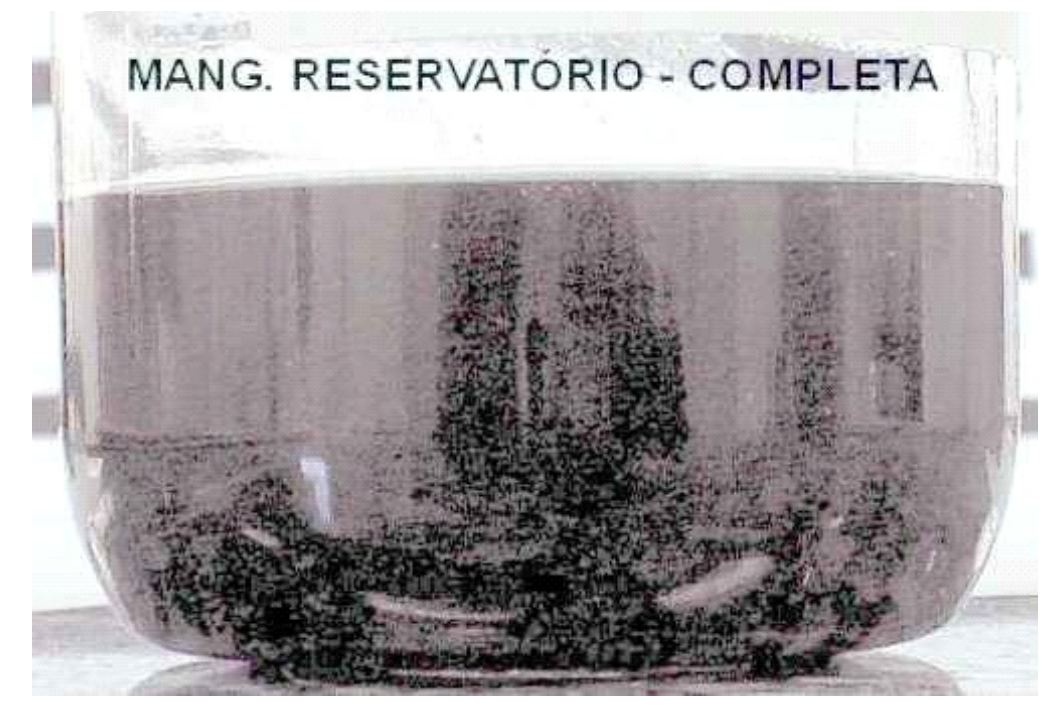

Figura 21 - Fluido escurecido após teste de compatibilidade química com mangueira do reservatório de fluido de embreagem 
Ao avaliar a mangueira percebe-se que a mesma era constituída de duas camadas de borracha separadas por uma camada de lona. Verificou-se também que a camada interna apresentava uma consistência diferente da camada exterior.

Como o estudo restringiu-se a verificação da compatibilidade química dos componentes que tinham contacto direto com o fluido, foi realizada uma nova etapa de testes, nos quais retirou-se a camada de borracha externa.

Neste novo ensaio, conforme figura 22, o fluido não apresentou escurecimento e a camada interna da mangueira não apresentou nenhum sinal de degradação, o que sugere que o material selecionado para a camada interna da mangueira é compatível com o fluido DOT4.

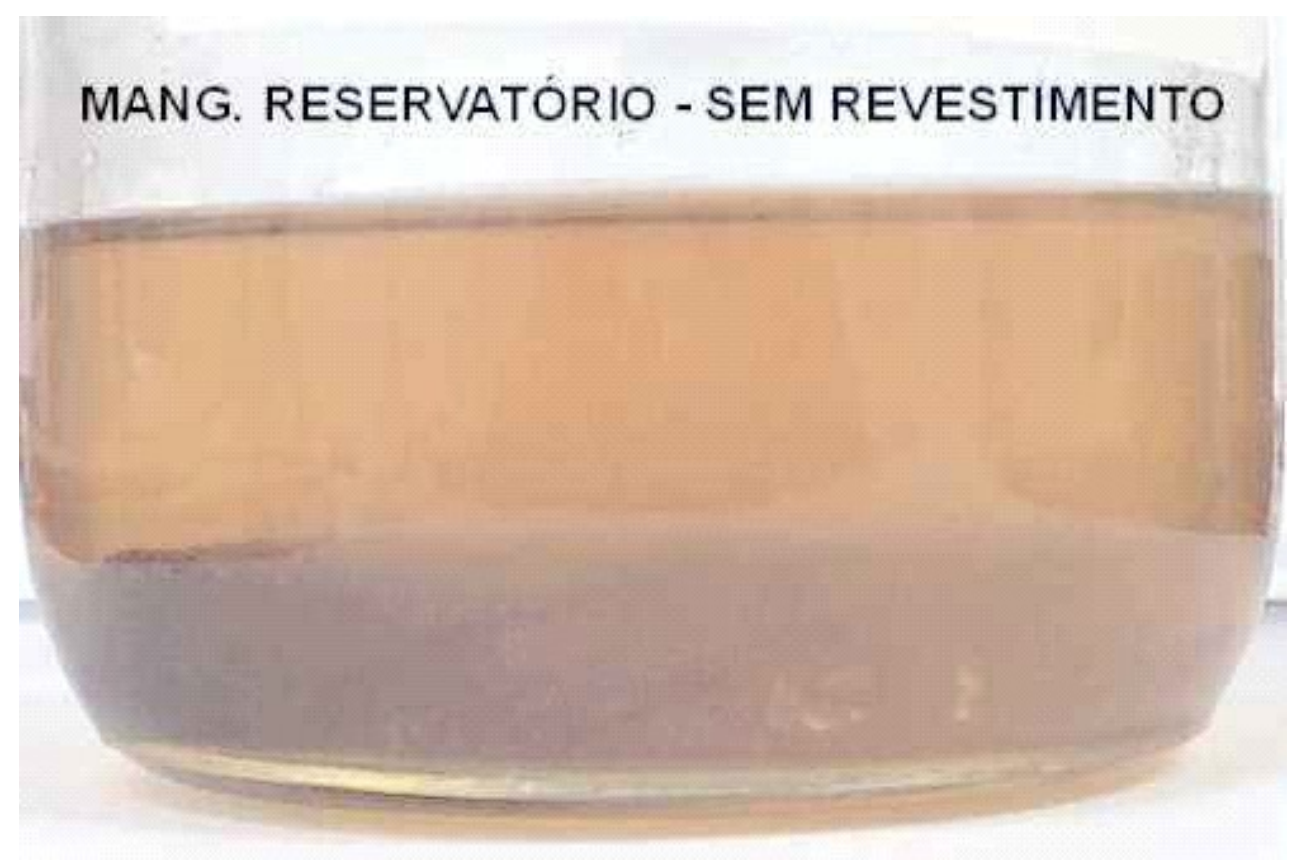

Figura 22 - Aspecto do fluido após teste de compatibilidade química com camada de borracha interna da mangueira do reservatório 


\subsection{Estudo da Compatibilidade Química entre Fluido DOT 4 com a Mangueira do}

Chassi

O aspecto de robustez e consistência da mangueira do chassi, demonstrada na figura 23, é semelhante àquele encontrado na camada interna da mangueira do reservatório do fluido DOT 4 (figura 22), contudo, ao contrário desta última, a camada externa da mangueira do chassi apresenta maior rigidez.

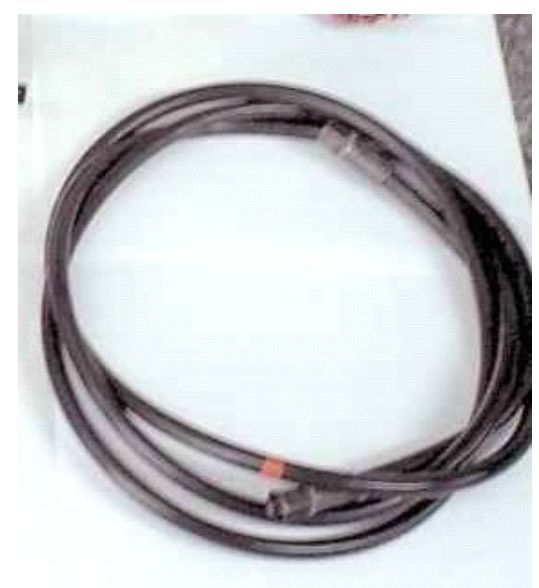

Figura 23 - Mangueira do chassi

Neste ensaio, verificou-se que não houve nenhum sinal de ataque químico ou mesmo de degradação da mangueira do chassi, conforme demonstrado na figura 24 , indicando que o material empregado na mesma não apresenta nenhuma incompatibilidade química com o fluido DOT4.

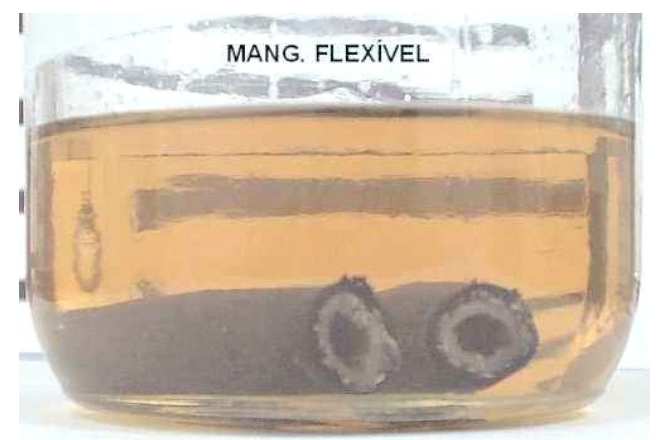

Figura 24 - Aspecto do fluido após teste de compatibilidade química com camada de borracha interna da mangueira do reservatório 


\subsection{Estudo da Compatibilidade Química entre Fluido DOT 4 com os Anéis de Vedação do Servo-Mestre}

Dentre os materiais analisados, os anéis de vedação do servo-mestre (figura 25) são um dos poucos elastômeros do sistema de embreagem com composição conhecida previamente.

Estes são compostos de Etileno Propileno Dieno Monômero (EPDM) que segundo SATAS et. al (2000, 480p.), podem operar em temperaturas entre $-60^{\circ} \mathrm{C}$ e $135^{\circ} \mathrm{C}$.

Ao final das 120 hs os anéis apresentaram um incremento volumétrico de $1 \%$, o que é desejável para a manutenção da propriedade de vedação. Do ponto de vista de compatibilidade química, não houve nenhuma indicação de trincas ou fragilização, pois o fluido DOT 4 utilizado no teste permaneceu com a mesma coloração inicial conforme demonstrado na figura 26.

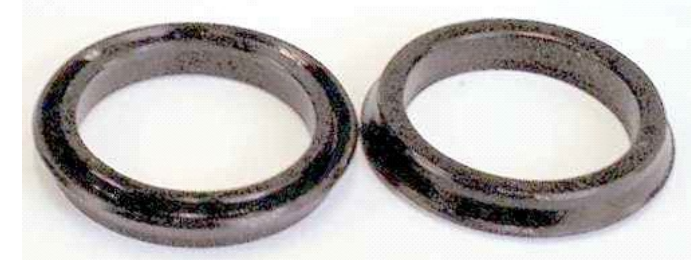

Figura 25 - Anéis de vedação do servo-mestre

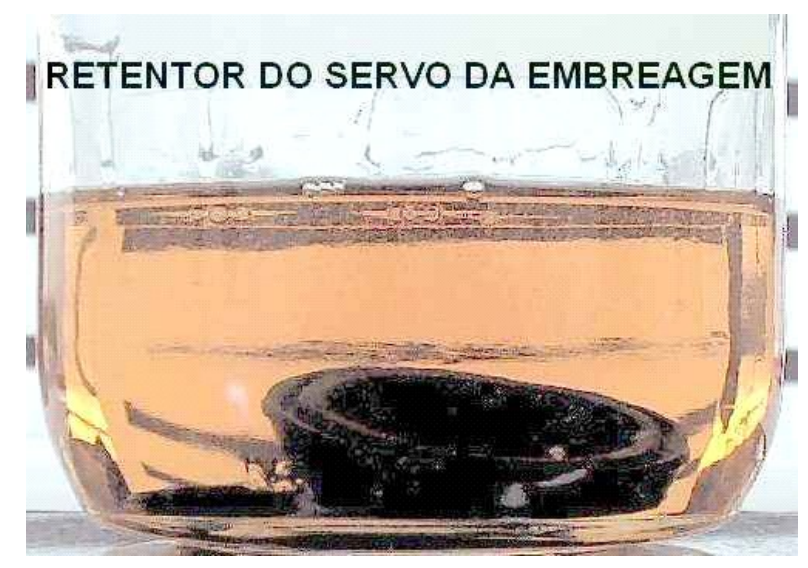

Figura 26 - Aspecto do fluido após teste de compatibilidade química com os anéis de vedação do servo-mestre 


\subsection{Estudo da Compatibilidade Química entre Fluido DOT 4 com os Anéis de Vedação do Cilindro Escravo Concêntrico}

O cilindro escravo concêntrico é dotado de quatro anéis funcionais, dois de compressão (frontal e traseiro) e dois anéis raspadores (figura 12, página 19).

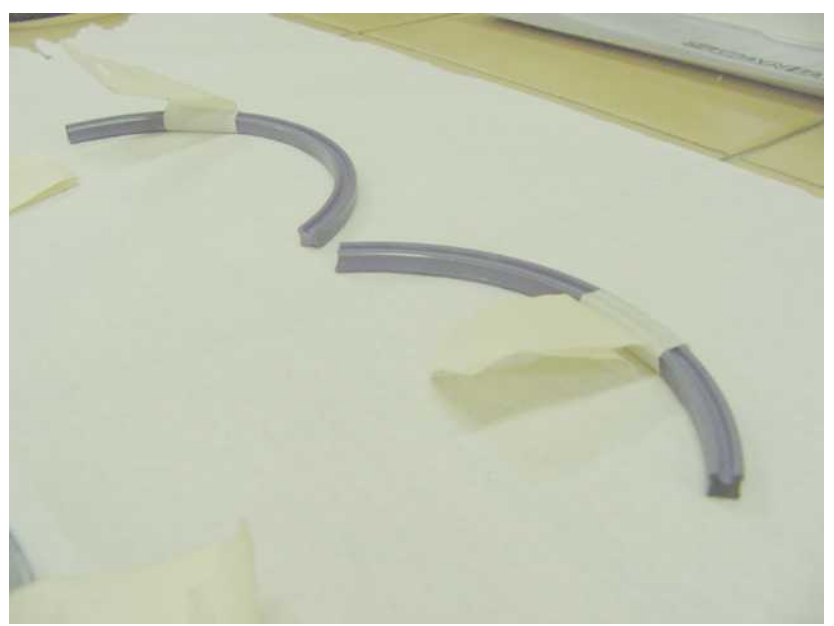

Figura 27 - Anéis de compressão frontal e traseiro

A composição química dos anéis de compressão frontal e traseiro não era conhecida o que requereu uma investigação especial para a determinação da mesma.

A figura 27, apresenta as amostras dos anéis que foram submetidas a ensaios com infravermelho para a verificação da transmitância dos mesmos. A curva gerada neste ensaio, conforme demonstrado na figura 28 , foi então comparada com curvas padrões de diferentes tipos de elastômeros (figura 29), possibilitando assim a determinação com da composição do material em estudo. 


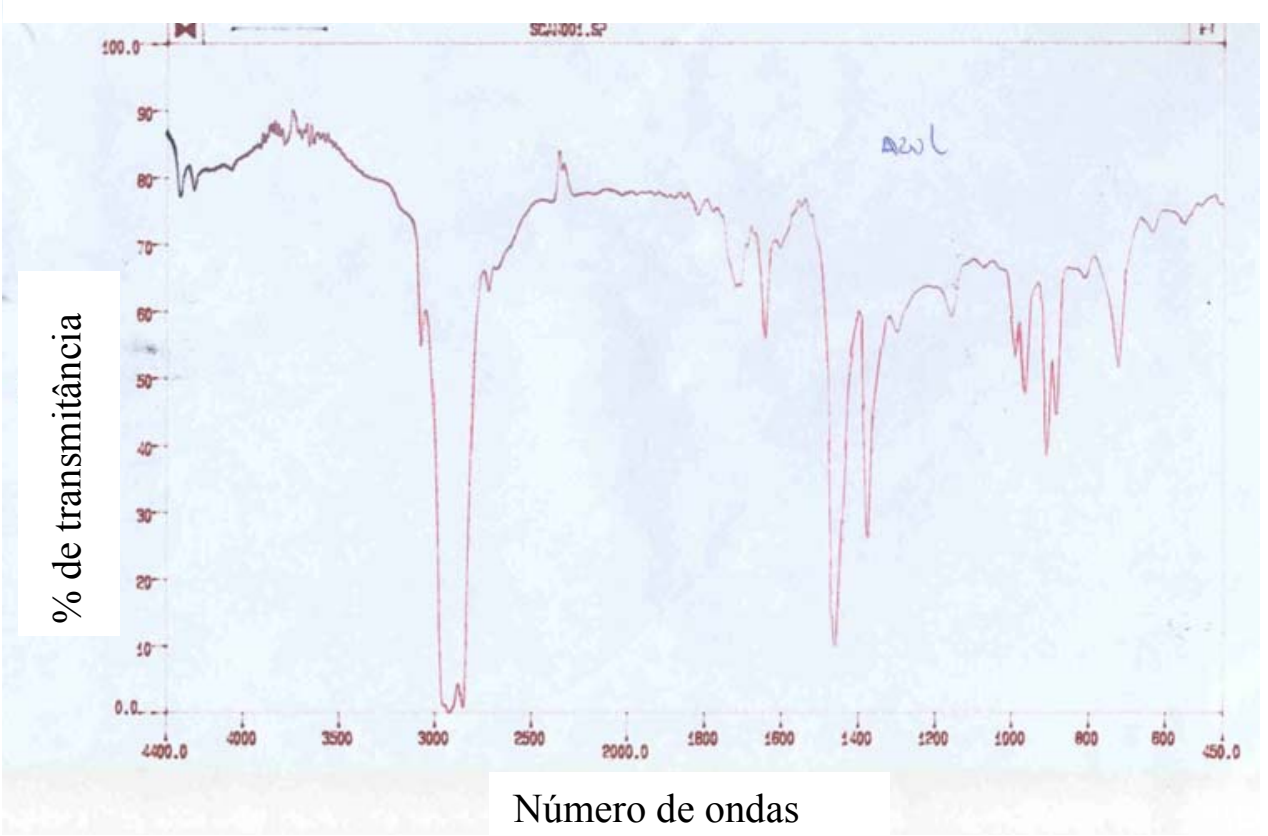

Figura 28 - Curva gerada no ensaio de infravermelho para a determinação da composição química do elastômero.

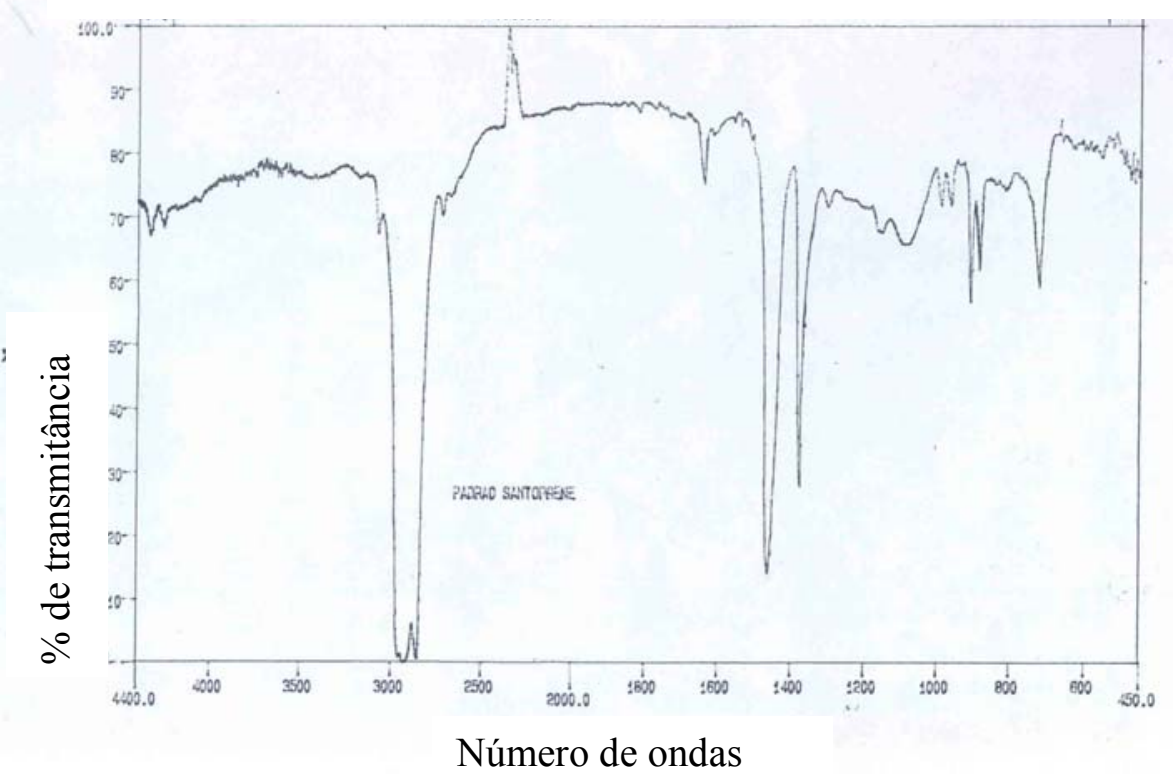

Figura 29 - Curva padrão para elastômeros com misturas de EPDM e Polipropileno (Santoprene) 
Pela similaridade das curvas apresentadas nas figuras 28 e 29, definiu-se então que os anéis de compressão frontal e traseiro são fabricados a partir de matéria-prima termoplástica conhecida comercialmente como Santoprene.

SEYMOUR (2002, 91p.), define Santoprene como sendo "misturas de polipropileno (PP) com EPDM", sendo que as características de resistência mecânica podem variar de acordo com as diferentes misturas.

O resultado dos ensaios de compatibilidade química deste composto (Santoprene) com o fluido DOT 4 não demonstrou nenhum indício de trincas ou modificações significativas nas características do material. Foi verificado que o material apresentou um incremento volumétrico da ordem de $3 \%$, o qual conforme já explanado, é desejável para manter as propriedades de vedação do anel.

Os anéis raspadores, conforme demonstrado na figura 30, similarmente aos anéis de compressão, não tinham a sua composição química conhecida para a realização dos testes de compatibilidade com o fluido DOT 4.

Portanto, aplicou-se a mesma metodologia para a determinação da composição destes anéis, curva gerada através de infravermelho e comparação com curvas padrões.

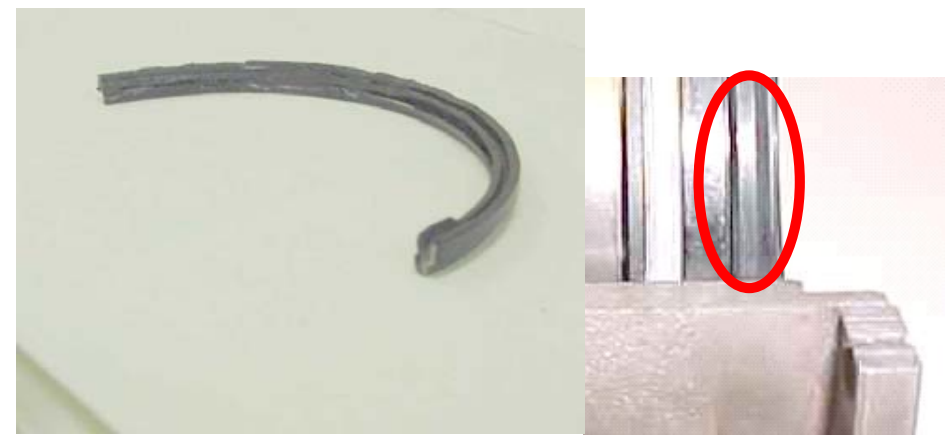

Figura 30 - Anéis raspadores 


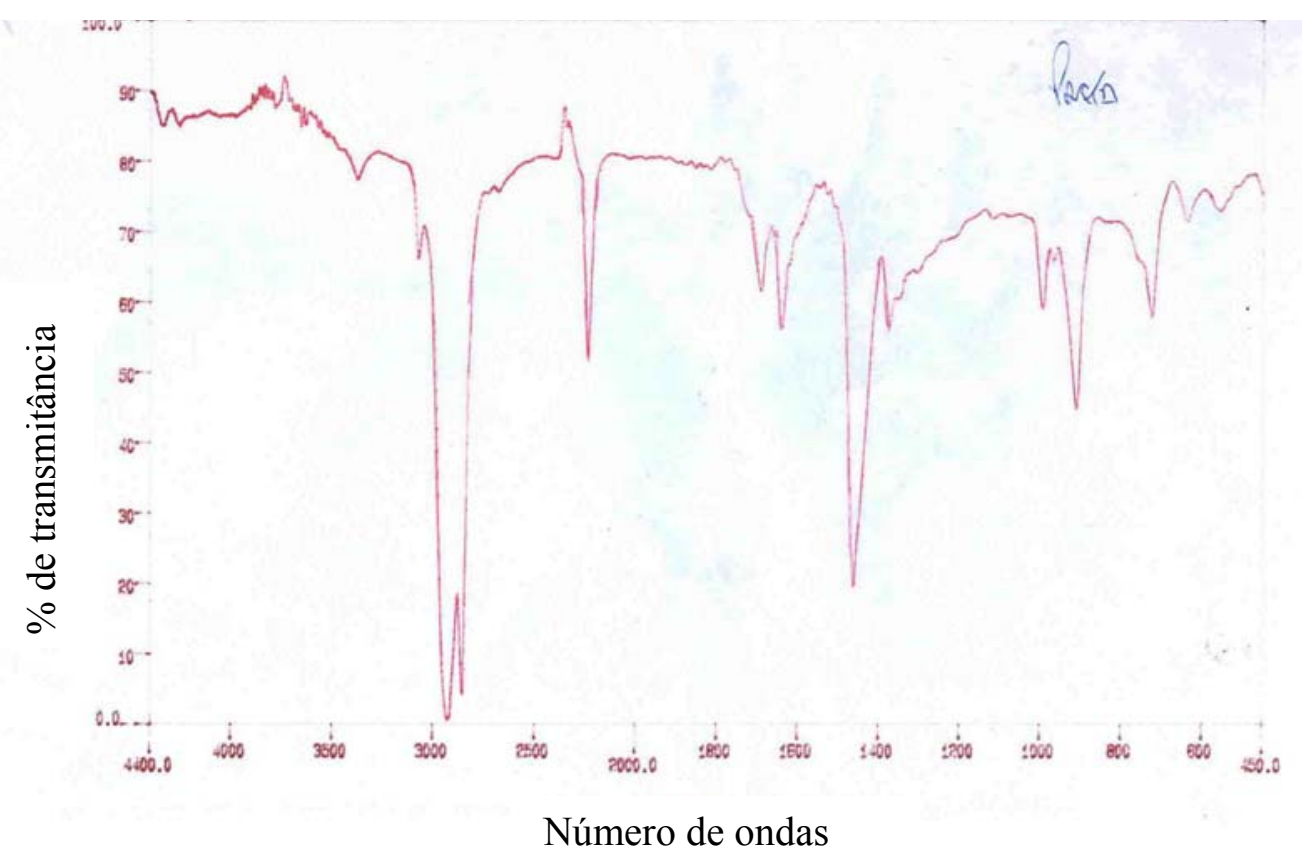

Figura 31 - Curva gerada no ensaio de infravermelho para a determinação da composição química do elastômero

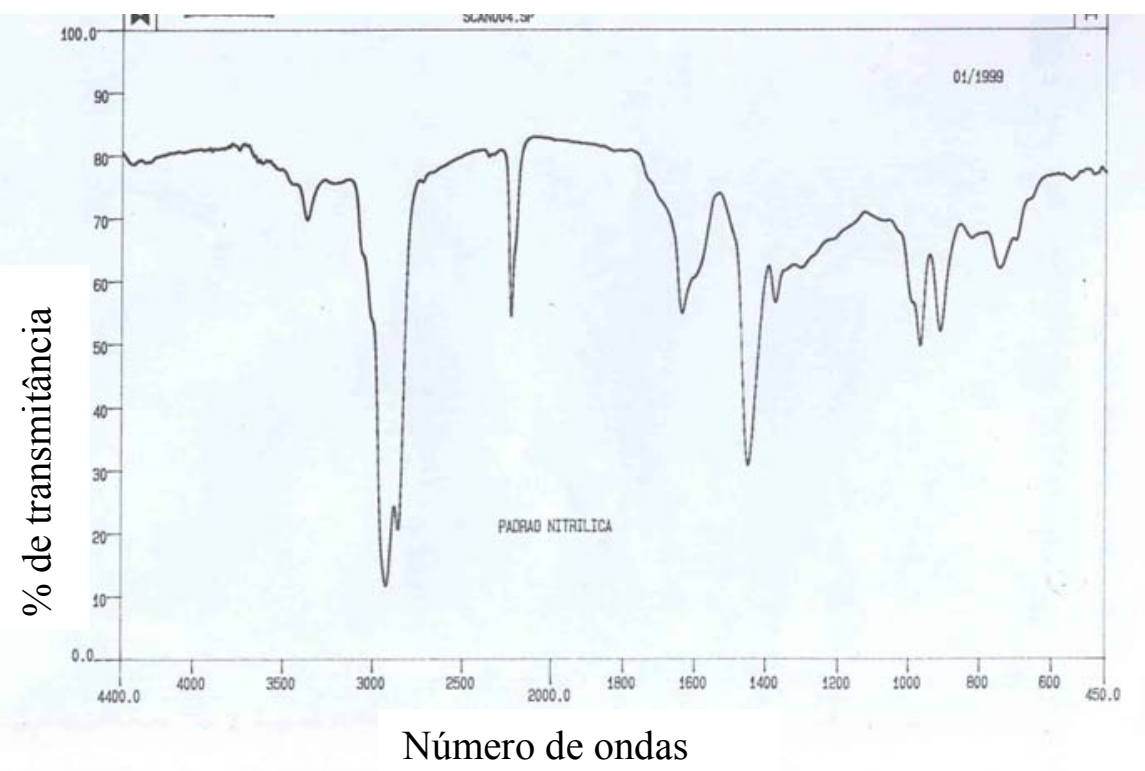

Figura 32 - Curva padrão para borracha nitrílicas 
Pela similaridade das curvas apresentadas nas figuras 31 e 32, definiu-se então que os anéis raspadores são fabricados de borracha nitrílica. Esta informação foi confirmada por JOHANSSON (2004) ${ }^{1}$ que ainda acrescentou que a borracha selecionada na fase de projeto do cilindro escravo concêntrico foi a borracha nitrílica hidrogenada e segundo BARLOW $(1993,75 \mathrm{p})$ suporta picos de temperatura de até $150^{\circ} \mathrm{C}$.

Os anéis foram então submetidos aos ensaios de compatibilidade química com o fluido DOT 4 e ao final do procedimento, estes apresentaram uma taxa de incremento volumétrico de $11 \%$, que significa uma boa manutenção da capacidade de vedação ao longo de sua vida e não apresentaram nenhum sinal de incompatibilidade química com o fluido DOT 4.

Portanto, pode-se concluir a partir dos resultados obtidos nas investigações de compatibilidade química relatados neste capítulo, que os materiais foram corretamente selecionados para a construção do sistema. 


\section{ESTUDO PARA A AVALIAÇÃO DA COMPATIBILIDADE QUÍMICA ENTRE O FLUIDO DE FREIO DOT 4 E AS GRAXAS EMPREGADAS NO PROCESSO DE MONTAGEM DOS CONJUNTOS DO CILINDRO ESCRAVO CONCÊNTRICO E SERVO MESTRE}

No desenvolvimento das atividades descritas no capítulo 6, ao desmontar os conjuntos de cilindro escravo concêntrico e servo mestre constatou-se que os fabricantes destes equipamentos utilizavam graxas para a montagem dos componentes de borracha. Por desconhecimento da composição química destas graxas na ocasião dos estudos e seus eventuais impactos no funcionamento do sistema de embreagem, foram efetuadas análises laboratoriais para a determinação da composição química das mesmas.

\subsection{Estudo dos Impactos Funcionais da Graxa Empregada na Montagem do Êmbolo do Cilindro Escravo Concêntrico}

Os resultados mostraram que a graxa utilizada para a montagem do êmbolo no cilindro escravo, conforme demonstrado na figura 33, era composta predominantemente por silicone.

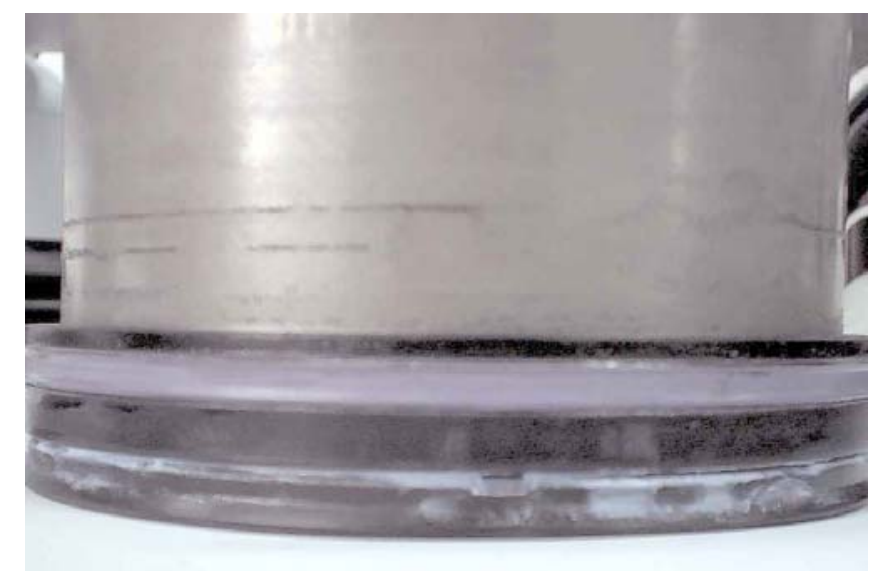

Figura 33 - Graxa colhida do êmbolo do Cilindro Escravo Concêntrico para análise laboratorial 
Para a avaliação de características da diluição e compatibilidade química da graxa com o fluido, desenvolveu-se uma metodologia de ensaio na qual a mesma era misturada ao fluido na proporção de uma parte de graxa para mil partes do fluido DOT 4 (1/1000). As borrachas padrão Estireno-butadieno (SBR) e EPDM foram adicionadas a esta mistura por um período de 120 horas a $120^{\circ} \mathrm{C}$. Ao fim dos testes comparou-se os resultados obtidos no envelhecimento das borrachas padrão com as especificações DOT 4, conforme demonstrado na tabela 10 .

\begin{tabular}{|c|c|c|}
\hline Resultados & Ensaio & Padrão DOT 4 \\
\hline Viscosidade $\left(-40^{\circ} \mathrm{C}\right)$ & $1200 \mathrm{cSt}$ & $1100 \mathrm{cSt}$ \\
\hline Variação de Volume & $+9 \%$ & $+6 \%$ \\
\hline Variação de Dureza (shore A) & -7 & -6 \\
\hline Variação do Diâmetro (mm) & 0,5 & 0,5 \\
\hline Compatibilidade Química & Sem ataque & Sem ataque \\
\hline
\end{tabular}

Tabela 10 - Resultados de ensaio com graxa de silicone em fluido DOT 4.

Os resultados apresentados na tabela 10 não demonstram nenhum desvio que justifique a eliminação desta graxa do processo produtivo, uma vez que os valores obtidos após os ensaios são muito próximos dos valores de referência para fluidos DOT 4.

Outra característica estudada na mistura entre o fluido DOT 4 e a graxa foi a capacidade de diluição da mesma. Verificou-se, conforme demonstrado na figura 34 , que não há homogeneização da graxa no fluido, contudo, não se sabe ao certo qual seria o impacto da presença desta graxa no sistema de embreagem do ponto de vista funcional, visto que não houve nenhuma incompatibilidade química. 

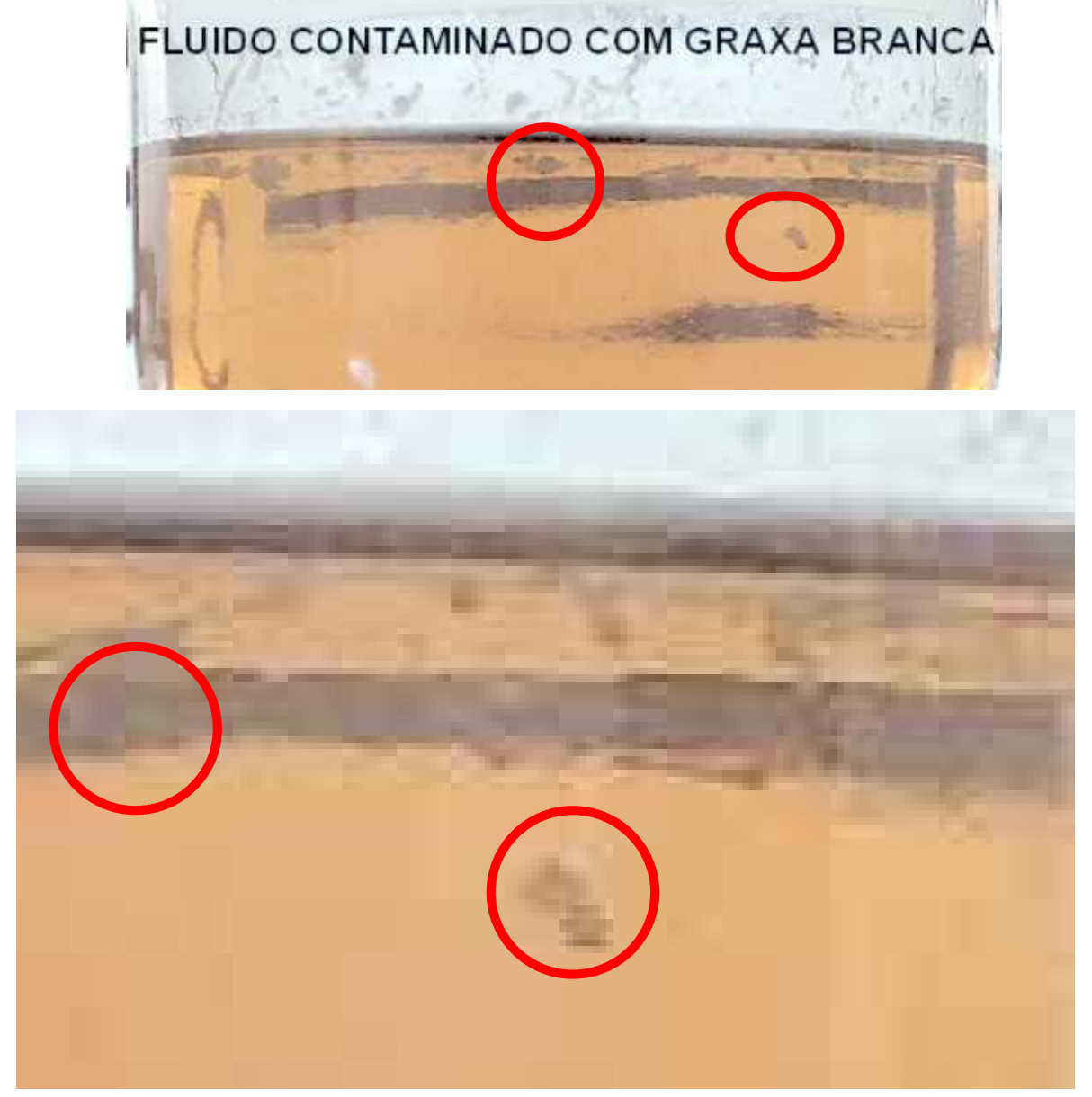

Figura 34 - Bolhas de graxa não diluídas no fluido DOT 4

\subsection{Estudo dos Impactos Funcionais da Graxa Empregada na Montagem do Êmbolo do Servo Mestre}

Para permitir a montagem do êmbolo do servo mestre em sua carcaça o fabricante do equipamento utiliza uma graxa de coloração avermelhada (conforme demonstrado na figura 35), a qual tinha composição desconhecida no momento do estudo, portanto, foram realizados ensaios químicos para a determinação da sua composição bem como testes de compatibilidade com o fluido DOT 4 conforme metodologia já descrita no capítulo 7.1 . 

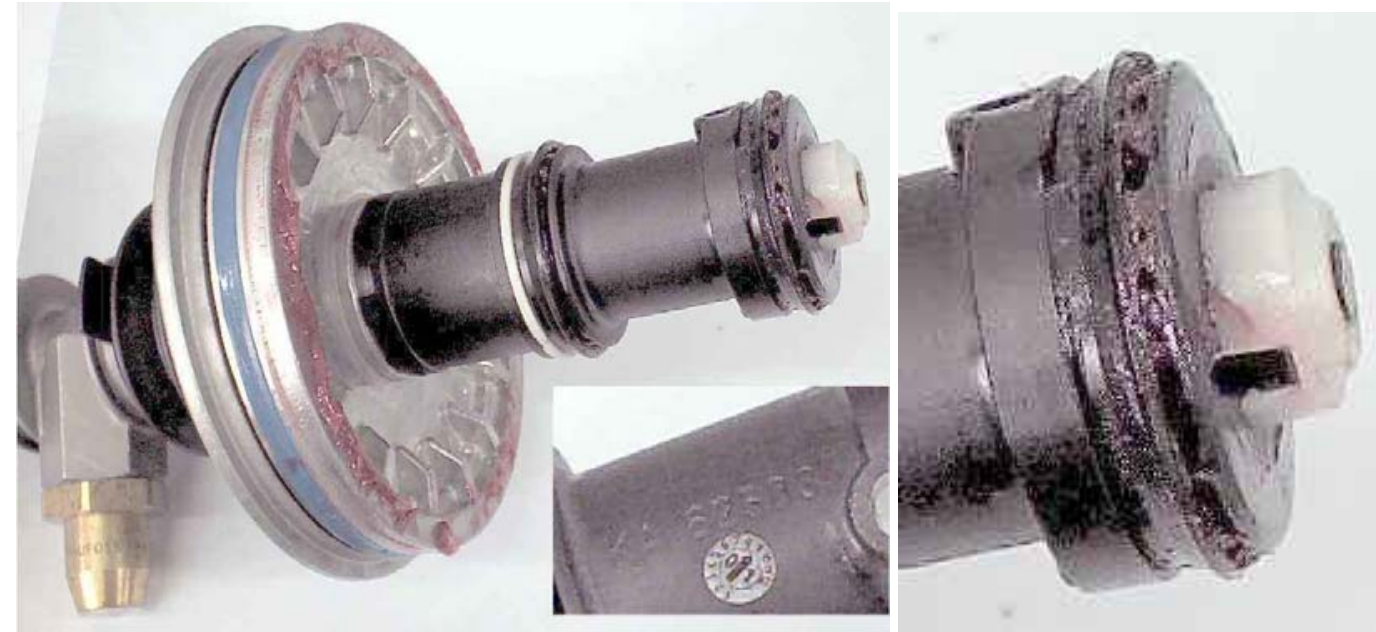

Figura 35 - Graxa colhida do êmbolo do servo mestre para análise laboratorial

As análises de laboratório indicaram que a graxa era composta predominantemente de poliglicol, e os resultados obtidos nos ensaios de compatibilidade química com fluido DOT 4 estão descritos na tabela 11 .

\begin{tabular}{|c|c|c|}
\hline Resultados & Ensaio & Padrão DOT 4 \\
\hline Viscosidade $\left(-40^{\circ} \mathrm{C}\right)$ & $1170 \mathrm{cSt}$ & $1100 \mathrm{cSt}$ \\
\hline Variação de Volume & $+8 \%$ & $+6 \%$ \\
\hline Variação de Dureza (shore A) & -8 & -6 \\
\hline Variação do Diâmetro (mm) & 0,5 & 0,5 \\
\hline Compatibilidade Química & Sem ataque & Sem ataque \\
\hline
\end{tabular}

Tabela 11 - Resultados de ensaio com graxa de poliglicol em fluido DOT 4.

Similarmente à graxa utilizada no cilindro escravo concêntrico (graxa de silicone), a graxa de poliglicol não apresentou nenhuma incompatibilidade química com o fluido DOT 4, apresentando também falta de capacidade de diluição no fluido, tornando da mesma maneira, as análises inconclusivas do ponto de vista funcional do sistema de embreagem. 
Portanto, pode-se concluir que por falta de informação de projeto do cilindro escravo concêntrico, não se pode afirmar qual é o impacto da insolubilidade das graxas no fluido durante a operação do mesmo. 


\section{TESTES PARA AVALIAÇÃO DAS FUNCIONALIDADES MECÂNICAS DO SISTEMA DE ACIONAMENTO DE EMBREAGEM POR CILINDRO ESCRAVO CONCÊNTRICO}

Os testes para a avaliação das funcionalidades mecânicas foram desenhados a partir da matriz de dados colhidos ao longo das investigações de compatibilidade química do fluido com os componentes do sistema.

Conforme descrito anteriormente, as análises das amostras de fluido colhidas em campo indicaram uma alta taxa de contaminação por água (da ordem de até 13,7 \% em volume), indicando, portanto, que de certa forma o mecanismo de falha estaria ligado à tal contaminação. Esta proposição foi confirmada por JOHANSSON (2004) ${ }^{1}$, pois de acordo com a afirmação do mesmo, a temperatura no ambiente da carcaça da embreagem varia entre $130^{\circ} \mathrm{C}$ e $170^{\circ} \mathrm{C}$, indicando que poderia haver o fenômeno do cruzamento do ponto de ebulição do fluido contaminado por água e a temperatura de trabalho no ambiente da embreagem.

Para a validação de tal proposição optou-se por conduzir o sistema de embreagem à falha, e para tanto o fluido DOT4 utilizado no sistema foi contaminado propositadamente com $14 \%$ em volume de água reduzindo o seu ponto de ebulição para $117^{\circ} \mathrm{C}$ (conforme demonstrado na figura 17 do capítulo 5.1.1).

\subsection{Descrição da Metodologia dos Testes para Avaliação das Funcionalidades Mecânicas do Cilindro Escravo Concêntrico}

Os testes foram realizados com um veículo comercial pesado (trator articulado 4x2) com 42 toneladas de peso bruto total combinado testado nas cidades de São Paulo sob tráfego intenso das marginais Pinheiros e Tiête e da rodovia Presidente Dutra até a cidade de Guarulhos (Bonsucesso). 
O sistema de acionamento da embreagem por cilindro escravo concêntrico foi devidamente monitorado com transdutores de pressão e termopares para a avaliação do mesmo durante o percurso de teste.

Devido à indisponibilidade de um veículo de teste na configuração $6 \times 2$ bi-trem articulado de 7 eixos, houve a necessidade de criar um ambiente de teste severizado a fim de simular as condições de temperatura e pressão esperadas conforme a proposição de JOHANSSON (2004), para tanto o veículo foi utilizado apenas nos horários de pico de tráfego no corredor já mencionado. Usou-se largamente o sistema de embreagem através do controle no pedal para manter a composição parada em semáforos e em pequenos aclives.

\subsection{Descrição do Aparato para Aquisição de Dados Experimentais}

O monitoramento do comportamento do sistema de acionamento por cilindro escravo concêntrico foi realizado através de equipamentos de medição de temperatura e pressão, demandando a preparação do cilindro escravo concêntrico através de operações de usinagem da sua carcaça externa para permitir a conexão dos nípeis de adaptação dos instrumentos. Esta operação foi bastante delicada pois a eventual contaminação do interior do cilindro escravo por restos de usinagem poderia causar danos aos anéis de vedação. Portanto optou-se por, inicialmente furar a carcaça através de broca convencional numa profundidade máxima de $2 / 3$ da sua espessura, sendo que o resto da usinagem foi feito pelo método de eletro-erosão seguido de "flushing" da voluta com fluido de embreagem DOT4 para a retirada de eventuais contaminantes sólidos. Este processo de preparação dos componentes garantiu a integridade dos anéis de vedação quanto à isenção de contaminantes sólidos, assegurando assim a qualidade dos resultados dos ensaios. 


\subsubsection{Descrição dos Equipamentos de Medição de Temperatura e Pressão}

O processo de seleção dos equipamentos de medição deve ser feito levando-se em conta as condições de contorno do ambiente em que estes irão trabalhar.

No caso do ambiente da embreagem, onde eram esperadas temperaturas da ordem de até $170^{\circ} \mathrm{C}$ (JOHANSSON 2004), optou-se pela seleção de termopares revestidos do tipo " $\mathrm{k}$ " com range de medição de temperatura entre $-40^{\circ} \mathrm{C} \mathrm{a}+1050^{\circ} \mathrm{C}$ com incerteza de $+/-2,5^{\circ} \mathrm{C}$ para a faixa de temperatura entre $-40^{\circ} \mathrm{C}$ e $+333^{\circ} \mathrm{C}$ e de $+/-0,0075^{*} \mathrm{t}$ para $\mathrm{t}>333^{\circ} \mathrm{C}$, conforme norma estabelecida pela "International Electrothecnical Commission" (IEC) 584.2 classe 2.

As medições de pressão do sistema foram realizadas com transdutores de pressão para faixas de pressão de 0 a 20 bar com incerteza de $0,15 \%$ dimensionado para acelerações de 0 a $20 \mathrm{~g}$ máximo a freqüências de vibrações de 15 a $2000 \mathrm{~Hz}$ de acordo com IEC 68-26. O sistema de aquisição de dados foi suportado por note book para o armazenamento dos mesmos.

\subsubsection{Descrição dos Pontos de Coleta de Dados de Temperatura e Pressão}

Os pontos de coleta de dados de temperatura e pressão foram distribuídos ao longo dos componentes do sistema, conforme demonstrado nas figuras de 36 a 46 e na tabela 12 , de maneira a preservar a precisão e confiabilidade dos mesmos, para tanto, procurou-se instalar mais de um ponto de medição para um mesmo parâmetro (Ex.: temperatura no interior do cilindro escravo concêntrico). 


\begin{tabular}{|c|c|c|}
\hline $\begin{array}{l}\text { Ponto de } \\
\text { medição }\end{array}$ & Localização & $\begin{array}{c}\text { Demonstrado } \\
\text { nas figuras }\end{array}$ \\
\hline TC 1 & Interior do CSC parte superior - Temperatura do Fluido & 36,38 \\
\hline TC2 & $\begin{array}{l}\text { Interior do CSC nípel de drenagem - Temperatura do } \\
\text { Fluido }\end{array}$ & 37 \\
\hline TC3 & Interior do CSC parte inferior - Temperatura do Fluido & 39 \\
\hline TC4 & $\begin{array}{l}\text { Temperatura do ambiente da embreagem }\left({ }^{\circ} \mathrm{C}\right) \text { - parte } \\
\text { superior direita }\end{array}$ & 36,37 \\
\hline TC5 & $\begin{array}{l}\text { Temperatura do ambiente da embreagem }\left({ }^{\circ} \mathrm{C}\right) \text { - parte } \\
\text { inferior direita }\end{array}$ & 36 \\
\hline TC6 & $\begin{array}{l}\text { Temperatura do ambiente da embreagem }\left({ }^{\circ} \mathrm{C}\right) \text { - parte } \\
\text { superior esquerda }\end{array}$ & 37 \\
\hline TC7 & $\begin{array}{l}\text { Temperatura do ambiente da embreagem }\left({ }^{\circ} \mathrm{C}\right) \text { - parte } \\
\text { inferior direita }\end{array}$ & 36,37 \\
\hline TC8 & Temperatura ambiente $\left({ }^{\circ} \mathrm{C}\right)$ & 41 \\
\hline TC9 & Temperatura da carcaça do $\operatorname{CSC}\left({ }^{\circ} \mathrm{C}\right)$ & 36,38 \\
\hline TC10 & Temperatura da carcaça do ventilador $\left({ }^{\circ} \mathrm{C}\right)$ & 46 \\
\hline TC11 & Temperatura de entrada do ar antes ventilador $\left({ }^{\circ} \mathrm{C}\right)$ & 45 \\
\hline TC12 & Temperatura de saída do ar após ventilador $\left({ }^{\circ} \mathrm{C}\right)$ & 40 \\
\hline TC13 & $\begin{array}{l}\text { Temperatura da ventilação (Venturi) }\left({ }^{\circ} \mathrm{C}\right) \text { - Saída da } \\
\text { carcaça da embreagem }\end{array}$ & 43 \\
\hline TC14 & $\begin{array}{l}\text { Temperatura da ventilação (Venturi) }\left({ }^{\circ} \mathrm{C}\right) \text { - Saída no } \\
\text { tubo de escape }\end{array}$ & 42 \\
\hline P1 & Pressão do fluido dentro do CSC (bar) & 36,38 \\
\hline
\end{tabular}

Tabela 12 - Pontos de medição de temperatura e pressão e suas localizações 


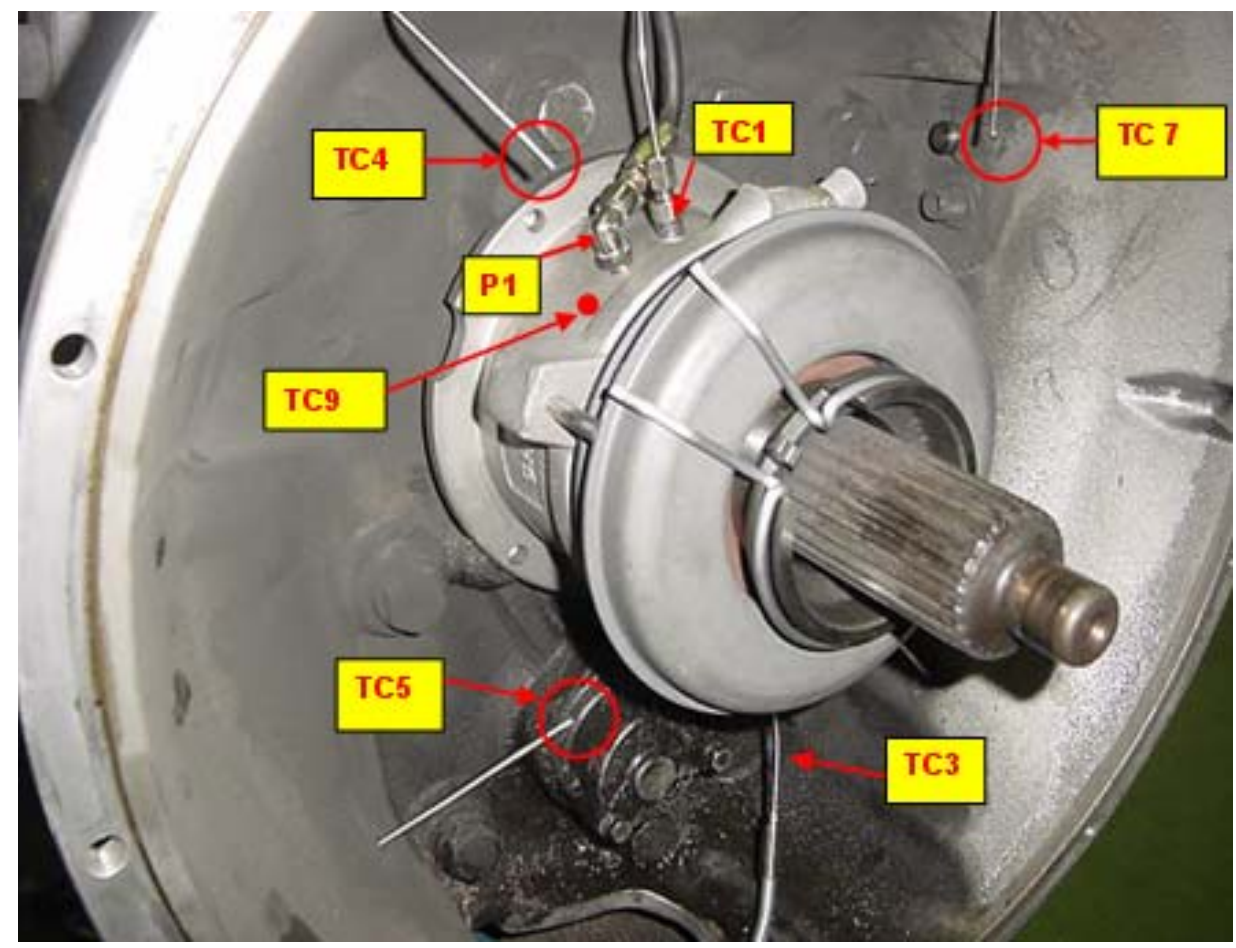

Figura 36 - Instalação de equipamentos de medição de temperatura e pressão no ambiente da embreagem.

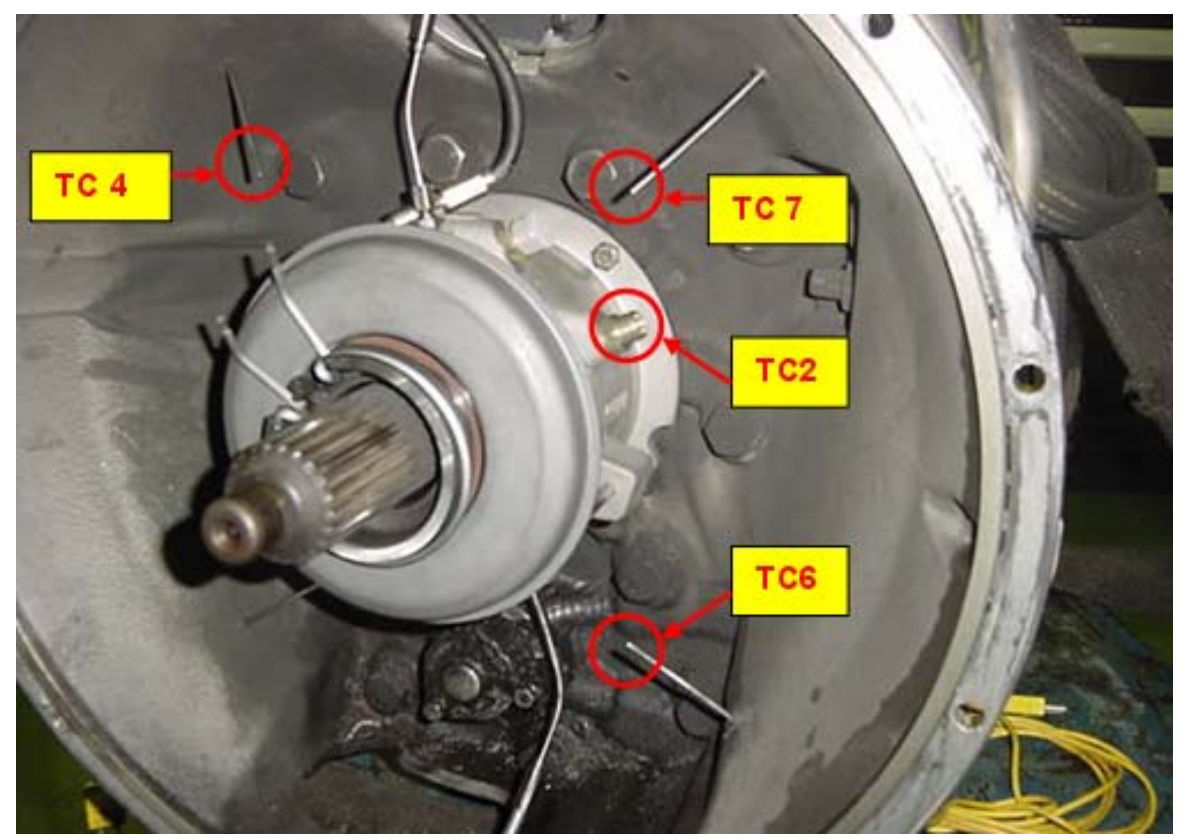

Figura 37 - Instalação de equipamentos de medição de temperatura e pressão no ambiente da embreagem. 


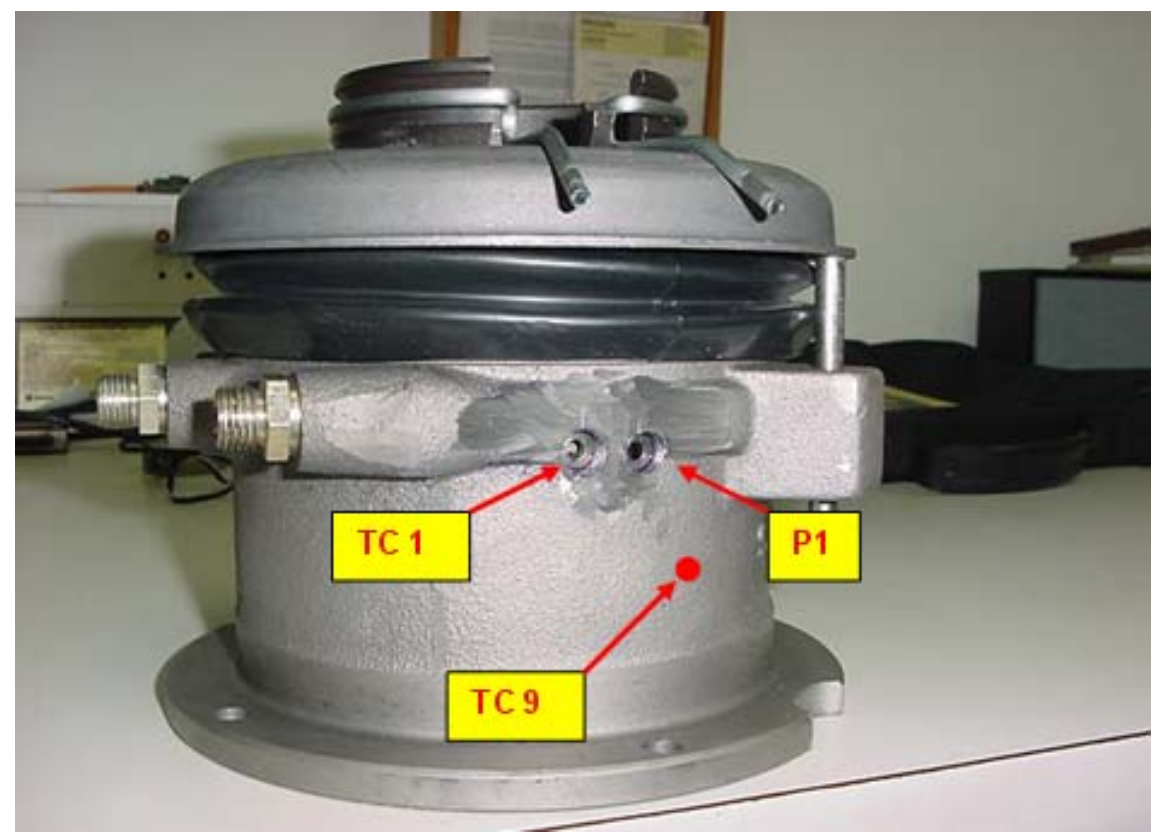

Figura 38 - Pontos para instalação de termopares e transdutores de pressão no cilindro escravo concêntrico.

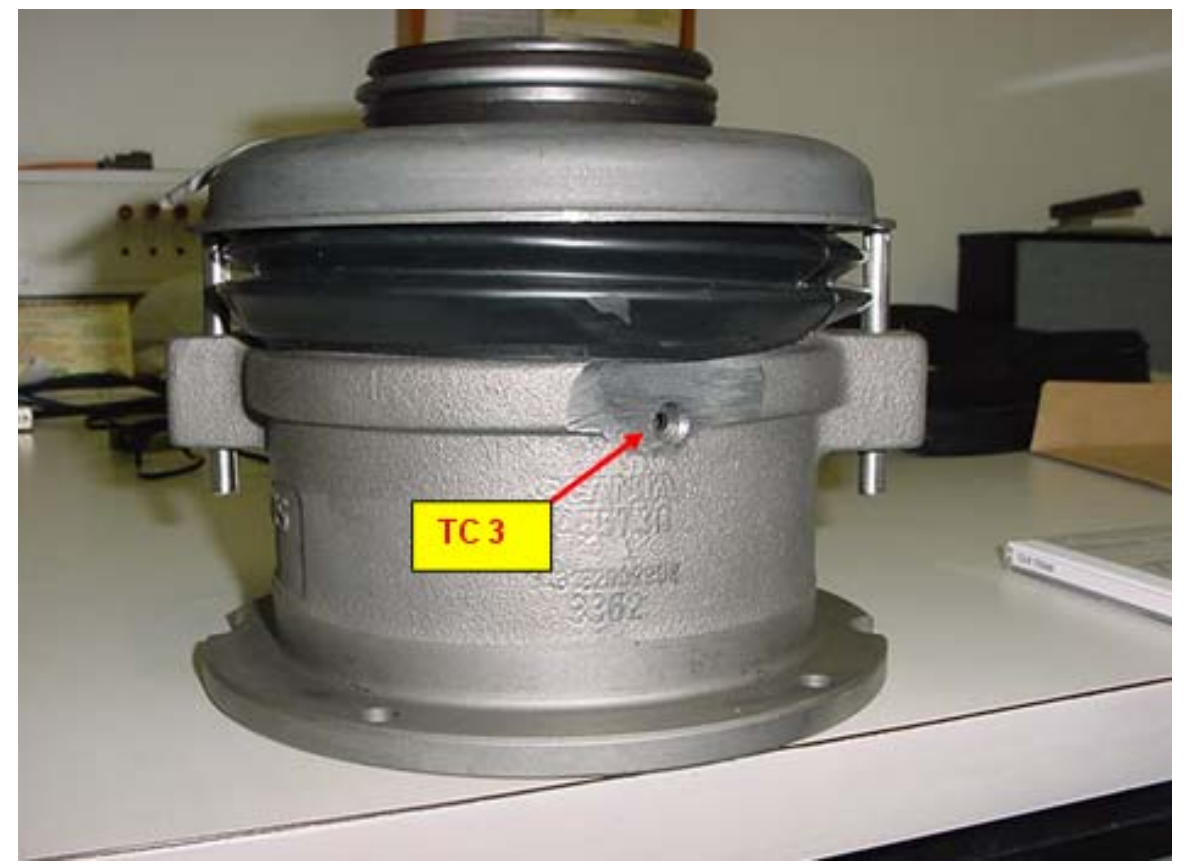

Figura 39 - Ponto para instalação de termopar para medição de temperatura no interior do cilindro escravo concêntrico. 


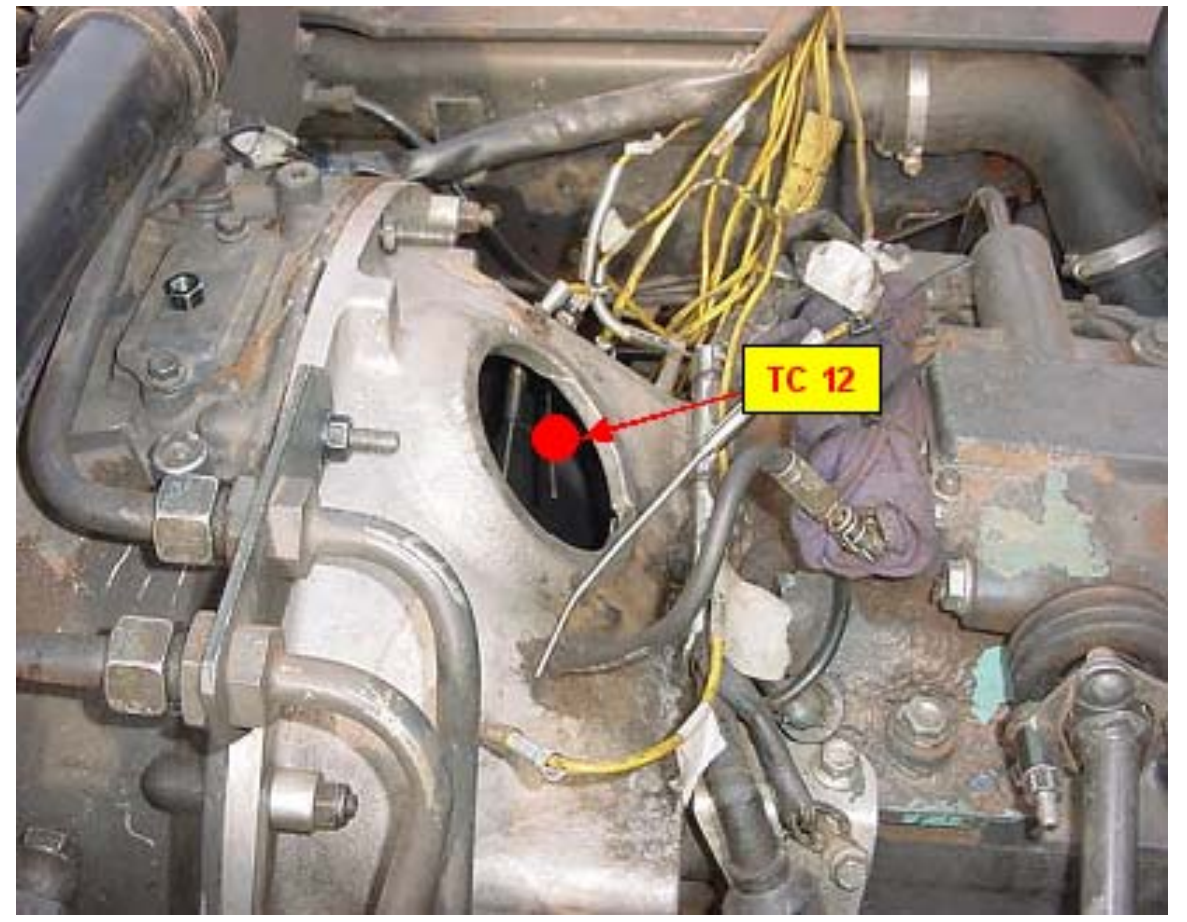

Figura 40 - Ponto para instalação de termopar para medição de temperatura na carcaça da embreagem.

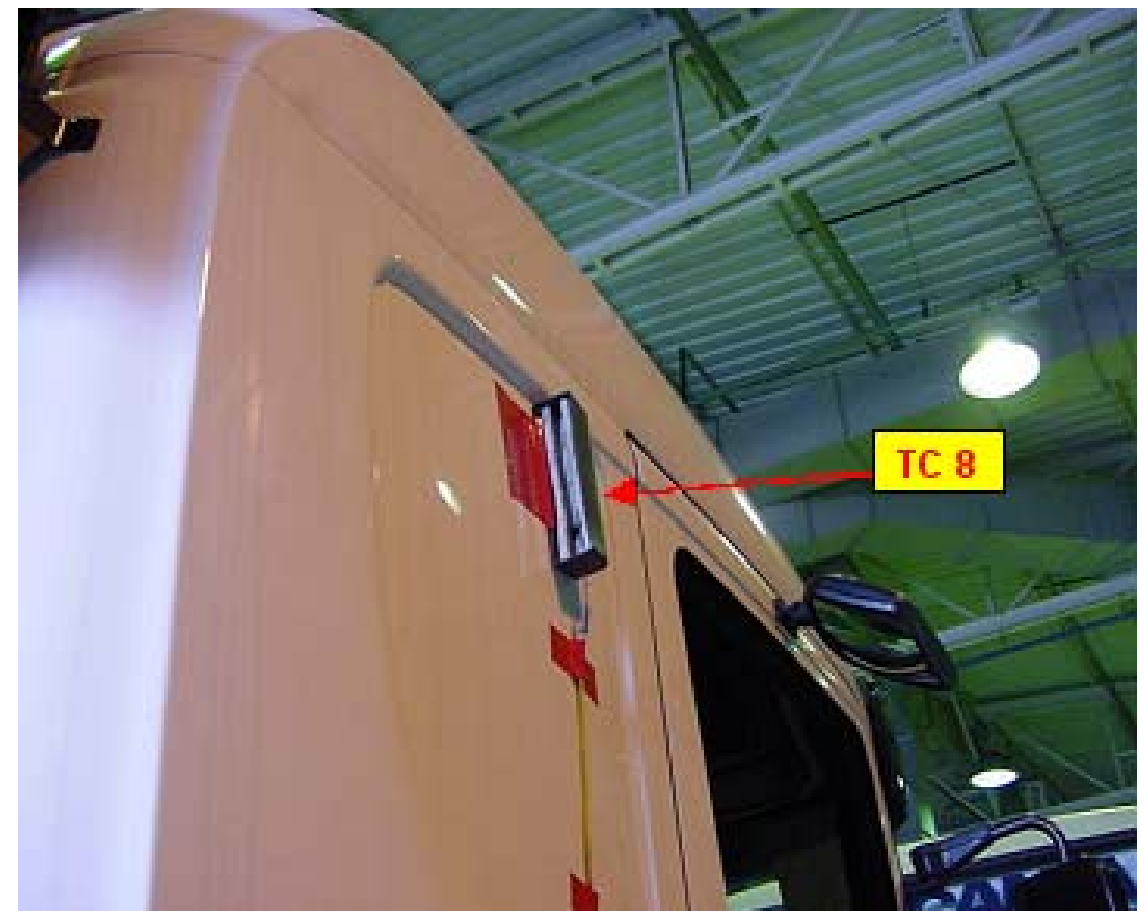

Figura 41 - Ponto para instalação de termopar para medição de temperatura ambiente 


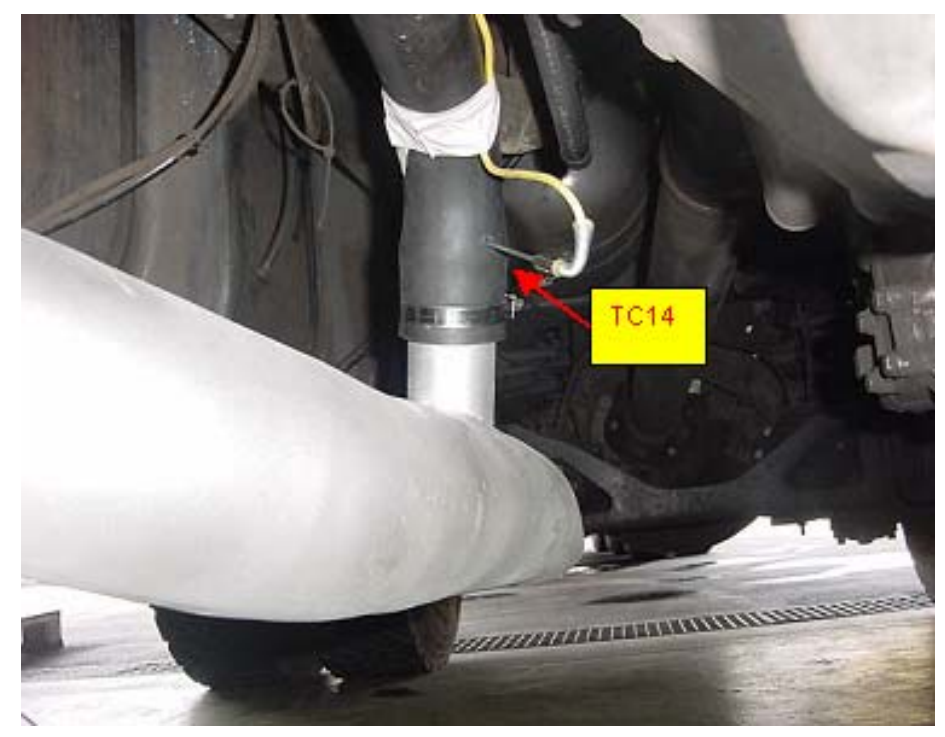

Figura 42 - Instalação de termopar para medição de temperatura com sistema de recirculação de ar

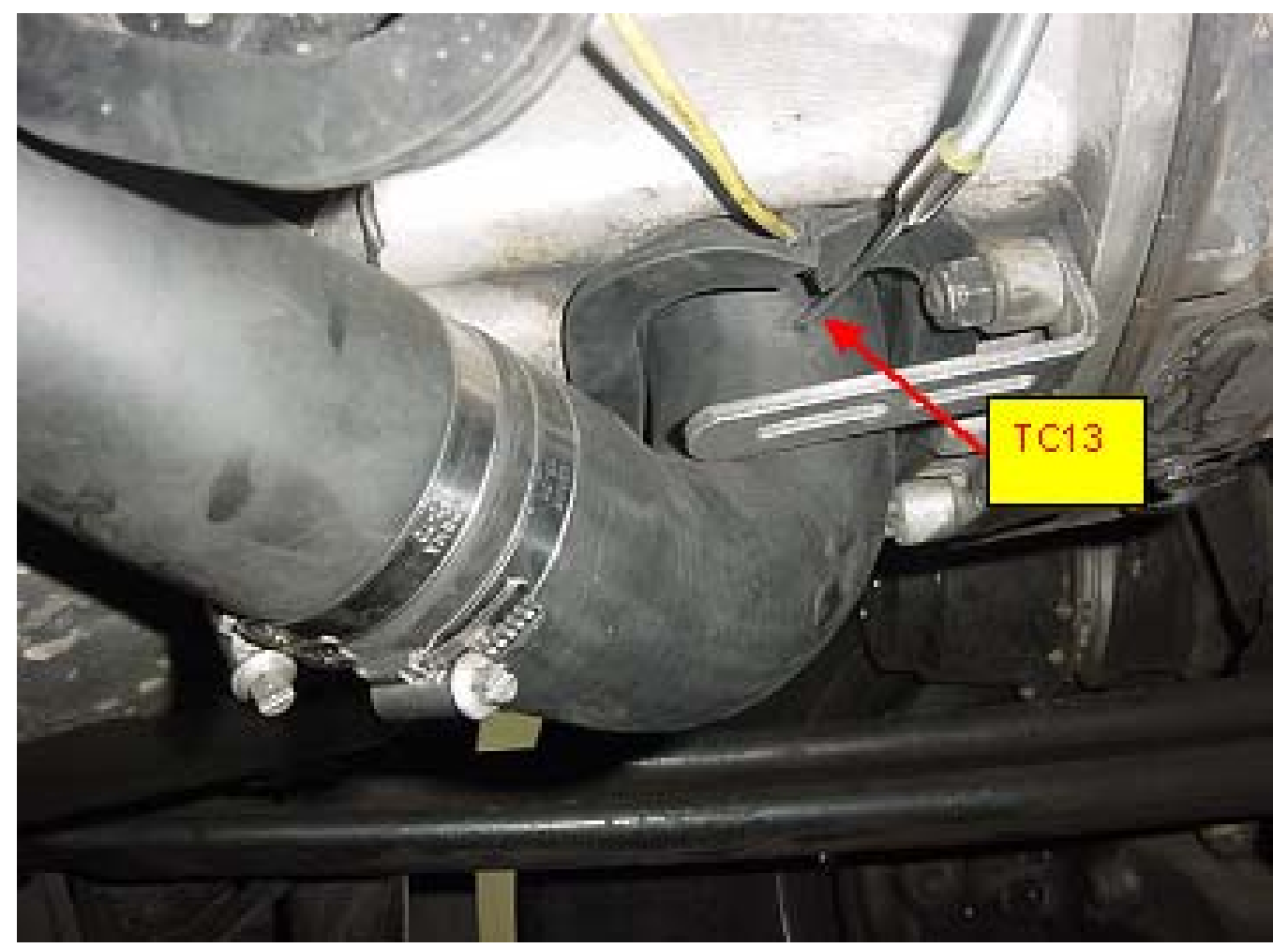

Figura 43 - Instalação de termopar para medição de temperatura na região da carcaça da embreagem com sistema de recirculação de ar 


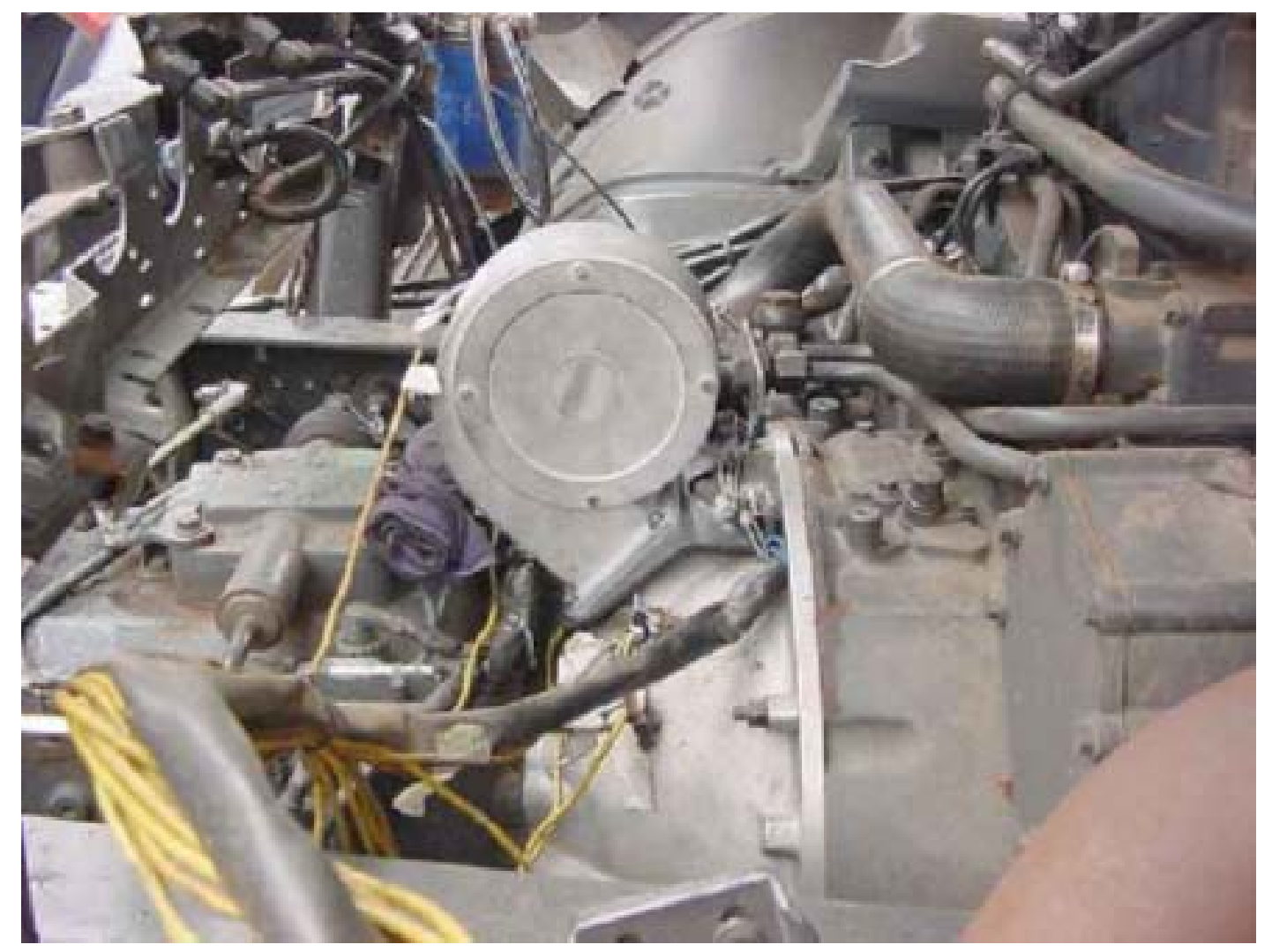

Figura 44 - Instalação de ventilação forçada no ambiente da embreagem

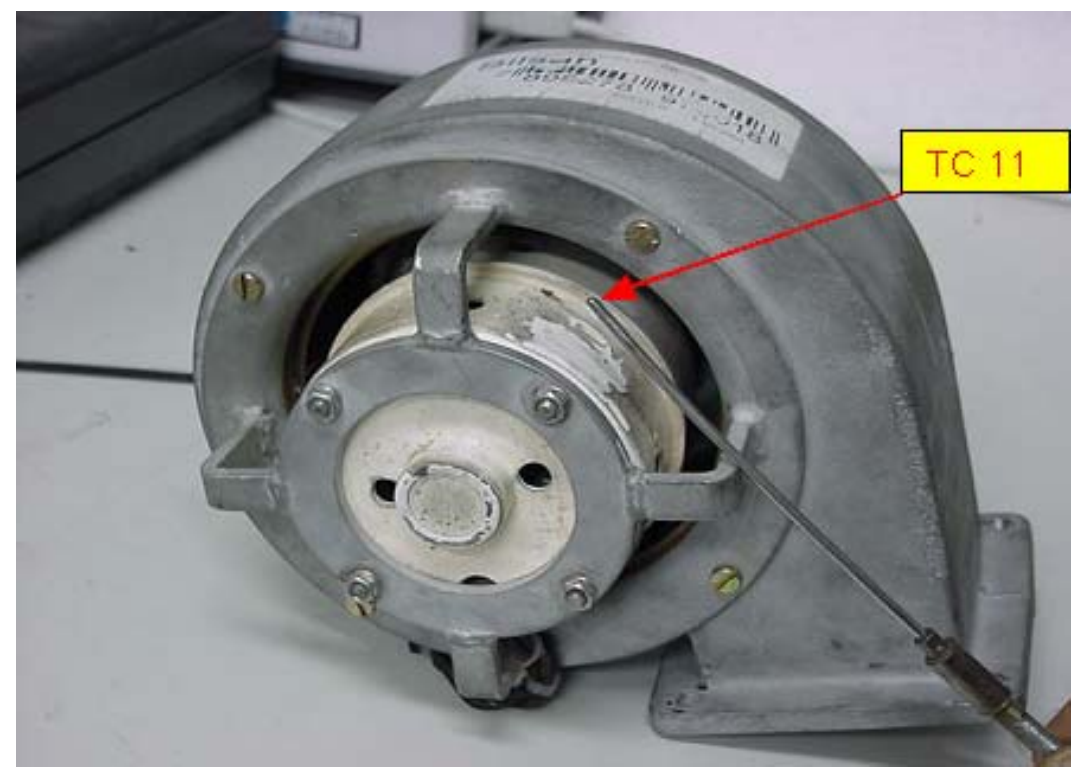

Figura 45 - Ponto de medição de temperatura no ventilador 


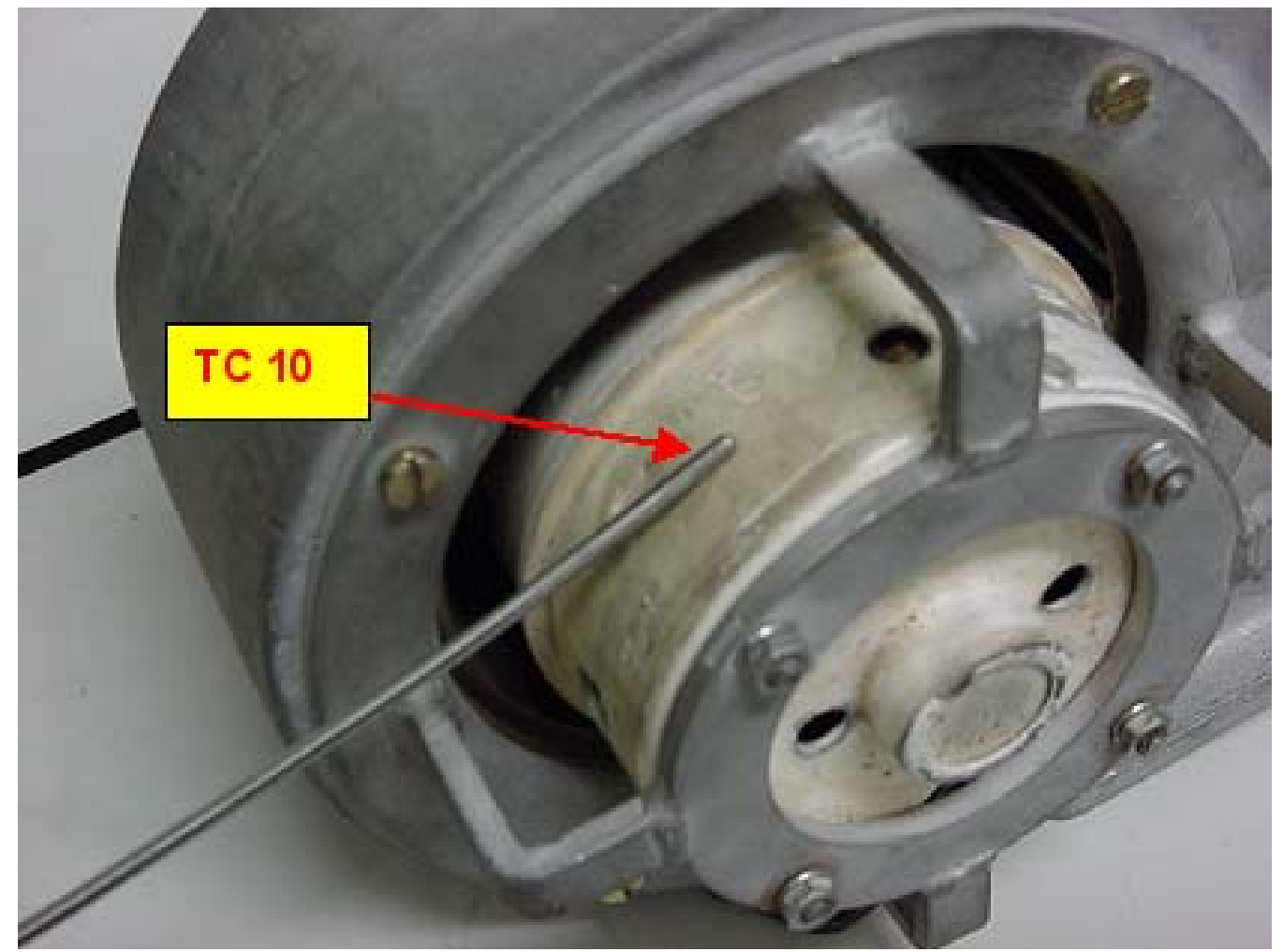

Figura 46 - Ponto de medição de temperatura no ventilador

\subsection{Testes de Funcionalidade do Sistema em Condições Severas de Operação Utilizando Fluido Contaminado (14\% em Volume de Água)}

O primeiro teste foi realizado com fluido contaminado com $14 \%$ de volume de água e carcaça de embreagem totalmente fechada com os tampões de borracha que normalmente são utilizados pela montadora para prevenir a entrada de contaminantes no ambiente da embreagem.

A figura 47 demonstra a janela de medição das temperaturas entre as $17 \mathrm{~h} 30 \mathrm{~min}$ e $23 \mathrm{~h} 16 \mathrm{~min}$. 
Teste 1 - Parada na Rampa \& saida - $14 \%$ de quantidade de Agua no Fluido Carcaça da Embreagem totalmente fechada

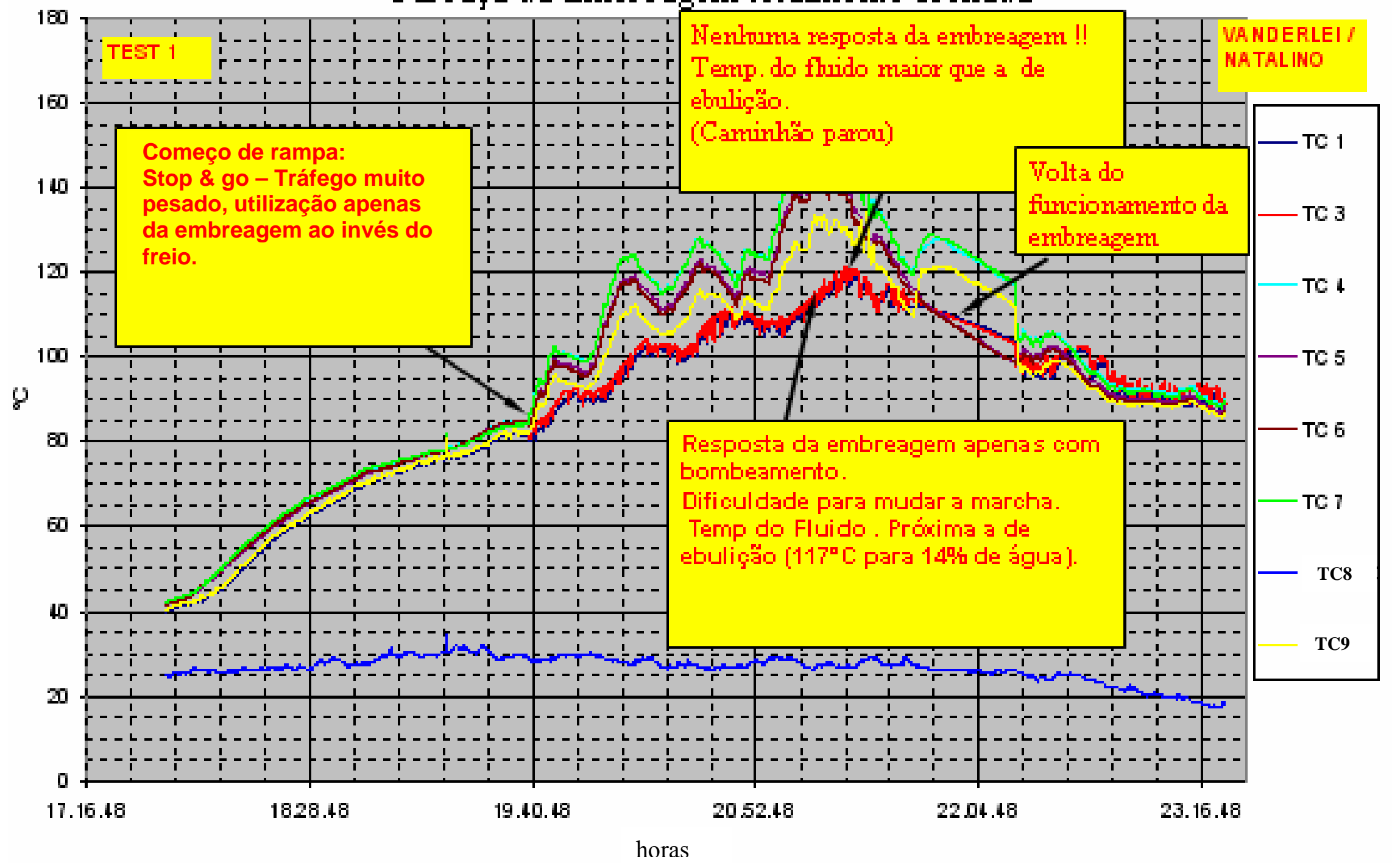

Figura 47 - Teste em tráfego urbano intenso com parada em rampa e saída com utilização da embreagem 
No início da rampa, por volta das 19h40min, o veículo é submetido a tráfego intenso com constantes paradas e partidas.Verifica-se que a partir deste momento a temperatura no interior do cilindro escravo concêntrico (temperatura do fluido TC1 e TC3) apresenta sinais de incremento. Percebe-se que ocorre o mesmo fenômeno com a temperatura do ambiente da embreagem (TC4, TC5, TC6 e TC7), contudo a temperatura ambiente (TC8 em azul no gráfico) se mantém entre $25^{\circ} \mathrm{C}$ e $30^{\circ} \mathrm{C}$.

A continuação de submissão do sistema de embreagem à condição de severidade imposta pelo teste demonstra um aumento ainda maior das temperaturas mencionadas, porém verifica-se que há um "descolamento" da curva de temperatura do ambiente da carcaça da embreagem se comparado à temperatura do fluido, sendo que a primeira apresenta incrementos de temperatura maiores que aqueles encontrados no fluido, indicando "um atraso" na transferência de calor do ambiente para o interior do cilindro escravo.

Por volta das $20 \mathrm{~h} 52 \mathrm{~min}$ a temperatura do ambiente da embreagem sobe vertiginosamente atingindo valores superiores a $140^{\circ} \mathrm{C}$, sendo que a curva de temperatura no interior do cilindro escravo concêntrico atinge valores próximos ao ponto esperado de ebulição do fluido DOT4 contaminado com $14 \%$ de água $\left(117^{\circ} \mathrm{C}\right)$. Neste momento percebe-se que o pedal da embreagem começa a apresentar vibrações, apresentando também variações de resposta ao longo do curso do mesmo. Verifica-se que quanto maiores as temperaturas, maiores são as vibrações e menores são as respostas do sistema de embreagem.

No instante em que a temperatura no interior do cilindro escravo concêntrico ultrapassa o ponto de ebulição esperado para o fluido contaminado, o sistema de embreagem apresenta a total falta de funcionalidade, impossibilitando as trocas de marcha e conseqüentemente causando a parada total do veículo.

Após alguns minutos de espera, a temperatura no interior do cilindro escravo concêntrico baixou para valores inferiores aos esperados para ebulição do fluido contaminado, sendo então restaurado o funcionamento do sistema de acionamento da embreagem permitindo o encerramento dos testes às $23 \mathrm{~h} 16 \mathrm{~min}$. Os resultados obtidos neste teste denotam que a contaminação do fluido DOT4 por água é a causa para as 
falhas do sistema de embreagem por cilindro escravo concêntrico, uma vez que a evolução dos sintomas induzidos pelo teste é idêntica àqueles reportados em campo conforme descrito no capítulo 4.

\subsection{Testes de Funcionalidade do Sistema em Condições Severas de Operação Utilizando Fluido Contaminado (14\% de água) com Instalação de um Sistema de Recirculação de ar no Ambiente da Embreagem (Carcaça da Embreagem Aberta).}

$\mathrm{O}$ segundo teste de funcionalidade do sistema de acionamento de embreagem por cilindro escravo concêntrico foi realizado mantendo-se as condições de contorno estabelecidas no teste 1 , porém neste caso, utilizando um sistema de recirculação natural para o ar no ambiente de embreagem.

Os testes tiveram início por volta das $18 \mathrm{~h} 15 \mathrm{~min}$ conforme demonstrado na figura 48 , quando a temperatura média do ambiente da embreagem se encontrava na faixa de $80^{\circ} \mathrm{C}$. Percebe-se que neste caso, houve uma variação maior das curvas de temperatura ao longo do teste se compararmos estas àquelas apresentadas no teste 1. Por volta das 19h00min o sistema de acionamento de embreagem começou a apresentar vibrações no pedal da embreagem (mesmo sintoma de falha detectado no teste 1) e, após alguns instantes, houve a perda total de funcionalidade.

Neste momento percebe-se que há um grande descolamento das curvas de temperatura do fluido com as do ambiente da embreagem. Isto pode ser percebido na figura 48 entre as $18 \mathrm{~h} 30 \mathrm{~min}$ até às $19 \mathrm{~h} 40 \mathrm{~min}$. Sendo que, a temperatura no ambiente da embreagem apresentou picos acima de $220^{\circ} \mathrm{C}$ enquanto neste exato momento a temperatura do fluido dentro do cilindro escravo concêntrico apresentava temperaturas da ordem de $135^{\circ} \mathrm{C}$, demonstrando a reprodutibilidade do modo de falha verificado anteriormente pelo já referido teste 1 .

Portanto, constatou-se neste teste que o sistema de recirculação natural para o ambiente da embreagem não pode ser considerado como uma eventual solução para a diminuição 
da temperatura no ambiente da embreagem, e conseqüentemente do fluido, a fim de evitar-se a ebulição do mesmo no interior do cilindro escravo concêntrico. 
Teste 2 - Parada na Rampa \& saida - 14\% de quantidade de Agua no Fluido - Carcaça da Embreagem Aberta

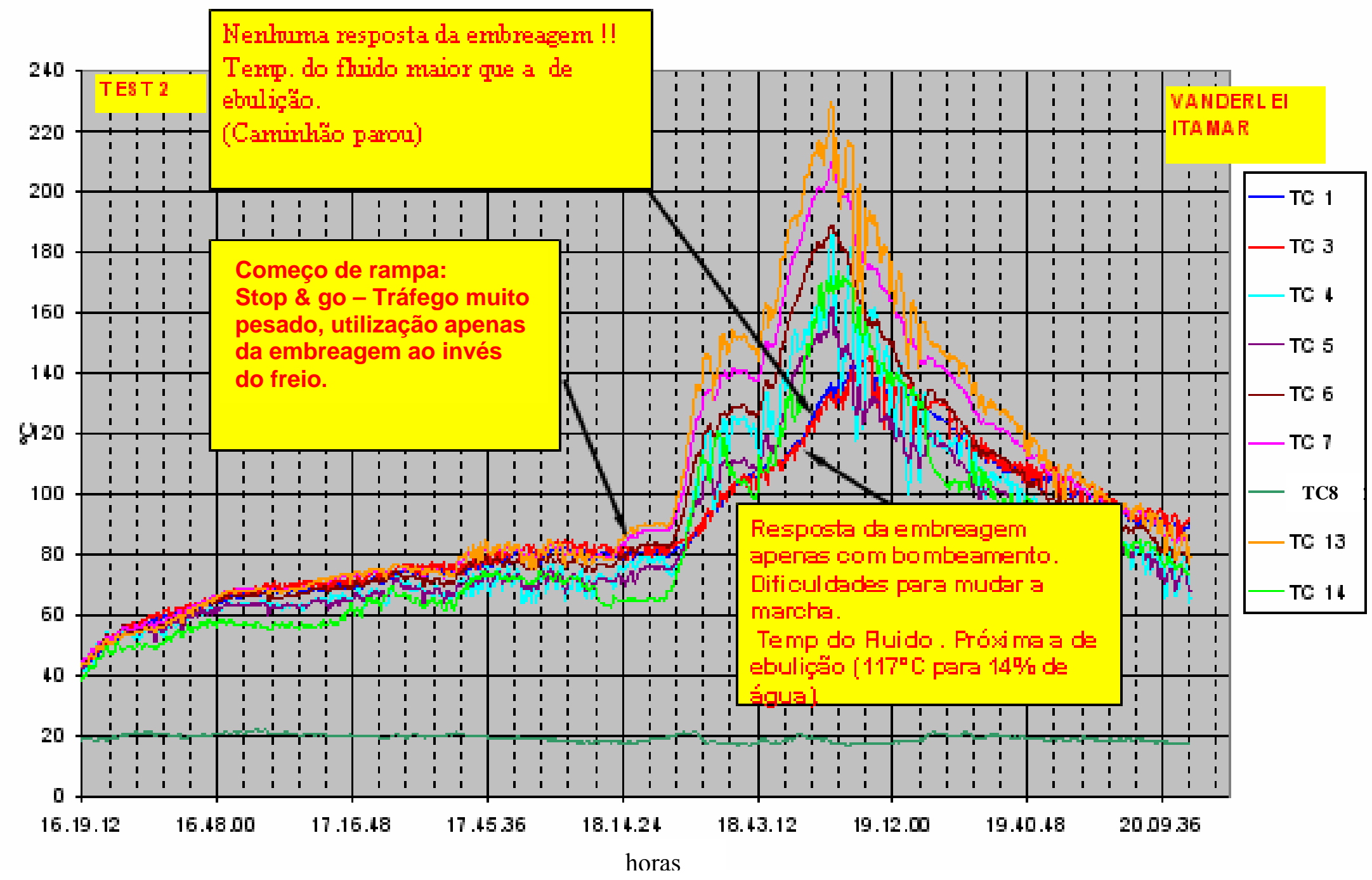

Figura 48 - Repetição do teste 1 com carcaça da embreagem aberta (recirculação do ar no ambiente da embreagem) 


\subsection{Testes de Funcionalidade em Condições Severas de Operação Utilizando Fluido Contaminado (14\% de água) com Instalação de um Sistema de Ventilação Forçada no Ambiente da Embreagem}

Os resultados obtidos no teste 2 demonstraram que a ventilação natural para o ambiente da embreagem não era suficiente para o arrefecimento do mesmo. Portanto, neste terceiro teste optou-se por introduzir um sistema de ventilação forçada.

O ventilador instalado sobre o olhal de ventilação superior da carcaça de embreagem tinha, segundo seu fabricante, vazão de ar máxima de $180 \mathrm{~m} / \mathrm{h}$ a $25^{\circ} \mathrm{C}$.

O funcionamento do ventilador dava-se através de um sinal enviado por um interruptor instalado no mecanismo do pedal da embreagem e este, por sua vez, era processado por uma unidade de controle eletrônica, através da qual pôde-se ajustar o tempo de funcionamento do mesmo após a liberação do pedal da embreagem pelo motorista.

Para este ensaio optou-se em ajustar o sistema para que o ventilador funcionasse por um período de até dois minutos, devido ao grande número de trocas de marchas em tráfego intenso.

Conforme demonstrado na figura 49, o teste 3 foi dividido em duas fases: a primeira utilizando-se um motorista treinado pela montadora, operando em condições ideais e sem a utilização do ventilador; a segunda utilizando as mesmas condições de contorno operacionais (incluindo motorista padrão) e com a utilização do ventilador.

Conforme se pode verificar na figura 48 , o teste teve seu início por volta das $17 \mathrm{~h} 00 \mathrm{~min}$, quando as temperaturas no ambiente da embreagem se encontravam em torno de $80^{\circ} \mathrm{C}$ e, durante o período de operação do motorista padrão dentro das condições ideais (das $17 \mathrm{~h} 02 \mathrm{~min}$ às $17 \mathrm{~h} 31 \mathrm{~min}$ ), as temperaturas não apresentaram descolamento entre as suas curvas e chegaram a valores da ordem de $85^{\circ} \mathrm{C}$.

A partir do momento em que o ventilador foi acionado, por volta das $17 \mathrm{~h} 40 \mathrm{~min}$, verifica-se que as curvas de temperatura apresentam um declínio da ordem de $10^{\circ} \mathrm{C}$, indicando a eficácia da ventilação forçada.

Durante o processo de teste da ventilação forçada para o ambiente da embreagem, entendeu-se que esta solução não seria viável devido à sua complexidade de instalação. 


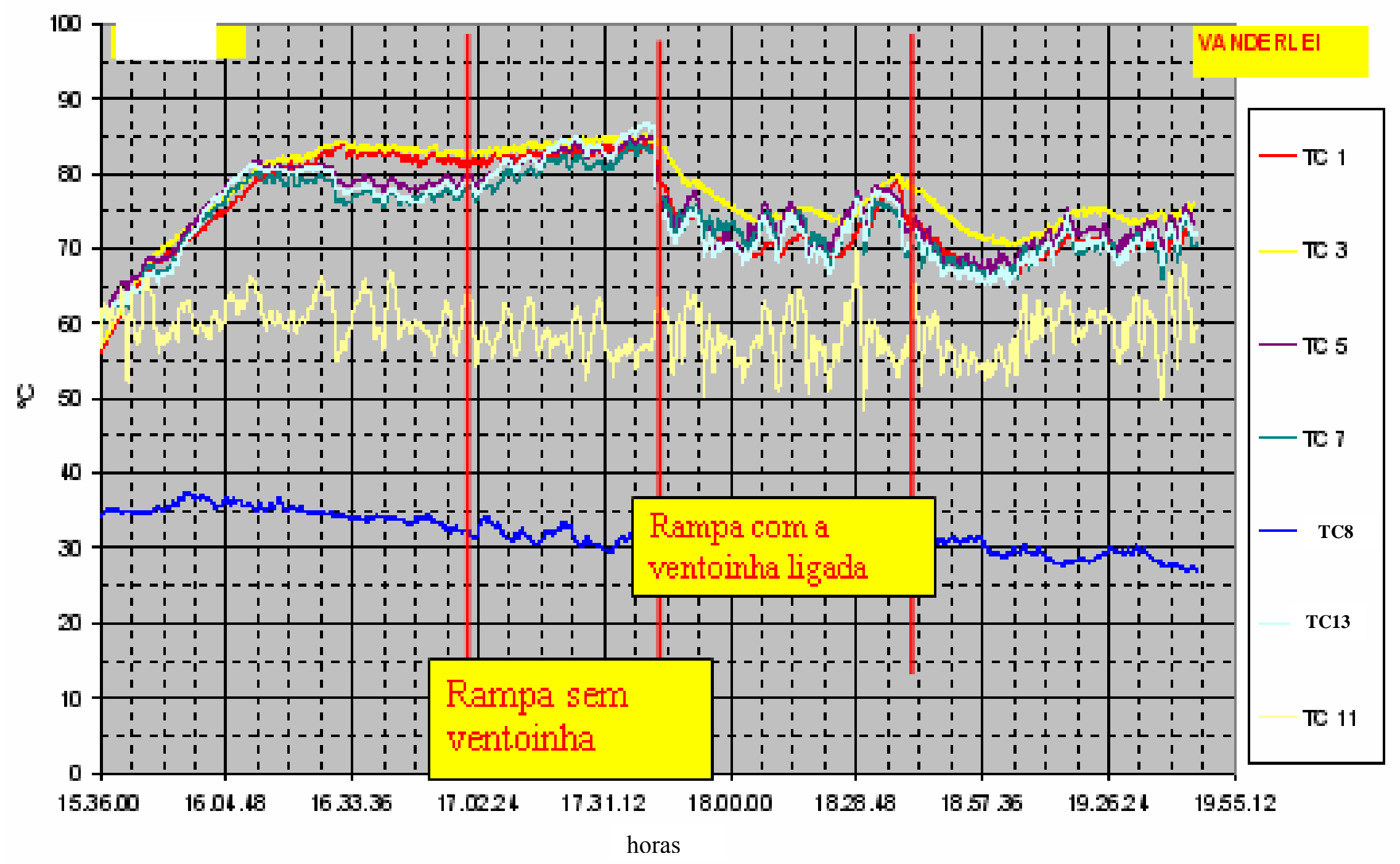

Figura 49 - Teste com ventilação forçada no ambiente da embreagem. 


\subsection{Testes de Funcionalidade em Condições Severas de Operação Utilizando Fluido Contaminado (14\% de água) com Motorista Padrão Treinado pela Montadora}

O quarto teste foi realizado com motorista padrão da montadora, tentando simular as condições normais esperadas em campo. Neste teste houve um pequeno aumento da severidade de operação do sistema da embreagem através de saídas em segunda marcha, controle da embreagem em pequenas rampas, de acordo com a experiência de campo do motorista.

O teste teve seu início por volta das $11 \mathrm{~h} 00 \mathrm{~min}$, conforme demonstrado na figura 50 , onde se percebe que há um início de descolamento das temperaturas do fluido e do ambiente da embreagem. A primeira fase do teste encerrou-se em torno das $12 \mathrm{~h} 00 \mathrm{~min}$ (parada para almoço), onde se verificou a queda das temperaturas de forma constante.

O reinício dos testes se deu por volta das $13 \mathrm{~h} 15 \mathrm{~min}$, onde se verifica uma estabilização das temperaturas (que ocorre até às $14 \mathrm{~h} 24 \mathrm{~min}$ ), sendo que a partir deste momento as temperaturas apresentam novamente um incremento significativo seguido de um novo descolamento entre as mesmas.

Conclui-se então que, em condições severas de operação, sempre haverá descolamento das curvas de temperatura entre o fluido e o ambiente da embreagem. 


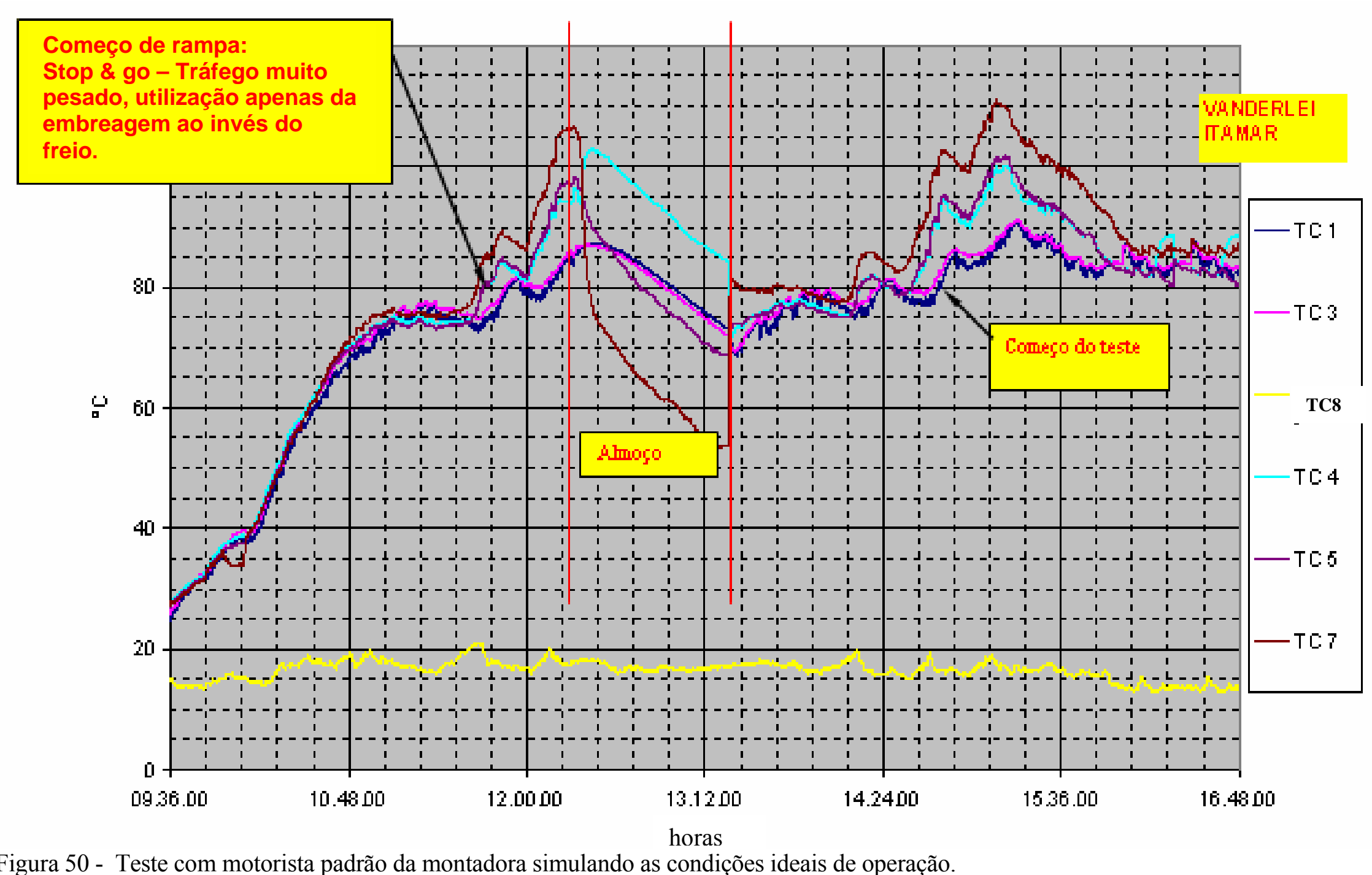

Figura 50 - Teste com motorista padrão da montadora simulando as condições ideais de operação. 


\subsection{Estudos para Determinação da Fonte de Contaminação do Fluido por Umidade}

Os ensaios de funcionabilidade demonstraram que a contaminação do fluido por água, causa a redução da temperatura de ebulição do mesmo apresentando a falha do sistema quando a temperatura de trabalho do ambiente da embreagem é igual ou superior ao valor da temperatura de ebulição do fluido.

Segundo CARVALHO ${ }^{1}$, a metodologia utilizada na industria automobilística para determinação do ponto de contaminação por água em qualquer sistema que utiliza fluidos de freio DOT 4 ou 5.1, baseia-se na coleta de amostras em diversos pontos do sistema, sendo que aquele ponto que apresenta maior taxa de contaminação é considerado como a fonte da mesma.

Para a complementação do estudo e determinação da causa raiz para a contaminação do fluido, optou-se por coletar amostras de fluido em diferentes pontos do sistema de acionamento da embreagem em um ônibus rodoviário. A amostras foram recolhidas através de seringa e agulha no nípel de conexão da mangueira de alimentação do cilindro escravo concêntrico (figura 10, pág. 15), sendo esta então a região mais próxima possível do interior do cilindro escravo, e no reservatório de fluido que se encontrava instalado no painel de instrumentos do ônibus, os resultados são demonstrados na tabela 13.

\begin{tabular}{|c|c|c|}
\hline Local da amostra & Nípel do CSC & Reservatório \\
\hline \% Água (vol) & 7,4 & 4,4 \\
\hline
\end{tabular}

Tabela 13 - Resultado de amostras coletadas em diferentes pontos do sistema

Portanto, conforme afirmação de CARVALHO, os resultados demonstram que a origem da contaminação por água no sistema de acionamento da embreagem por cilindro escravo concêntrico ocorre pelo êmbolo do mesmo. 


\section{DISCUSSÃO DOS RESULTADOS DE COMPATIBILIDADE QUÍMICA E TESTES DE FUNCIONALIDADES MECÂNICAS}

Os ensaios realizados para a avaliação da compatibilidade química do fluido com os materiais selecionados para componentes do sistema de acionamento da embreagem por cilindro escravo concêntrico não demonstraram nenhum sinal de incompatibilidade.

Deve-se atentar para o fato de que as graxas utilizadas para a montagem do cilindro escravo concêntrico e cilindro mestre não se diluem no fluido da embreagem.

As bolhas de graxa, se associadas com materiais de desgaste natural do sistema, podem formar misturas, aumentando assim a dureza destas e conseqüentemente o eventual entupimento dos condutos do sistema.

Os testes do funcionamento mecânico e indução à falha foram realizados com sucesso pois o mecanismo de falha foi repetido por diversas vezes com um alto grau de controle sobre o mesmo, adicionalmente, verificou-se que os sintomas apresentados nas falhas induzidas ocorreram exatamente como relatado pelos motoristas em campo.

Conclui-se que o cilindro escravo concêntrico é muito sensível ao comportamento de condução e a temperatura na carcaça da embreagem (foram detectados picos superiores a $\left.200^{\circ} \mathrm{C}\right)$.

Adicionalmente pelos resultados obtidos, pode-se afirmar que:

- Altas temperaturas são normalmente geradas em operações pesadas associadas com mau uso do sistema (alta relação de arranque, utilização da embreagem em rampas \& semáforos, ao invés de utilizar os freios, etc.);

- O calor gerado pela fricção entre o disco e o volante é transferido para o ambiente da embreagem e conseqüentemente para o CSC;

- Foram detectadas temperaturas de até $140^{\circ} \mathrm{C}$ no fluido e ainda valores maiores no CSC;

- Os materiais de vedação do CSC estão dimensionados em condições limítrofes de temperatura; 
- Podem ocorrer picos de pressão negativa no CSC (ao tirar o pé do pedal) causando a entrada de ar no fluido (ar + umidade) conforme demonstrado na figura 51;

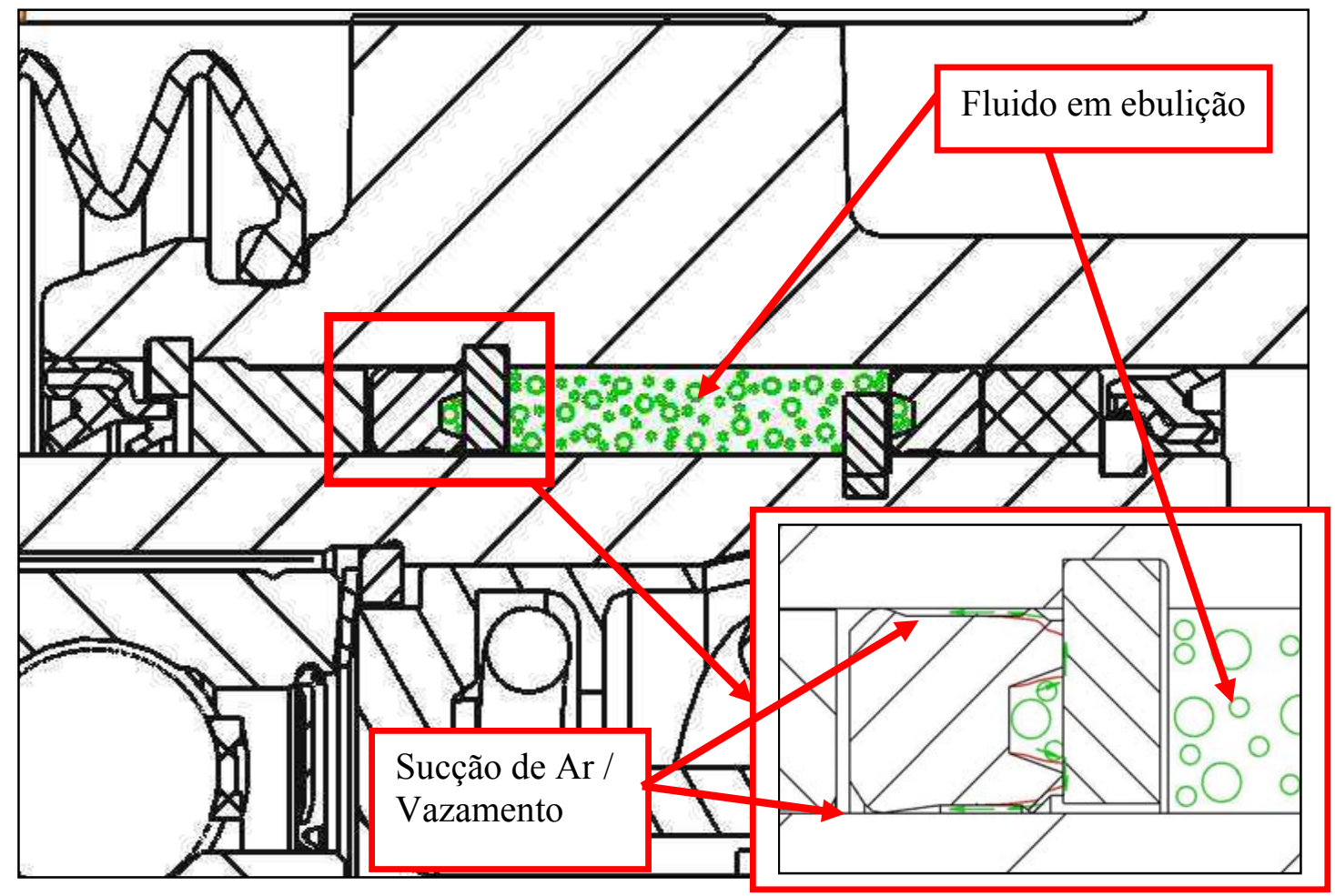

Figura 51 - Fluido de embreagem em processo de ebulição dentro do CSC

- O fluido absorve umidade e a temperatura de ebulição diminui (B.P.14\% água = $\left.117^{\circ} \mathrm{C}\right)$

- Quando a temperatura do fluido dentro do CSC atinge $117^{\circ} \mathrm{C}$ com $14 \%$ de água - não há resposta aos comandos do pedal da embreagem;

- Após a redução de temperatura, o funcionamento da embreagem é restaurado.

Finalmente, pode-se afirmar que o componente de maior suscetibilidade às falhas no sistema de acionamento de embreagem por cilindro escravo concêntrico, é o fluido de freio utilizado no mesmo.

O mecanismo de falhas ocorre através da contaminação do fluido por água (que é altamente higroscópico) através da absorção de umidade do ambiente da embreagem, pois ao longo da vida do sistema, o fluido absorve a umidade em taxas crescentes, tendo 
a queda do seu ponto de ebulição como conseqüência direta. Quando o ponto de ebulição do fluido contaminado é reduzido para valores próximos aos encontrados para a temperatura de trabalho do sistema, o fenômeno da falha se manifesta.

As condições de operação tais como sobre-carga, umidade relativa do ambiente de operação do veículo, a falta de manutenção preventiva e modo de condução são fatores que podem contribuir para a falha do sistema de acionamento da embreagem por cilindro escravo concêntrico. 


\section{PROPOSTA DE NOVA SOLUÇÃO CONSTRUTIVA PARA SISTEMA DE ACIONAMENTO DE EMBREAGEM}

As investigações demonstraram claramente que as falhas estão ligadas às altas taxas de contaminação do fluido por água, causando assim a diminuição do seu ponto de ebulição. Ao cruzarem-se as temperaturas de trabalho do ambiente da embreagem e de ebulição do fluido, este passa a ferver causando a falha do sistema pelo comprometimento da propriedade de incompressibilidade do mesmo.

Dentre os ensaios realizados, uma das tentativas foi diminuir a temperatura do ambiente da embreagem a fim de preservar o funcionamento do sistema através da adoção de ventilação forçada. Contudo, conforme já mencionado no capítulo 8 , a solução demonstrou-se inviável.

Portanto, adotando-se a mesma linha de pensamento, optou-se por desenvolver uma solução alternativa para a construção do sistema de acionamento da embreagem, alocando o cilindro escravo para o ambiente externo da embreagem conforme demonstrado nas figuras 52 e 53.

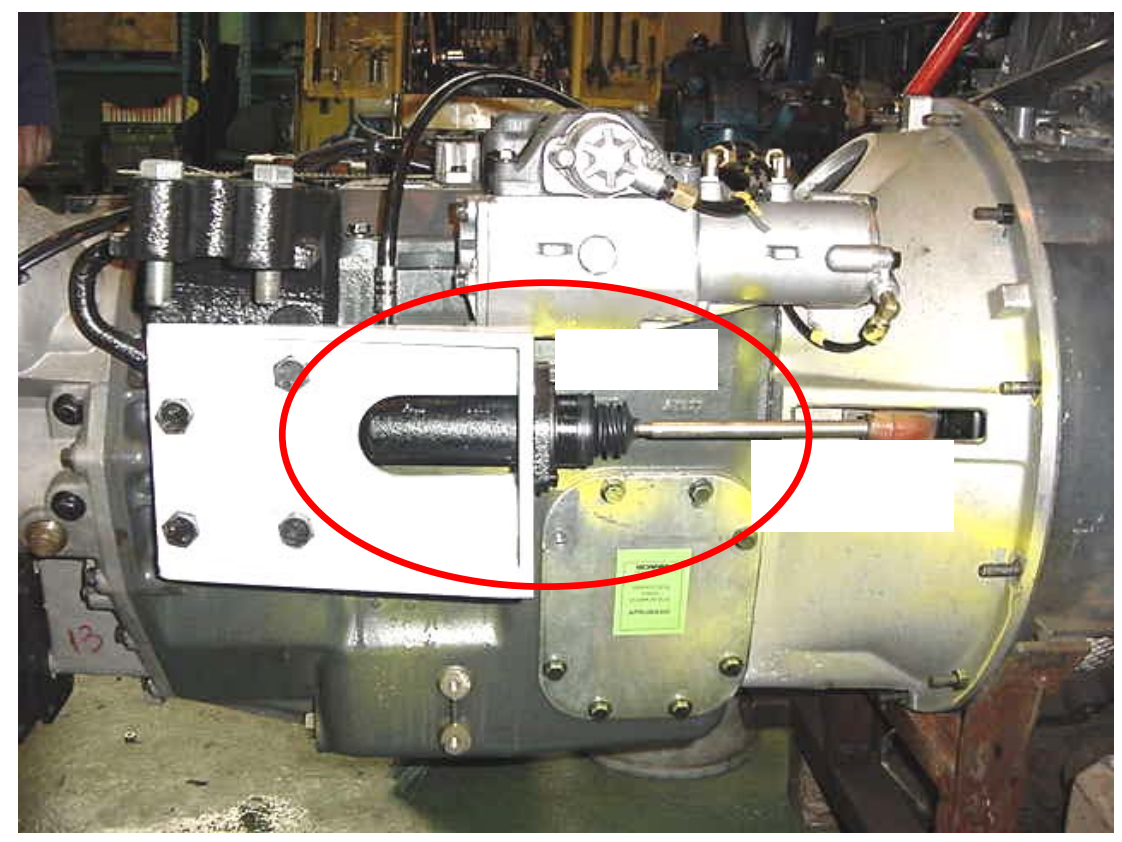

Figura 52 - Cilindro escravo externo ao ambiente da embreagem - vista lateral 


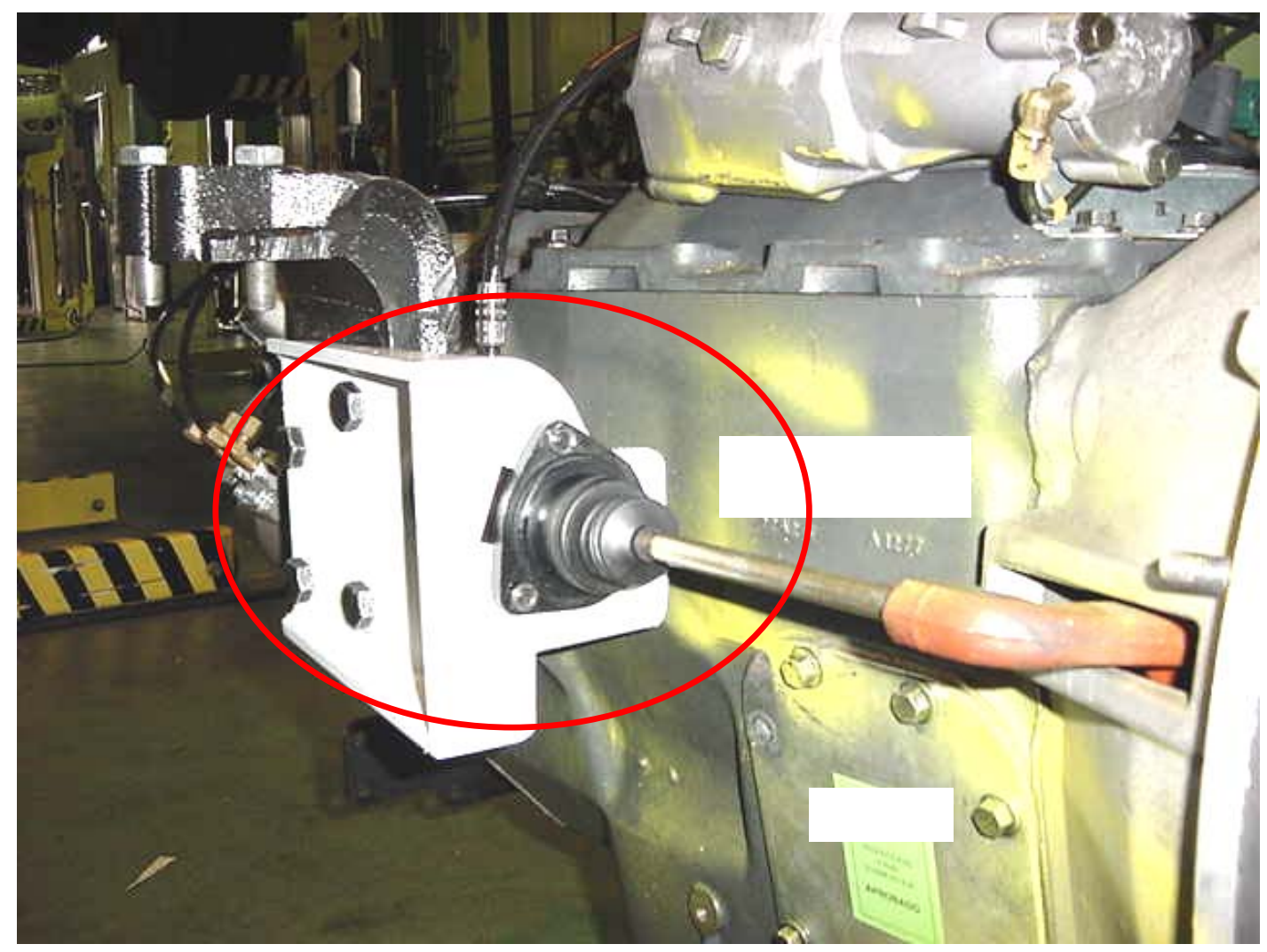

Figura 53 - Cilindro escravo externo ao ambiente da embreagem - vista diagonal

A vantagem deste sistema é que em caso de falhas de campo o mesmo se encontra em região de fácil acesso (ao lado da caixa de câmbio).

Não se pode afirmar que este novo sistema está isento de contaminação do fluido por água, porém esta solução não está exposta às altas temperaturas do ambiente da embreagem (ambiente fechado) pois a sua localização permite a troca de calor com o ambiente externo do veículo durante a condução do mesmo. 


\section{PROPOSTA DE MODELO MATEMÁtico PARA PREDIÇÃo DE INTERVALO DE TROCA PARA FLUIDOS DE FREIO}

A proposição de um modelo matemático para a predição do intervalo mínimo de troca de um fluido de freio que opera sob a exposição contínua à umidade do ambiente da carcaça da embreagem requer algumas considerações.

A primeira recai sobre a rugosidade superficial e respectiva área de exposição do êmbolo ao ambiente contaminado pela umidade, a segunda sobre o número de acionamentos requeridos para as trocas de marcha num determinado intervalo de operação e a terceira sobre a taxa de contaminação do fluido por taxa de tempo de exposição do mesmo à umidade ambiente. A somatória destes três fatores indicará a taxa de aquisição de contaminação pelo o volume de fluido retido nos vales da superfície, região em que os anéis não possuem eficácia de vedação.

11.1 Proposição de modelo Teórico para Determinação do Volume de Fluido Exposto a Contaminação por Água no Ambiente de Operação do Cilindro escravo Concêntrico.

Segundo BHUSHAN (2002), a textura (ou rugosidade) de uma superfície é uma repetição randômica do desvio da superfície nominal que forma uma topografia tridimensional da mesma. A rugosidade pode ser medida de diferentes maneiras, utilizando-se diversos parâmetros.

Para a proposição de um modelo matemático genérico para a determinação da área e volume de exposição à contaminação por água no cilindro escravo concêntrico, optou-se pela seleção de dois êmbolos para a medição das rugosidades médias Ra e totais Rt das superfícies expostas à ação do ambiente da embreagem durante o acionamento da embreagem. 
A rugosidade Ra (figura 54) é definida como sendo a média aritmética das coordenadas das alturas no comprimento em estudo e a rugosidade total Rt (figura 54) é definida como sendo o a distância encontrada entre o vale mais profundo e o pico mais alto no comprimento de superfície em estudo.

A figura 56 demonstra o procedimento de medição e os respectivos resultados são apresentados na tabela 14 .

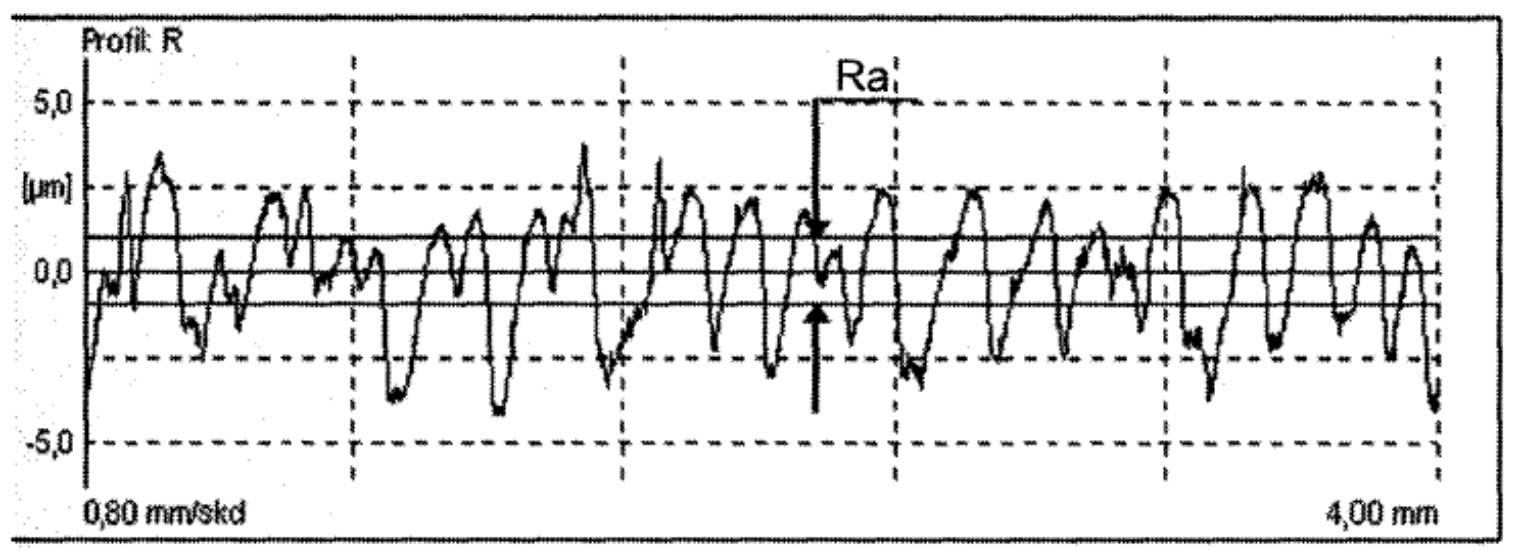

Figura 54 - Representação esquemática da rugosidade superficial Ra.

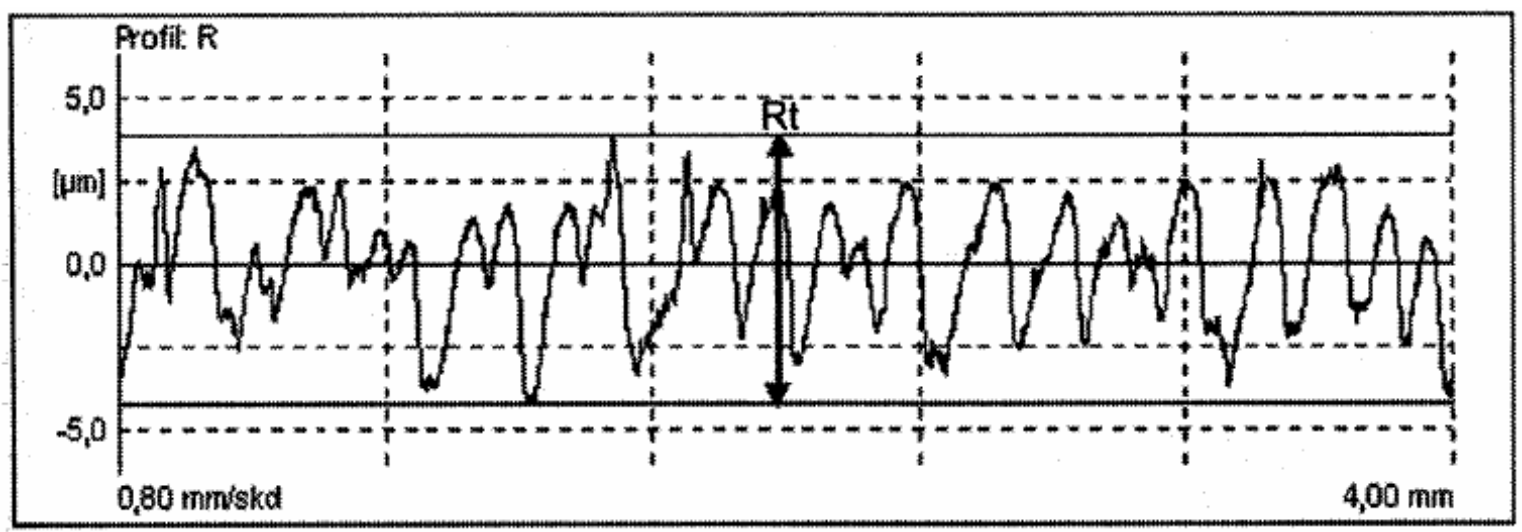

Figura 55 - Representação esquemática da rugosidade superficial Rt. 


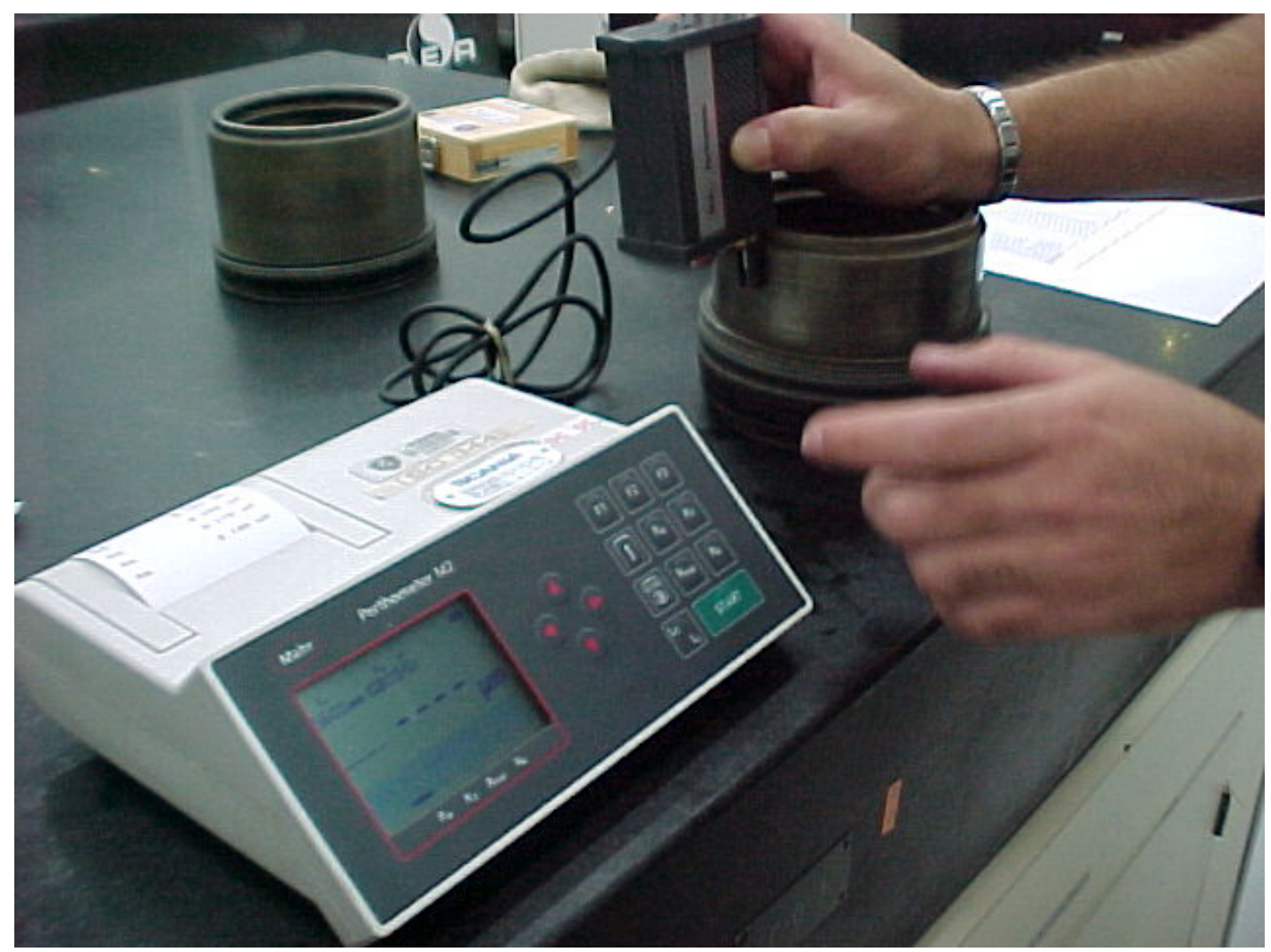

Figura 56 - Procedimento experimental para medição de rugosidade em êmbolos

\begin{tabular}{|c|c|c|c|c|}
\hline \multirow{2}{*}{ Medição } & \multicolumn{2}{|c|}{ Peça 1 } & \multicolumn{2}{c|}{ Peça 2 } \\
\cline { 2 - 5 } & $\operatorname{Ra}(\mu \mathrm{m})$ & $\operatorname{Rt}(\mu \mathrm{m})$ & $\mathrm{Ra}(\mu \mathrm{m})$ & $\mathrm{Rt}(\mu \mathrm{m})$ \\
\hline 1 & 0,273 & 2,310 & 0,270 & 2,250 \\
\hline 2 & 0,275 & 2,580 & 0,295 & 2,150 \\
\hline 3 & 0,312 & 2,900 & 0,387 & 2,520 \\
\hline 4 & 0,294 & 2,530 & 0,271 & 2,260 \\
\hline 5 & 0,302 & 2,380 & 0,246 & 2,180 \\
\hline Média & 0,346 & 2,540 & 0,294 & 2,272 \\
\hline
\end{tabular}

Tabela 14 - Valores experimentais de rugosidade Ra e Rt de duas amostras de êmbolos 
Portanto, tem-se que o perímetro do êmbolo do cilindro escravo concêntrico é dado pela equação:

$P=2 * \pi * R[\mathrm{~mm}]$

Onde:

$\mathrm{R}=$ Raio do êmbolo $[\mathrm{mm}]$

$\mathrm{P}=$ Perímetro $[\mathrm{mm}]$

$\mathrm{A}$ área de exposição à contaminação do êmbolo é dada pelo produto do perímetro $\mathrm{P}$ pelo curso do mesmo, que é delimitado pelas as coordenadas $X_{n}$ e $X_{n-1}$, sendo assim, tem-se que:

$$
\begin{aligned}
& A=\int_{x_{n-1}}^{x_{n}}\left[(2 \times \pi \times R)\left(x_{n}-x_{n-1}\right)\right] d x \\
& A=(2 \times \pi \times R) \int_{x_{n-1}}^{x_{n}}\left[\left(x_{n}-x_{n-1}\right)\right] d x\left[\mathrm{~mm}^{2}\right][\mathrm{Eq} 1]
\end{aligned}
$$

Onde:

$\mathrm{A}=$ Área de exposição à contaminação em um acionamento da embreagem $\left[\mathrm{mm}^{2}\right]$.

$\mathrm{X}_{\mathrm{n}-1}=$ Posição inicial (de repouso) do êmbolo [mm]

$\mathrm{X}_{\mathrm{n}}=$ Posição final (acionado) do êmbolo (com $\left.\mathrm{Xn} \geq 1\right)$ [mm]

Admitindo-se que o volume total de fluido retido no êmbolo, não retirado pelo anel de vedação em acionamento único do cilindro escravo concêntrico, seja definido pelo produto entre a rugosidade média superficial Ra e a área de exposição A (Eq.1), tem-se que: 


$$
V=2 \times \pi \times R \times R a \times 10^{-3}\left(x_{n}-x_{n-1}\right) \quad\left[\mathrm{mm}^{3}\right][\mathrm{Eq} 2]
$$

Onde:

$\mathrm{V}=$ Volume de fluido exposto a contaminação em um acionamento da embreagem $\left[\mathrm{mm}^{3}\right]$.

$\mathrm{Ra}=$ Rugosidade média $[\mu \mathrm{m}]$

O modelo pode ser ajustado com a adição da equação que define o número de acionamentos da embreagem, a qual define a somatória dos volumes de fluidos expostos à contaminação por água proveniente do ambiente da embreagem:

$n=\sum_{n_{1}}^{n_{n}}\left(x_{n}-x_{n-1}\right)[\operatorname{Eq} 3]$

Onde:

$\mathrm{n}_{\mathrm{n}}=$ Último acionamento da embreagem no fim da vida útil do fluido

$\mathrm{n}_{1}=$ Primeiro acionamento da embreagem no início da vida útil do fluido

Pode-se dizer que o modelo matemático representativo para o volume total de exposição do fluido à contaminação pode ser definido através da equação:

$$
V_{T}=2 \times \pi \times R \times R a \times 10^{-3} \times \sum_{n_{1}}^{n_{n}}\left(x_{n}-x_{n-1}\right)\left[\mathrm{mm}^{3}\right][\mathrm{Eq} 4]
$$

Portanto, para complementação do desenvolvimento do modelo matemático, faz-se necessário estudar-se o comportamento da taxa de contaminação de fluido ao longo do tempo. 


\subsection{Estudo da Taxa de Contaminação de um Fluido DOT4 Exposto a Ambiente com} Umidade Relativa $81 \%$.

O desenvolvimento de um modelo matemático para a predição do tempo de vida útil de um fluido de freio exposto a um ambiente úmido, requer algumas simulações laboratoriais para a coleta de dados da higroscopia do mesmo. Para tanto, os testes foram realizados de acordo com o procedimento padronizado do fabricante e encontrado no anexo 14.1. deste trabalho. Os resultados são demonstrados nas figuras 57 e 58.

A figura 58 demonstra a taxa de absorção de água ao longo do ensaio possibilitando a continuidade da formulação do modelo matemático.

$$
T=\int_{t_{1}}^{t_{n n}} \int_{S_{1}}^{S_{n n}}\left[\sum_{t_{1}}^{t_{n n}}\left(\frac{t_{n}-t_{n-1}}{t_{n}}\right) \times \sum_{S_{1}}^{S_{n n}}\left(\frac{S_{n}-S_{n-1}}{S_{n}}\right)\right] d t \cdot d s[\mathrm{Eq} 5]
$$

Onde:

$\mathrm{T}=$ Taxa de tempo de versus taxa de absorção de água $[\mathrm{h} * \% \mathrm{vol}]$

$\mathrm{S}_{\mathrm{nn}}=$ Taxa de absorção final de água [\%vol]

$\mathrm{S}_{\mathrm{n}}=$ Taxa de absorção inicial de água [\%vol]

$\mathrm{t}_{1}=$ Tempo inicial do acionamento $[\mathrm{h}]$

$\mathrm{t}_{\mathrm{n}}=$ Tempo final do acionamento $[\mathrm{h}]$

$t_{n n}=$ Taxa de tempo final do estudo $[\mathrm{h}]$

$\mathrm{t}_{\mathrm{n} 1}=$ Taxa de tempo inicial do estudo $[\mathrm{h}]$

Portanto, o volume total de água acumulada ao longo da vida útil do fluido pode ser definida ao introduzir-se o volume total de exposição (eq.4) na equação 5, formando assim a equação 6 como se segue: 
$V_{v}=2 \times \pi \times R \times R a \times 10^{-3} \times \sum_{n 1}^{n_{n}}\left(x_{n}-x_{n-1}\right) \times \int_{t_{1}}^{t_{n n}} \int_{S_{1}}^{S_{n n}}\left[\sum_{t_{1}}^{t_{n n}}\left(\frac{t_{n}-t_{n-1}}{t_{n}}\right) \times \sum_{S_{1}}^{S_{n n}}\left(\frac{S_{n}-S_{n-1}}{S_{n}}\right)\right] d t \cdot d s$

[Eq.6]

Onde:

$\mathrm{Vv}=$ Volume de absorção de água pelo fluido para o número de acionamentos da embreagem (n) e limites de integração da taxa de contaminação final (Sn) definidos no projeto do sistema de freio ou embreagem.

A equação 7 (demonstrada na figura 57) define a curva de tendência do acúmulo de água no fluido ao longo do tempo.

$Y=\left(1,3064 X^{0.7519}\right) \times 10^{-1}[$ Eq. 7$]$

Onde:

$\mathrm{Y}=$ Porcentagem volumétrica acumulada de água durante o ensaio [\%vol]

$\mathrm{X}=$ Tempo acumulado de ensaio $[\mathrm{h}]$

Para a continuação do desenvolvimento matemático, pode-se redefinir a equação como:

$V=\left(1,3064 t^{0.7519}\right) \times 10^{-1}[$ Eq. 8$]$

Onde:

$\mathrm{V}=\mathrm{Y}=$ Porcentagem de volume acumulado de água durante o ensaio [\%vol]

$\mathrm{t}=\mathrm{X}=$ Tempo acumulado de ensaio $[\mathrm{h}]$

A fim de facilitar o desenvolvimento da equação, pode-se assumir a simplificação da equação 6: 
$\mathrm{A}=V_{v}=2 \times \pi \times R \times R a \times 10^{-3} \times \sum_{n 1}^{n_{n}}\left(x_{n}-X_{n-1}\right) \times \int_{t_{1}}^{t_{n n} S_{n n}} \int_{S_{1}}\left[\sum_{t_{1}}^{t_{n n}}\left(\frac{t_{n}-t_{n-1}}{t_{n}}\right) \times \sum_{S_{1}}^{S_{n n}}\left(\frac{S_{n}-S_{n-1}}{S_{n}}\right)\right] d t \cdot d s$ [Eq.9]

A equação simplificadora $\mathrm{Vv}=\mathrm{A}$ pode ser, então, igualada a equação 8:

$$
\begin{aligned}
& A=\left(1,3064 t^{0.7519}\right) \times 10^{-1} \\
& t=\left(\frac{A \times 10}{1,3064}\right) \Rightarrow t=\sqrt[0,7519]{7,654 \times A} \Rightarrow t=14,98 \times \sqrt[0,7519]{A} \quad[\mathrm{~h}] \text { [Eq. 10] }
\end{aligned}
$$

Onde:

$\mathrm{t}$ = Tempo máximo de operação esperado para o fluido dentro das condições definidas por projeto para número de acionamentos, taxa de contaminação e umidade relativa do ar dentro das características do ensaio realizado ( $81 \%$ de umidade).

Portanto, através da equação 10 , pode-se prever a expectativa de vida útil do fluido da embreagem e conseqüentemente o intervalo mínimo de manutenção para o sistema, desde que obedecidas as condições de contorno que foram utilizadas para o desenvolvimento do modelo.

Há de se considerar que o sistema de embreagem é normalmente submetido a variações bruscas de umidade, temperatura e severidade de operação, portanto, o modelo aqui proposto pode ser validado e ajustado posteriormente com as variações operacionais as quais o sistema é submetido. 


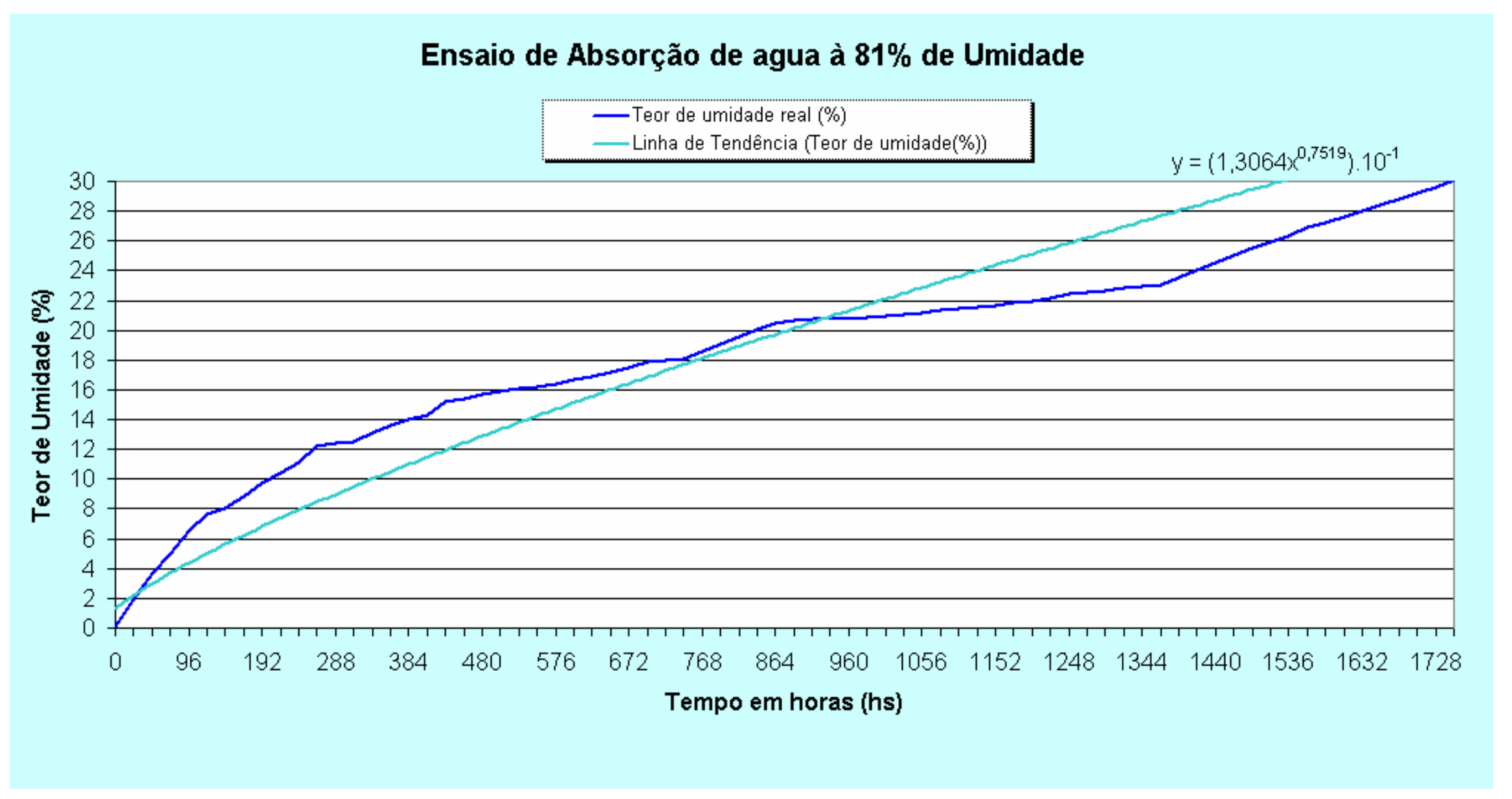

Figura 57 - Curva de absorção de água de um fluido DOT 4 exposto a ambiente com $81 \%$ de umidade relativa 


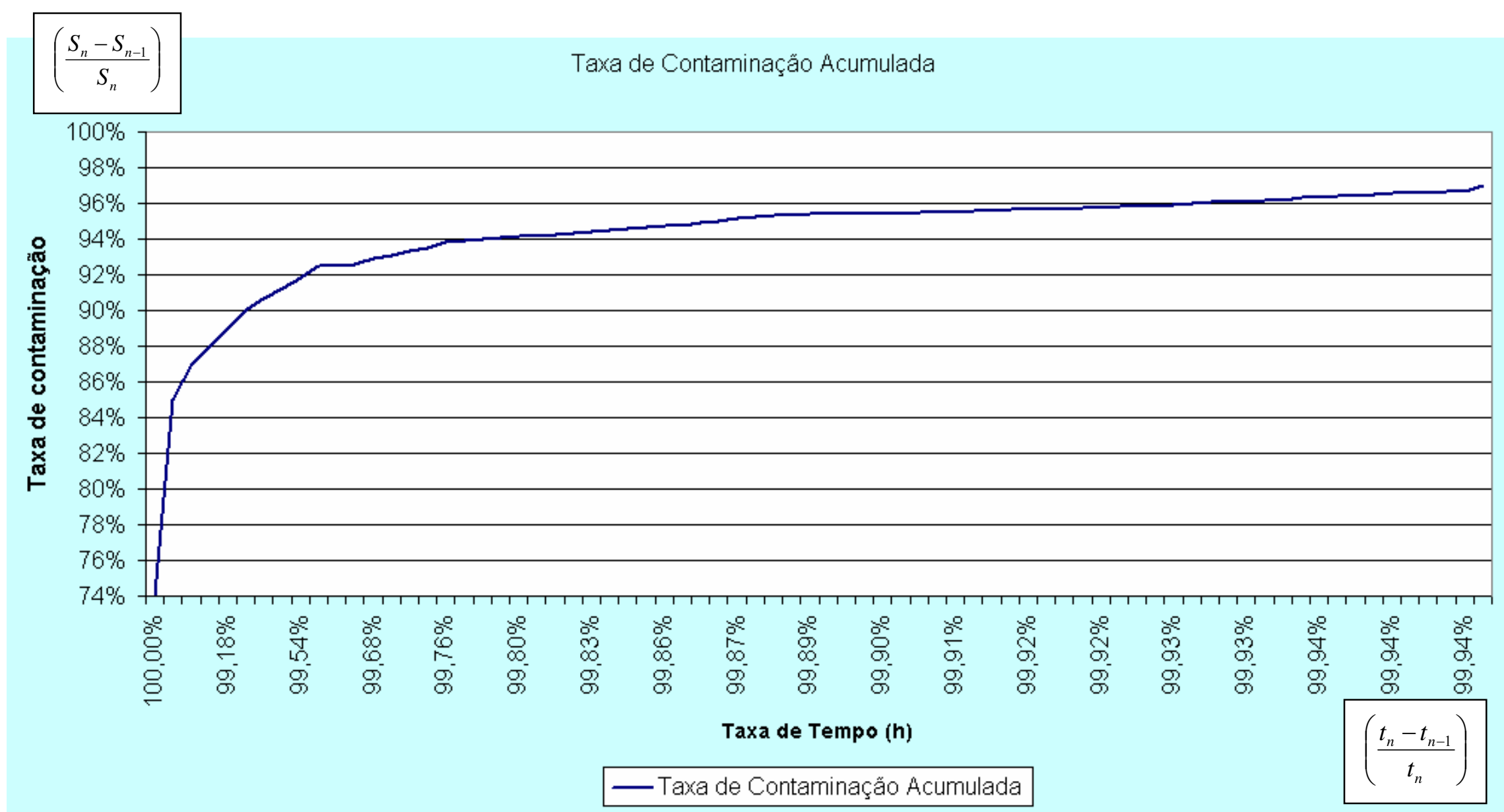

Figura 58 - Curva de taxa de absorção de água por taxa de tempo de um fluido DOT 4 exposto a ambiente com umidade relativa de $81 \%$ 


\section{CONCLUSÕES}

As falhas do sistema de acionamento de embreagem por cilindro escravo concêntrico verificadas no mercado brasileiro são causadas pela exposição deste sistema a vários fatores operacionais em conjunto.

Os anéis de vedação, embora dimensionados apropriadamente para a aplicação, não são capazes de eliminar os resíduos de fluido que permanecem nos vales da superfície rugosa do êmbolo.

Este volume residual de fluido absorve a umidade do ambiente da embreagem quando exposto ao mesmo através dos acionamentos do sistema.

Conforme verificado no transcorrer deste trabalho, a população brasileira de veículos bitrem tem crescido consideravelmente, e conforme mostrado no capítulo 2 , as condições de operação dos veículos comerciais pesados no mercado brasileiro são mais severas do que aquelas encontradas no mercado europeu. Adicionalmente verificou-se que a capacidade máxima de tração para os veículos da versão tratora 4x2 é aumentada para valores limítrofes de resistência para o conjunto de trem de força com a adaptação do terceiro eixo, o que reforça a teoria apresentada quanto ao aumento da severidade de operação.

Os testes de compatibilidade química entre os materiais empregados no sistema não apresentaram nenhuma incompatibilidade para com o fluido, porém verificou-se a contaminação por água em taxas de até $13,7 \%$ nas amostras de fluido coletadas no campo.

Portanto, verifica-se que as falhas do sistema de acionamento da embreagem por cilindro escravo concêntrico ocorreram face à combinação dos seguintes fatores operacionais:

1. Aumento da severidade através do aumento de capacidade de carga, exigindo um maior número de trocas de marchas;

2. Operação dos veículos em ambientes com altas taxas de umidade relativa do ar;

3. Aumento da temperatura no ambiente da embreagem causada por erros de condução do veículo; 
4. Contaminação do fluido por umidade proveniente do ambiente da embreagem, ocasionando a redução da temperatura de ebulição do mesmo.

Referente ao último item, pode-se levantar questionamentos quanto à eficiência do sistema de vedação, no entanto há de se considerar que o mesmo não é capaz de reter totalmente o fluido, mesmo que o êmbolo tenha o "estado da arte" na qualidade da sua rugosidade superficial.

Portanto, como não se pode afirmar de modo conclusivo a existência de uma causa raiz única para as falhas do sistema de acionamento da embreagem por cilindro escravo concêntrico, este trabalho apresenta duas alternativas para a solução deste problema:

1. Proposta de nova solução técnica construtiva com instalação do cilindro escravo fora do ambiente da embreagem;

2. Proposição de um modelo matemático visando determinar o tempo de vida do fluido sob condições operacionais previamente estipuladas para definição de intervalo de troca do mesmo.

O modelo matemático apresentado no capítulo 11 deve ser submetido à validação experimental com posteriores ajustes.

Portanto, verifica-se que o fluido utilizado no acionamento do sistema da embreagem é o componente de maior suscetibilidade a falhas, especialmente pela redução do ponto de ebulição do mesmo causado pelo aumento da taxa de contaminação por água ao longo do tempo de operação.

\subsection{Considerações Finais}

Este trabalho pode trazer desdobramentos científicos que poderão ser futuramente explorados. A primeira opção de linha de pesquisa científica, a qual complementa diretamente este trabalho, pode ser descrita como a validação com posterior ajuste do modelo matemático proposto para a avaliação da taxa de contaminação do fluido por água e o seu conseqüente intervalo mínimo de troca. 
Para aumentar a abrangência deste estudo, pode-se também desenvolver pesquisas adicionais com a exposição do fluido a diferentes porcentagens de umidade relativa do ar.

A segunda linha de pesquisa pode ser aberta através da avaliação da confiabilidade do sistema de acionamento da embreagem por cilindro escravo concêntrico, que pode ser comparada posteriormente com outros conceitos de acionamento de embreagem disponíveis no mercado.

Finalmente, como terceira e última linha de pesquisa apontada neste trabalho, pode-se aplicar o modelo matemático para a determinação do intervalo de troca de fluidos de freio aplicados em sistemas de freio automotivos, para isto, o modelo deverá ser submetido à validação com ajustes posteriores. 


\section{REFERÊNCIAS BIBLIOGRÁFICAS}

ANFIR - ASSOCIAÇÃO NACIONAL DO FABRICANTES DE IMPLEMENTOS RODOVIÁRIOS - Estatísticas de Produção de Implementos Rodoviários, Fevereiro de 2005. Disponível em: < http://www.anfir.org.br>

Acesso em: Fevereiro/2005 - atualizado em 03/03/2006

BARLOW, F. W. Rubber Compounding. $2^{\text {nd }}$ Edition. Marcel Dekker, New York, 75p, 1993.

BASF Brake Fluids Specification, march 2006

Disponível em: $<\underline{\text { http: } / / \text { www.performancechemicals.basf.com }>}$

Acessado em: 02/03/2006

BHUSHAN, B. (2002) Introduction to Tribology. EUA John Wiley \& Sons Inc, 2002. 16p, ISBN 0471158933.

CNT - CONFEDERAÇÃO NACIONAL DO TRANSPORTES - Transdados Indicadores de Transportes, Março 2006.

Disponível em: < http://www.cnt.org.br/cnt/downloads/becnt/becnt_122005.pdf> Acesso em: 02/03/2006

DAER RS - DEPARTAMENTO AUTÔNOMO DE ESTRADAS DE RODAGEM DO RIO GRANDE DO SUL - Autorização especial de Trânsito (AET), Novembro de 2005. Disponível em: < http://www.daer.rs.gov.br>

Acesso em: 02/03/2006

GEFRAN SPA ITALY Products Sensors, march 2006

Disponível em: $<$ http://www.gefran.com/pt/products/product_705.aspx $>$

Acessado em: 24/04/2006 
GUESSER, W. L. et all. Ferros Fundidos Empregados para Discos e Tambores de Freio. Brake Colloquium SAE Brasil, Gramado, RS. 2003.

Disponível em: $<\underline{\text { http://www.tupy.com.br }>}$

Acesso em: 03/03/2006

HADDAD, E.A. Retornos Crescentes, Custos de Transportes e Crescimento Regional. Tese (Livre Docência em Economia), Universidade de São Paulo - Faculdade de Economia, Administração e Contabilidade, São Paulo, 2004.

HEINRICH, J. S.S. Aplicação da Análise de Riscos a Atividades do Transporte Rodoviário de Carga Geral. Dissertação (Mestrado em Engenharia Civil), Universidade Estadual de Campinas, Campinas, 1998.

HEISLER, H. (2002) Advanced Vehicle Technology. 2a. Edição. EUA Saint Louis: Butterworth-Heinemann, 2002. 41p, 54p. ISBN 0750651318.

International Standards and Conformity Assessment for Government, Business and Society for all Electrical, Electronic and Related Technologies, march 2006.

Disponível em: $<$ http://www.iec.ch/>

Acessado em: 24/04/2006

LANG, J. Feeding a Hungry Planet : Rice, Research \& Development in Asia \& Latin America. University of North Carolina: UNC Press, 1996. 119p. ISBN 0807845930 .

MACEDO, P.; et all. Técnicas e Métodos de Investigação em Engenharia Organizacional. Projeto de Investigação em Modelação de Processos de Produção. Instituto Politécnico de Setúbal, Setúbal, Portugal, 2004. Disponível em: $<\mathrm{http}: / /$ www.inesc-id.pt $>$

Acesso em: Março 03/03/2006 
MERCEDES-BENZ DO BRASIL Especificações Técnicas de Veículos Comerciais Pesados, Março 2006. Disponível em: < http://www.mercedes-benz.com.br> Acesso em: 02/03/2006

NATIONAL HIGHWAY TRAFFIC SAFETY ADMINISTRATION (NHTSA - USA), Laboratory Test Procedure for FVMSS 116 Motor Vehicle Brake Fluids, April 22, 2005. Disponível em: $<\underline{\text { http://www.nhtsa.dot.gov }>}$

Acesso em: Março 29/03/2006

SATAS, D. ; et all Coatings Technology Handbook. $2^{\text {nd }}$ edition. Marcel Dekker, New York, 480p., 2000.

SCANIA LATIN AMERICA Especificações Técnicas Cabinas R, Março 2006. Disponível em: $<$ http://www.scania.com.br $>$

Acesso em: 01/03/2006

SCHIPPER, L.; et all Energy Efficiency and Human Activity. England : Cambridge University Press, 1992. 144p, 145p. ISBN 0521432979

SERBINO, E. M. Um estudo dos Mecanismos de Desgaste em Disco de Freio Automotivo Ventilado de Ferro Fundido Cinzento Perlítico com Grafita Lamelar. Dissertação (Mestrado em Engenharia Metalurgica), Escola Politécnica da Universidade de São Paulo, São Paulo, 2005.

SEYMOUR, R. B. Polymeric Composities. VSP, The Netherlands, 91p,118p, 1990.

SILVA, S. S. S. Logística Aplicada a Colheita Mecanizada de Cereais. Dissertação (Mestrado em Agronomia), Universidade de São Paulo - Escola Superior de Agricultura Luiz de Queiroz, Piracicaba, 2004. 
TEIXEIRA, A. R. A Confiabilidade como Fator de Valor na Melhoria de Produtos.

Estudo de Caso: Sistema de Embreagem Automotiva. Dissertação (Mestrado Profissional em Gestão da Qualidade Total), Universidade Estadual de Campinas Unicamp, Campinas, 2004.

VARSANO, R. (1998) “A guerra fiscal do ICMS quem ganha e quem perde” Texto para discussão n`500, Disponível em : <http://www.ipea.gov.br> Acesso em 28/07/2006

VOLVO TRUCKS Especificações Técnicas de Veículos Comerciais Pesados, Março 2006. Disponível em: $<$ http://www.volvo.com/trucks/brazil-market>

Acesso em: 01/03/2006 


\section{ANEXOS}

14.1 Tirreno - Procedimento para Análise de Absorção de Água pelo Fluido para Freio / Embreagem

\begin{tabular}{|c|c|c|c|}
\hline & & Método de Análise & FLU/MA/155 \\
\hline \multirow{3}{*}{ tirreno } & \multirow[t]{3}{*}{ Título } & \multirow{3}{*}{$\begin{array}{c}\text { ABSORÇÄO DE AGUA PELO FLUIDO } \\
\text { PARA FREIOIEMBRAGEM }\end{array}$} & Item Norma: 7.6.3.1 \\
\hline & & & Revisẵo: 00 \\
\hline & & & Página 1 de 2 \\
\hline
\end{tabular}

1. Objetivo:

Descrever o procedimento para determinação da quantidade a água absorvida pelo fluido para freio/embreagem em um ambiente com a umidade relativa do ar controlada em $81 \%$.

2. Norma:

TL 766 (como referência).

\section{Instrumentos:}

3.1. Dessecadores, diâmetro interno $250 \mathrm{~mm}$, com fecho para retirada de prova;

3.2. Placas do dessecador, diâmetro $235 \mathrm{~mm}$;

3.3. Recipientes para ensaio de corrosão SAE RM-49;

3.4. Pipeta de medição com êmbolo de sucção $1 \mathrm{ml}$.

4. Reagentes:

4.1. Sulfato de amônio saturado;

4.2. Água deionizada ou destilada. 


\section{Procedimento:}

O fundo do dessecador é enchido com $425 \mathrm{~g}$ de sulfato de amônio + $150 \mathrm{ml}$ de água destilada.

No recipiente de ensaio de corrosão é colocado $150 \mathrm{ml}$ do fluido para freios a ser testado.

O dessecador é fechado e armazenado em uma estufa apropriada a (50 $+1)^{\circ} \mathrm{C}$.

Deve-se evitar, aqui, a incidência de raios solares.

Após realização do exame, deve-se determinar o comportamento a longo prazo da absorção de água/tempo de armazenamento.

Elaborado por: Joel Lopes de Carvalho Data: 04/04/2006

Função: Enc Lab. Div. Fluidos Área: LPDF
Aprovado por: Rogério P. Silva Data: 04/04/2006

Função: Gerente FLU

Área: FLU 
14.2 Autorização Especial de Trânsito (AET) Distribuído pela Secretaria dos Transportes do Departamento Autônomo de Estradas de Rodagem

\section{SECRETARIA DOS TRANSPORTES DEPARTAMENTO AUTÔNOMO DE ESTRADAS DE RODAGEM DIRETORIA DE OPERAÇÃO E CONCESSÕES}

Autorização Especial de Trânsito -AET's

(atualizada em Novembro-2005)

\section{1 -O QUE É ?}

Autorização Especial de Trânsito -AET, é o documento legal fornecido pela Autoridade de Trânsito, com circunscrição sobre a via, cujo o objetivo é disciplinar a, circulação em rodovias estaduais e rodovias federais delegadas, de veículos destinados ao transporte especial de cargas e excesso de peso e dimensões, previstos no Art. 101 da Lei 9503/97 (CTB). Os excessos aqui referenciados são aqueles que extrapolam o limite máximo admitidos pelo CTB e legislação complementar.

\section{2 -EM QUE RODOVIAS É EXIGIDO PORTAR AET}

É exigido portar AET, fornecido pelo DEPARTAMENTO AUTÔNOMO DE ESTRADAS DE RODAGEM -DAER, os veículos enquadrados no item 4 dessa orientação cujos tipos estão no quadro em anexo, em todas as rodovias com sigla "RS", limitado as restrições do item 8, e nas Rodovias Federais Delegadas da relação abaixo: 


\begin{tabular}{|c|c|c|c|c|c|}
\hline $\mathrm{n}^{\circ}$ & Rodovia & Trecho & Inicio & Fim & $\begin{array}{c}\text { Ext } \\
(\mathbf{k m})\end{array}$ \\
\hline 1 & BR116 & Divisa SC - Vacaria & $\operatorname{Km} 0$ & $\mathrm{Km} \mathrm{41,0}$ & 41,00 \\
\hline 2 & BR116 & Vacaria - Campestre & $\mathrm{Km} \mathrm{41,}$ & $\operatorname{Km} 79,2$ & 38,24 \\
\hline 3 & BR116 & Campestre - Caxias do Sul & $\operatorname{Km~79,2}$ & Km 141 & 62,74 \\
\hline 4 & BR116 & Caxias do Sul - Nova Petrópolis & Km 153,8 & $\mathrm{Km} \mathrm{183,9}$ & 30,10 \\
\hline 5 & BR116 & Guaiba - Camaquã & $\mathrm{Km} \mathrm{301,5}$ & $\mathrm{Km} \mathrm{399,5}$ & 98,00 \\
\hline 6 & BR386 & Carazinho - Tabai & Km 135,0 & $\mathrm{Km} 342$ & 207,00 \\
\hline 7 & BR285 & Vacaria - Lagoa Vermelha & $\mathrm{Km} \mathrm{3,5}$ & Km 62,6 & 59,10 \\
\hline 8 & BR285 & Panambi - Passo Fundo & $\mathrm{Km} \mathrm{283,7}$ & $\mathrm{Km} \mathrm{376,7}$ & 93,00 \\
\hline 9 & BR290 & $\begin{array}{l}\text { EntroncamentoBR290/116(Eldorado) } \\
\text { Entroncamento BR290/153(Cordilheira) }\end{array}$ & $\mathrm{Km} \mathrm{112,3}$ & $\mathrm{Km} \mathrm{463,3}$ & 204,00 \\
\hline 10 & BR153 & $\begin{array}{l}\text { Entroncamento BR153/392(Caçapava) - } \\
\text { Entroncamento BR153/290 }\end{array}$ & $\mathrm{Km} \mathrm{463,8}$ & $\mathrm{Km} \mathrm{489,3}$ & 26,00 \\
\hline 11 & BR471 & Entroncamento BR290 - Sta Cruz do Sul & Km 131,71 & Km 179,37 & 47,66 \\
\hline & & & & Total Geral & 906,84 \\
\hline
\end{tabular}

\section{3 -LEGISLAÇÃO SOBRE AUTORIZAÇÃO ESPECIAL DE TRÂNSITO}

a) Art. 101 da Lei 9503, de 21 de Setembro de 1997(CTB);

b) Resolução n. ${ }^{\circ}$ 12/98 do CONTRAN

c) Resolução $n,{ }^{\circ}$ 68/98 do CONTRAN

d) Resolução n..$^{\circ}$ 75/98 do CONTRAN

e) Resolução n. ${ }^{\circ}$ 76/98 do CONTRAN

f) Portaria n. ${ }^{\circ}$ 12/2002 do DENATRAN

g) Portaria n. ${ }^{\circ}$ 13/2002 do DENATRAN

h) Portaria n. ${ }^{\circ}$ 18/2002 do DENATRAN

i) Decisão Normativa do DAER n. ${ }^{\circ} 01 / 98$

j) Decisão Normativa do DAER n. ${ }^{o}$ 32/02

k)Resolução $n^{\circ}$ 164/04 do CONTRAN

1) Resolução $n^{\circ} 184 / 04$ do CONTRAN

m) Decisão Normativa do DAER n. ${ }^{\circ}$ 39/04

n) Decisão Normativa do DAER n. ${ }^{\circ}$ 41/04 


\section{4 -QUEM DEVE PORTAR A AUTORIZAÇÃO ESPECIAL DE TRÂNSITO}

Os veículos ou Combinações de Veículos de Carga -CVC's abaixo relacionados, devem, obrigatoriamente, portar a Autorização Especial de Trânsito -AET, quando transitarem em rodovias sob jurisdição do DAER /RS:

a) Veículos transportadores de carga onde a mesma exceder a altura de 4,40m ou exceder a largura de 2,20m do veículo, mas com PBTC até 45 toneladas;

b) Veículo de Carga ou Combinações de Veículo de Carga, para Cargas Divisíveis, cujo PBTC fique entre 45 toneladas e 57 toneladas; (excluído pela resolução 184/05 do CONTRAN)

c) Veículo de Carga ou Combinações de Veículo de Carga, para Cargas Divisíveis, cujo PBTC fique entre 57 toneladas e 74 toneladas;

d) Veículos de Carga ou Combinações de Veículos de Carga, para Cargas Divisíveis e Indivisíveis, cujo PBTC ultrapasse as 74 toneladas;

e) Guindastes com PBTC acima de 45 toneladas;

\section{5 -REQUERIMENTO DA AUTORIZAÇÃO ESPECIAL DE TRÂNSITO -AET}

Os veículos acima relacionados, podem requerer a Autorização Especial de Transito, preenchendo o requerimento "Requisição de Autorização Especial de Transito", obtido na Sede do DAER, em Porto Alegre, ou consultando o Site do DAER no endereço www.daer.rs.gov.br, ou clicando na linha anterior.

Os veículos de carga que se enquadram na letra "a" do item 3 anterior podem protocolar as solicitações nos Distritos Operacionais do DAER, nas localidades abaixo relacionadas, e obter no próprio distrito a AET, após o pagamento das respectivas taxas. Na letra "c" e "d" e "e" do item 3 anterior devem protocolar seus requerimentos no Protocolo Geral do DAER, em Porto Alegre, com a antecedência e anexando a documentação definida nas normas do DAER, e retirar no mesmo local a AET, após pagamento das respectivas taxas.

O requerimento deve ser preenchido com todas as informações solicitadas no documento e protocolado nos locais abaixo relacionados. 
6 -LOCAIS PARA PROTOCOLAR O REQUERIMENTO E OBTER A AUTORIZAÇÃO

a) em Porto Alegre -Av. Borges de Medeiros, $15551^{\circ}$ Andar Protocolo Geral;

b) em Esteio -Av Padre Claret, 1453 Bairro Centro fone (51)-473-4500

c) em Bento Gonçalves -Rua Eugênio Valduga, 103 Bairro São Francisco , Fone (54) 452-1911

d) em Santa Cruz do Sul -Av João Pessoa, 13 Bairro Centro Fone (51)-3711-2014

e) em Santa Maria -Av Medianeira, 1685 Bairro Centro Fone (55) 221-3375

f) em Cruz Alta -Rua Presidente Vargas, 577, Bairro Centro, Fone (55)-3322-6550

g) em Passo Fundo -Av Presidente Vargas, 255, Bairro Centro, Fone (54)-311-4343

h) em Pelotas -Rua João Simões Neto, 2273, Bairro Fragata, Fone (53)-271-3200

i) em Bagé -Rua Nei Ribeiro Flores, 861, Bairro Loteamento São Pedro, fone (53)-2428566

j) em Alegrete -Av Assis Brasil, 960, Bairro Cidade Baixa, Fone (55)-422-4744

k) em Cachoeira do Sul -Av. Brasil, 700, Bairro Centro, Fone (51)-722-2088

1) em Lajeado -Av Benjamim Constante, 1256, Bairro Centro, Fone (51)-3748-4044

m) em Santiago -Rua Pinheiro Machado, 1193, Bairro Centro, Fone (55) 252-1178

n) em Erechim -Av 7 de Setembo, 1107, Bairro Centro, Fone (54)-321-1270

o) em Santa Rosa -Rua das Missões, 70, Bairro Centro, Fone (55)-512-5575

p) em São Francisco de Paula -Rua Curupaiti, 1378, Bairro Cipó, Fone (54)-244-1117

q) em Osório -Rua Ildenfonso Simões Lopes, 960, Bairro Sulbrasileiro, fone (51)-6631635 r) em Palmeira as Missões -Rua Dari Kurtz, 215, Bairro Vista Alegre, Fone (55)$3742-2036$ 
7 -VALOR DAS TAXAS PARA OBTENÇÃO DA AET

\begin{tabular}{|l|c|l|}
\hline & $\begin{array}{c}\text { Taxa } \\
\text { Administrativa }\end{array}$ & $\begin{array}{l}\text { Taxa de } \\
\text { Utilização } \\
\text { da Via }\end{array}$ \\
\hline Excesso de altura ou largura & $25,38 / m e s$ & Isento \\
\hline $\begin{array}{l}\text { Carga de até } 57 \text { toneladas de } \\
\text { PBTC }\end{array}$ & $25,38 /$ mes & Isento \\
\hline $\begin{array}{l}\text { Carga de } 57 \text { até } 74 \text { toneladas de } \\
\text { PBTC }\end{array}$ & $25,38 /$ mes & $\begin{array}{l}\text { Valor } \\
\text { conforme } \\
\text { tabela }\end{array}$ \\
\hline Acima de 74 toneladas de PBTC & $25,38 /$ Viagem & $\begin{array}{l}\text { Valor } \\
\text { conforme } \\
\text { tabela }\end{array}$ \\
\hline
\end{tabular}

-Taxa Administrativa são custos para o fornecimento da AET;-TUV, Taxa de Utilização da Via, Calculando sobre o excesso de carga acima de 45 toneladas.

\section{8 -RESTRIÇÃO DE TRÁFEGO}

O Tráfego de veículos de carga ou Combinações de Veículos de Carga, estarão sujeitas a restrições de circulação nos trechos relacionados na "Relação de trechos Restritos a Circulação" , conforme definição pelo DAER.

A circulação noturna nas rodovias só é permitida para veículos com até 57 toneladas de PBTC e com até 7 (sete) eixos, sem qualquer restrição.

\section{9 -PENALIDADES PELO TRANSITO SEM PORTAR AET DAS} TRANSGRESSÕES E PENALIDADES

(transcrito da Decisão Normativa n. ${ }^{0}$ 32/02 do DAER)

Art. 23 -Aos infratores da presente Decisão Normativa serão aplicadas as seguintes penalidades, assegurando ao infrator amplo direito de defesa;

a) -Advertência verbal ou por escrito;

b) -Multa;

c) -Suspensão de concessão da Autorização Especial de Trânsito -AET, pelo prazo de 3 (três) meses; 
d) -Suspensão de concessão da Autorização Especial de Trânsito -AET, pelo prazo de 6 (seis) meses;

e) -Declaração de inidoneidade da empresa transportadora ou transportador autônomo, com o conseqüente

cancelamento definitivo do direito de pleitear Autorização Especial de Trânsito -AET, e revogação das que

houverem sido concedidas; Art. 24 -Qualquer veículo que transporte carga excedente aos limites legais de peso e/ou dimensões, sem a Autorização Especial de Trânsito -AET, será multado e, se o excesso ultrapassar às tolerâncias legais máximas para o transporte normal (Res. 12/98 CONTRAN), o mesmo será retido, e o prosseguimento da viagem somente será permitido após a regularização da carga e a concessão da competente AET. Parágrafo único: Se não for possível a regularização da carga ou a concessão de Autorização Especial de Trânsito -AET,

o veículo, além de multado, será escoltado pela Polícia Rodoviária Estadual, até o ponto em que teve acesso à Rodovia, ou à cidade mais próxima, cobrando-se a Tarifa de Escolta e comunicando a irregularidade à Diretoria de Operação e Concessões do DAER/RS.

Art. 25 -O veículo de transporte de carga que apresente qualquer característica própria de sua carga ou do itinerário, em

desacordo com o constante na Autorização Especial de Trânsito -AET , deverá ser retido e multado, sendo permitido o

prosseguimento da viagem, somente após sanada a irregularidade e concedida uma nova AET.

$\S 1^{\circ}$-No caso de ocorrência de infração prevista neste artigo, as multas sobre excesso de peso, de dimensões e alterações de itinerário, serão referidos aos limites constantes da Autorização Especial de Trânsito -AET inicial.

$\S 2^{\circ}$-A multa por excesso de peso será a prevista no Art. 231, inciso V, da Lei 9.503/97 (CTB).

$\S 3^{0}$-A infração aos excessos de dimensões constante da Autorização Especial de Trânsito -AET, inicialmente concedida será punida com multa nos termos do Art. 231, inciso VI, da Lei 9.503/97 (CTB). 
$\S 4^{\mathrm{o}}$-A alteração de itinerário para o qual foi concedida a Autorização Especial de Trânsito -AET, será punida com a multa.

$\S 5^{\circ}$-Quando o infrator praticar, simultaneamente, 2 (duas) ou mais infrações, ser-lhe-ão aplicadas, cumulativamente, as penalidades a elas cominadas.

\section{0 -OUTRAS INFORMAÇÕES}

Outras informações podem ser obtidas no telefone (51) 3210-5074

Atualizada em Novembro de 2005 , pela Divisão de Transito do DAER/RS

Quadro de tipos de Caminhões que necessitam AET's para transitar em rodovias sob Jurisdição do DAER 


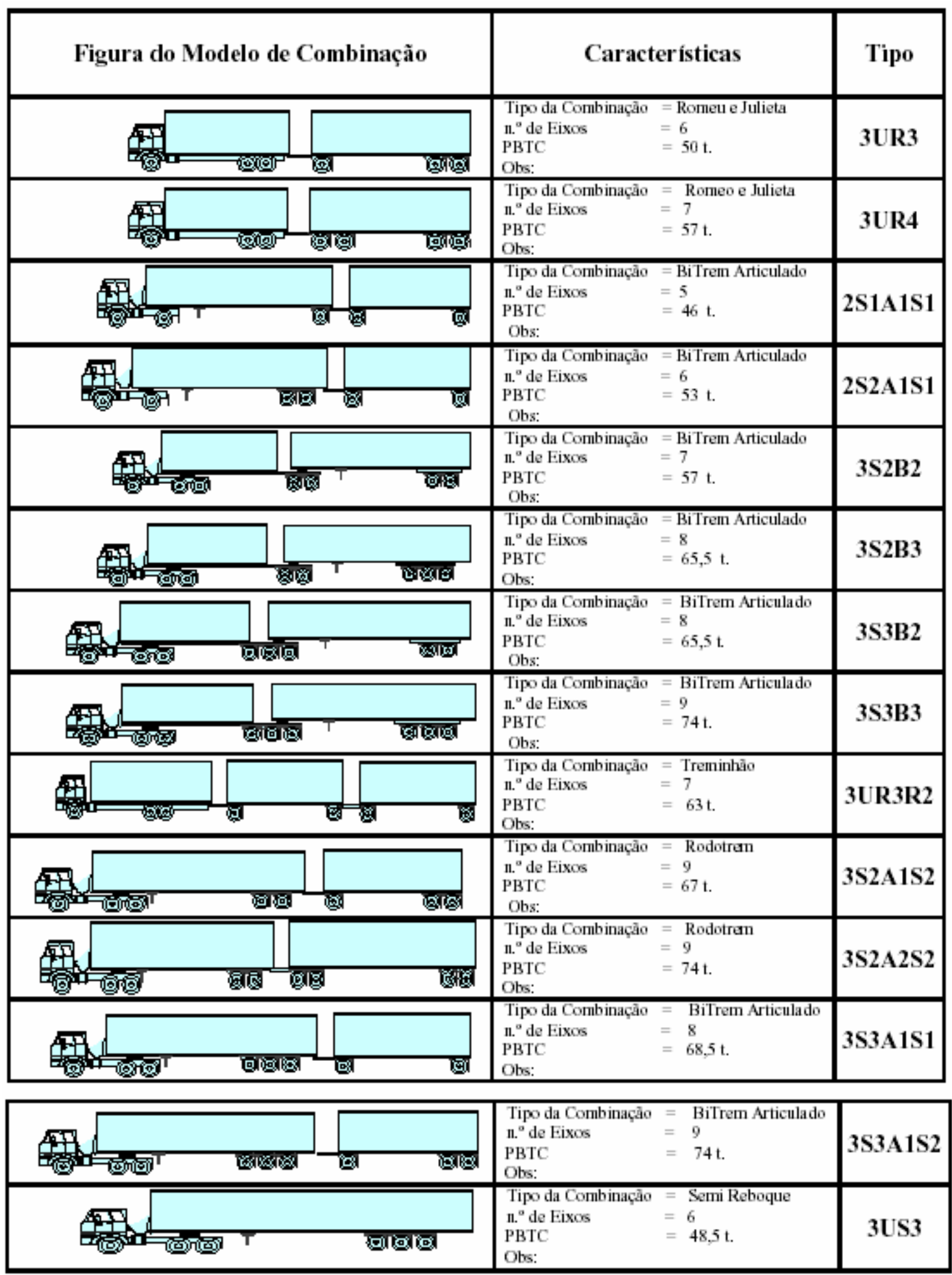


14.3 U.S. Department of Transportation - Laboratory Test Procedure for FMVSS 116 - Motor Vehicle Brake Fluids

TP-116-04

April 22, 2005

\title{
U.S. DEPARTMENT OF TRANSPORTATION
}

\author{
NATIONAL HIGHWAY TRAFFIC SAFETY \\ ADMINISTRATION
}

LABORATORY TEST PROCEDURE

FOR

FMVSS 116

Motor Vehicle Brake Fluids

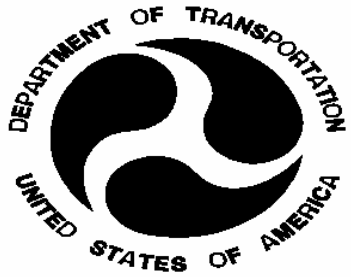

ENFORCEMENT

Office of Vehicle Safety Compliance

Room 6115, NVS-222

400 Seventh Street, SW

Washington, DC 20590 
OVSC LABORATORY TEST PROCEDURE NO. 116

\section{TABLE OF CONTENTS}

PAGE

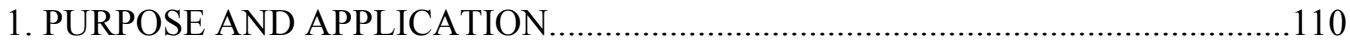

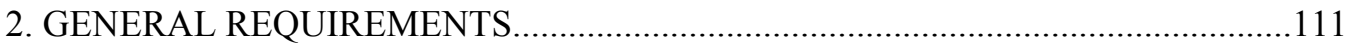

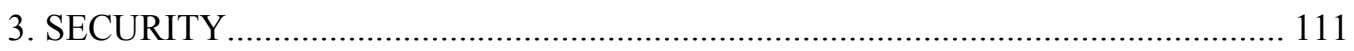

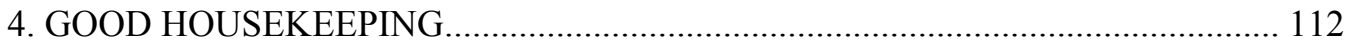

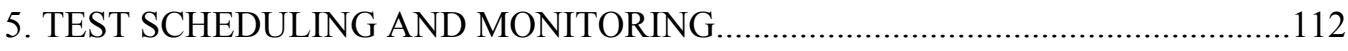

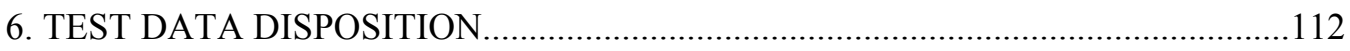

7. GOVERNMENT FURNISHED PROPERTY (GFP) _.................................................113

8. CALIBRATION OF TEST INSTRUMENTS...........................................................113

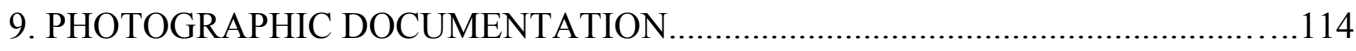

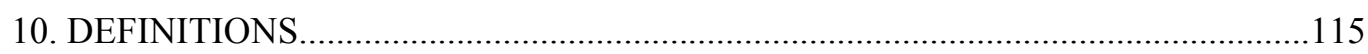

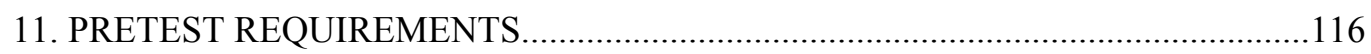

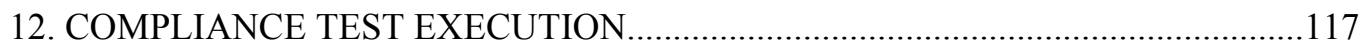

13. POST TEST

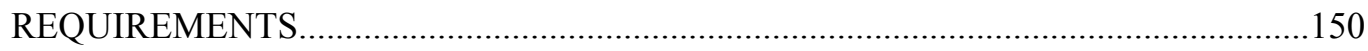

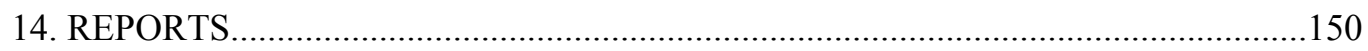

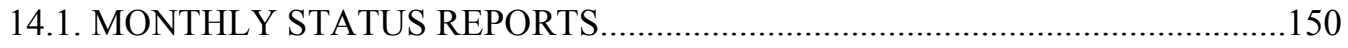

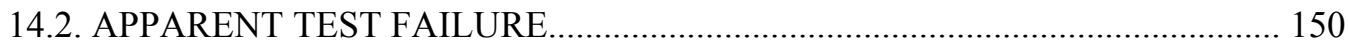

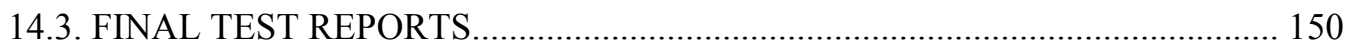

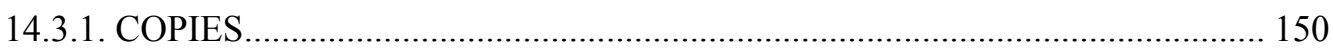

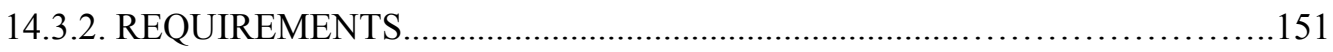

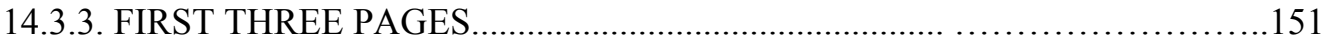

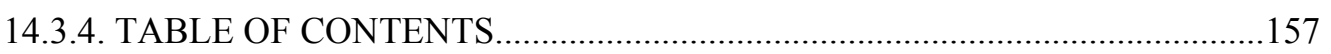

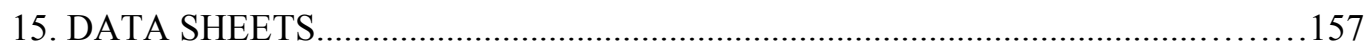


16. FORMS.

\section{REVISION CONTROL LOG \\ FOR OVSC LABORATORY \\ TEST PROCEDURES}

TP-116

Motor Vehicle Brake Fluids

\begin{tabular}{|c|c|c|c|c|}
\hline \multicolumn{2}{|c|}{ TEST PROCEDURE } & \multicolumn{2}{|c|}{ FMVSS 116} & \multirow[b]{2}{*}{ DESCRIPTION } \\
\hline $\begin{array}{l}\text { REV. } \\
\text { No. }\end{array}$ & DATE & AMENDMENT & $\begin{array}{l}\text { EFFECTIVE } \\
\text { DATE }\end{array}$ & \\
\hline 00 & & & & Original Issue \\
\hline 01 & & & & \\
\hline 02 & & & & \\
\hline 03 & & & & \\
\hline 04 & $\begin{array}{c}\text { April 22, } \\
2005\end{array}$ & 69 FR 67654 & $\begin{array}{l}\text { Jan. } 18,2005 \\
\text { Nov. } 21,2005\end{array}$ & $\begin{array}{l}\text { Deletion of evaporation test. } \\
\text { Modification of corrosion test. }\end{array}$ \\
\hline 05 & & & & \\
\hline 06 & & & & \\
\hline 07 & & & & \\
\hline 08 & & & & \\
\hline 09 & & & & \\
\hline 10 & & & & \\
\hline
\end{tabular}




\section{PURPOSE AND APPLICATION}

The Office of Vehicle Safety Compliance (OVSC) provides contracted laboratories with Laboratory Test Procedures (TPs) which serve as guidelines for obtaining compliance test data. The data are used to determine if a specific vehicle or item of motor vehicle equipment meets the minimum performance requirements of the subject Federal Motor Vehicle Safety Standard (FMVSS). The purpose of the OVSC Laboratory Test Procedures is to present a uniform testing and data recording format, and provide suggestions for the use of specific equipment and procedures. Any contractor interpreting any part of an OVSC Laboratory Test Procedure to be in conflict with a Federal Motor Vehicle Safety Standard or observing any deficiencies in a Laboratory Test Procedure is required to advise the Contracting Officer's Technical Representative (COTR) and resolve the discrepancy prior to the start of compliance testing.

Contractors are required to submit a detailed test procedure to the COTR before initiating the compliance test program. The procedure must include a step-bystep description of the methodology to be used.

The OVSC Laboratory Test Procedures are not intended to limit or restrain a contractor from developing or utilizing any testing techniques or equipment which will assist in procuring the required compliance test data.

\section{NOTE:}

The OVSC Laboratory Test Procedures, prepared for use by independent laboratories under contract to conduct compliance tests for the OVSC, are not intended to limit the requirements of the applicable FMVSS(s). In some cases, the OVSC Laboratory Test Procedures do not include all of the various FMVSS minimum performance requirements. Sometimes, recognizing applicable test tolerances, the Test Procedures specify test conditions which are less severe than the minimum requirements of the standards themselves. Therefore, compliance of a vehicle or item of motor vehicle equipment is not necessarily guaranteed if the manufacturer limits certification tests to those described in the OVSC Laboratory Test Procedures. 


\section{GENERAL REQUIREMENTS}

FMVSS 116 specifies requirements for fluids for use in hydraulic brake systems of motor vehicles, containers for these fluids, and labeling of the containers.

The purpose of FMVSS 116 is to reduce failures in the hydraulic braking systems of motor vehicles which may occur because of the manufacture or use of improper or contaminated fluid.

The standard applies to all fluid for use in hydraulic brake systems of passenger cars, multipurpose passenger vehicles, trucks, buses, trailers, and motorcycles which are equipped with a hydraulic brake system. The fluid for use in the referenced vehicle shall have been manufactured and packaged in conformity with the requirements of FMVSS 116. The tests which are contained within this test procedure are used to determine compliance with the specified requirements. These tests are as follows:

A. Equilibrium Reflux Boiling Point (ERBP)

B. Wet ERBP

C. Kinematic Viscosity

D. Ph Value

E. Fluid Stability

F. Corrosion

G. Fluidity and Appearance (Low Temperature)

H. Water Tolerance

I. Compatibility

J. Resistance to Oxidation

K. Effect on SBR Cups

L. Stroking Properties (This test is only conducted when specifically specified in the contract)

M. Container Information

\section{SECURITY}

The contractor shall provide appropriate security measures to protect the OVSC test equipment from unauthorized personnel during the entire compliance testing program. The contractor is financially responsible for any acts of theft and/or vandalism which occur during the storage of test equipment. Any security problems which arise shall be reported by telephone to the Industrial Property Manager (IPM), Office of Contracts and Procurement, within two working days after the incident. A letter containing specific details of the security problem will be sent to the IPM (with copy to the COTR) within 48 hours.

The contractor shall protect and segregate the data that evolves from compliance testing before and after each test. No information concerning the safety compliance testing program shall be released to anyone except the 
COTR, unless specifically authorized by the COTR, the COTR's Branch or Division Chief, or by the Contracting Officer.

\section{NO INDIVIDUALS, OTHER THAN CONTRACTOR PERSONNEL, SHALL BE ALLOWED TO WITNESS ANY COMPLIANCE TEST UNLESS SPECIFICALLY AUTHORIZED BY THE COTR.}

\section{GOOD HOUSEKEEPING}

Contractors shall maintain the entire equipment compliance testing area, test fixtures and instrumentation in a neat and clean condition with test instruments arranged in an orderly manner consistent with good test laboratory housekeeping practices.

\section{TEST SCHEDULING AND MONITORING}

The contractor shall submit a test schedule to the COTR prior to testing. Tests shall be completed as required in the contract. All testing shall be coordinated to allow monitoring by the COTR.

\section{TEST DATA DISPOSITION}

The contractor shall make all equipment preliminary compliance test data available to the COTR on location within four hours after the test. Final test data, including digital printouts and computer generated plots (if applicable), shall be furnished to the COTR in accordance with the contract schedule.

All backup data sheets, strip charts, recordings, plots, technicians notes, etc., shall be retained by the contractor for a minimum of five years after conclusion of each delivery order, purchase order, etc. The COTR shall direct final disposition at that time. 


\section{GOVERNMENT FURNISHED PROPERTY (GFP) AND TEST SAMPLES}

\section{TEST SAMPLE IDENTIFICATION AND STORAGE}

Upon receipt at the laboratory, the items to be tested shall be assigned laboratory serial numbers.

\section{EXAMPLE:}

Brand X Heavy Duty Brake Fluid; Lab Group \#00X

An inventory shall be made of the number, name and condition of samples received.

The test samples shall be stored in a dry and clean area specifically designated by the Laboratory Project Manager.

\section{CALIBRATION OF TEST INSTRUMENTS}

Before the contractor initiates the safety compliance test program, a test instrumentation calibration system will be implemented and maintained in accordance with established calibration practices. Guidelines for setting up and maintaining such calibration systems are described in MIL-C-45662A, "Calibration System Requirements". The calibration system shall be set up and maintained as follows: 


\section{CALIBRATION....Continued}

A. Standards for calibrating the measuring and test equipment will be stored and used under appropriate environmental conditions to assure their accuracy and stability.

B. All measuring instruments and standards shall be calibrated by the contractor, or a commercial facility, against a higher order standard at periodic intervals NOT TO EXCEED TWELVE (12) MONTHS except for static types of measuring devices such as rulers, weights, etc., which shall be calibrated at periodic intervals not to exceed two years. Records, showing the calibration traceability to the National Institute of Standards and Technology (NIST), shall be maintained for all measuring and test equipment.

C. All measuring and test equipment and measuring standards will be labeled with the following information:

(1) Date of calibration

(2) Date of next scheduled calibration

D. A written calibration procedure shall be provided by the contractor

which includes as a minimum the following information for all measurement and test equipment unless the calibration is performed by a licensed commercial facility.

(1) Type of equipment, manufacturer, model number, etc.

(2) Measurement range

(3) Accuracy

(4) Calibration interval

(5) Type of standard used to calibrate the equipment (calibration traceability of the standard must be evident)

E. Records of calibration for all test instrumentation shall be kept by the contractor in a manner which assures the maintenance of established calibration schedules. All such records shall be readily available for inspection when requested by the COTR. The calibration system will need the acceptance of the COTR before the test program commences.

\section{PHOTOGRAPHIC DOCUMENTATION}

Each final test report shall include glossy photographs (minimum size 4 x 6 inches) of the test setup used for each phase of testing. One set of original photographs shall be included in the final test report which will be used for optical scanning by the OVSC. Other copies of the final test report may contain multilith or other suitable photographic copies of the original photographs. 


\section{DEFINITIONS}

\section{BLISTER}

Cavity or sac on the surface of a brake cup.

\section{BRAKE FLUID}

Liquid designed for use in a motor vehicle hydraulic brake system in which it will contact elastomeric components made of styrene and butadiene rubber (SBR), ethylene and propylene rubber (EPR), polychloroprene (CR) brake hose inner tube stock or natural rubber (NR).

\section{CHIPPING}

Condition in which small pieces are missing from the outer surface of a brake cup.

\section{DUPLICATE SAMPLES}

Two samples of brake fluid taken from a single packaged lot and tested simultaneously.

\section{HYDRAULIC SYSTEM MINERAL OIL}

Mineral-oil-based fluid designed for use in motor vehicle hydraulic brake systems in which the fluid is not in contact with components made of SBR, EPR or NR.

\section{PACKAGED LOT}

That quantity of brake fluid shipped by the manufacturer to the packager in a single container, or that quantity of brake fluid manufactured by a single plant run of 24 hours or less, through the same processing equipment and with no change in ingredients.

\section{PACKAGER}

Person who fills containers with brake fluid that are distributed for retail sale.

\section{SCUFFING}

Visible erosion of a portion of the outer surface of a brake cup. 


\section{SILICONE BASE BRAKE FLUID (SBBF)}

A brake fluid which consists of not less than 70 percent by weight of a diorgano polysiloxane.

\section{SLOUGHING}

Degradation of a brake cup as evidenced by the presence of carbon black loosely held on the brake cup surface, such that a visible black streak is produced when the

cup, with a $500 \forall 10$ gram dead weight on it, is drawn base down over a sheet of white bond paper placed on a firm flat surface.

\section{STICKINESS}

Condition on the surface of a brake cup such that fibers will be pulled from a wad of U.S.P. absorbent cotton when it is drawn across the surface.

\section{PRETEST REQUIREMENTS}

\section{IN-HOUSE TEST PROCEDURE}

Prior to conducting any compliance test, contractors are required to submit a detailed in-house compliance test procedure to the COTR which includes a step-by-step description of the methodology to be used. Written approval must be obtained from the COTR before initiating the compliance test program so that all parties are in agreement.

\section{TEST DATA LOSS}

A compliance test is not to be conducted unless all of the various test conditions specified in the applicable OVSC Laboratory Test Procedure have been met. Failure of a contractor to obtain the required test data and to maintain acceptable limits on test parameters in the manner outlined in the applicable OVSC Laboratory Test Procedure may require a retest at the expense of the contractor. The retest costs will include the cost of the replacement brake fluid and all costs associated with conducting the retest.

The Contracting Officer of NHTSA is the only NHTSA official authorized to notify the contractor that a retest is required. The retest shall be completed within two (2) weeks after receipt of notification by the Contracting Officer that a retest is required. If a retest is conducted, no test report is required for the original test. 


\section{TEST CONDITIONS}

Unless otherwise specified, all tests and measurements shall be conducted under the following environmental conditions:
A. Temperature $75 \mathrm{EF} \forall 15 \mathrm{EF}$
B. Relative Humidity $50 \% \forall 10 \%$
C. Atmospheric Pressure 28 to 32 inches of mercury

Continuous recording of environmental temperature and relative humidity of the testing area shall be available during all tests. Test samples, unless otherwise specified, shall be stabilized at test room conditions for a period of at least 24 hours immediately prior to testing.

\section{TEST PERSONNEL PERFORMANCE}

Personnel supervising and/or performing the compliance test program shall be thoroughly familiar with the requirements, test conditions, equipment for the test to be conducted, and safety requirements.

\section{RECORDING OF TEST DATA}

Environmental data and test data shall be recorded on permanent strip charts, circular recording charts, or other acceptable print-out media. Where permanent trace recording is not required, data will be recorded on standard report forms. Changes or corrections shall be made by drawing a line through the original entry, which must still remain legible, and adding the change alongside.

Test data will be submitted on the standard form Test Data Sheets specified for use in the final test report and shown in Section 15. Data will be typed before the sheets are submitted. If stroking test is conducted, Data Sheet No. 3 shall be used.

\section{COMPLIANCE TEST EXECUTION}

\section{TEST QUANTITIES}

The amount of brake fluid required for one complete test group is shown below:

TEST QUANT.

6.1 Equilibrium Reflux Boiling Point (ERBP) $125 \mathrm{ml}$

6.2 Wet ERBP $205 \mathrm{ml}$

6.3 Kinematic Viscosity $120 \mathrm{ml}$

$6.4 \mathrm{pH}$ Value $55 \mathrm{ml}$

6.5 Fluid Stability $125 \mathrm{ml}$ 
6.6 Corrosion $1520 \mathrm{ml}$

6.7 Fluidity \& Appearance (Low Temp.) $205 \mathrm{ml}$

6.8 Water Tolerance $105 \mathrm{ml}$

6.9 Compatibility $55 \mathrm{ml}$

6.10 Resistance to Oxidation $65 \mathrm{ml}$

6.11 Effect on SBR Cups $150 \mathrm{ml}$

6.12 Stroking Properties $3785 \mathrm{ml}$

6.13 Container Information $348 \mathrm{ml}$

Reserve $2850 \mathrm{ml}$

TOTAL $9713 \mathrm{ml}(328 \mathrm{oz})$

\section{TEST REQUIREMENTS}

The fluid samples shall meet specific requirements when tested in accordance with the procedures in FMVSS 116.

6.1 Equilibrium reflux boiling point. Determine the ERBP of a brake fluid by running duplicate samples according to the following procedure and averaging the results.

6.1.1 Summary of procedure. Sixty milliliters (ml.) of brake fluid are boiled under specified equilibrium conditions (reflux) at atmospheric pressure in a $100-\mathrm{ml}$. flask. The average temperature of the boiling fluid at the end of the reflux period, corrected for variations in barometric pressure if necessary, is the ERBP.

6.1.2 Apparatus. (See Figure 1) The test apparatus shall consist of - (a) Flask. (See Figure 2) A 100-ml. round-bottom, short-neck heat-resistant glass flask having a neck with a 19.38 standard taper, female groundglass joint and a side-entering tube, with an outside diameter of 10 millimeters $(\mathrm{mm}$.), which centers the thermometer bulb in the flask $6.5 \mathrm{~mm}$. from the bottom; (b) Condenser. A water-cooled, reflux, glass-tube type, condenser having a jacket $200 \mathrm{~mm}$. in length, the bottom end of which has a 19.38 standard-taper, driptip, male ground-glass joint; (c) Boiling stones. Three clean, unused silicon carbide grains (approximately $2 \mathrm{~mm}$. (0.08 inch) in diameter, grit No. 8); (d) Thermometer. Standardized calibrated partial immersion $(76 \mathrm{~mm}$.), solid stem, thermometers conforming to the requirements for an ASTM $2 \mathrm{C}$ or $2 \mathrm{~F}$, and an ASTM 3C or 3F thermometer; and (e) Heat source. Variable autotransformer-controlled heating mantle designed to fit the flask, or an electric heater with rheostat heat control.

6.1.3 Preparation of apparatus. (a) Thoroughly clean and dry all glassware. (b) Insert thermometer through the side tube until the tip of the bulb is $6.5 \mathrm{~mm}$. (1.4 inch) from the bottom center of the flask. Seal with a short piece of natural rubber, EPDM, SBR, or butyl tubing. (c) Place $60 \pm 1 \mathrm{ml}$. of brake fluid and the silicon carbide grains into the flask. (d) Attach the flask to the condenser. When using a heating mantle, place the mantle under the flask and 


\section{COMPLIANCE....Continued}

support it with a ring-clamp and laboratory-type stand, holding the entire assembly in place by a clamp. When using a rheostat- controlled heater, center a standard porcelain or hard asbestos refractory, having a diameter opening 32 to $38 \mathrm{~mm}$., over the heating element and mount the flask so that direct heat is applied only through the opening in the refractory. Place the assembly in an area free from drafts or other types of sudden temperature changes. Connect the cooling water inlet and outlet tubes to the condenser. Turn on the cooling water. The water supply temperature shall not exceed 28 ${ }^{\circ} \mathrm{C}$. $\left(82.4^{\circ} \mathrm{F}\right.$.) and the temperature rise through the condenser shall not exceed $2{ }^{\circ} \mathrm{C} .\left(3.6^{\circ} \mathrm{F}.\right)$.

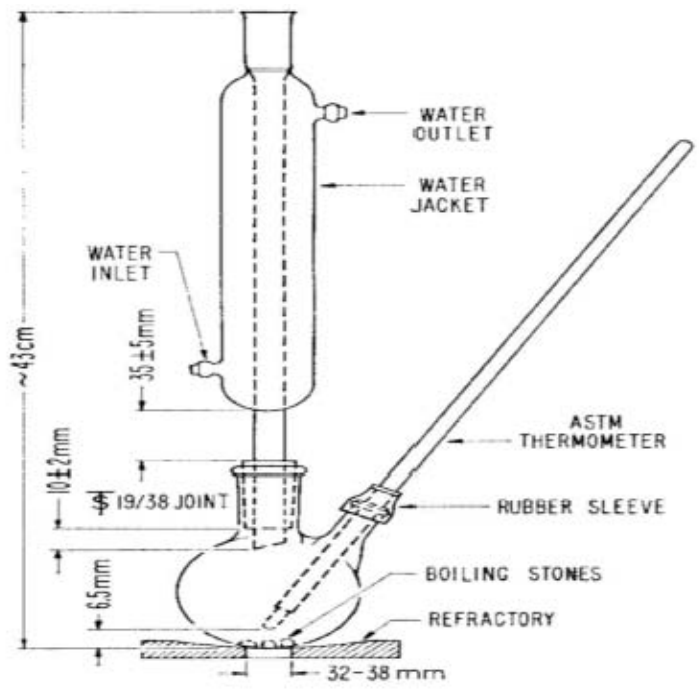

FG. 1. BOIUNG PONT TEST AFPARATUS

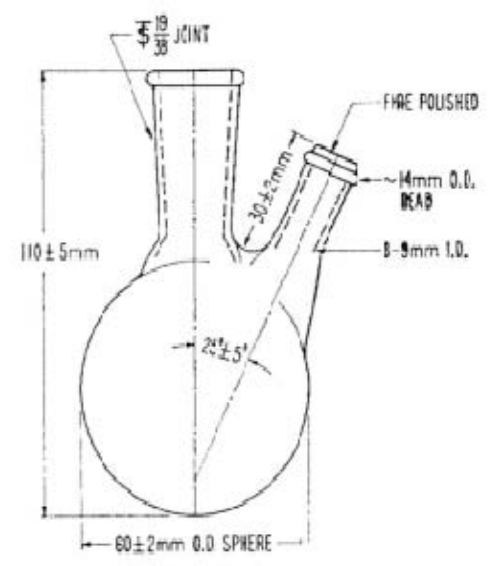

FIG. 2. DETAIL OF $100 \mathrm{M}$ GORT-NECKRASK 


\section{COMPLIANCE....Continued}

6.1.4 Procedure. Apply heat to the flask so that within $10 \pm 2$ minutes the fluid is refluxing in excess of 1 drop per second. The reflux rate shall not exceed 5 drops per second at any time. Immediately adjust the heating rate to obtain an equilibrium reflux rate of 1 to 2 drops per second over the next $5 \pm 2$ minutes. Maintain this rate for an additional 2 minutes, taking four temperature readings at 30-second intervals. Record the average of these as the observed ERBP. If no reflux is evident when the fluid temperature reaches $260{ }^{\circ} \mathrm{C}(500$ $\left.{ }^{\circ} \mathrm{F}\right)$, discontinue heating and report ERBP as in excess of $260^{\circ} \mathrm{C}\left(500^{\circ} \mathrm{F}\right)$.

6.1.5 Calculation. (a) Thermometer inaccuracy. Correct the observed ERBP by applying any correction factor obtained in standardizing the thermometer. (b) Variation from standard barometric pressure. Apply the factor shown in Table I to calculate the barometric pressure correction to the ERBP.

(c) If the two corrected observed ERBP's agree within $2{ }^{\circ} \mathrm{C}$. $\left(4{ }^{\circ} \mathrm{C}\right.$. for brake fluids having an ERBP over $230{ }^{\circ} \mathrm{C} . / 446^{\circ} \mathrm{F}$.) average the duplicate runs as the ERBP; otherwise, repeat the entire test, averaging the four corrected observed values to determine the original ERBP.

Table I - Correction for Barometric Pressure

\begin{tabular}{|l|l|l|}
\hline \multirow{2}{*}{$\begin{array}{l}\text { Observed ERBP corrected for thermometer } \\
\text { inaccuracy }\end{array}$} & \multicolumn{2}{|l|}{$\begin{array}{l}\text { Correction per } 1 \mathrm{~mm} \text { difference in } \\
\text { pressure }\end{array}$} \\
\cline { 2 - 3 } & ${ }^{\circ} \mathrm{C}$. & ${ }^{\circ} \mathrm{F}$. \\
\hline $100^{\circ} \mathrm{C} .\left(212^{\circ} \mathrm{F}.\right)$ to $190^{\circ} \mathrm{C} .\left(374^{\circ} \mathrm{F}.\right)$ & 0.039 & $(0.07)$ \\
\hline Over $190^{\circ} \mathrm{C} .\left(374{ }^{\circ} \mathrm{F}.\right)$ & 0.04 & $(0.08)$ \\
\hline
\end{tabular}

${ }^{3}$ To be added in case barometric pressure is below $760 \mathrm{~mm}$.; to be subtracted in case barometric pressure is above $670 \mathrm{~mm}$.

6.1.6 Pass/Fail Criteria. The ERBP shall not be less than the following value for the grade indicated: (a) DOT 3: $205^{\circ} \mathrm{C}$. $\left(401{ }^{\circ} \mathrm{F}\right.$.). (b) DOT 4: $230{ }^{\circ} \mathrm{C}$. $\left(446^{\circ} \mathrm{F}\right.$.). (c) DOT 5: $260^{\circ} \mathrm{C}$. $\left(500^{\circ} \mathrm{F}\right.$.).

6.2 Wet ERBP. Determine the wet ERBP of a brake fluid by running duplicate samples according to the following procedure.

6.2.1. Summary of procedure. A $350 \mathrm{ml}$. sample of the brake fluid is humidified under controlled conditions; $350 \mathrm{ml}$. of SAE triethylene glycol monomethyl ether, brake fluid grade, referee material (TEGME) as described in appendix E of SAE Standard J1703 Nov. 83, "Motor Vehicle Brake Fluid,' November 1983, is used to establish the end point for humidification. After humidification, the water content and ERBP of the brake fluid are determined. 


\section{COMPLIANCE....Continued}

6.2.2 Apparatus for humidification. (See Figure 3). Test apparatus shall consist of - (a) Glass jars. Four SAE RM-49 corrosion test jars or equivalent screwtop, straight-sided, round glass jars each having a capacity of about 475 $\mathrm{ml}$. and approximate inner dimensions of $100 \mathrm{~mm}$. in height by $75 \mathrm{~mm}$. in diameter, with matching lids having new, clean inserts providing water-vaporproof seals; (b) Desiccator and cover. Two bowlform glass desiccators, 250$\mathrm{mm}$. inside diameter, having matching tabulated covers fitted with No. 8 rubber stoppers; and (c) Desiccator plate. Two 230-mm. diameter, perforated porcelain desiccator plates, without feet, glazed on one side.

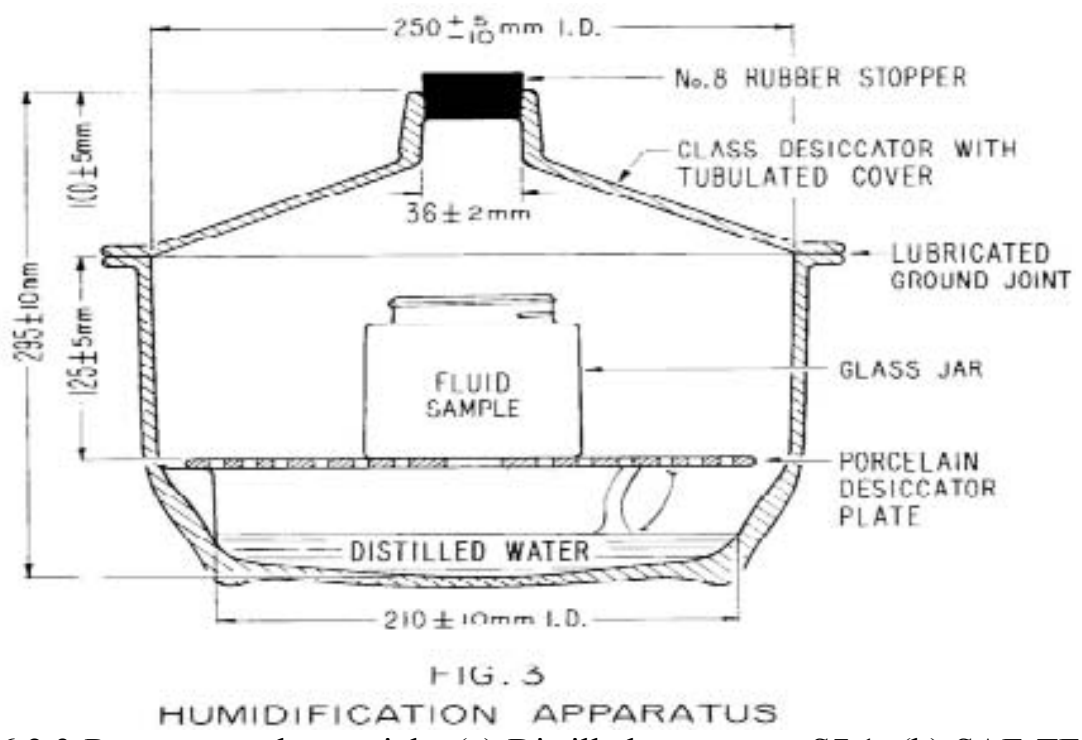

6.2.3 Reagents and materials. (a) Distilled water, see S7.1. (b) SAE TEGME referee material.

6.2.4 Preparation of apparatus. Lubricate the ground-glass joint of the desiccator. Pour $450 \pm 10 \mathrm{ml}$. of distilled water into each desiccator and insert perforated porcelain desiccator plates. Place the desiccators in an oven with temperature controlled at $50 \pm 1{ }^{\circ} \mathrm{C} . \quad\left(122 \pm 1.8{ }^{\circ} \mathrm{F}\right.$. $)$ throughout the humidification procedure.

6.2.5 Procedure. Pour $350 \pm 5 \mathrm{ml}$. of brake fluid into an open corrosion test jar. Prepare in the same manner a duplicate test fluid sample and two duplicate specimens of the SAE TEGME referee material $(350 \pm 5 \mathrm{ml}$. of TEGME in each jar). The water content of the SAE TEGME fluid is adjusted to 


\section{COMPLIANCE....Continued}

$0.50 \pm 0.05$ percent by weight at the start of the test in accordance with S7.2. Place one sample each of the test brake fluid and the prepared TEGME sample into the same desiccator. Repeat for the second sample of test brake fluid and TEGME in a second desiccator. Place the desiccators in the $50{ }^{\circ} \mathrm{C}$. $\left(122{ }^{\circ} \mathrm{F}\right.$.) controlled oven and replace desiccator covers. At intervals, during oven humidification, remove the rubber stoppers in the tops of desiccators. Using a long needled hypodermic syringe, take a sample of not more than 2 $\mathrm{ml}$. from each TEGME sample and determine its water content. Remove no more than $10 \mathrm{ml}$. of fluid from each SAE TEGME sample during the humidification procedure. When the water content of the SAE fluid reaches $3.70 \pm 0.05$ percent by weight (average of the duplicates). remove the two test fluid specimens from their desiccators and promptly cap each jar tightly. Allow the sealed jars to cool for 60 to 90 minutes at $23^{\circ} \pm 5^{\circ} \mathrm{C}$. $\left(73.4^{\circ} \pm 9^{\circ} \mathrm{F}\right.$.). Measure the water contents of the test fluid specimens in accordance with S7.2 and determine their ERBP's in accordance with S6.1. If the two ERBPs agree within $4{ }^{\circ} \mathrm{C}$. $\left(8^{\circ} \mathrm{F}\right.$.), average them to determine the wet ERBP; otherwise repeat and average the four individual ERBPs as the wet ERBP of the brake fluid.

6.2.6 Pass/Fail Criteria. The wet ERBP shall not be less than the following value for the grade indicated: (a) DOT 3: $140{ }^{\circ} \mathrm{C}$. $\left(284^{\circ} \mathrm{F}\right.$.). (b) DOT 4: 155 ${ }^{\circ} \mathrm{C}$. $\left(311^{\circ} \mathrm{F}\right.$.). (c) DOT 5: $1180^{\circ} \mathrm{C}$. $\left(356^{\circ} \mathrm{F}\right.$.).

6.3 Kinematic viscosities. Determine the kinematic viscosity of a brake fluid in $\mathrm{mm} 2 / \mathrm{s}$ by the following procedure. Run duplicate samples at each of the specified temperatures, making two timed runs on each sample.

6.3.1 Summary of the procedure. The time is measured for a fixed volume of the brake fluid to flow through a calibrated glass capillary viscometer under an accurately reproducible head and at a closely controlled temperature. The kinematic viscosity is then calculated from the measured flow time and the calibration constant of the viscometer.

6.3.2 Apparatus. (a) Viscometers. Calibrated glass capillary- type viscometers, ASTM D2515- 66, "Standard Specification for Kinematic Glass Viscometers," measuring viscosity within the precision limits of S6.4.7. Use suspended level viscometers for viscosity measurements at low temperatures. Use Cannon-Fenske Routine or other modified Ostwald viscometers at ambient temperatures and above. (b) Viscometer holders and frames. Mount a viscometer in the constanttemperature bath so that the mounting tube is held within 1. of the vertical. (c) Viscometer bath. A transparent liquid bath of sufficient depth such that at no time during the measurement will any portion of the sample in the viscometer be less than $2 \mathrm{~cm}$. below the surface or less than $2 \mathrm{~cm}$. above the bottom. The bath shall be cylindrical in shape, with turbulent agitation sufficient to meet the temperature control requirements. For measurements within $15^{\circ}$, to $100^{\circ} \mathrm{C}$. $\left(60^{\circ}\right.$ to $212^{\circ} \mathrm{F}$.) the temperature of the 


\section{COMPLIANCE....Continued}

bath medium shall not vary by more than $0.01{ }^{\circ} \mathrm{C}$. $\left(0.02{ }^{\circ} \mathrm{F}\right.$.) over the length of the viscometers, or between the positions of the viscometers, or at the locations of the thermometers. Outside this range, the variation shall not exceed $0.03{ }^{\circ} \mathrm{C}$. $\left(0.05{ }^{\circ} \mathrm{F}\right.$.). (d) Thermometers. Liquid-in-Glass Kinematic Viscosity Test Thermometers, covering the range of test temperatures indicated in Table II and conforming to ASTM E1-68, "Specifications for ASTM Thermometers," and in the IP requirements for IP Standard Thermometers. Standardize before use (see S6.3.3(b)). Use two standardized thermometers in the bath.

Table II - Kinematic Viscocity Thermometers

\begin{tabular}{|l|l|l|l|l|l|l|l|}
\hline \multicolumn{2}{|c|}{} & \multicolumn{2}{|c|}{ For tests at } & \multicolumn{2}{c|}{ Subdivisions } & \multicolumn{2}{l|}{ Thermometer Number } \\
\hline${ }^{\circ} \mathrm{C}$. & ${ }^{\circ} \mathrm{F}$. & ${ }^{\circ} \mathrm{C}$. & ${ }^{\circ} \mathrm{F}$. & ${ }^{\circ} \mathrm{C}$. & ${ }^{\circ} \mathrm{F}$. & ASTM & IP \\
\hline $\begin{array}{l}\text { Minus } 55.3 \text { to } \\
\text { minus } 52.5\end{array}$ & $\begin{array}{l}\text { Minus } 67.5 \text { to minus } \\
62.5\end{array}$ & Minus 55 & Minus 67 & 0.05 & 0.1 & $74 \mathrm{~F}$ & $69 \mathrm{~F}$. or $\mathrm{C}$. \\
\hline $\begin{array}{l}\text { Minus } 41.4 \text { to } \\
\text { minus } 38.6\end{array}$ & $\begin{array}{l}\text { Minus } 42.5 \text { to minus } \\
37.5\end{array}$ & Minus 40 & Minus 40 & 0.05 & 0.1 & $73 \mathrm{~F}$ & $68 \mathrm{~F}$. or $\mathrm{C}$. \\
\hline 98.6 to 101.4 & 207.5 to 212.5 & 100 & 212 & 0.05 & 0.1 & $30 \mathrm{~F}$ & $32 \mathrm{~F}$. or $\mathrm{C}$. \\
\hline
\end{tabular}

(e) Timing device. Stop watch or other timing device graduated in divisions representing not more than 0.2 second, with an accuracy of at least \pm 0.05 percent when tested over intervals of 15 minutes. Electrical timing devices may be used when the current frequency is controlled to an accuracy of 0.01 percent or better.

6.3.3 Standardization. (a) Viscometers. Use viscometers calibrated in accordance with appendix 1 of ASTM D445-65, "Viscosity of Transparent and Opaque Liquids (Kinematic and Dynamic Viscosities)." The calibration constant, $\mathrm{C}$, is dependent upon the gravitational acceleration at the place of calibration. This must, therefore, be supplied by the standardization laboratory together with the instrument constant. Where the acceleration of gravity, $g$, in the two locations differs by more than 0.1 percent, correct the calibration constant as follows:

$$
\mathrm{C}_{2}=\left(\mathrm{g}_{2} / \mathrm{g}_{1}\right) * \mathrm{C}_{1}
$$

where the subscripts 1 and 2 indicate respectively the standardization laboratory and the testing laboratory. (b) Thermometers. Check liquid-inglass thermometers to the nearest $0.01{ }^{\circ} \mathrm{C} .\left(0.02{ }^{\circ} \mathrm{F}\right.$.) by direct comparison with a standardized thermometer. Kinematic Viscosity Test Thermometers shall be standardized at "total immersion." The ice point of standardized thermometers shall be determined before use and the official corrections shall be adjusted to conform to the changes in ice points. (See ASTM E77-66, "Verification and Calibration of Liquid-in-Glass Thermometers.") (c) Timers. Time signals are broadcast by the National Bureau of Standards, 


\section{COMPLIANCE....Continued}

Station WWV, Washington, DC at 2.5, 5, 10, 15, 20, 25, 30, and $35 \mathrm{Mc} / \mathrm{sec}$ $(\mathrm{MHz})$. Time signals are also broadcast by Station CHU from Ottawa, Canada, at 3.330, 7.335, and $14.670 \mathrm{Mc} / \mathrm{sec}$, and Station MSF at Rugby, United Kingdom, at 2.5, 5, and $10 \mathrm{Mc} / \mathrm{sec}$.

6.3.4 Procedure. (a) Set and maintain the bath at the appropriate test temperature (see S5.1.3) within the limits specified in S6.3.2(c). Apply the necessary corrections, if any, to all thermometer readings. (b) Select a clean, dry, calibrated viscometer giving a flow time not less than its specified minimum, or 200 seconds, whichever is the greater. (c) Charge the viscometer in the manner used when the instrument was calibrated. Do not filter or dry the brake fluid, but protect it from contamination by dirt and moisture during filling and measurements. (1) Charge the suspended level viscometers by tilting about $30^{\circ}$. from the vertical and pouring sufficient brake fluid through the fill tube into the lower reservoir so that when the viscometer is returned to vertical position the meniscus is between the fill marks. For measurements below $0{ }^{\circ} \mathrm{C}$. $\left(32{ }^{\circ} \mathrm{F}\right.$.), before placing the filled viscometer into the constant temperature bath, draw the sample into the working capillary and timing bulb and insert small rubber stoppers to suspend the fluid in this position, to prevent accumulation of water condensate on the walls of the critical portions of the viscometer. Alternatively, fit loosely packed drying tubes into the open ends of the viscometer to prevent water condensation, but do not restrict the flow of the sample under test by the pressures created in the instrument. (2) If a Cannon-Fenske Routine viscometer is used, charge by inverting and immersing the smaller arm into the brake fluid and applying vacuum to the larger arm. Fill the tube to the upper timing mark, and return the viscometer to an upright position. (d) Mount the viscometer in the bath in a true vertical position (see S6.3.2(b)). (e) The viscometer shall remain in the bath until it reaches the test temperature. (f) At temperatures below $0{ }^{\circ} \mathrm{C}$. $\left(32^{\circ} \mathrm{F}\right.$.) conduct an untimed preliminary run by allowing the brake fluid to drain through the capillary into the lower reservoir after the test temperature has been established. (g) Adjust the head level of the brake fluid to a position in the capillary arm about $5 \mathrm{~mm}$. above the first timing mark. (h) With brake fluid flowing freely measure to within 0.2 second the time required for the meniscus to pass from the first timing mark to the second. If this flow time is less than the minimum specified for the viscometer, or 200 seconds, whichever is greater, repeat using a viscometer with a capillary of smaller diameter. (i) Repeat S6.3.4 (g) and (h). If the two timed runs do not agree within 0.2 percent, reject and repeat using a fresh sample of brake fluid.

6.3.5 Cleaning the viscometers. (a) Periodically clean the instrument with chromic acid to remove organic deposits. Rinse thoroughly with distilled water and acetone, and dry with clean dry air. (b) Between successive samples rinse the viscometer with ethanol (isopropanol when testing DOT 5 fluids) followed by an acetone or ether rinse. Pass a slow stream of filtered dry air through the viscometer until the last trace of solvent is removed. 


\section{COMPLIANCE....Continued}

6.3.6 Calculation. (a) The following viscometers have a fixed volume charged at ambient temperature, and as a consequence $\mathrm{C}$ varies with test temperature: Cannon-Fenske Routine, Pinkevitch, Cannon-Manning Semi- Micro, and Cannon Fenske Opaque. To calculate $\mathrm{C}$ at test temperatures other than the calibration temperature for these viscometers, see ASTM D2515-66, "Kinematic Glass Viscometers" or follow instructions given on the manufacturer's certificate of calibration. (b) Average the four timed runs on the duplicate samples to determine the kinematic viscosities.

6.3.7 Precision (at 95 percent confidence level). (a) Repeatability. If results on duplicate samples by the same operator differ by more than 1 percent of their mean, repeat the tests.

6.3.8. Pass/Fail Criteria. The kinematic viscosities in square millimeters per second at stated temperatures shall be neither less than $1.5 \mathrm{~mm} 2 / \mathrm{s}$ at $100{ }^{\circ} \mathrm{C}$. $\left(212^{\circ} \mathrm{F}\right.$.) nor more than the following maximum value for the grade indicated: (a) DOT 3: $1,500 \mathrm{~mm} 2 / \mathrm{s}$ at minus $40^{\circ} \mathrm{C}$. (minus $40{ }^{\circ} \mathrm{F}$.). (b) DOT 4: 1,800 $\mathrm{mm} 2 / \mathrm{s}$ at minus $40{ }^{\circ} \mathrm{C}$. (minus $40{ }^{\circ} \mathrm{F}$.). (c) DOT 5: $900 \mathrm{~mm} 2 / \mathrm{s}$ at minus 40 ${ }^{\circ} \mathrm{C}$. (minus $40^{\circ} \mathrm{F}$.).

$6.4 \mathrm{pH}$ value. Determine the $\mathrm{pH}$ value of a brake fluid by running one sample according to the following procedure.

6.4.1 Summary of the procedure. Brake fluid is diluted with an equal volume of an ethanol-water solution. The $\mathrm{pH}$ of the resultant mixture is measured with a prescribed $\mathrm{pH}$ meter assembly at $23{ }^{\circ} \mathrm{C}$. $\left(73.4^{\circ} \mathrm{F}\right.$.).

6.4.2 Apparatus. The $\mathrm{pH}$ assembly consists of the $\mathrm{pH}$ meter, glass electrode, and calomel electrode, as specified in Appendices A1.1, A1.2, and A1.3 of ASTM D 1121-67, "Standard Method of Test for Reserve Alkalinity of Engine Antifreezes and Antirusts." The glass electrode is a full range type (pH 0-14), with low sodium error.

6.4.3 Reagents. Reagent grade chemicals conforming to the specifications of the Committee on Analytical Reagents of the American Chemical Society. (a) Distilled water. Distilled water (S7.1) shall be boiled for about 15 minutes to remove carbon dioxide, and protected with a soda-lime tube or its equivalent while cooling and in storage. (Take precautions to prevent contamination by the materials used for protection against carbon dioxide.) The $\mathrm{pH}$ of the boiled distilled water shall be between 6.2 and 7.2 at $25^{\circ} \mathrm{C}$. ( $\left(77^{\circ} \mathrm{F}\right.$.). (b) Standard buffer solutions. Prepare buffer solutions for calibrating the $\mathrm{pH}$ meter and electrode pair from salts sold specifically for use, either singly or in combination, as $\mathrm{pH}$ standards. Dry salts for 1 hour at $110^{\circ} \mathrm{C}$. $\left(230^{\circ} \mathrm{F}\right.$.) before use except for borax which shall be used as the decahydrate. Store solutions with $\mathrm{pH}$ less than 9.5 in bottles of chemically resistant glass or polyethylene. Store the alkaline phosphate solution in a glass bottle coated inside with paraffin. Do not use a standard with an age exceeding three months. 


\section{COMPLIANCE....Continued}

(1) Potassium hydrogen phthalate buffer solution $\left(0.05 \mathrm{M}, \mathrm{pH}=4.01\right.$ at $25{ }^{\circ} \mathrm{C}$. $\left(77^{\circ} \mathrm{F}\right.$.)). Dissolve $10.21 \mathrm{~g}$. of potassium hydrogen phthalate (KHC8 H4 O4) in distilled water. Dilute to 1 liter. (2) Neutral phosphate buffer solution $\left(0.025 \mathrm{M}\right.$ with respect to each phosphate salt, $\mathrm{pH}=6.86$ at $25^{\circ} \mathrm{C}$. $\left(77^{\circ} \mathrm{F}\right.$.)). Dissolve $3.40 \mathrm{~g}$. of potassium dihydrogen phosphate (KH2 PO4) and $3.55 \mathrm{~g}$. of anhydrous disodium hydrogen phosphate (Na2 HPO4) in distilled water. (3) Borax buffer solution $\left(0.01 \mathrm{M}, \mathrm{pH}=9.18\right.$ at $25^{\circ} \mathrm{C}$. $\left(77^{\circ} \mathrm{F}\right.$. $)$ ). Dissolve 3.81 g. of disodium tetraborate decahydrate $\left(\mathrm{Na} 2 \mathrm{~B} 4 \mathrm{O} 7^{\circ} 10 \mathrm{H} 2 \mathrm{O}\right)$ in distilled water, and dilute to 1 liter. Stopper the bottle except when actually in use. (4) Alkaline phosphate buffer solution (0.01 M trisodium phosphate, $\mathrm{pH}=11.72$ at $25^{\circ} \mathrm{C}$. $\left(77^{\circ} \mathrm{F}\right.$.)). Dissolve 1.42 g. of anhydrous disodium hydrogen phosphate (Na2 HPO4) in $100 \mathrm{ml}$. of a $0.1 \mathrm{M}$ carbonate-free solution of sodium hydroxide. Dilute to 1 liter with distilled water. (5) Potassium chloride electrolyte. Prepare a saturated solution of potassium chloride $(\mathrm{KCl})$ in distilled water. (c) Ethanol-water mixture. To 80 parts by volume of ethanol (S7.3) add 20 parts by volume of distilled water. Adjust the $\mathrm{pH}$ of the mixture to $7 \pm 0.1$ using $0.1 \mathrm{~N}$ sodium hydroxide $(\mathrm{NaOH})$ solution. If more than $4 \mathrm{ml}$. of $\mathrm{NaOH}$ solution per liter of mixture is required for neutralization, discard the mixture.

6.4.4 Preparation of electrode system. (a) Maintenance of electrodes. Clean the glass electrode before using by immersing in cold chromic-acid cleaning solution. Drain the calomel electrode and fill with $\mathrm{KCl}$ electrolyte, keeping level above that of the mixture at all times. When not in use, immerse the lower halves of the electrodes in distilled water, and do not immerse in the mixture for any appreciable period of time between determinations. (b) Preparation of electrodes. Condition new glass electrodes and those that have been stored dry as recommended by the manufacturer. Before and after using, wipe the glass electrode thoroughly with a clean cloth, or a soft absorbent tissue, and rinse with distilled water. Before each $\mathrm{pH}$ determination, soak the prepared electrode in distilled water for at least 2 minutes. Immediately before use, remove any excess water from the tips of the electrode.

6.4.5 Standardization of the $\mathrm{pH}$ assembly and testing of the electrodes. (a) Immediately before use, standardize the $\mathrm{pH}$ assembly with a standard buffer solution. Then use a second standard buffer solution to check the linearity of the response of the electrodes at different $\mathrm{pH}$ values, and to detect a faulty glass electrode or incorrect temperature compensation. The two buffer solutions bracket the anticipated $\mathrm{pH}$ value of the test brake fluid. (b) Allow instrument to warm up, and adjust according to the manufacturer's instructions. Immerse the tips of the electrodes in a standard buffer solution and allow 


\section{COMPLIANCE....Continued}

the temperature of the buffer solution and the electrodes to equalize. Set the temperature knob at the temperature of the buffer solution. Adjust the standardization or asymmetry potential control until the meter registers a scale reading, in $\mathrm{pH}$ units, equal to the known $\mathrm{pH}$ of the standardizing buffer solution. (c) Rinse the electrodes with distilled water and remove excess water from the tips. Immerse the electrodes in a second standard buffer solution. The reading of the meter shall agree with the known $\mathrm{pH}$ of the second standard buffer solution within \pm 0.05 unit without changing the setting of the standardization of asymmetry potential control. (d) A faulty electrode is indicated by failure to obtain a correct value for the $\mathrm{pH}$ of the second standard buffer solution after the meter has been standardized with the first.

6.4.6 Procedure. To $50 \pm 1 \mathrm{ml}$. of the test brake fluid add $50 \pm 1 \mathrm{ml}$. of the ethanol- water $(6.4 .3(\mathrm{c}))$ and mix thoroughly. Immerse the electrodes in the mixture. Allow the system to come to equilibrium, readjust the temperature compensation if necessary, and take the $\mathrm{pH}$ reading.

6.4.6 Pass/Fail Criteria. The $\mathrm{pH}$ value shall not be less than 7.0 nor more than 11.5 (except DOT $5 \mathrm{SBBF}$ ).

6.5 Fluid stability. Evaluate the heat and chemical stability of a brake fluid by the following procedure, running duplicate samples for each test and averaging the results.

6.5.1 Summary of the procedure. The degradation of the brake fluid at elevated temperature, alone or in a mixture with a reference fluid, is evaluated by determining the change in boiling point after a period of heating under reflux conditions.

6.5.2 Apparatus. Use the apparatus and preparation specified in S6.1.2 and S6.1.3.

6.5.3 High temperature stability.

6.5.3.1 Procedure. (a) Heat a new $60 \pm 1 \mathrm{ml}$. sample of the brake fluid to $185^{\circ} \pm 2{ }^{\circ} \mathrm{C}$. $\left(365^{\circ} \pm 3.6^{\circ} \mathrm{F}\right.$.). Hold at this temperature for $120 \pm 5$ minutes. Bring to a reflux rate in excess of 1 drop per second within 5 minutes. The reflux rate should not exceed 5 drops per second at any time. Over the next $5 \pm 2$ minutes adjust the heating rate to obtain an equilibrium reflux rate of 1 to 2 drops per second. Maintain this rate for an additional 2 minutes, taking four temperature readings at 30-second intervals. Average these as the observed ERBP. If no reflux is evident when the fluid temperature reaches $260^{\circ} \mathrm{C}$. $(500$ $\left.{ }^{\circ} \mathrm{F}\right)$, discontinue heating and report ERBP as in excess of $260^{\circ} \mathrm{C}$. $\left(500{ }^{\circ} \mathrm{F}\right.$.).

6.5.3.2 Calculation. Correct the observed ERBP for thermometer and barometric pressure factors according to $\mathrm{S6.1.5}$ (a) and (b). Average the 


\section{COMPLIANCE....Continued}

corrected ERBP's of the duplicate samples. The difference between this average and the original ERBP obtained in S6.1 is the change in ERBP of the fluid.

\subsubsection{Chemical stability.}

6.5.4.1 Materials. SAE RM-66-04 Compatibility Fluid as described in appendix B of

SAE Standard J1703 JAN 1995, "Motor Vehicle Brake Fluid." (SAE RM66-03 Compatibility Fluid as described in appendix A of SAE Standard J1703 Nov83, "Motor Vehicle Brake Fluid," November 1983, may be used in place of SAE RM-66-04 until January 1, 1995.)

6.5.4.2 Procedure. (a) Mix $30 \pm 1 \mathrm{ml}$. of the brake fluid with $30 \pm 1 \mathrm{ml}$. of SAE RM-66-04 Compatibility Fluid in a boiling point flask (S6.1.2(a)). Determine the initial ERBP of the mixture by applying heat to the flask so that the fluid is refluxing in $10 \pm 2$ minutes at a rate in excess of 1 drop per second, but not more than 5 drops per second. Note the maximum fluid temperature observed during the first minute after the fluid begins refluxing at a rate in excess of 1 drop per second. Over the next $15 \pm 1$ minutes, adjust and maintain the reflux rate at 1 to 2 drops per second. Maintain this rate for an additional 2 minutes, recording the average value of four temperature readings taken at 30 second intervals as the final ERBP. (b) Thermometer and barometric corrections are not required.

6.5.4.3 Calculation. The difference between the initial ERBP and the final average temperature is the change in temperature of the refluxing mixture. Average the results of the duplicates to the nearest $0.5^{\circ} \mathrm{C}\left(1.0^{\circ} \mathrm{F}\right)$.

\subsubsection{Pass/Fail Criteria.}

6.5.5.1 High-temperature stability. When brake fluid is tested according to S6.5.3 the ERBP shall not change by more than $3{ }^{\circ} \mathrm{C}$. $\left(5.4^{\circ} \mathrm{F}\right.$.) plus $0.05^{\circ}$. for each degree that the ERBP of the fluid exceeds $225^{\circ} \mathrm{C}$. $\left(437^{\circ} \mathrm{F}\right.$.).

6.5.5.2 Chemical stability. When brake fluid, except DOT 5 SBBF, is tested according to S6.5.4, the change in temperature of the refluxing fluid mixture shall not exceed $3.0^{\circ} \mathrm{C}\left(5.4^{\circ} \mathrm{F}\right.$.) plus $0.05^{\circ}$. for each degree that the ERBP of the fluid exceeds $225^{\circ} \mathrm{C}\left(437^{\circ} \mathrm{F}\right.$. $)$.

6.6 Corrosion. Evaluate the corrosiveness of a brake fluid by running duplicate samples according to the following procedure. 


\section{COMPLIANCE....Continued}

6.6.1 Summary of the procedure. Six specified metal corrosion test strips are polished, cleaned, and weighed, then assembled as described. Assembly is placed on a standard wheel cylinder cup in a corrosion test jar, immersed in the water-wet brake fluid, capped and placed in an oven at $100^{\circ} \mathrm{C} .\left(212^{\circ} \mathrm{F}\right.$.) for 120 hours. Upon removal and cooling, the strips, fluid, and cups are examined and tested.

6.6.2 Equipment. (a) Balance. An analytical balance having a minimum capacity of 50 grams and capable of weighing to the nearest $0.1 \mathrm{mg}$. (b) Desiccators. Desiccators containing silica gel or other suitable desiccant. (c) Oven. Gravity convection oven capable of maintaining the desired set point within $2{ }^{\circ} \mathrm{C}$. ( $3.6^{\circ} \mathrm{F}$.). (d) Micrometer. A machinist's micrometer 25 to 50 $\mathrm{mm}$. (1 to 2 inches) capacity, or an optical comparator, capable of measuring the diameter of the SBR wheel cylinder (WC) cups to the nearest $0.02 \mathrm{~mm}$. (0.001 inch).

6.6.3 Materials. (a) Corrosion test strips. Two sets of strips from each of the metals listed in appendix C of SAE Standard J1703b. Each strip shall be approximately $8 \mathrm{~cm}$. long, $1.3 \mathrm{~cm}$. wide, not more than $0.6 \mathrm{~cm}$. thick, and have a surface area of $25 \pm 5 \mathrm{sq}$. $\mathrm{cm}$. and a hole 4 to $5 \mathrm{~mm}$. (0.16 to 0.20 inch) in diameter on the centerline about $6 \mathrm{~mm}$. from one end. The hole shall be clean and free from burrs. Tinned iron strips shall be unused. Other strips, if used, shall not be employed if they cannot be polished to a high finish. (b) SBR cups. Two unused standard SAE SBR wheel cylinder (WC) cups, as specified in S7.6. (c) Corrosion test jars and lids. Two screw-top straightsided round glass jars, each having a capacity of approximately $475 \mathrm{ml}$. and inner dimensions of approximately $100 \mathrm{~mm}$. in height and $75 \mathrm{~mm}$. in diameter, and a tinned steel lid (no insert or organic coating) vented with a hole $0.8 \pm 0.1 \mathrm{~mm}$. $(0.031 \pm 0.004$ inch) in diameter (No. 68 drill). (d) Machine screws and nuts. Clean, rust and oil-free, uncoated mild steel round or fillister head machine screws, size 6 or 8-32 UNC-Class $2 \mathrm{~A}$, fiveeighths or threefourths inch long (or equivalent metric sizes), and matching uncoated nuts. (e) Supplies for polishing strips. Waterproof silicon carbide paper, grit No. $320 \mathrm{~A}$ and grit 1200; lint-free polishing cloth. (f) Distilled water as specified in S7.1. (g) Ethanol as specified in S7.3. (h) Isopropanol as specified in S7.7.

6.6.4 Preparation. (a) Corrosion test strips. Except for the tinned iron strips, abrade corrosion test strips on all surface areas with 320A silicon carbide paper wet with ethanol (isopropanol when testing DOT 5 SBBF fluids) until all surface scratches, cuts and pits visible to an observer having corrected visual acuity of 20/40 (Snellen ratio) at a distance of $300 \mathrm{~mm}$ (11.8 inches) are removed. Use a new piece of paper for each different type of metal. Except for the tinned iron strips, further abrade the test strips on all surface areas with 1200 silicon carbide paper wet with ethanol (isopropanol when testing DOT 5 SBBF fluids), again using a new piece of paper for each different type of metal. Wash all strips, including the tinned iron and the assembly hardware, with ethanol (isopropanol when testing DOT 5 SBBF 


\section{COMPLIANCE....Continued}

fluids); dry the strips and assembly hardware with a clean lint free cloth or use filtered compressed air and place the strips and hardware in a desiccator containing silica gel or other suitable desiccant and maintained at $23^{\circ} \pm 5{ }^{\circ} \mathrm{C}$. $\left(73.4^{\circ} \pm 9{ }^{\circ} \mathrm{F}\right.$.), for at least 1 hour. Handle the strips with forceps after polishing. Weigh and record the weight of each strip to the nearest $0.1 \mathrm{mg}$. Assemble the strips on a clean dry machine screw, with matching plain nut, in the order of tinned iron, steel, aluminum, cast iron, brass, and copper. Bend the strips, other than the cast iron, so that there is a separation of $3 \pm 1.2 \mathrm{~mm}$. $(1.8 \pm 1.64$ inch) between adjacent strips for a distance of about $5 \mathrm{~cm}$. (2 inches) from the free end of the strips. (See Figure 4.) Tighten the screw on each test strip assembly so that the strips are in electrolytic contact, and can be lifted by either of the outer strips (tinned iron or copper) without any of the strips moving relative to the others when held horizontally. Immerse the strip assemblies in 90 percent ethyl alcohol. Dry with dried filtered compressed air, then desiccate at least 1 hour before use.

(b) SBR WC cups. Measure the base diameters of the two standard SBR cups, using an optical comparator or micrometer, to the nearest $0.02 \mathrm{~mm}$. $(0.001$ inch) along the centerline of the SAE and rubber-type identifications and at right angles to this centerline. Take the measurements at least $0.4 \mathrm{~mm}$. (0.015 inch) above the bottom edge and parallel to the base of the cup. Discard any cup if the two measured diameters differ by more than $0.08 \mathrm{~mm}$. (0.003 inch). Average the two readings on each cup. Determine the hardness of the cups according to S7.4.

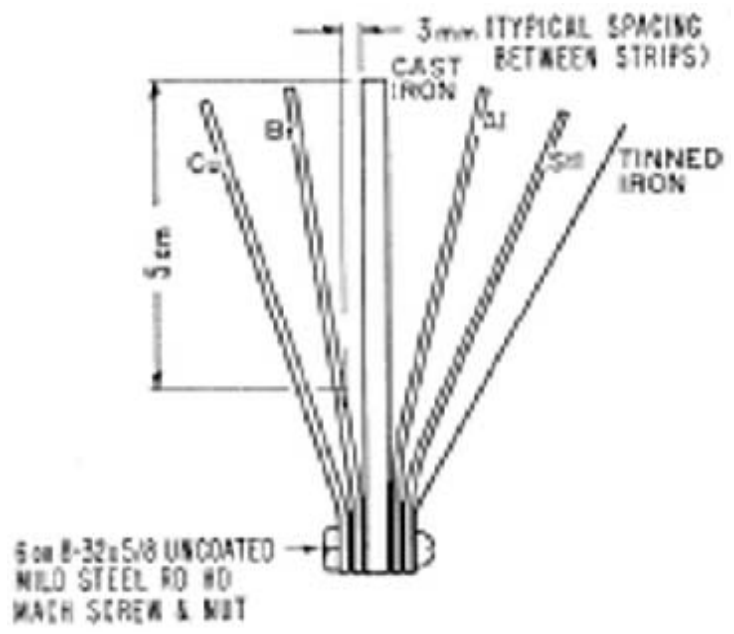




\section{COMPLIANCE....Continued}

6.6.5 Procedure. Rinse the cups in ethanol (isopropanol when testing DOT 5 SBBF fluids) for not more than 30 seconds and wipe dry with a clean lintfree cloth. Place one cup with lip edge facing up, in each jar. Insert a metal strip assembly inside each cup with the fastened end down and the free end extending upward. (See Figure 5.) When testing brake fluids, except DOT 5 SBBF, mix $760 \mathrm{ml}$. of brake fluid with $40 \mathrm{ml}$. of distilled water. When testing DOT 5 SBBF's, humidify $800 \mathrm{ml}$. of brake fluid in accordance with S6.2, eliminating determination of the ERBP. Using this water-wet mixture, cover each strip assembly to a minimum depth of $10 \mathrm{~mm}$. above the tops of the strips. Tighten the lids and place the jars for $120 \pm 2$ hours in an oven maintained at $100^{\circ} \pm 2{ }^{\circ} \mathrm{C}$. $\left(212^{\circ} \pm 3.6^{\circ} \mathrm{F}\right.$.). Allow the jars to cool at $23^{\circ} \pm 5^{\circ} \mathrm{C}$. $\left(73.4^{\circ} \pm 9^{\circ} \mathrm{F}\right.$.) for 60 to 90 minutes. Immediately remove the strips from the jars using forceps, agitating the strip assembly in the fluid to remove loose adhering sediment. Examine the test strips and jars for adhering crystalline deposits. Disassemble the metal strips, and remove adhering fluid by flushing with water; clean each strip by wiping with a clean cloth wetted with ethanol (isopropanol when testing DOT 5 fluids). Examine the strips for evidence of corrosion and pitting. Disregard staining or discoloration. Place the strips in a desiccator containing silica gel or other suitable desiccant, maintained at $23^{\circ} \pm 5{ }^{\circ} \mathrm{C}$. $\left(73.4^{\circ} \pm 9^{\circ} \mathrm{F}\right.$.), for at least 1 hour. Weigh each strip to the nearest $0.1 \mathrm{mg}$. Determine the change in weight of each metal strip. Average the results for the two strips of each type of metal. Immediately following the cooling period, remove the cups from the jars with forceps. Remove loose adhering sediment by agitation of the cups in the mixture. Rinse the cups in ethanol (isopropanol when testing DOT 5 fluids) and air-dry. Examine the cups for evidence of sloughing, blisters, and other forms of disintegration. Measure the base diameter and hardness of each cup within 15 minutes after removal from the mixture. Examine the mixture for gelling. Agitate the mixture to suspend and uniformly disperse sediment. From each jar, transfer a $100 \mathrm{ml}$. portion of the mixture to an ASTM cone-shaped centrifuge tube. Determine the percent sediment after centrifuging as described in S7.5. Measure the $\mathrm{pH}$ value of the corrosion text fluid according to S6.4.6. Measure the $\mathrm{pH}$ value of the test mixture according to S6.4.6.

6.6.6 Calculation. (a) Measure the area of each type of test strip to the nearest square 


\section{COMPLIANCE....Continued}

centimeter. Divide the average change in mass for each type by the area of that type. (b) Note other data and evaluations indicating compliance with S5.1.6. In the event of a marginal pass on inspection by attributes, or of a failure in one of the duplicates, run another set of duplicate samples. Both repeat samples shall meet all requirements of S5.1.6.

6.6.7 Pass/Fail Criteria. (a) The metal test strips shall not show weight changes exceeding the limits stated in Table III below;

\begin{tabular}{|l|l|}
\multicolumn{1}{l}{ Table III - Weight Change Limits } \\
\hline Test Strip Material & Maximum permissible weight change, mg./sq.cm. of surface \\
\hline Steel, tinned iron, cast iron & 0.2 \\
\hline Aluminum & 0.1 \\
\hline Brass, copper & 0.4 \\
\hline
\end{tabular}

(b) Excluding the area of contact $(13 \pm 1 \mathrm{~mm}$. $(1.2 \pm 1.32 \mathrm{inch})$ measured from the bolt hole end of the test strip), the metal test strips shall not show pitting or etching to an extent discernible without magnification; (c) The water-wet brake fluid at the end of the test shall show no jelling at $23 \pm 5^{\circ} \mathrm{C}\left(73.4 \pm 9{ }^{\circ} \mathrm{F}\right.$.); (d) No crystalline deposit shall form and adhere to either the glass jar walls or the surface of the metal strips; (e) At the end of the test, sedimentation of the water-wet brake fluid shall not exceed 0.10 percent by volume; (f) The $\mathrm{pH}$ value of water-wet brake fluid, except DOT $5 \mathrm{SBBF}$, at the end of the test shall not be less than 7.0 nor more than 11.5; (g) The cups at the end of the test shall show no disintegration, as evidenced by blisters or sloughing; (h) The hardness of the cup shall not decrease by more than 15 International Rubber Hardness Degrees (IRHD); and (i) The base diameter of the cups shall not increase by more than $1.4 \mathrm{~mm}$. (0.055 inch). 


\section{COMPLIANCE....Continued}

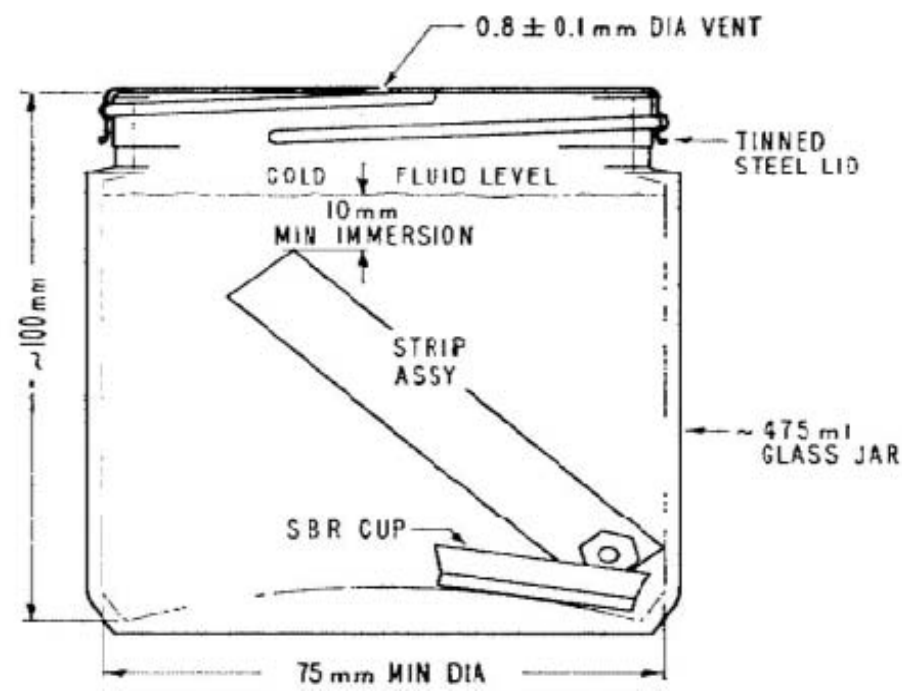

6.7 Fluidity and appearance at low temperatures. Determine the fluidity and appearance of a sample of brake fluid at each of two selected temperatures by the following procedure.

6.7.1 Summary of procedure. Brake fluid is chilled to expected minimum exposure temperatures and observed for clarity, gellation, sediment, separation of components, excessive viscosity or thixotropy.

6.7.2 Apparatus. (a) Oil sample bottle. Two clear flint glass 4-ounce bottles made especially for sampling oil and other liquids, with a capacity of approximately $125 \mathrm{ml}$., an outside diameter of $37 \pm 0.05 \mathrm{~mm}$. and an overall height of $165 \pm 2.5 \mathrm{~mm}$. (b) Cold chamber. An air bath cold chamber capable of maintaining storage temperatures down to minus $55^{\circ} \mathrm{C}$. (minus $67^{\circ} \mathrm{F}$.) with an accuracy of $\pm 2{ }^{\circ} \mathrm{C}$. (3.6 ${ }^{\circ} \mathrm{F}$.). (c) Timing device. A timing device in accordance with S6.3.2(e).

6.7.3 Procedure. (a) Place $100 \pm 1 \mathrm{ml}$. of brake fluid at room temperature in an oil sample bottle. Stopper the bottle with an unused cork and place in the cold chamber at the higher storage temperature specified in Table II (S5.1.7(c)). After $144 \pm 4$ hours remove the bottle from the chamber, quickly wipe it with a clean, lint-free cloth, saturated with ethanol (isopropanol when testing DOT 5 fluids) or acetone. Examine the fluid for evidence of sludging, sedimentation, crystallization, or stratification. Invert the bottle and determine the number of seconds required for the air bubble to travel to the top of the fluid. Let sample warm to room temperature and examine. (b) Repeat 6.7.3(a), substituting the lower cold chamber temperature specified in Table II, and a storage period of 6 hours \pm 12 minutes. NOTE: Test specimens from either storage temperature may be used for the other only after warming up to room temperature. 


\section{COMPLIANCE....Continued}

6.7.4 Pass/Fail Criteria. At the storage temperature and for the storage times given in Table II- (a) The fluid shall show no sludging, sedimentation, crystallization, or stratification; (b) Upon inversion of the sample bottle, the time required for the air bubble to travel to the top of the fluid shall not exceed the bubble flow times shown in Table IV; and (c) On warming to room temperature, the fluid shall resume the appearance and fluidity that it had before chilling.

\begin{tabular}{|c|c|c|}
\hline \multicolumn{3}{|c|}{ Table IV - Fluidity and Appearance at Low Temperatures } \\
\hline Storage temperature & $\begin{array}{c}\text { Storage } \\
\text { time } \\
\text { (hours) }\end{array}$ & $\begin{array}{c}\text { Maximum bubble } \\
\text { flow time } \\
\text { (seconds) }\end{array}$ \\
\hline $\begin{array}{c}\text { Minus } 40 \pm 2^{\circ} \mathrm{C} \text {. (minus } \\
\left.40 \pm 3.6^{\circ} \mathrm{F} .\right)\end{array}$ & $144 \pm 4.0$ \\
\hline $\begin{array}{c}\text { Minus } 50 \pm 2^{\circ} \mathrm{C} .(\text { minus } \\
58 \pm 3.6^{\circ} \mathrm{F} \text {.) }\end{array}$ & $6 \pm 0.2$ & 10 \\
\hline
\end{tabular}

6.8 Water tolerance. Evaluate the water tolerance characteristics of a brake fluid by running one test specimen according to the following procedure.

6.8.1 Summary of the procedure. Brake fluid, except DOT $5 \mathrm{SBBF}$, is diluted with 3.5 percent water (DOT $5 \mathrm{SBBF}$ is humidified), then stored at minus 40 ${ }^{\circ} \mathrm{C}$. (minus $40{ }^{\circ} \mathrm{F}$.) for 120 hours. The cold, water-wet fluid is first examined for clarity, stratification, and sedimentation, then placed in an oven at $60{ }^{\circ} \mathrm{C}$. $\left(140{ }^{\circ} \mathrm{F}\right.$.) for 24 hours. On removal, it is again examined for stratification, and the volume percent of sediment determined by centrifuging.

6.8.2 Apparatus. (a) Centrifuge tube. See S7.5.1(a). (b) Centrifuge. See S7.5.1(b). (c) Cold chamber. See S6.7.2(b). (d) Oven. Gravity or forced convection oven. (e) Timing device. See S6.3.2(e). S6.9.3 Procedure. (a) At low temperature. Humidify $100 \pm 1 \mathrm{ml}$. of DOT $5 \mathrm{SBBF}$ brake fluid in accordance with S6.2 eliminating determination of the ERBP. When testing brake fluids except DOT $5 \mathrm{SBBF}$, mix $3.5 \pm 0.1 \mathrm{ml}$. of distilled water with $100 \pm 1 \mathrm{ml}$. of the brake fluid; pour into a centrifuge tube. Stopper the tube with a clean cork and place in the cold chamber maintained at minus $40 \pm 2{ }^{\circ} \mathrm{C}$. (minus $40 \pm 3.6^{\circ} \mathrm{F}$.). After 120 hours \pm 2 hours remove the tube, quickly wipe with clean lint-free cloth saturated with ethanol or acetone and examine the fluid for evidence of sludging, sedimentation, crystallization, or stratification. Invert the tube and determine the number of seconds required for the air bubble to travel to the top of the fluid. (The air bubble is considered to have reached the top of the fluid when the top of the bubble reaches the $2 \mathrm{ml}$. graduation of the centrifuge tube.) If the wet fluid has become cloudy, warm to $23 \pm 5{ }^{\circ} \mathrm{C}$. $\left(73.4 \pm 9^{\circ} \mathrm{F}\right.$.) and note appearance and fluidity. (b) At $60{ }^{\circ} \mathrm{C}$. (140 ${ }^{\circ} \mathrm{F}$.). Place tube and brake fluid from 


\section{COMPLIANCE....Continued}

6.8.3(a) in an oven maintained at $60^{\circ} \pm 2{ }^{\circ} \mathrm{C}$. $\left(140^{\circ} \pm 3.6^{\circ} \mathrm{F}\right.$.) for $24 \pm 2$ hours. Remove the tube and immediately examine the contents for evidence of stratification. Determine the percent sediment by centrifuging as described in S7.5.

6.8.4 Pass/Fail Criteria. (a) At low temperature. (1) The fluid shall show no sludging, sedimentation, crystallization, or stratification; (2) Upon inversion of the centrifuge tube, the air bubble shall travel to the top of the fluid in not more than 10 seconds; (3) If cloudiness has developed, the wet fluid shall regain its original clarity and fluidity when warmed to room temperature; and (b) At $60{ }^{\circ} \mathrm{C}$. $\left(140{ }^{\circ} \mathrm{F}\right.$.). At At $60{ }^{\circ} \mathrm{C}$. $\left(140{ }^{\circ} \mathrm{F}\right.$.) (1) The fluid shall show no stratification; and (2) Sedimentation shall not exceed 0.15 percent by volume after centrifuging.

6.9 Compatibility. The compatibility of a brake fluid with other brake fluids shall be evaluated by running one test sample according to the following procedure.

6.9.1 Summary of the procedure. Brake fluid is mixed with an equal volume of SAE RM-66-04 Compatibility Fluid, then tested in the same way as for water tolerance (S6.9) except that the bubble flow time is not measured. This test is an indication of the compatibility of the test fluid with other motor vehicle brake fluids at both high and low temperatures.

6.9.2 Apparatus and materials. (a) Centrifuge tube. See S7.5.1(a). (b) Centrifuge. See S7.5.1(b). (c) Cold Chamber. See S6.7.2(b) (d) Oven. See S6.9.2(d) (e) SAE RM-66-04 Compatibility Fluid. As described in appendix B of SAE Standard J1703 JAN 1995 "Motor Vehicle Brake Fluid." (SAE RM-66-03 Compatibility Fluid as described in appendix A of SAE Standard J1703 NOV83, "Motor Vehicle Brake Fluid," November 1983, may be used in place of SAE RM-66-04 until January 1, 1995.)

6.9.3 Procedure. (a) At low temperature. Mix $50 \pm 0.5 \mathrm{~mL}$ of brake fluid with $50 \pm 0.5 \mathrm{~mL}$ of SAE RM-66-04 Compatibility Fluid. Pour this mixture into a centrifuge tube and stopper with a clean dry cork. Place tube in the cold chamber maintained at minus $40^{\circ} \pm 2{ }^{\circ} \mathrm{C}$. (minus $40^{\circ} \pm 4^{\circ} \mathrm{F}$ ). After $24 \pm 2$ hours, remove tube, quickly wipe with a clean lint-free cloth saturated with ethanol (isopropanol when testing DOT 5 fluids) or acetone. Examine the test specimen for evidence of slugging, sedimentation, or crystallization. Test fluids, except DOT $5 \mathrm{SBBF}$, shall be examined for stratification.

6.9.4 Pass/Fail Criteria. (a) At low temperature. When brake fluid is tested according to S6.10.3(a), the test specimen shall show no sludging, sedimentation, or crystallization. In addition, fluids, except DOT 5 SBBF, shall show no stratification. (b) At $60{ }^{\circ} \mathrm{C}$. $\left(140^{\circ} \mathrm{F}\right.$.). When brake fluid is tested according to S6.10.3(b) - (1) Sedimentation shall not exceed 0.05 


\section{COMPLIANCE....Continued}

percent by volume after centrifuging; and (2) Fluids, except DOT 5 SBBF, shall show no stratification.

6.10 Resistance to oxidation. The stability of a brake fluid under oxidative conditions shall be evaluated by running duplicate samples according to the following procedure.

6.10.1 Summary of procedure. Brake fluids, except DOT 5 SBBF, are activated with a mixture of approximately 0.2 percent benzoyl peroxide and 5 percent water. DOT $5 \mathrm{SBBF}$ is humidified in accordance with S6.2 eliminating determination of the ERBP, and then approximately 0.2 percent benzoyl peroxide is added. A corrosion test strip assembly consisting of cast iron and an aluminum strip separated by tinfoil squares at each end is then rested on a piece of SBR WC cup positioned so that the test strip is half immersed in the fluid and oven aged at $70^{\circ} \mathrm{C}$. $\left(158^{\circ} \mathrm{F}\right.$.) for 168 hours. At the end of this period, the metal strips are examined for pitting, etching, and loss of mass.

6.10.2 Equipment. (a) Balance. See S6.6.2(a). (b) Desiccators. See S6.6.2(b). (c) Oven. See S6.6.2(c). (d) Three glass test tubes approximately $22 \mathrm{~mm}$. outside diameter by $175 \mathrm{~mm}$. in length.

6.10.3 Reagents and materials. (a) Benzoyl peroxide, reagent grade, 96 percent. (Benzoyl peroxide that is brownish, or dusty, or has less than 90 percent purity, must be discarded.) Reagent strength may be evaluated by ASTM E298-68, "Standard Methods for Assay of Organic Peroxides.'” (b) Corrosion test strips. Two sets of cast iron and aluminum metal test strips as described in appendix C of SAE Standard J1703b. (c) Tinfoil. Four unused pieces of tinfoil approximately $12 \mathrm{~mm}$. (1.2 inch) square and between 0.02 and $0.06 \mathrm{~mm}$. (0.0008 and $0.0024 \mathrm{inch})$ in thickness. The foil shall be at least 99.9 percent tin and contain not more than 0.025 percent lead. (d) SBR cups. Two unused, approximately one-eighth sections of a standard SAE SBR WC cup (as described in S7.6). (e) Machine screw and nut. Two clean oil-free, No. 6 or $8-32 \sim 3.8 ¥$ or 1.2 -inch long (or equivalent metric size), round or fillister head, uncoated mild steel machine screws, with matching plain nuts.

6.10.4 Preparation. (a) Corrosion test strips. Prepare two sets of aluminum and cast iron test strips according to S6.6.4(a) except for assembly. Weigh each strip to the nearest $0.1 \mathrm{mg}$. and assemble a strip of each metal on a machine screw, separating the strips at each end with a piece of tinfoil. Tighten the nut enough to hold both pieces of foil firmly in place. (b) Test mixture.Place $30 \pm 1 \mathrm{ml}$. of the brake fluid under test in a 22 


\section{COMPLIANCE....Continued}

by $175 \mathrm{~mm}$. test tube. For all fluids except DOT $5 \mathrm{SBBF}$, add $0.060 \pm .002$ grams of benzoyl peroxide, and $1.50 \pm 0.05 \mathrm{ml}$. of distilled water. For DOT 5 SBBF, use test fluid humidified in accordance with S6.2, and add only the benzoyl peroxide. Stopper the tube loosely with a clean dry cork, shake, and place in an oven for 2 hours at $70^{\circ} \pm 2{ }^{\circ} \mathrm{C}$. $\left(158^{\circ} \pm 3.6^{\circ} \mathrm{F}\right.$.). Shake every 15 minutes to effect solution of the peroxide, but do not wet cork. Remove the tube from the oven and allow to cool to $23^{\circ} \pm 5^{\circ} \mathrm{C}$. $\left(73.4^{\circ} \pm 9^{\circ} \mathrm{F}\right.$.) Begin testing according to paragraph S6.11.5 not later than 24 hours after removal of tube from oven.

6.10.5 Procedure. Place a one-eighth SBR cup section in the bottom of each tube. Add $10 \mathrm{ml}$. of prepared test mixture to each test tube. Place a metalstrip assembly in each, the end of the strip without the screw resting on the rubber, and the solution covering about one-half the length of the strips. Stopper the tubes with clean dry corks and store upright for $70 \pm 2$ hours at $23^{\circ} \pm 5{ }^{\circ} \mathrm{C}$. $\left(73.4^{\circ} \pm 9^{\circ} \mathrm{F}\right.$.). Loosen the corks and place the tubes for $168 \pm 2$ hours in an oven maintained at $70^{\circ} \pm 2{ }^{\circ} \mathrm{C}$. $\left(158^{\circ} \pm 3.6{ }^{\circ} \mathrm{F}\right.$.). Afterwards remove and disassemble strips. Examine the strips and note any gum deposits. Wipe the strips with a clean cloth wet with ethanol (isopropanol when testing DOT 5 fluids) and note any pitting, etching or roughening of surface disregarding stain or discoloration. Place the strips in a desiccator over silica gel or other suitable desiccant, at $23^{\circ} \pm 5^{\circ} \mathrm{C}$. $\left(73 \cdot 4^{\circ} \pm 9^{\circ} \mathrm{F}\right.$.) for at least 1 hour. Again weigh each strip to the nearest $0.1 \mathrm{mg}$.

6.10.6 Calculation. Determine corrosion loss by dividing the change in mass of each metal strip by the total surface area of each strip measured in square millimeters $(\mathrm{mm} 2)$, to the nearest square millimeter $(\mathrm{mm} 2)$. Average the results for the two strips of each type of metal, rounding to the nearest 0.05 $\mathrm{mg}$. per 100 square millimeter $(\mathrm{mm} 2)$. If only one of the duplicates fails for any reason, run a second set of duplicate samples. Both repeat samples shall meet all requirements of S5.1.11.

6.10.7 Pass/Fail Criteria. (a) The metal test strips outside the areas in contact with the tinfoil shall not show pitting or etching to an extent discernible without magnification; (b) No more than a trace of gum shall be deposited on the test strips outside the areas in contact with the tinfoil; (c) The aluminum strips shall not change in weight by more than $0.05 \mathrm{mg}$./sq. $\mathrm{cm}$.; and (d) The cast iron strips shall not change in weight by more than $0.3 \mathrm{mg} . / \mathrm{sq} . \mathrm{cm}$.

6.11 Effect on SBR cups. The effects of a brake fluid in swelling, softening, and otherwise affecting standard SBR WC cups shall be evaluated by the following procedure.

6.11.1 Summary of the procedure. Four standard SAE SBR WC cups are measured and their hardnesses determined. The cups, two to a jar, are immersed in the test brake fluid. One jar is heated for 70 hours at $70{ }^{\circ} \mathrm{C}$. $(158$ 


\section{COMPLIANCE....Continued}

$\left.{ }^{\circ} \mathrm{F}\right)$, and the other for 70 hours at $120^{\circ} \mathrm{C}\left(248{ }^{\circ} \mathrm{F}\right)$. Afterwards, the cups are washed, examined for disintegration, remeasured and their hardnesses redetermined.

6.11.2 Equipment and supplies. (a) Oven. See S6.6.2(c). (b) Glass jars and lids. Two screw-top, straight-sided round glass jars, each having a capacity of approximately $250 \mathrm{ml}$. and inner dimensions of approximately $125 \mathrm{~mm}$. in height and $50 \mathrm{~mm}$. in diameter, and a tinned steel lid (no insert or organic coating). (c) SBR cups. See S7.6.

6.11.3 Preparation. Measure the base diameters of the SBR cups as described in 6.6.4(b), and the hardness of each as described in 7.4.

6.11.4 Procedure. Wash the cups in 90 percent ethanol (isopropanol when testing DOT 5 fluids) (see S7.3), for not longer than 30 seconds and quickly dry with a clean, lint-free cloth. Using forceps, place two cups into each of the two jars; add $75 \mathrm{ml}$. of brake fluid to each jar and cap tightly. Place one jar in an oven held at $70^{\circ} \pm 2{ }^{\circ} \mathrm{C}$. $\left(158 \pm 3.6^{\circ} \mathrm{F}\right.$.) for $70 \pm 2$ hours. Place the other jar in an oven held at $120^{\circ} \pm 2{ }^{\circ} \mathrm{C}$. $\left(248^{\circ} \pm 3.6^{\circ} \mathrm{F}\right.$.) for $70 \pm 2$ hours. Allow each jar to cool for 60 to 90 minutes at $23^{\circ} \pm 5{ }^{\circ} \mathrm{C}$. $\left(73.4^{\circ} \pm 9^{\circ} \mathrm{F}\right.$.). Remove cups, wash with ethanol (isopropanol when testing DOT 5 fluids) for not longer than 30 seconds, and quickly dry. Examine the cups for disintegration as evidenced by stickiness, blisters, or sloughing. Measure the base diameter and hardness of each cup within 15 minutes after removal from the fluid.

6.11.5 Calculation. (a) Calculate the change in base diameter for each cup. If the two values, at each temperature, do not differ by more than $0.10 \mathrm{~mm}$. $(0.004 \mathrm{inch})$ average them to the nearest $0.02 \mathrm{~mm}$. (0.001 inch). If the two values differ by more than $0.10 \mathrm{~mm}$., repeat the test at the appropriate temperature and average the four values as the change in base diameter. (b) Calculate the change in hardness for each cup. The average of the two values for each pair is the change in hardness. (c) Note disintegration as evidenced by stickiness, blisters, or sloughing.

6.11.6 Pass/Fail Criteria. (a) The increase in the diameter of the base of the cups shall be not less than $0.15 \mathrm{~mm}$. (0.006 inch) or more than $1.40 \mathrm{~mm}$. (0.055 inch); (b) The decrease in hardness of the cups shall be not more than 10 IRHD at $70^{\circ} \mathrm{C} .\left(158^{\circ} \mathrm{F}\right.$.) or more than 15 IRHD at $120^{\circ} \mathrm{C}$. $\left(248^{\circ} \mathrm{F}\right.$.), and there shall be no increase in hardness of the cups; and (c) The cups shall show no disintegration as evidenced by stickiness, blisters, or sloughing.

6.12 Stroking properties. Evaluate the lubricating properties, component compatibility, resistance to leakage, and related qualities of a brake fluid by running one sample according to the following procedures.

6.12.1 Summary of the procedure. Brake fluid is stroked under controlled conditions at an elevated temperature in a simulated motor vehicle hydraulic 


\section{COMPLIANCE....Continued}

braking system consisting of three slave wheel cylinders and an actuating master cylinder connected by steel tubing. Referee standard parts are used. All parts are carefully cleaned, examined, and certain measurements made immediately prior to assembly for test. During the test, temperature, rate of pressure rise, maximum pressure, and rate of stroking are specified and controlled. The system is examined periodically during stroking to assure that excessive leakage of fluid is not occurring. Afterwards, the system is torn down. Metal parts and SBR cups are examined and remeasured. The brake fluid and any resultant sludge and debris are collected, examined, and tested.

6.12.2 Apparatus and equipment. Either the drum and shoe type of stroking apparatus (see Figure 1 of SAE Standard J1703b) except using only three sets of drum and shoe assemblies, or the stroking fixture type apparatus as shown in Figure 2 of SAE J1703Nov83, with the components arranged as shown in Figure 1 of SAE J1703Nov83. The following components are required. (a) Brake assemblies. With the drum and shoe apparatus: three drum and shoe assembly units (SAE RM-29a) consisting of three forward brake shoes and three reverse brake shoes with linings and three front wheel brake drum assemblies with assembly component parts. With stroking fixture type apparatus: three fixture units including appropriate adapter mounting plates to hold brake wheel cylinder assemblies. (b) Braking pressure actuation mechanism. An actuating mechanism for applying a force to the master cylinder pushrod without side thrust. The amount of force applied by the actuating mechanism shall be adjustable and capable of applying sufficient thrust to the master cylinder to create a pressure of at least $6895 \mathrm{kPa}(1,000$ p.s.i.) in the simulated brake system. A hydraulic gage or pressure recorder, having a range of at least 0 to $6895 \mathrm{kPa}(0$ to 1,000 p.s.i), shall be installed between the master cylinder and the brake assemblies and shall be provided with a shutoff valve and with a bleeding valve for removing air from the connecting tubing. The actuating mechanism shall be designed to permit adjustable stroking rates of approximately 1,000 strokes per hour. Use a mechanical or electrical counter to record the total number of strokes. (c) Heated air bath cabinet. An insulated cabinet or oven having sufficient capacity to house the three mounted brake assemblies or stroking fixture assemblies, master cylinder, and necessary connections. A thermostatically controlled heating system is required to maintain a temperature of $70^{\circ} \pm 5^{\circ} \mathrm{C}$ $\left(158^{\circ} \pm 9^{\circ} \mathrm{F}\right)$ or $120^{\circ} \pm 5^{\circ} \mathrm{C}\left(248^{\circ} \pm 9^{\circ} \mathrm{F}\right)$. Heaters shall be shielded to prevent direct radiation to wheel or master cylinder. (d) Master cylinder (MC) assembly (SAE RM-15a). One cast iron housing hydraulic brake system cylinder having a diameter of approximately $28 \mathrm{~mm}$. (11.8 inch) and fitted for a filler cap and standpipe (see S6.13.2(e)). The MC piston shall be made from SAE CA360 copperbase alloy (half hard). A new MC assembly is required for each test. (e) Filler cap and standpipe. MC filler cap provided with a glass or uncoated steel standpipe. Standpipe must provide adequate volume for thermal expansion, yet permit measurement and adjustment of the fluid level in the system to $\pm 3 \mathrm{ml}$. Cap and standpipe may be cleaned and reused. (f) Wheel cylinder (WC) assemblies (SAE RM-14a). Three unused cast iron 


\section{COMPLIANCE....Continued}

housing straight bore hydraulic brake WC assemblies having diameters of approximately $28 \mathrm{~mm}$ (11.8 inch) for each test. Pistons shall be made from unanodized SAE AA 2024 aluminum alloy. (g) Micrometer. Same as S6.6.2(d).

6.12.3 Materials. (a) Standard SBR brake cups. Six standard SAE SBR wheel cylinder test cups, one primary MC test cup, and one secondary MC test cup, all as described in S7.6, for each test. (b) Steel tubing. Double wall steel tubing meeting SAE specification J527. A complete replacement of tubing is essential when visual inspection indicates any corrosion or deposits on inner surface of tubing. Tubing from master cylinder to one wheel cylinder shall be replaced for each test (minimum length $.9 \mathrm{~m}$.) Uniformity in tubing size is required between master cylinder and wheel cylinder. The standard master cylinder has two outlets for tubing, both of which must be used.

6.12.4 Preparation of test apparatus. (a) Wheel cylinder assemblies. Use unused wheel cylinder assemblies. Disassemble cylinders and discard cups. Clean all metal parts with ethanol (isopropanol when testing DOT 5 fluids). Inspect the working surfaces of all metal parts for scoring, galling, or pitting and cylinder bore roughness, and discard all defective parts. Remove any stains on cylinder walls with crocus cloth and ethanol (isopropanol when testing DOT 5 fluids). If stains cannot be removed, discard the cylinder. Measure the internal diameter of each cylinder at a location approximately 19 $\mathrm{mm}$. (0.75 inch) from each end of the cylinder bore, taking measurements in line with the hydraulic inlet opening and at right angles to this centerline. Discard the cylinder if any of these four readings exceeds the maximum or minimum limits of 28.66 to $28.60 \mathrm{~mm}$. (1.128 to 1.126 inch). Measure the outside diameter of each piston at two points approximately $90^{\circ}$ apart. Discard any piston if either reading exceeds the maximum or minimum limits of 28.55 to $28.52 \mathrm{~mm}$. (1.124 to $1.123 \mathrm{inch}$ ). Select parts to insure that the clearance between each piston and mating cylinder is within 0.08 to $0.13 \mathrm{~mm}$. $(0.003$ to 0.005 inch). Use unused SBR cups. To remove dirt and debris, rinse the cups in 90 percent ethyl alcohol for not more than 30 seconds and wipe dry with a clean lint-free cloth. Discard any cups showing defects such as cuts, molding flaws, or blisters. Measure the lip and base diameters of all cups with an optical comparator or micrometer to the nearest $0.02 \mathrm{~mm}$. (0.001 inch) along the centerline of the SAE and rubber-type identifications and at right angles to this centerline. Determine base diameter measurements at least $0.4 \mathrm{~mm}$. (0.015 inch) above the bottom edge and parallel to the base of the cup. Discard any cup if the two measured lip or base diameters differ by more than $0.08 \mathrm{~mm}$. (0.003 inch). Average the lip and base diameters of each cup. Determine the hardness of all cups according to S7.4. Dip the rubber and metal parts of wheel cylinders, except housing and rubber boots, in the fluid to be tested and install them in accordance with the manufacturer's instructions. Manually stroke the cylinders to insure that they operate easily. Install cylinders in the simulated brake system. (b) Master cylinder assembly. Use an unused master cylinder and unused standard SBR primary and 


\section{COMPLIANCE....Continued}

secondary MC cups which have been inspected, measured and cleaned in the manner specified in S6.13.4(a), omitting hardness of the secondary MC cup. However, prior to determining the lip and base diameters of the secondary cup, dip the cup in test brake fluid, assemble on the $\mathrm{MC}$ piston, and maintain the assembly in a vertical position at $23^{\circ} \pm 5^{\circ} \mathrm{C}$. $\left(73.4^{\circ} \pm 9^{\circ} \mathrm{F}\right.$.) for at least 12 hours. Inspect the relief and supply ports of the master cylinder; discard the cylinder if ports have burrs or wire edges. Measure the internal diameter of the cylinder at two locations (approximately midway between the relief and supply ports and approximately $19 \mathrm{~mm}$. $(0.75 \mathrm{inch})$ beyond the relief port toward the bottom or discharge end of the bore), taking measurements at each location on the vertical and horizontal centerline of the bore. Discard the cylinder if any reading exceeds the maximum or minimum limits of 28.65 to $28.57 \mathrm{~mm}$. (1.128 to $1.125 \mathrm{inch}$ ). Measure the outside diameter of each end of the master cylinder piston at two points approximately $90^{\circ}$ apart. Discard the piston if any of these four readings exceed the maximum or minimum limits of 28.55 to $28.52 \mathrm{~mm}$. (1.124 to $1.123 \mathrm{inch}$ ). Dip the rubber and metal parts of the master cylinder, except the housing and push rod-boot assembly, in the brake fluid and install in accordance with manufacturer's instructions. Manually stroke the master cylinder to insure that it operates easily. Install the master cylinder in the simulated brake system. (c) Assembly and adjustment of test apparatus. (1) When using a shoe and drum type apparatus, adjust the brake shoe toe clearances to $1.0 \pm 0.1 \mathrm{~mm}(0.040 \pm 0.004 \mathrm{inch})$. Fill the system with brake fluid, bleeding all wheel cylinders and the pressure gage to remove entrapped air. Operate the actuator manually to apply a pressure greater than the required operating pressure and inspect the system for leaks.

Adjust the actuator and/or pressure relief valve to obtain a pressure of 6895 $\mathrm{kPa} \pm 345 \mathrm{kPa}(1,000 \pm 50$ p.s.i.). A smooth pressure stroke pattern is required when using a shoe and drum type apparatus. The pressure is relatively low during the first part of the stroke and then builds up smoothly to the maximum stroking pressure at the end of the stroke, to permit the primary cup to pass the compensating hole at a relatively low pressure. Using stroking fixtures, adjust the actuator and/or pressure relief valve to obtain a pressure of $6895 \mathrm{kPa} \pm 345 \mathrm{kPa}(1,000 \pm 50$ p.s.i.). (2) Adjust the stroking rate to $1,000 \pm 100$ strokes per hour. Record the fluid level in the master cylinder standpipe.

6.12.5 Procedure. Operate the system for $16,000 \pm 1,000$ cycles at $23^{\circ} \pm 5{ }^{\circ} \mathrm{C}$. $\left(73.4^{\circ} \pm 9^{\circ} \mathrm{F}\right.$.). Repair any leakage, readjust the brake shoe clearances, and add fluid to the master cylinder standpipe to bring to the level originally recorded, if necessary. Start the test again and raise the temperature of the cabinet within $6 \pm 2$ hours to $120^{\circ} \pm 5{ }^{\circ} \mathrm{C}$. $\left(248^{\circ} \pm 9{ }^{\circ} \mathrm{F}\right.$.). During the test observe operation of wheel cylinders for improper functioning and record the amount of fluid required to replenish any loss, at intervals of 24,000 strokes. Stop the test at the end of 85,000 total recorded strokes. These totals shall include the number of strokes during operation at $23^{\circ} \pm 5{ }^{\circ} \mathrm{C}$. $\left(73.4^{\circ} \pm 9{ }^{\circ} \mathrm{F}\right.$.) and the number of strokes required to bring the system to the operating temperature. Allow equipment to cool to room temperature. Examine the wheel cylinders for leakage. Stroke the assembly an additional 100 strokes, examine wheel 


\section{COMPLIANCE....Continued}

cylinders for leakage and record volume loss of fluid. Within 16 hours after stopping the test, remove the master and wheel cylinders from the system, retaining the fluid in the cylinders by immediately capping or plugging the ports. Disassemble the cylinders, collecting the fluid from the master cylinder and wheel cylinders in a glass jar. When collecting the stroked fluid, remove all residue which has deposited on rubber and metal internal parts by rinsing and agitating such parts in the stroked fluid and using a soft brush to assure that all loose adhering sediment is collected. Clean SBR cups in ethanol (isopropanol when testing DOT 5 fluids) and dry. Inspect the cups for stickiness, scuffing, blistering, cracking, chipping, and change in shape from original appearance. Within 1 hour after disassembly, measure the lip and base diameters of each cylinder cup by the procedures specified in S6.13.4 (a) and (b) with the exception that lip or base diameters of cups may now differ by more than $0.08 \mathrm{~mm}$. (0.003 inch). Determine the hardness of each cup according to S7.4. Note any sludge or gel present in the test fluid. Within 1 hour after draining the cylinders, agitate the fluid in a glass jar to suspend and uniformly disperse sediment and transfer a $100 \mathrm{ml}$. portion of this fluid to a centrifuge tube and determine percent sediment as described in S7.5. Allow the tube and fluid to stand for 24 hours, recentrifuge and record any additional sediment recovered. Inspect cylinder parts, note any gumming or any pitting on pistons and cylinder walls. Disregard staining or discoloration. Rub any deposits adhering to cylinder walls with a clean soft cloth wetted with ethanol (isopropanol when testing DOT 5 fluids) to determine abrasiveness and removability. Clean cylinder parts in ethanol (isopropanol when testing DOT 5 fluids) and dry. Measure and record diameters of pistons and cylinders according to S6.13.4(a) and (b). Repeat the test if mechanical failure occurs that may affect the evaluation of the brake fluid.

6.12.6 Calculation. (a) Calculate the changes in diameters of cylinders and pistons (see S5.1.13(b)). (b) Calculate the average decrease in hardness of the seven cups tested, as well as the individual values (see S5.1.13(c)). (c) Calculate the increases in base diameters of the eight cups (see S5.1.13(e)). (d) Calculate the lip diameter interference set for each of the eight cups by the following formula and average the eight values (see S5.1.13(f)).

$\left[\left(\mathrm{D}_{1} ¥ \mathrm{D}_{2}\right) /\left(\mathrm{D}_{1} ¥ \mathrm{D}_{3}\right)\right]^{*} 100=$ PERCENTAGE LIP DIAMETER INTERFERENCE SET

where: $\mathrm{D}_{1}=$ Original lip diameter.

$\mathrm{D}_{2}=$ Final lip diameter.

$\mathrm{D}_{3}=$ Original cylinder bore diameter.

6.12.7 Pass/Fail Criteria. (a) Metal parts of the test system shall show no pitting or etching to an extent discernible without magnification; (b) The change in diameter of any cylinder or piston shall not exceed $0.13 \mathrm{~mm}$. $(0.005$ 


\section{COMPLIANCE....Continued}

inch); (c) The average decrease in hardness of seven of the eight cups tested (six wheel cylinder and one master cylinder primary) shall not exceed 15 IRHD. Not more than one of the seven cups shall have a decrease in hardness greater than 17 IRHD; (d) None of the eight cups shall be in an unsatisfactory operating condition as evidenced by stickiness, scuffing, blisters, cracking, chipping, or other change in shape from its original appearance; (e) None of the eight cups shall show an increase in base diameter greater than $0.90 \mathrm{~mm}$ (0.035 inch); (f) The average lip diameter set of the eight cups shall not be greater than 65 percent. (g) During any period of 24,000 strokes, the volume loss of fluid shall not exceed 36 milliliters; (h) The cylinder pistons shall not freeze or function improperly throughout the test; (i) The total loss of fluid during the 100 strokes at the end of the test shall not exceed 36 milliliters; (j) The fluid at the end of the test shall show no formation of gels; (k) At the end of the test the amount of sediment shall not exceed 1.5 percent by volume; and (1) Brake cylinders shall be free of deposits that are abrasive or that cannot be removed when rubbed moderately with a nonabrasive cloth wetted with ethanol.

6.13 Container information. Each container with information marked directly on the container surface or on a label (labels) affixed to the container pursuant to S5.2.2.2 or S5.2.2.3 is subjected to the following procedure: (a) If the container has a label affixed to it, make a single vertical cut all the way through the label with the container in the vertical position. (b) Immerse the container in the same brake fluid or hydraulic system mineral oil contained therein for 15 minutes at room temperature $\left(23 \pm 5^{\circ} \mathrm{C} ; 73.4 \pm 9{ }^{\circ} \mathrm{F}\right)$. (c) Within 5 minutes after removing the container from the fluid or oil, remove excess liquid from the surface of the container by wiping with a clean dry cloth.

6.13.1 Pass/Fail Criteria. The information required by this section shall be legible to an observer having corrected visual acuity of 20/40 (Snellen ratio) at a distance of $305 \mathrm{~mm}$, and any label affixed to the container in compliance with this section shall not be removable without its being destroyed or defaced.

\subsection{Marking and Labeling Inspection.}

6.14.1 Each packager of brake fluid shall furnish the information specified in paragraphs (a) through (g) by clearly marking it on each brake fluid container or on a label (labels) permanently affixed to the container, in any location except a removable 


\section{COMPLIANCE....Continued}

part such as a lid. (a) Certification that the brake fluid conforms to $\S 571.116$. (b) The name of the packager of the brake fluid, which may be in code form. (c) The name and complete mailing address of the distributor. (d) A serial number identifying the packaged lot and date of packaging. (e) Designation of the contents as "DOT-MOTOR VEHICLE BRAKE FLUID" (Fill in DOT 3, DOT 4, DOT 5 SILICONE BASE, or DOT 5.1 NON-SILICONE BASE as applicable). (f) The minimum wet boiling point in Fahrenheit of the DOT brake fluid in the container. (g) The following safety warnings in capital and lower case letters as indicated: (1) FOLLOW VEHICLE MANUFACTURER'S RECOMMENDATIONS WHEN ADDING BRAKE FLUID. (2) KEEP BRAKE FLUID CLEAN AND DRY. Contamination with dirt, water, petroleum products or other materials may result in brake failure or costly repairs. (3) STORE BRAKE FLUID ONLY IN ITS ORIGINAL CONTAINER. KEEP CONTAINER CLEAN AND TIGHTLY CLOSED TO PREVENT ABSORPTION OF MOISTURE. (4) CAUTION: DO NOT REFILL CONTAINER, AND DO NOT USE FOR OTHER LIQUIDS. (Not required for containers with a capacity in excess of $19 \mathrm{~L}$.)

6.14.2 Each packager of hydraulic system mineral oil shall furnish the information specified in paragraphs (a) through (e) by clearly marking it on each brake fluid container or on a label (labels) permanently affixed to the container, in any location except a removable part such as a lid. (a) The name of the packager of the hydraulic system mineral oil, which may be in code form. (b) The name and complete mailing address of the distributor. (c) A serial number identifying the packaged lot and date of packaging. (d) Designation of the contents as "HYDRAULIC SYSTEM MINERAL OIL" in capital letters at least $3 \mathrm{~mm}$ high. (e) The following safety warnings in capital and lower case letters as indicated: (1) FOLLOW VEHICLE MANUFACTURER'S RECOMMENDATIONS WHEN ADDING HYDRAULIC SYSTEM MINERAL OIL. (2) Hydraulic System Mineral Oil is NOT COMPATIBLE with the rubber components of brake systems designed for use with DOT brake fluids. (3) KEEP HYDRAULIC SYSTEM MINERAL OIL CLEAN. Contamination with dust or other materials may result in brake failure or costly repair. (4) CAUTION: STORE HYDRAULIC SYSTEM MINERAL OIL ONLY IN ITS ORIGINAL CONTAINER. KEEP CONTAINER CLEAN AND TIGHTLY CLOSED. DO NOT REFILL CONTAINER OR USE OTHER LIQUIDS. (The last sentence is not required for containers with a capacity in excess of $19 \mathrm{~L}$.)

6.14.3 If a container for brake fluid or hydraulic system mineral oil is not normally visible but designed to be protected by an outer container or carton during use, the outer container or carton rather than the inner container shall meet the labeling requirements of 6.14 .2 or 6.14 .3 , as appropriate. 


\section{COMPLIANCE....Continued}

S7. Auxiliary test methods and reagent standards. S7.1 Distilled water. Nonreferee reagent water as specified in ASTM D1193- 70, "Standard Specifications for Reagent Water," or water of equal purity.

S7.2 Water content of motor vehicle brake fluids. Use analytical methods based on ASTM D1123-59, "Standard Method of Test for Water in Concentrated Engine Antifreezes by the Iodine Reagent Method," for determining the water content of brake fluids, or other methods of analysis yielding comparable results. To be for use, such other method must measure the weight of water added to samples of the SAE RM-66-04 and TEGME Compatibility Fluids within \pm 15 percent of the water added for additions up to 0.8 percent by weight, and within \pm 5 percent of the water added for additions greater than 0.8 percent by weight. The SAE RM-66-04 Compatibility Fluid used to prepare the samples must have an original ERBP of not less than $205{ }^{\circ} \mathrm{C}\left(401{ }^{\circ} \mathrm{F}\right)$ when tested in accordance with S6.1. The SAE TEGME fluid used to prepare the samples must have an original ERBP of not less than $240{ }^{\circ} \mathrm{C}\left(464^{\circ} \mathrm{F}\right)$ when tested in accordance with S6.1.

S7.3 Ethanol. 95 percent (190 proof) ethyl alcohol, USP or ACS, or Formula 3-A Specially Denatured Alcohol of the same concentration (as specified at 27 CFR 21.35). For pretest washings of equipment, use approximately 90 percent ethyl alcohol, obtained by adding 5 parts of distilled water to 95 parts of ethanol.

S7.4 Measuring the hardness of SBR brake cups. Hardness measurements on SBR wheel cylinder cups and master cylinder primary cups shall be made by using the following apparatus and the following procedure.

S7.4.1 Apparatus. (a) Anvil. A rubber anvil having a flat circular top $20 \pm 1$ $\mathrm{mm}$. (13.16 \pm 1.16 inch) in diameter, a thickness of at least $9 \mathrm{~mm}$. (3.8 inch) and a hardness within 5 IRHDs of the SBR test cup. (b) Hardness tester. A hardness tester meeting the requirements for the standard instrument as described in ASTM D1415-68, "Standard Method of Test for International Hardness of Vulcanized Natural and Synthetic Rubbers," and graduated directly in IRHD units.

S7.4.2 Procedure. Make hardness measurements at $23^{\circ} \pm 2{ }^{\circ} \mathrm{C}$. $\left(73.4^{\circ} \pm 4^{\circ} \mathrm{F}\right.$.). Equilibrate the tester and anvils at this temperature prior to use. Center brake cups lip side down on an anvil of appropriate hardness. Following the manufacturer's operating instructions for the hardness tester, make one measurement at each of four points $6 \mathrm{~mm}$ from the center of the cup and spaced $90^{\circ}$ apart. Average the four values, and round off to the nearest IRHD.

S7.5 Sediment by centrifuging. The amount of sediment in the test fluid shall be determined by the following procedure. 


\section{COMPLIANCE....Continued}

S7.5.1 Apparatus. (a) Centrifuge tube. Cone-shaped centrifuge tubes conforming to the dimensions given in Figure 6, and made of thoroughly annealed glass. The graduations shall be numbered as shown in Figure 6, and shall be clear and distinct. Scale-error tolerances and smallest graduations between various calibration marks are given in Table $\mathrm{V}$ and apply to calibrations made with airfree water at $20^{\circ} \mathrm{C}$. $\left(68^{\circ} \mathrm{F}\right.$. $)$.

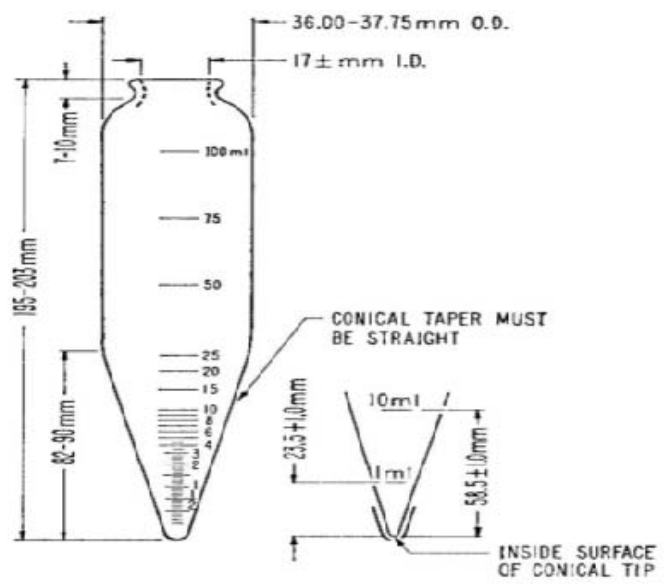

Fra. 6. AstM 8-in. Centrifuge Tube

Table V - Calibration Tolerances for 8-Inch Centrifugue Tube

\begin{tabular}{|l|l|l|}
\hline $\begin{array}{l}\text { Range, } \\
\text { ml }\end{array}$ & $\begin{array}{l}\text { Subdivision, } \\
\text { ml }\end{array}$ & $\begin{array}{l}\text { Volume } \\
\text { Tolerance, } \mathbf{m l}\end{array}$ \\
\hline 0 to 0.1 & 0.05 & \pm 0.02 \\
\hline $\begin{array}{l}\text { Above } 0.1 \\
\text { to 0.3 }\end{array}$ & 0.05 & \pm 0.03 \\
\hline $\begin{array}{l}\text { Above } 0.3 \\
\text { to 0.5 }\end{array}$ & 0.05 & \pm 0.05 \\
\hline $\begin{array}{l}\text { Above } 0.5 \\
\text { to 1 }\end{array}$ & 0.10 & \pm 0.05 \\
\hline $\begin{array}{l}\text { Above } 1 \\
\text { to 2 }\end{array}$ & 0.10 & \pm 0.10 \\
\hline $\begin{array}{l}\text { Above } 2 \\
\text { to 3 }\end{array}$ & 0.20 & \pm 0.10 \\
\hline $\begin{array}{l}\text { Above } 3 \\
\text { to 5 }\end{array}$ & 0.5 & \pm 0.20 \\
\hline $\begin{array}{l}\text { Above } 5 \\
\text { to 10 }\end{array}$ & 1. & \pm 0.50 \\
\hline $\begin{array}{l}\text { Above } 10 \\
\text { to 25 }\end{array}$ & 5. & \pm 1.00 \\
\hline $\begin{array}{l}\text { Above 25 } \\
\text { to 100 }\end{array}$ & 25. & \pm 1.00 \\
\hline
\end{tabular}




\section{COMPLIANCE....Continued}

(b) Centrifuge. A centrifuge capable of whirling two or more filled centrifuge tubes at a speed which can be controlled to give a relative centrifugal force (r.c.f.) between 600 and 700 at the tip of the tubes. The revolving head, trunnion rings, and trunnion cups, including the rubber cushion, shall withstand the maximum centrifugal force capable of being delivered by the power source. The trunnion cups and cushions shall firmly support the tubes when the centrifuge is in motion. Calculate the speed of the rotating head using this equation:

$$
\text { r.p.m. }=265[\sqrt{ } 25.4 * \text { r.c.f./d }]
$$

where: r.c.f. - Relative centrifugal force

\section{COMPLIANCE....Continued}

d - Diameter of swing, in millimeters, measured between tips of opposing tubes when in rotating position.

Table VI shows the relationship between diameter, swing, relative centrifugal force (r.c.f.), and revolutions per minute.

Table VI - Rotation Speeds for Centrifugues of Various Diameters

\begin{tabular}{|l|l|l|}
\hline \multicolumn{1}{|c|}{ Diameter of swing in millimeters $^{3}$} & \multicolumn{1}{c|}{ r.p.m. at 600 r.c.f } & r.p.m. at 700 r.c.f. \\
\hline 483 & 1490 & 1610 \\
\hline 508 & 1450 & 1570 \\
\hline 533 & 1420 & 1530 \\
\hline 559 & 1390 & 1500 \\
\hline
\end{tabular}

${ }^{9}$ Measured in millimeters between tips of opposite tubes when in rotating position.

S7.5.2 Procedure. Balance the corked centrifuge tubes with their respective trunnion cups in pairs by weight on a scale, according to the centrifuge manufacturer's instructions, and place them on opposite sides of the centrifuge head. Use a dummy assembly when one sample is tested. Then whirl them for 10 minutes, at a rate sufficient to produce a r.c.f. between 600 and 700 at the tips of the whirling tubes. Repeat until the volume of sediment in each tube remains constant for three consecutive readings.

S7.5.3 Calculation. Read the volume of the solid sediment at the bottom of the centrifuge tube and report the percent sediment by volume. Where replicate determinations are specified, report the average value.

S7.6 Standard styrene-butadiene rubber (SBR) brake cups. SBR brake cups for testing motor vehicle brake fluids shall be manufactured using the following formulation: 


\section{COMPLIANCE....Continued}

Formulation of Rubber Compunds

\begin{tabular}{|c|c|}
\hline Ingredient & $\begin{array}{l}\text { Parts by } \\
\text { weight }\end{array}$ \\
\hline SBR type 1503 & 100 \\
\hline Oil furnace black (NBS 378) & 40 \\
\hline Zinc oxide (NBS 370) & 5 \\
\hline Sulfur (NBS 371) & 0.25 \\
\hline Stearic Acid (NBS 372) & 1 \\
\hline $\begin{array}{l}1 \text { n-tertiary butyl-2-benzothiazole } \\
\text { sulfenamide (NBS 384) }\end{array}$ & 1 \\
\hline $\begin{array}{ll}\text { Symmetrical } & \text { dibetanaphthyl-p- } \\
\text { phenylenediamine } & \end{array}$ & 1.5 \\
\hline $\begin{array}{l}\text { Dicumyl peroxide }{ }_{b}(40 \text { percent on } \\
\text { precipitated } \mathrm{CaCO} 3)^{b}\end{array}$ & 4.5 \\
\hline Total & 153.25 \\
\hline \multicolumn{2}{|l|}{ Philprene 1503 has been found suitable. } \\
\hline $\begin{array}{l}{ }^{\mathrm{b}} \text { Use only within } 90 \text { days of manufacture an } \\
{ }^{\circ} \mathrm{C} .\left(80^{\circ} \mathrm{F} .\right) \text {. }\end{array}$ & erature below 27 \\
\hline
\end{tabular}

NOTE: The ingredients labeled (NBS) must have properties identical with those supplied by the National Bureau of Standards.

Compounding, vulcanization, physical properties, size of the finished cups, and other details shall be as specified in appendix B of SAE J1703b. The cups shall be used in testing brake fluids either within 6 months from date of manufacture when stored at room temperature below $30^{\circ} \mathrm{C}$. $\left(86^{\circ} \mathrm{F}\right.$.) or within 36 months from date of manufacture when stored at temperatures below minus $15^{\circ} \mathrm{C}$. $\left(+5^{\circ} \mathrm{F}\right.$.). After removal of cups from refrigeration they shall be conditioned base down on a flat surface for at least 12 hours at room temperature in order to allow cups to reach their true configuration before measurement.

S7.7 Isopropanol. ACS or reagent grade.

\section{TEST PERFORMANCE}

The test program shall be conducted by more than one person in the laboratory to assure that monitoring of the program can be continuous, complete, and expeditious, unless automated equipment is used. Test technicians shall be aware of all requirements for each test phase which is being performed.

\section{COMPLIANCE....Continued} TEST SAMPLE IDENTIFICATION AND STORAGE 
All containers of a sample used for any single test shall be identically labeled and shall have the same lot code. Each container shall be tightly sealed after a small

quantity of fluid has been removed, to prevent changes in fluid characteristics which might adversely affect test results.

The following data shall be recorded for each test sample. If different lot codes are used for each test, the codes shall be recorded on the data entry for that test.

A. Name of manufacturer, distributor, packager, and the mailing address if this information is on the container.

B. Packaged lot and date of packaging (may be in a coded form).

C. DOT grade.

All containers of test samples must be stored in a clean, dry, security storage area to prevent deterioration of the fluids in any manner which may affect test results.

\section{RECORDING OF DATA}

Test data shall be recorded on permanent strip charts, circular recording charts, or other acceptable printout media. Where permanent trace recording is not required, data will be recorded on standard report forms. Changes or corrections shall be made by drawing a line through the original entry, which must still remain legible, and adding the change alongside.

\section{PARTS DATA AND SUMMARY OF RESULTS}

On the brake fluid information section of the Compliance Data Summary in the final report, each space shall be filled out. Where information is not available, write "None". 


\section{COMPLIANCE....Continued}

The summary of results shall indicate pass or fail of each phase of the test program as supported by the results tabulated on the test data sheets.

\section{TEST DATA REPORTING FORMS}

Data will be submitted on the Test Data Sheet forms specified for use in the final report. Data will be typed before the sheets are submitted.

\section{POST TEST REQUIREMENTS}

The contractor shall re-verify all instrumentation and check data sheets and photographs. Make sure that data is recorded in all applicable data blocks on every Data Sheet.

\section{REPORTS}

\subsection{MONTHLY STATUS REPORTS}

The contractor shall submit a monthly Test Status Report and an Equipment Status Report to the COTR. The Equipment Status Report shall be submitted until all items of equipment are disposed of. Samples of the required Monthly Status Reports are contained in the report forms section.

\subsection{TEST FAILURE}

Any indication of a test failure shall be communicated by telephone to the COTR within 1 working day with written notification mailed within 2 working days. A Notice of Test Failure (see report forms section) with a copy of the particular compliance test data sheet(s) and preliminary data plot(s) shall be included. In the event of a test failure, a post test calibration check of some critically sensitive test equipment and instrumentation may be required for verification of accuracy. The necessity for the calibration shall be at the COTR's discretion and shall be performed without additional costs to the OVSC.

\subsection{FINAL TEST REPORTS}

\subsubsection{COPIES}

In the case of a test failure, SEVEN copies of the Final Test Report shall be submitted to the COTR for acceptance within three weeks of test completion. The Final Test Report format to be used by all contractors can be found in the attachment. 
Where there has been no indication of a test failure, FOUR copies of each Final Test Report shall be submitted to the COTR within three weeks of test completion.

Payment of contractor's invoices for completed compliance tests may be withheld until the Final Test Report is accepted by the COTR. Contractors are requested to NOT submit invoices before the COTR is provided copies of the Final Test Report.

Contractors are required to submit the first Final Test Report in typed draft form within two weeks after the compliance test is conducted. The contractor and the COTR will then be able to discuss the details of both test conduct and report content early in the compliance test program.

Contractors are required to PROOF READ all Final Test Reports before submittal to the COTR. The OVSC will not act as a report quality control office for contractors. Reports containing a significant number of errors will be returned to the contractor for correction, and a "hold" will be placed on invoice payment for the particular test.

\subsubsection{REQUIREMENTS}

The Final Test Report, associated documentation (including photographs) are relied upon as the chronicle of the compliance test. The Final Test Report will be released to the public domain after review and acceptance by the COTR. For these reasons, each final report must be a complete document capable of standing by itself. The contractor should use detailed descriptions of all compliance test events. Any events that are not directly associated with the standard but are of technical interest should also be included. The contractor should include as much detail as possible in the report. Instructions for the preparation of the first three pages of the final test report are provided below for the purpose of standardization.

\subsubsection{FIRST THREE PAGES}

\section{A. FRONT COVER}

A heavy paperback cover (or transparency) shall be provided for the protection of the final report. The information required on the cover is as follows:

(1) Final Report Number such as 116-ABC-XX-001 


\title{
14. REPORTS....Continued
}

\author{
where $\mathrm{C}$
}

116 is the FMVSS tested

$\mathrm{ABC}$ are the initials for the laboratory

$\mathrm{XX}$ is the Fiscal Year of the test program

001 is the Group Number (001 for the 1st brand,

002 for the 2 nd brand, etc.)

(2) Final Report Title And Subtitle such as

\section{SAFETY COMPLIANCE TESTING FOR FMVSS 116}

Motor Vehicle Brake Fluid

$* * * * * * * * * * * * * * * *$

ACE Distributors

Little Tiger DOT 3 H.D. Brake Fluid

(3) Contractor's Name and Address such as

COMPLIANCE TESTING LABORATORIES, INC.

4335 West Dearborn Street

Detroit, Michigan 48090-1234

NOTE: DOT SYMBOL WILL BE PLACED BETWEEN ITEMS (3) AND (4)

(4) Date of Final Report completion

(5) The words "FINAL REPORT"

(6) The sponsoring agency's name and address as follows

U. S. DEPARTMENT OF TRANSPORTATION

National Highway Traffic Safety Administration

Enforcement

Office of Vehicle Safety Compliance

Room 6115 (NVS-222)

400 Seventh Street, SW

Washington, DC 20590 


\section{REPORTS....Continued}

\section{B. FIRST PAGE AFTER FRONT COVER}

A disclaimer statement and an acceptance signature block for the COTR shall be provided as follows

This publication is distributed by the U. S. Department of Transportation, National Highway Traffic Safety Administration, in the interest of information exchange. The opinions, findings and conclusions expressed in this publication are those of the author(s) and not necessarily those of the Department of Transportation or the National Highway Traffic Safety Administration. The United States Government assumes no liability for its contents or use thereof. If trade or manufacturers' names or products are mentioned, it is only because they are considered essential to the object of the publication and should not be construed as an endorsement. The United States Government does not endorse products or manufacturers.

Prepared By:

Approved By:

Approval Date:

FINAL REPORT ACCEPTANCE BY OVSC:

Accepted By:

Acceptance Date 


\section{REPORTS....Continued}

C. SECOND PAGE AFTER FRONT COVER

A completed Technical Report Documentation Page (Form DOT F1700.7) shall be completed for those items that are applicable with the other spaces left blank. Sample data for the applicable block numbers of the title page follows.

Block 1 C REPORT NUMBER

116-ABC-XX-001

Block 2 C GOVERNMENT ACCESSION NUMBER

Leave blank

Block 3 C RECIPIENT'S CATALOG NUMBER

Leave blank

Block 4 C TITLE AND SUBTITLE

Final Report of FMVSS 116 Compliance Testing of Little Tiger DOT 3 Heavy Duty Brake Fluid

Block 5 C REPORT DATE

March 1, 20XX

Block 6 C PERFORMING ORGANIZATION CODE ABC

Block 7 C AUTHOR(S) John Smith, Project Manager / Bill Doe, Project Engineer

Block 8 C PERFORMING ORGANIZATION REPORT NUMBER

ABC-DOT-XXX-001

Block 9 C PERFORMING ORGANIZATION NAME AND ADDRESS

ABC Laboratories

405 Main Street

Detroit, MI 48070-1234 


\section{REPORTS....Continued}

Block 10 C WORK UNIT NUMBER

Leave blank

Block 11 C CONTRACT OR GRANT NUMBER

DTNH22-XX-D-12345

\section{Block 12 C SPONSORING AGENCY NAME AND ADDRESS}

US Department of Transportation

National Highway Traffic Safety Administration

Enforcement

Office of Vehicle Safety Compliance (NVS-222)

400 Seventh Street, SW, Room 6115

Washington, DC 20590

\section{Block 13 C TYPE OF REPORT AND PERIOD COVERED}

Final Test Report

Feb. 15 to Mar. 15, 20XX (Start Date to Completion Date)

\section{Block 14 C SPONSORING AGENCY CODE}

NVS-222

\section{Block 15 C SUPPLEMENTARY NOTES}

Leave blank

\section{Block 16 C ABSTRACT}

Compliance tests were conducted on Little Tiger DOT 3 H.D. Brake Fluid in accordance with the specifications of the Office of Vehicle Safety Compliance Test Procedure No. TP-116-XX for the determination of FMVSS 116 compliance. Test failures identified were as follows:

None

NOTE: Above wording must be shown with appropriate changes made for a particular compliance test. Any questions should be resolved with the COTR. 
14. REPORTS....Continued

Block 17 C KEY WORDS

Compliance Testing

Safety Engineering

FMVSS 116

Block 18 C DISTRIBUTION STATEMENT

Copies of this report are available from C

National Highway Traffic Safety Administration

Technical Information Services

Room PL403 (NPO-405)

400 Seventh Street, SW

Washington, DC 20590

Telephone No.: 202-366-2588

Block 19 C SECURITY CLASSIFICATION OF REPORT

Unclassified

Block 20 C SECURITY CLASSIFICATION OF PAGE

Unclassified

Block 21 C NUMBER OF PAGES

Add appropriate number

Block 22 C PRICE

Leave blank 


\section{REPORTS....Continued}

\subsubsection{TABLE OF CONTENTS}

Final test report Table of Contents shall include the following:

A. Section 1 C Purpose of Compliance Test

B. Section 2 C Compliance Test Data Summary

C. Section 3 C Test Data

D. Section 4 C Test Failure Details (if applicable)

E. Appendix A C Interpretations or Deviations From FMVSS 116

F. Appendix B C Test Equipment List and Calibration Information

G. Appendix C C Photographs

\section{DATA SHEETS}

DATA SHEET 1

SUMMARY OF TEST RESULTS

GROUP NO.: $\quad ; \quad$ LAB.:

BRAKE FLUID BRAND:

DISTRIBUTOR:

ADDRESS:

LOT I.D./PACKAGE CODE: ～～～～DOT GRADE:

INDICATE P - PASS OR F - FAIL PASS FAIL

1. Boiling Point (ERBP)

2. Wet ERBP

3. Viscosity at $-40 \mathrm{EF}$

Viscosity at $212 \mathrm{EF}$ 


\section{DATA SHEETS....Continued}

4. $\mathrm{pH}$ Value

5. Fluid Stability

6. Corrosion:

Weight Change, $\mathrm{mg} / \mathrm{cm} 5$

Tinned Iron

Steel

Aluminum

Cast Iron

Brass

Copper

Pitting or Roughening

Jelling of Mixture

Crystalline Deposit

Sedimentation, $\%$ by volume

Disintegration of cups

$\mathrm{pH}$ after test

Decrease in cup hardness

Increase in cup diameter

INDICATE P - PASS OR F - FAIL PASS FAIL

7. Fluidity and Appearance at Low Temperature:

Crystallization at $-40 \mathrm{EF}$

Crystallization at $-58 \mathrm{EF}$

Sedimentation at $-40 \mathrm{EF}$

Sedimentation at $-58 \mathrm{EF}$

Air Bubble Rise Time at $-40 \mathrm{EF}$

Air Bubble Rise Time at -58EF

8. Water Tolerance:

Stratification at $-40 \mathrm{EF}$

Stratification at $140 \mathrm{EF}$

Sedimentation at $-40 \mathrm{EF}$

Sedimentation at $140 \mathrm{EF}$

Air Bubble Rise Time at -40EF

9. Compatibility:

Stratification, Crystallization

Sedimentation, Sludging

10. Resistance to Oxidation:

Weight loss, $\mathrm{mg} / \mathrm{cm} 5$ 


\title{
15. DATA SHEETS....Continued
}

\author{
Aluminum \\ Cast iron \\ Pitting and etching \\ Gum deposit on strips
}

11. Effect on SBR Cups:

Hardness increase at $158 \mathrm{EF}$

Hardness increase at 248E

Hardness decrease at $158 \mathrm{EF}$

Hardness decrease at $248 \mathrm{E}$

Base diameter change at $158 \mathrm{EF}$

Base diameter change at $248 \mathrm{E}$

\section{INDICATE P - PASS OR F - FAIL PASS FAIL}

12. Effect on SBR Cups....Continued

Disintegration at $158 \mathrm{EF}$

Disintegration at $248 \mathrm{E}$

13. Stroking Properties

14. Color:

Clear to Amber (DOT $3 \& 4$ )

Purple (DOT 5)

15. Container Sealing:

Resealable

Tamper-Proof Feature

16. Certification, Marking and Labeling:

Certification - -

FMVSS 116 Statement

Marking -

Lot I.D. Code Shown

Grade Type Shown

Minimum Wet ERBP Shown

Complete Mailing Address

Labeling - -

Safety Warning Statements

Removability

Legibility 
15. DATA SHEETS....Continued

COMMENTS:

15. DATA SHEETS....Continued

DATA SHEET 2

TEST DATA

GROUP NO.: ； LAB.:

BRAKE FLUID BRAND:

; DOT- 


\begin{tabular}{|c|c|c|c|c|c|}
\hline $\begin{array}{l}\text { Test } \\
\text { No. }\end{array}$ & Test Description & Test Requirements & Test Results & $\begin{array}{l}\text { Start } \\
\text { Date }\end{array}$ & $\begin{array}{c}\text { Complete } \\
\text { Date }\end{array}$ \\
\hline $1^{*}$ & Boiling Point (ERBP) & Min. $=401 \mathrm{EF}$ & $\mathrm{EF}$ & & \\
\hline $2 *$ & Wet ERBP & Min. $=284 \mathrm{EF}$ & $\mathrm{EF}$ & & \\
\hline \multirow[t]{2}{*}{$3^{*}$} & Viscosity at $-40 \mathrm{EF}$ & \multirow{2}{*}{$\begin{aligned} \text { Max. } & =1500 \mathrm{cSt} \\
\text { Min. } & =1.5 \mathrm{cSt}\end{aligned}$} & cSt & & \\
\hline & Viscosity at 212EF & & $c S t$ & & \\
\hline 4 & $\mathrm{pH}$ Value & 7 to 11.5 & & & \\
\hline \multirow[t]{4}{*}{5} & Fluid Stability: & Max. Change & & & \\
\hline & High Temperature & $5.4+\Delta$ & $\mathrm{EF}$ & & \\
\hline & Chemical & $5.4+\Delta$ & $\mathrm{EF}$ & & \\
\hline & & $\begin{array}{c}\Delta=+0.05 \mathrm{EF} / \mathrm{E} \text { that } \\
\mathrm{BP} \text { is }>437 \mathrm{EF}\end{array}$ & $\Delta={ }_{\mathrm{EF}}$ & & \\
\hline \multirow[t]{16}{*}{6} & Corrosion: & & & & \\
\hline & Weight Change, $\mathrm{mg} / \mathrm{cm} 5$ & & & & \\
\hline & Tinned Iron & Max. $=0.2$ & & & \\
\hline & Steel & Max. $=0.2$ & & & \\
\hline & Aluminum & Max. $=0.1$ & & & \\
\hline & Cast Iron & Max. $=0.2$ & & & \\
\hline & Brass & Max. $=0.4$ & & & \\
\hline & Copper & Max. $=0.4$ & & & \\
\hline & Pitting/Roughening & None & & & \\
\hline & Jelling of mixture & None & & & \\
\hline & Crystalline deposits & None & & & \\
\hline & Sedimentation, $\%$ by vol. & Max. $=0.10 \%$ & & & \\
\hline & Disintegration of cups & None & & & \\
\hline & $\mathrm{pH}$ after Test & 7 to 11.5 & & & \\
\hline & Decrease in cup hardness & Max. $=15 \mathrm{IRHD}$ & & & \\
\hline & Increase in cup hardness & Max. $=0.055^{\prime \prime}$ & & & \\
\hline
\end{tabular}


15. DATA SHEETS....Continued

\begin{tabular}{|c|c|c|c|c|c|c|}
\hline \multirow{2}{*}{$\begin{array}{l}\text { Test } \\
\text { No. } \\
7\end{array}$} & \multirow{2}{*}{$\begin{array}{l}\text { Test Description } \\
\text { Fluidity and Appearance at } \\
\text { Low Temperature: }\end{array}$} & \multicolumn{2}{|c|}{ Test Requirements } & \multirow[t]{2}{*}{ Test Results } & \multirow[t]{2}{*}{$\begin{array}{l}\text { Start } \\
\text { Date }\end{array}$} & \multirow[t]{2}{*}{$\begin{array}{c}\text { Complete } \\
\text { Date }\end{array}$} \\
\hline & & $-40 E F$ & $-58 E F$ & & & \\
\hline & Stratification & None & None & & & \\
\hline & Sedimentation & None & None & & & \\
\hline & Air Bubble Rise Time - sec. & $10 \max$ & $35 \max$ & & & \\
\hline \multirow[t]{4}{*}{8} & Water Tolerance: & $-40 E F$ & $140 \mathrm{EF}$ & & & \\
\hline & Stratification & None & None & & & \\
\hline & Sedimentation, \% & None & $.15 \max$ & & & \\
\hline & Air Bubble Rige Time - sec. & $10 \max$ & & & & \\
\hline \multirow[t]{4}{*}{9} & Compatibility: & $-40 E F$ & 140EF & & & \\
\hline & Stratification & None & None & & & \\
\hline & Crystallization & None & None & & & \\
\hline & Sedimentation, Sludging, $\%$ & None & $.05 \max$ & & & \\
\hline \multirow[t]{6}{*}{10} & Resistance to Oxidation: & & & & & \\
\hline & Weight Loss, mg/cm5 & & & & & \\
\hline & Aluminum & Mas & 0.05 & & & \\
\hline & Cast Iron & $\operatorname{Max}$ & 0.30 & & & \\
\hline & Pitting/Etching & & & & & \\
\hline & Gum Deposits on Strips & & & & & \\
\hline \multirow[t]{5}{*}{11} & Effect on SBR Cups: & $158 \mathrm{EF}$ & $248 \mathrm{EF}$ & & & \\
\hline & Hardness Increase & None & None & & & \\
\hline & Hardness Decrease, IRHD & $10 \max$ & $15 \max$ & & & \\
\hline & Base Diameter Change - in. & $\begin{array}{c}0.006 \text { to } \\
0.055\end{array}$ & $\begin{array}{c}0.006 \text { to } \\
0.055 \\
\end{array}$ & & & \\
\hline & Disintegration & None & None & & & \\
\hline 12 & Stroking Properties & & & N/P & & \\
\hline
\end{tabular}


15. DATA SHEETS....Continued

\begin{tabular}{|c|c|c|c|c|c|}
\hline $\begin{array}{l}\text { Test } \\
\text { No. }\end{array}$ & Test Description & Test Requirements & Test Results & $\begin{array}{l}\text { Start } \\
\text { Date }\end{array}$ & $\begin{array}{c}\text { Complete } \\
\text { Date }\end{array}$ \\
\hline \multirow[t]{3}{*}{13} & Color: & & & & \\
\hline & DOT $3 \&$ DOT 4 & Clear to Amber & & & \\
\hline & DOT 5 & Purple & & & \\
\hline \multirow[t]{2}{*}{14} & Container Sealing: & Resealable & & & \\
\hline & & Tamper-Proof Feature & & & \\
\hline \multirow[t]{8}{*}{15} & Certification: & FMVSS 116 Statement & & & \\
\hline & Marking - Lot ID Code & Shown & & & \\
\hline & Marking - Grade Type & Shown & & & \\
\hline & Marking - Min Wet ERBP & Shown & & & \\
\hline & Marking - Mailing Address & Complete & & & \\
\hline & Labeling & $\begin{array}{l}\text { Safety Warning } \\
\text { Statements }\end{array}$ & & & \\
\hline & & Removability & & & \\
\hline & & Legibility & & & \\
\hline
\end{tabular}

Values shown are for DOT-3 Brake Fluid ONLY. Values for DOT-4 and DOT-5 Brake Fluid are shown below:

\begin{tabular}{||l||l|l||}
\hline & $\begin{array}{l}\text { DOT } \\
-4\end{array}$ & DOT-5 \\
\hline \hline & $\begin{array}{l}446 \mathrm{E} \\
\mathrm{F}\end{array}$ & $500 \mathrm{EF}$ \\
\hline TEST 2 & $\begin{array}{l}\text { 311E } \\
\mathrm{F}\end{array}$ & $356 \mathrm{EF}$ \\
\hline TEST 3 & $\begin{array}{l}1800 \mathrm{c} \\
\mathrm{St}\end{array}$ & $900 \mathrm{cSt}$ \\
\hline
\end{tabular}

REMARKS:

RECORDED BY:

; DATE:

APPROVED BY: 
15. DATA SHEETS....Continued

\section{DATA SHEET 3}

\section{STROKING TEST DATA}

GROUP NO.: $\quad$; LAB.:

BRAKE FLUID BRAND:

\begin{tabular}{|c|c|c|c|c|c|}
\hline $\begin{array}{l}\text { Test } \\
\text { No. }\end{array}$ & Test Description & Test Requirements & Test Results & $\begin{array}{l}\text { Start } \\
\text { Date }\end{array}$ & $\begin{array}{c}\text { Complete } \\
\text { Date }\end{array}$ \\
\hline \multirow[t]{18}{*}{12} & Stroking Properties: & $248 \mathrm{EF}$ & $248 \mathrm{EF}$ & & \\
\hline & Metal & & & & \\
\hline & Pitting/Etching & Max. $=$ None & & & \\
\hline & Diameter Change: & & & & \\
\hline & Piston/Cylinder & Max. $=0.005^{\prime \prime}$ & & & \\
\hline & Cylinder/Piston Oper. & Not Frozen & & & \\
\hline & Cups & & & & \\
\hline & Hard Decrease, Average & Max $=15 I R H D$ & & & \\
\hline & Hard Decrease, One & Max $=17 \mathrm{IRHD}$ & & & \\
\hline & Operating Condition & Satisfactory & & & \\
\hline & Base Diameter, Increase & Max. $=0.035^{\prime \prime}$ & & & \\
\hline & Lip Diameter, Set Average & Max. $=65 \%$ & & & \\
\hline & Fluid & & & & \\
\hline & Volume Loss/24.000 St & Max. $=36 \mathrm{ml}$ & & & \\
\hline & Volume Loss/last $100 \mathrm{St}$ & Max. $=36 \mathrm{ml}$ & & & \\
\hline & Gel & Max $=$ None & & & \\
\hline & Sediment Volume & Max. $=1.5 \%$ & & & \\
\hline & Abrasive Deposits & Max. $=$ None & & & \\
\hline
\end{tabular}

REMARKS:

RECORDED BY:

; DATE:

APPROVED BY: 
16. FORMS

\section{LABORATORY NOTICE OF TEST FAILURE TO OVSC}

FMVSS 116 TEST DATE:

LABORATORY:

CONTRACT NO.: $\quad$; DELV. ORDER NO.:

LABORATORY PROJECT ENGINEER'S NAME:

TEST SPECIMEN DESCRIPTION - -

BRAND NAME \& GRADE TYPE:

MANUFACTURER OR DISTRIBUTOR:

LABEL INFO.:

PART NO:

TEST FAILURE DESCRIPTION:

FMVSS REQUIREMENT, PARAGRAPH '

NOTIFICATION TO NHTSA (COTR):

DATE: $\quad$ BY:

REMARKS: 
16. FORMS....Continued

\section{MONTHLY TEST STATUS REPORT}

FMVSS 116

DATE OF REPORT:

\begin{tabular}{|c|c|c|c|c|c|}
\hline $\begin{array}{l}\text { GROUP } \\
\text { NO. }\end{array}$ & $\begin{array}{l}\text { BRAKE FLUID } \\
\text { BRAND AND GRADE }\end{array}$ & $\begin{array}{l}\text { TEST START } \\
\text { DATE }\end{array}$ & $\begin{array}{l}\text { TEST COMPLETE } \\
\text { DATE }\end{array}$ & $\begin{array}{c}\text { PASS } \\
1 \\
\text { FAIL }\end{array}$ & $\begin{array}{l}\text { DATE FINAL } \\
\text { REPORT } \\
\text { SUBMITTED }\end{array}$ \\
\hline \multicolumn{6}{|l|}{001} \\
\hline \multicolumn{6}{|l|}{002} \\
\hline \multicolumn{6}{|l|}{003} \\
\hline \multicolumn{6}{|l|}{004} \\
\hline \multicolumn{6}{|l|}{005} \\
\hline \multicolumn{6}{|l|}{006} \\
\hline \multicolumn{6}{|l|}{007} \\
\hline \multicolumn{6}{|l|}{008} \\
\hline \multicolumn{6}{|l|}{009} \\
\hline \multicolumn{6}{|l|}{010} \\
\hline \multicolumn{6}{|l|}{011} \\
\hline \multicolumn{6}{|l|}{012} \\
\hline \multicolumn{6}{|l|}{013} \\
\hline \multicolumn{6}{|l|}{014} \\
\hline \multicolumn{6}{|l|}{015} \\
\hline \multicolumn{6}{|l|}{016} \\
\hline \multicolumn{6}{|l|}{017} \\
\hline \multicolumn{6}{|l|}{018} \\
\hline \multicolumn{6}{|l|}{019} \\
\hline 020 & & & & & \\
\hline
\end{tabular}

REMARKS: 
16. FORMS....Continued

\begin{tabular}{|c|c|c|c|c|c|c|}
\hline $\begin{array}{l}\text { GROUP } \\
\text { NO. }\end{array}$ & BRAND NAME & $\begin{array}{c}\text { GRAD } \\
E \\
\text { TYPE }\end{array}$ & $\begin{array}{c}\text { NO. OF } \\
\text { SPECIMEN } \\
\text { S } \\
\text { RECVD. }\end{array}$ & LOT NUMBERS & $\begin{array}{c}\text { CONDITION } \\
\text { OF } \\
\text { SAMPLE }\end{array}$ & $\begin{array}{c}\text { DATE } \\
\text { RECEIVED }\end{array}$ \\
\hline \multicolumn{7}{|l|}{001} \\
\hline \multicolumn{7}{|l|}{002} \\
\hline \multicolumn{7}{|l|}{003} \\
\hline \multicolumn{7}{|l|}{004} \\
\hline \multicolumn{7}{|l|}{005} \\
\hline \multicolumn{7}{|l|}{006} \\
\hline \multicolumn{7}{|l|}{007} \\
\hline \multicolumn{7}{|l|}{008} \\
\hline \multicolumn{7}{|l|}{009} \\
\hline \multicolumn{7}{|l|}{010} \\
\hline \multicolumn{7}{|l|}{011} \\
\hline \multicolumn{7}{|l|}{012} \\
\hline \multicolumn{7}{|l|}{013} \\
\hline \multicolumn{7}{|l|}{014} \\
\hline \multicolumn{7}{|l|}{015} \\
\hline \multicolumn{7}{|l|}{016} \\
\hline \multicolumn{7}{|l|}{017} \\
\hline \multicolumn{7}{|l|}{018} \\
\hline 019 & & & & & & \\
\hline 020 & & & & & & \\
\hline
\end{tabular}

REMARKS:

\section{APPENDIX A}

INTERPRETATIONS OR DEVIATIONS FROM FMVSS 116

\section{APPENDIX B}

\section{EQUIPMENT LIST AND CALIBRATION SCHEDULES}

TESTING LABORATORY:

NOTE: Information to be included for each item of test instrumentation is as follows:

EQUIPMENT DESCRIPTION:

EQUIPMENT MANUFACTURER: 